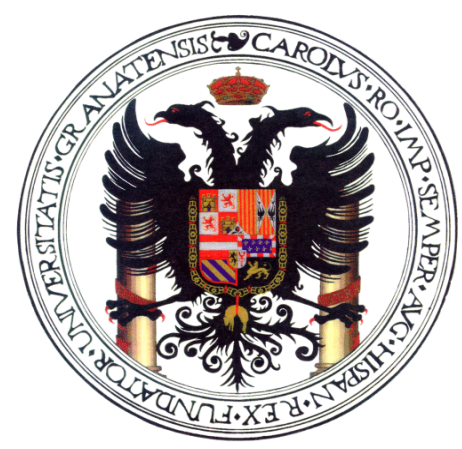

\title{
Optimización del rendimiento en un jugador de baloncesto durante el periodo transitorio
}

\author{
Trabajo Fin de Máster
}

\author{
Alumno: \\ Carlos Vallés Ortega \\ Tutor: \\ Guillermo Sánchez Delgado
}

Master Universitario en Entrenamiento Personal. III Edición 
A mi sobrino Hugo, por convertír los momentos de tristeza en felicidad y llenarme de fuerza en este camino cuando surgieron las dudas. 


\section{Índice}

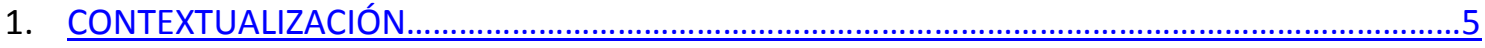

1.1. Descripción, situación y propósito del cliente.....................................................................6

1.2. Recursos materiales, espaciales y temporales....................................................................

1.3. Aspectos éticos, legales y jurídicos................................................................................10

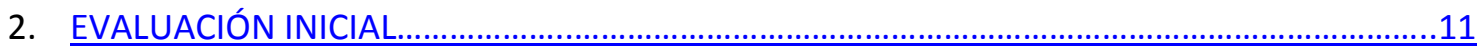

2.1. ¿Qué evalúo? Evaluación integral del sujeto.........................................................................9

2.2. ¿Cómo evalúo? Herramientas de evaluación.......................................................................12

2.3. ¿¿Qué datos he obtenido? Resultado de la evaluación.........................................................24

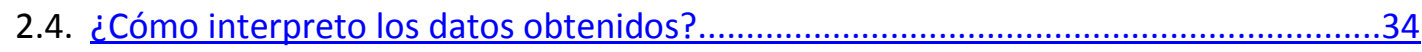

3. EXPOSICIÓN Y ANÁLISIS DE LA CASUÍSTICA Y/O PATOLOGÍA ………….....................................

3.1. Factores limitantes del deporte. Indicadores de carga externa.......................................38

3.2. Factores limitantes del deporte. Indicadores de carga interna.....................................45

3.3. La prevención de lesiones en el deporte....................................................................48

3.3.1.Epidemiología en el baloncesto...........................................................................50

3.3.2.Epidemiología de tendinitis...................................................................................5

3.4. Adaptaciones fisiológicas el entrenamiento de fuerza....................................................56

3.4.1.Curva fuerza-tiempo...............................................................................................58

3.4.2.Curva fuerza-velocidad...................................................................................59

3.4.3. Factores morfológicos..................................................................................................61

4. JUSTIFICACIÓN DEL PROGRAMA DE INTERVENCIÓN..........................................................62

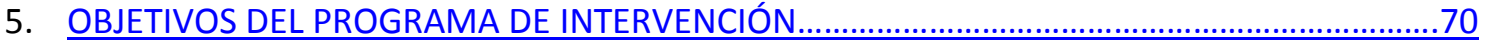

5.1. Objetivo generales........................................................................................................

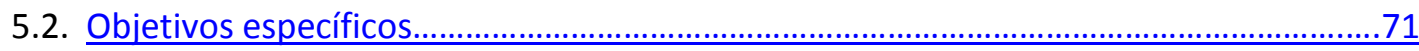

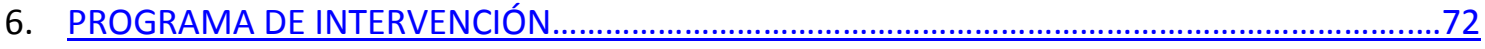

6.1. Secuencias de las fases de entrenamiento del programa de intervención......................72

6.2. Fase 1 del programa de intervención..................................................................................74

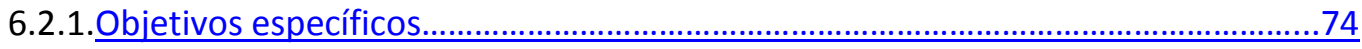

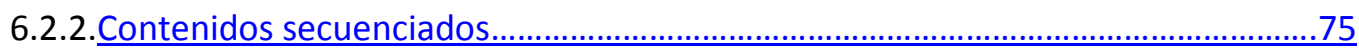

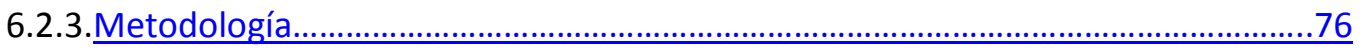

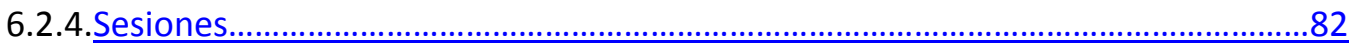

6.2.5.Evaluación y control del proceso.......................................................................................96

6.3. Fase 2 del programa de intervención ....................................................................104

6.3.1. Objetivos específicos......................................................................................104

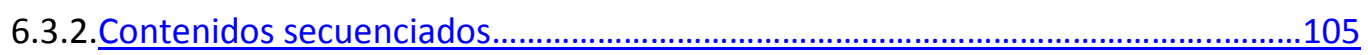

6.3.3. Metodología............................................................................................................. 106

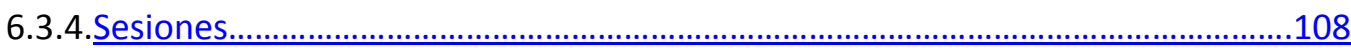

6.3.5.Evaluación y control del proceso .............................................................................133

6.4. Fase 3 del programa de intervención ............................................................................ 140

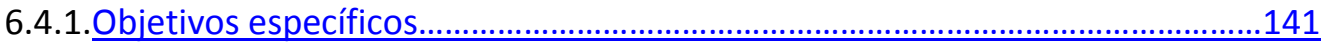

6.4.2.Contenidos secuenciados................................................................................

6.4.3.Metodología.............................................................................................................

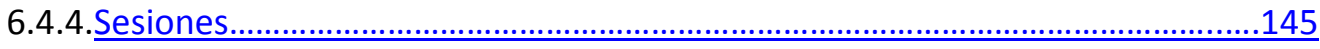

6.4.5. Evaluación y control del proceso.........................................................................146 


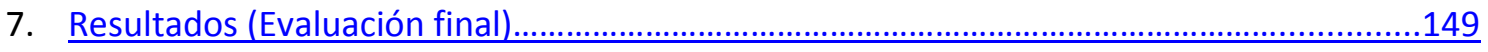

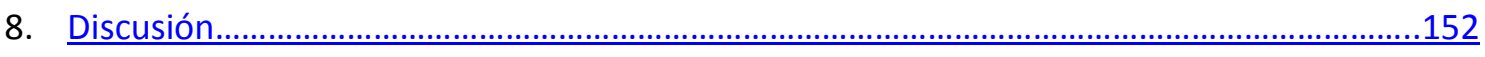

8.1. Discusión del grado de consecución de los objetivos planteados y posibles causas.. 152

8.2. Puntos fuertes y débiles del programa de intervención.............................................155

8.3. Limitaciones y dificultades..................................................................................156

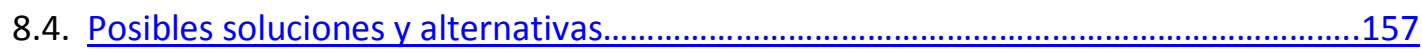

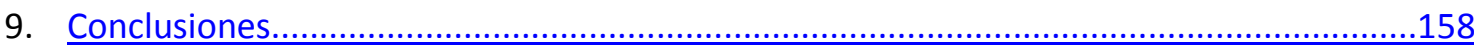

10. Líneas futuras de intervención.........................................................................................159

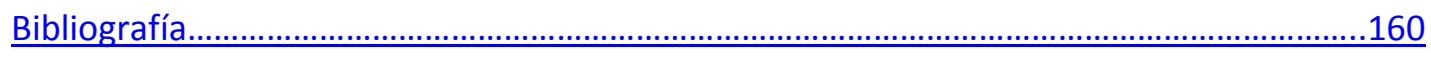

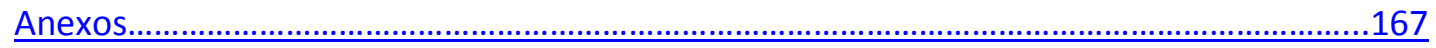




\section{CONTEXTUALIZACIÓN.}

En el presente trabajo se desarrolla la preparación de un jugador de baloncesto, Liga EBA, durante el periodo transitorio. Según expone Bompa (2006) dicho periodo representa un vínculo entre dos ciclos anuales con unos objetivos concretos que según Azolin (1995) se basan en el mantenimiento y mejora de la preparación del sujeto. Por lo tanto podríamos considerar el periodo transitorio en Baloncesto como la fase que comprende desde el final de la temporada hasta el inicio de la siguiente, con unos objetivos concretos, como son: descanso psicológico, regeneración biológica Bompa (2006) mantenimiento y mejora de la condición física (Bompa, 2006; Ozolin, 1995), y entrenamiento con objetivo compensatorio (ej. la restructuración de los patrones motores alterados en el deportista). 


\subsection{Descripción, situación y propósito del cliente.}

Este punto se desarrolló en base a una entrevista semiestructurada con el sujeto del trabajo llevada a cabo el 15 de mayo de 2015, con una hora de duración, como contacto previo a las evaluaciones posteriores. Para el encuentro se llevaron desarrolladas varias preguntas junto con la anamnesis (anexo 1), como guía para conocer mejor la situación y el propósito del jugador. A la vez se realizó otra entrevista al entrenador (anexo 2) para poder conocer las fortalezas y debilidades del sujeto en el juego.

La relación personal entre el sujeto y el entrenador viene dada por ser la pareja de una jugadora a la cual entreno. La proposición de realizar el trabajo de intervención con él fue realizada por mi parte, por la compatibilidad de horarios con mi jornada laboral. El sujeto se encuentra jugando en la categoría de Primera Nacional, actividad por la cual es retribuido económicamente y compagina con sus estudios universitario los cuales realiza de forma matinal. Los entrenamientos se realizarán de forma gratuita.

El Sujeto tiene 23 años de edad, una altura 1,88 centímetros, y un peso de 103 kilogramos, siendo su índice de masa corporal 28,29. Hasta la fecha del programa de intervención realizaba actividad física consistente en entrenar 3 días por semana, Lunes, Martes y Jueves de 20:30 a 22:30 con su club de baloncesto, además de jugar partido los fines de semana. Dichos entrenamientos dieron comienzo el 1 de Junio de 2015. El sujeto, como se puede comprobar en la tabla 1.1, ha jugado a baloncesto de forma interrumpida desde el año 2004 hasta la actualidad (12 años).

Tabla 1.1 Trayectoria como jugador.

\begin{tabular}{|c|c|c|c|}
\hline Equipo & Temporada & Categoría & Palmarés \\
\hline Ciudad de Huelva & $2004-2005$ & Infantil & \\
\hline Ciudad de Huelva & 2005-2006 & Cadete & \\
\hline Ciudad de Huelva & $2006-2007$ & Cadete & $\begin{array}{l}\text { Campeón } \\
\text { Provincial }\end{array}$ \\
\hline Ciudad de Huelva & $2007-2008$ & Junior & \\
\hline Ciudad de Huelva & 2008-2009 & $\begin{array}{l}\text { Junior } / 1^{\circ} \text { Andaluza } \\
\text { con el Sénior }\end{array}$ & $\begin{array}{l}\text { Campeón } \\
\text { Provincial }\end{array}$ \\
\hline Ciudad de Huelva & 2009-2010 & Sénior/1ํAndaluza & \\
\hline Club Baloncesto Punta & 2010-2011 & $1^{\circ}$ provincial & \\
\hline Club Baloncesto Palos & 2011-2012 & 1Nacional & \\
\hline Club Baloncesto Palos & 2012-2013 & 1№ Nacional & $\begin{array}{l}\text { Fase de } \\
\text { ascenso EBA }\end{array}$ \\
\hline $\begin{array}{l}\text { AMPESA Club } \\
\text { Baloncesto San Juan }\end{array}$ & 2013- 2014 & 1ํ Nacional & \\
\hline $\begin{array}{l}\text { AMPESA Club } \\
\text { Baloncesto San Juan }\end{array}$ & 2014-2015 & 1№ Nacional & $\begin{array}{l}\text { Fase de } \\
\text { ascenso EBA }\end{array}$ \\
\hline
\end{tabular}

A lo largo de la pasada temporada, comprendida desde el 26 de Agosto de 2014 hasta el 16 de Abril de 2015, realizó 3 entrenamientos por semana con una 
duración de una hora y media, donde todas las tareas que realizaban se orientaban a un objetivo técnico-táctico, exceptuando la primera parte de los entrenamiento de los lunes, que si realizan tareas a nivel condicional, como circuitos de adaptación anatómica Bompa (2006) y fartlek. El sujeto, además de los días de entrenamiento, asistió al gimnasio a partir de Enero, 3 días a la semana de forma no supervisada, alternándolos con dos días de natación.

En la tabla 1.2 podemos observar el historial de lesiones de nuestro sujeto hasta el momento, persistiendo en el momento del comienzo de este trabajo molestias en su rodilla derecha causadas por una tendinosis. El tratamiento de esta patología fue realizado por un fisioterapeuta con magnetoterapia y electroestimulación.

Por otro lado, durante la entrevista inicial el sujeto refirió que con asiduidad suele tener contracturas musculares en la parte izquierda de la zona lumbar. En noviembre de 2013 tuvieron su origen las últimas, siendo también tratadas por un fisioterapeuta durante el mes de febrero de 2014, tres meses después de la aparición de las mismas. El tratamiento que recibió consistió en calor y electroestimulación, a la vez que el fisioterapeuta recomendó al sujeto realizar natación, actividad que realizó durante el mes de Febrero y referenciando mejoría. Está actividad la combinó con el trabajo de musculación a lo largo del mes, sin supervisión alguna, realizando 8 series de 125 metros a crol por sesión, en una piscina de 25 metros de largo.

Tabla 1.2 Historial de lesiones.

\begin{tabular}{|c|c|c|c|c|}
\hline Lesiones & Año & $\begin{array}{l}\text { Tiempo de } \\
\text { inactividad }\end{array}$ & $\begin{array}{l}\text { Estado de la } \\
\text { lesión }\end{array}$ & Secuelas \\
\hline $\begin{array}{l}\text { Rotura del dedo } \\
\text { alunar de la mano } \\
\text { izquierda }\end{array}$ & 2003 & 7 semanas & Recuperado & Sin secuelas \\
\hline $\begin{array}{l}\text { Rotura del dedo } \\
\text { corazón de la } \\
\text { mano izquierda }\end{array}$ & 2003 & 7 semanas & Recuperado & Sin Secuelas \\
\hline $\begin{array}{l}\text { Fractura de la } \\
\text { muñeca derecha }\end{array}$ & 2006 & 8 semanas & Recuperado & Sin secuelas \\
\hline $\begin{array}{l}\text { Esguince tobillo } \\
\text { derecho grado } 3\end{array}$ & 2007 & 9 semanas & Recuperado & Sin secuelas \\
\hline $\begin{array}{l}\text { Esguince tobillo } \\
\text { derecho grado } 1\end{array}$ & 2011 & 1 semana & Recuperado & Sin secuelas \\
\hline $\begin{array}{l}\text { Esguince tobillo } \\
\text { izquierdo Grado } 1\end{array}$ & $\begin{array}{l}\text { Noviembre } \\
2013\end{array}$ & 1 Semana & Recuperado & $\begin{array}{l}\text { Retención de } \\
\text { líquido articulación } \\
\text { calcáneo cuboidea }\end{array}$ \\
\hline $\begin{array}{l}\text { Contractura } \\
\text { musculares } \\
\text { espalda, zona } \\
\text { lumbar }\end{array}$ & $\begin{array}{l}\text { Noviembre } \\
2013\end{array}$ & $\begin{array}{l}\text { No } \\
\text { inactividad }\end{array}$ & Recuperado & $\begin{array}{l}\text { Se le carga con } \\
\text { facilidad }\end{array}$ \\
\hline $\begin{array}{l}\text { Esguince de } \\
\text { tobillo izquierdo } \\
\text { grado } 2\end{array}$ & $\begin{array}{l}\text { Febrero } \\
2014\end{array}$ & 2 semanas & Recuperado & $\begin{array}{l}\text { Pequeño bulto en } \\
\text { la línea articular del } \\
\text { Chopart }\end{array}$ \\
\hline Tendinosis rodilla & Febrero & No & Pequeñas & Persiste molestias \\
\hline
\end{tabular}


izquierda

2014

inactividad

molestias

Esguince tobillo Marzo 20142 semanas Recuperado

Inflamación

zona derecho grado 2 afectada

En la entrevista inicial el sujeto referenció varios propósitos u objetos para el programa de entrenamiento, detallados a continuación:

- Ganar velocidad. El baloncesto es un deporte en el cual se ven reflejadas todas las formas y características de la velocidad y por ello resulta fundamental su entrenamiento. (Terrados y Calleja-González, 2008).

- Perder peso (IMC 28,29). Hace un año el sujeto pesaba 10 kilos menos que en la actualidad. La composición corporal en deportistas es una parte importante e imprescindible a valorar. Mediante su estudio obtenemos los constituyentes principales del peso corporal y podemos valorar como se modifica la dieta o el entrenamiento. (Drobnic, Puigdellívol y Bové, 2009).

- Aumentar la capacidad de salto.

- Mejorar la ADM en general, sin centrarse en una articulación concreta. Además del efecto preventivo, es fundamental en la ejecución de movimientos simples de forma rápida (desplazamiento) o encadenar diferentes patrones motores en forma de gesto técnico específicos en el menor tiempo posible. (Terrados y Calleja-González, 2008).

De igual modo el entrenador durante su entrevista (anexo 2) menciono varias debilidades del sujeto determinantes para su actuación durante el juego:

- Trabajo de inteligencia emocional.

- Ganancia de musculatura en tren superior e inferior.

- Mejorar la velocidad de ejecución.

- Ser más rápido en el $1^{\circ}$ paso de salida, en las penetraciones y arrancadas.

En vista de los resultados de la entrevista inicial se puede sospechar la necesidad de mejorar algunos aspectos de control emocional, sus hábitos nutricionales y la velocidad en el juego, estas hipótesis deberían ser corroboradas en la evaluación inicial. Posiblemente tengamos que abordar también aspectos relacionados con la prevención y tratamiento de alguna lesión y emprender un programa de pérdida de peso.

A su vez conté con la colaboración de un especialista en biomecánica y activador postural, Muscle Activation Techinques (MAT), especialista en la identificación y corrección de desequilibrios musculares, para la evaluación de postura, longitudes y fuerza. El objetivo del proceso de evaluación de las técnicas de activación muscular es averiguar donde se muestra estas posiciones de vulnerabilidad mediante la identificación de la debilidad muscular. 


\subsection{Recursos materiales, espaciales y temporales.}

Tendremos a nuestra disposición una sala de usos múltiples en el Polideportivo Municipal Andrés Estradas, con unas medidas de 12,20 x 7,10 (véase anexo 4).

La instalación ha sido cedida por el Excmo. Ayuntamiento de Huelva a forma parte del cuerpo técnico del Club Baloncesto Conquero, equipo profesional de baloncesto femenino de Liga Femenina. Los materiales disponibles tanto de mi propiedad como los proporcionados se encuentran detallados en el anexo 5.

La sala la podremos utilizar de lunes a viernes de 14:00 a 21:30, aunque el horario de entrenamiento estará establecido de mutuo acuerdo entre el sujeto y el entrenador.

La intervención se llevara a cabo desde el 1 de Junio de 2015, hasta el 31 de Julio de 2015. Llegando de mutuo acuerdo que los días de entrenamiento serán los Lunes, Miércoles y Viernes de 20:00 horas a 21:00 horas. 
1.3. Aspectos éticos, legales y jurídicos.

Para atender a los asuntos éticos, legales y jurídicos relacionados con la aplicación del programa de intervención se procedió a la firma del contrato con el entrenador, acuerdo de asunción de riesgo y consentimiento informado (para más detalle véase anexo 3). 


\section{EVALUACIÓN INICIAL.}

En publicaciones recientes autores como Naranjo, Santalla y Manonelles (2013) ponen de manifiesto, la importancia dela valoración funcional en el humano, consistiendo ésta en medir y evaluar objetivamente las cualidades que son la base de una determinada función humana. En el deportista las funciones valoradas serán aquellas que contribuyen a un óptimo rendimiento motor en la competición deportiva.

Siguiendo en esta línea estos mismos autores Naranjo, Santalla y Manonelles (2013), definen el proceso de evaluar como el registro y la medición de una o más variable fisiológicas, psicológicas, biomecánicas y nutricionales entre otras, mediante la realización por parte del sujeto de una o más tareas motrices determinadas y emitir un juicio de valor, objetivo, de una capacidad funcional.

Ante la gran magnitud de test encontrados en la ciencia es primordial seleccionar los que más se ajusten a las características de nuestro sujeto, para ello como expone Martínez López, (2002) se han de tener en cuenta unos criterios de calidad en la selección de pruebas o test de aptitud física. Siguiendo este principio la selección de pruebas a realizar en nuestro caso, deben ser económicas, normalizadas, comparables y útiles, tal y como plasma Grosser y Stariscka (1998):

- Se puede ejecutar en un tiempo breve, sin agotar al sujeto con numerosos test.

- Se realiza con poco material o aparatos sencillos, optimizando los recursos de los cuales disponemos.

- Su descripción y demostración es fácilmente realizable, mediante evidencia científica.

- Se puede aplicar a grupos de sujetos.

- Es analizable y evaluable, para poder emitir un juicio de valor.

- Se puede utilizar cada valor obtenido como referencia, valorando la tendencia del sujeto en los tres meses de entrenamiento.

- Sus resultados son específicos según parámetros de edad, sexo, niveles de rendimiento, etc., analizándolos, sobre la base de análisis estadísticos de una masa de datos como promedio, desviación estándar o tabla de puntuaciones existentes. 


\section{1. ¿Qué evalúo? Evaluación integral del sujeto.}

Teniendo presente que el objetivo fundamental de nuestro sujeto es mejorar su rendimiento durante el juego, los aspectos a evaluar seleccionados son los que se presentan:

\section{A. Composición corporal.}

Se trata de un sujeto con sobrepeso, lo cual nos obliga a evaluar si se debe a un exceso de masa grasa o masa muscular, siendo la primera negativa para el rendimiento del sujeto.

\section{B. Resistencia.}

El baloncesto es un deporte en el cual los atributos físicos y fisiológicos del jugador se consideran importantes para desarrollar las acciones con éxito Stojanovic, Ostojic, Calleja-Gonzalez, Milosevic, and Mikic (2012). Siguiendo a estos mismos autores estas acciones se consideran movimientos con frecuentes cambio de dirección a una alta velocidad, variables en el tiempo y la distancia, y con amplias desaceleraciones y continuos saltos durante el juego. Como exponen Schelling and Torres-Ronda (2013), el sistema energético predominante en el baloncesto sigue siendo objeto de estudio, aun así se cree que principalmente predomina la capacidad anaeróbica, debido a la intermitencia de acciones de alta intensidad que existe. Siguiendo a estos autores exponen la importancia a su vez de la potencia aeróbica (VO2MAX), interviniendo en la capacidad de recuperación de los esfuerzos anaeróbicos durante el juego.

\section{Agilidad.}

Debido a los continuos cambios de direcciones que se producen en el baloncesto en un intervalo corto de tiempo, Stojanovic et al. (2012) es vital el diseño de tareas de agilidad a partid de patrones de movimientos específicos de baloncesto (López, Arias, Marín, \& Yuste, 2014). Estos nos servirán como herramienta para ir observando el efecto sobre parámetros de rendimiento en juego del programa de intervención. A sus vez podremos valorar la mejora de acciones específicas del juego, Terrados y Calleja-González (2008).

\section{Capacidad de repetir sprines (RSA).}

Varios estudios han informado que durante un partido de baloncesto los jugadores suelen realizar unas 105 acciones de alta intensidad que corto intervalos de tiempo (2-6 segundos) con un intervalo de 21 segundos entre una acción y otra Mclnnes, Carlson, Jones, and McKenna (1995), esto sugiere que la capacidad de repetir sprines en un periodo determinado de tiempo con un tiempo determinado de recuperación es de suma importancia en el baloncesto (Castagna, Abt, et al., 2008; Spencer, Bishop, Dawson, \& Goodman, 2005). 


\section{E. Fuerza; Curva fuerza-velocidad y CMJ.}

Siguiendo a Tous (1999) la fuerza puede considerarse la única cualidad física sobre la que se fundamenta o expresan otras. De esta manera, un entrenamiento adecuado de fuerza puede aumentar el nivel de rendimiento de un jugador de baloncesto Terrados y Calleja-González (2008), por lo que siguiendo la línea que estos mismos autores manifiestan que podremos mejorar objetivos principales en nuestro sujeto, como es el aumento de su velocidad de desplazamiento lineal y no lineal, su capacidad de salto, o la potencia de tren superior. Autores como Rodríguez, (2010) y Terrados y Calleja-González (2008) manifiestan que un déficit de fuerza muscular en jugadores de baloncesto aumenta el riesgo de sufrir lesión muscular o recuperarse de la misma.

\section{F. Evaluación de la estabilidad central.}

Siguiendo a Conde (2014) la región del Core tiene como función crear movimientos en las piernas y brazos sin movimientos compensatorios de la columna y la pelvis, y en el sentido más amplio la capacidad de permitir que la fuerza pase, sin fuga de energía, desde la tierra a través de las articulaciones de la cadera, la columna vertebral o escapulotorácica.

Siguiendo en esta línea S. McGill (2010) expone que un núcleo central bien entrenado es esencial para un rendimiento óptimo, y básico en la prevención de lesiones.

\section{G. Postura y longitudes musculares.}

Se llevarán a cabo evaluaciones de postura y longitudes musculares, ya que el mantenimiento o recuperación del movimiento preciso o de segmentos concretos es la clave para prevenir o paliar el dolor músculo-esquelético Sahrmann (2002). De esta forma quizás podríamos comprender la causa de algunas molestias de nuestro sujeto en la zona lumbar, rodilla o la reiteración de esguinces de tobillos.

\section{H. Hábitos nutricionales.}

Influencia en el balance energético y por lo tanto en el peso corporal del sujeto, indica parcialmente estado de salud general del mismo e incluso estos hábitos pueden influir en el rendimiento del sujeto en estados carenciales o al contrario, teniendo influencia positiva si se realiza una optimización de la nutrición.

\section{Aspectos psicológicos; Inteligencia emocional y ansiedad.}

El conocimiento especializado del comportamiento humano que la psicología aporta, y la metodología específica de esta ciencia para evaluarlo, estudiarlo, comprenderlo y modificarlo, puede ser de enorme utilidad en el ámbito del deporte de competición. No en vano, el funcionamiento psicológico de los deportistas, puede influir, positivamente o negativamente, en su funcionamiento físico, técnico y táctico y, por tanto, en su rendimiento deportivo. Así, la preparación psicológica debe integrarse en el conjunto de la preparación global de los deportistas, como un elemento más que tiene que interactuar, apropiadamente, con las parcelas físicas, técnica y táctica (Buceta, 1998). 


\section{J. Patrones motores básicos, evaluación del movimiento.}

Cuando el cuerpo se considera una serie de segmentos interconectados, a partir de los conceptos básicos de mecánicas se puede entender las limitaciones del movimiento que pueden perjudicar al potencial de rendimiento del sujeto, llegando en algún momento a ser lesivo para él, (Frost, Beach, Callaghan, \& McGill, 2012). E análisis de los patrones motores básicos, (sentadilla, tracción horizontal y vertical, empuje horizontal y vertical, peso muerto rumano, plancha, puente lateral y empuje de cadera), nos será útil para ver como se mueve nuestro sujeto y acercarnos al análisis de algún tipo de alteración del movimiento que pueda sufrir.

Para el análisis previo de movimientos fundamentales utilizaremos la propuesta de G. Cook, L. Burton, and B. Hoogenboom (2006a), esta evaluación determina si el sujeto se encuentra capacitado para realizar los movimientos básicos requerido en su actividad deportiva con un menor riesgo de lesión (G. Cook et al., 2006a).

\section{K. Patrones motores propios del juego.}

Las destrezas técnicas son también importantes para el rendimiento en el baloncesto. Estas destrezas tienen que ser valoradas por los profesionales del deporte dentro del campo de juego, (Terrados, N. \& Calleja-González, J. 2008), de esta forma podremos saber qué movimiento reeducar para hacer mejor jugador a nuestro sujeto dentro de la lógica interna del juego. 


\section{2. ¿Cómo evalúo? Herramientas de evaluación.}

\section{A. Herramientas de evaluación para la composición corporal.}

Para su medición utilizaremos Bioimpedancia eléctrica, aparato Impedanciometro Inbody 320, por ser como expone Alvero, Cabañas, Herrero, Martínez, Moreno, Porta, Sillero y Sirvento, (2010), un método rápido, barato y no invasivo. Para asegurar la exactitud de predicción de las ecuaciones de bioimpedancia, como exponen Cruz, Armesilla, and De Lucas (2009) los sujetos deben seguir estrictamente una serie de normas que a continuación se detallan:

- No comer ni beber en las 4 horas previas al test de bioimpedancia.

- No realizar ejercicio extenuante 12 horas antes.

- Orinar 30 minutos antes del test.

- No tomar diurético 7 días antes.

- No realizar preferentemente la bioimpedancia en la fase lútea del ciclo menstrual.

- Retirar todo elemento metálico del cuerpo (relojes, anillos, pulseras, pendientes, piercings, etc.)

- No realizar el test sobre una camilla metálica.

A su vez lo combinaremos con el índice cintura-cadera (IC-C), por su mayor sencillez e independencia de la disponibilidad del aparato siempre que lo deseemos: EI IC-C es una medida antropométrica específica para medir los niveles de grasa intra abdominal. Matemáticamente es el resultado de dividir el perímetro entre el de la cadera. Existen dos tipos de obesidad según el patrón de distribución de grasa corporal: androide y ginoide. Se ha comprobado que el índice cintura-cadera correlaciona bien con la cantidad de grasa visceral(Lavie, Milani, \& Ventura, 2009). Estudios como los de Arnason et al. (2004) han demostrado que es un factor de riesgo intrínseco modificable de enfermedades cardiovasculares. Valores de referencia pueden observarse en la tabla 2.1 la fórmula utilizada para hallar el ratio cintura cadera y su relación con el riesgo cardiovascular fue la siguiente cintura $(\mathrm{cm}) /$ cadera $(\mathrm{cm})$.

Tabla 2.1. Clasificación del ratio cintura - cadera de acuerdo al riesgo cardiovascular. Valores obtenido de la batería ALPHA, para la edades comprendida de 18 a 69 años. (Suni, Husu, \& Rinne, 2010).

\begin{tabular}{ccc}
\hline \multicolumn{3}{c}{ Ratio cintura - cadera } \\
\hline Riesgo cardiovascular & Hombre & Mujer \\
Sin riesgo $(\mathrm{cm})$ & $<.96$ & $<.81$ \\
Riesgo moderado $(\mathrm{cm})$ & $.96-.99$ & $.81-.84$ \\
Alto riesgo $(\mathrm{cm})$ & $>1$ & $>.85$ \\
\hline
\end{tabular}

\section{B. Herramientas de evaluación para la resistencia.}

La valoración de la resistencia del sujeto la realizaremos por medio de dos test, el Test Trive-Basket de Vaquera, Morante, and García - López (2007). Ésta prueba nos servirá como medida inicial para monitorizar la mejora en la tolerancia a los 
esfuerzos repetidos del propio juego, y la que se utilizará en mediciones posteriores y el Yo-Yo IR1 de Castagna, Impellizzeri, Rampinini, D'Ottavio, and Manzi (2008) como complemento al Test Trive-Basket, para la obtención de datos que no nos proporciona el primero, como el VO2max $(\mathrm{mL} / \mathrm{min} / \mathrm{kg})$.

El test Trive-Basket (Terrados \& Calleja, 2008); (F., J., \& T., 2009), es un test interválico incremental máximo para la valoración de la resistencia específica en baloncesto. Este test consiste en la alternancia de periodos de carrera y periodos de recuperación o pausas de 30 segundos. La velocidad de desplazamiento se incrementa en cada periodo de esfuerzo y los sujetos permanecen realizando la prueba hasta el agotamiento. El jugador realiza desplazamiento específicos (cambiando de ritmo y dirección) que pretende simular las exigencias de competición. (Vaquera, Morante, García-López, Rodríguez-Marroyo, Ávila, Mendonca y Villa, 2007, p. 22).

Aunque el rendimiento en baloncesto se cree que esta principalmente ligado a la capacidad anaeróbica de los jugadores, la capacidad aeróbica también es importante para mejorar el rendimiento, más concretamente la potencia aeróbica máxima se considera trascendente para mejorar la recuperación entre esfuerzo de alta intensidad demandados en el baloncesto(Castagna, Impellizzeri, et al., 2008). Estos autores demostraron la validez del Test Yo-Yo IR1 como medida específica de la resistencia en jugadores de baloncesto (Castagna, Impellizzeri, et al., 2008).

La estimación del $\mathrm{VO} 2 m a x$ en el Yo-Yo IR1 test se realiza mediante la fórmula $V_{2} \max (\mathrm{mL} / \mathrm{min} / \mathrm{kg})=\mathrm{IR} 1$ distancia (metros) $\times 0.0084+36.4$ (Bangsbo, laia, \& Krustrup, 2008). A sus vez la utilización del test nos permite obtener la Frecuencia Cardiaca máxima real del sujeto aunque la estimaremos a partir de la formula siguiente, HRmax 208 - 0,7 x edad (Tanaka, Monahan, \& Seals, 2001) y por tanto su uso posterior en la monitorización del entrenamiento de forma más precisa. El cálculo de la FCmax teórica es utilizada como criterio para determinar si la prueba de esfuerzo ha sido máxima o no, al alcanzar un 90-95\% de la FCmax teórica.

Es difícil hablar de un valor normalizado por supuesto, ya que los diversos estudios revelan diferencia con respecto a la muestra, y el tipo de evaluación empleado para obtener el VO2MAX, véase tabla 3.7. Si existe evidencia de que jugadores que juegan en posiciones más alejadas del aro (bases, escoltas) tienen un VO2MAX superior a jugadores interiores, como aleros y pivots. (Domingo, Arias, Martínez, García, \& Jiménez, 2010).

En la propuesta de (Karvonen, Kentala, \& Mustala, 1957) se define el concepto de Frecuencia cardiaca de reserva como la resultante de restar la Frecuencia Cardiaca Máxima y la Frecuencia Cardiaca de reposo (FCreposo), tomada decúbito supino tras despertarse por la mañana. Por medio de esta fórmula se puede establecer la Frecuencia Cardiaca de entrenamiento (FCENT) pretendida mediante la aplicación de la siguiente ecuación, FCENT $=$ FCrReposo $+\%$ (FCM- FCReposo), (Marins, Marins, \& Fernández, 2010). La frecuencia cardiaca de reposos nos facilitara también información de la adaptaciones cardiovasculares que se estén produciendo en el sujeto (Kenney, Wilmore, \& Costill, 1999). El instrumento utilizado para medir la frecuencia cardiaca fue un pulsómetro, Polar F7. 


\section{Herramienta para evaluar la Agilidad.}

La agilidad específica de jugadores de baloncesto se evaluará mediante el test Agility T-Test, figura 1 . En él se utilizan 4 conos dispuesto en $\mathrm{T}$. El jugador sale corriendo de la línea de base, situada a 9 metros del cono B, llega y toca la base del cono con la mano. A continuación sigue hasta el cono $\mathrm{C}$ realizando movimientos de defensa a 4,5 metros del cono $B$, tocando con la mano el cono $C$. Desde este va al cono $D$ situado a 9 metros tocando la base del cono con la mano derecha. Desde este vuelve al cono $B$ y regresa a la línea de partida (cono A) de espalda. Se mide el tiempo que se tarda en hacer el recorrido (Terrados \& Calleja, 2008). Investigaciones como las de ((Delextrat \& Cohen, 2008; Pauole, Madole, Garhammer, Lacourse, \& Rozenek, 2000) muestran la validez de este test.

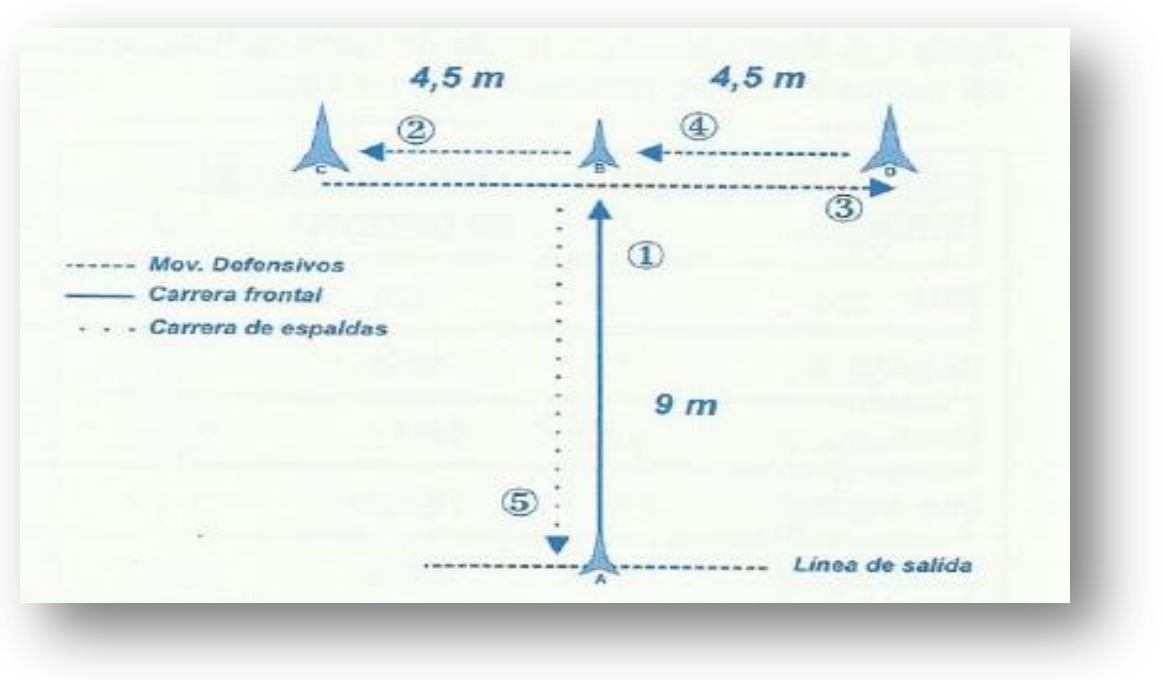

Figura 1. Prueba T-Test, figura extraída de (Terrados \& Calleja, 2008).

\section{Herramienta para la capacidad de repetir sprines (RSA).}

La capacidad de repetir sprint la mediremos con el test RSA figura 2, uno de los protocolas más citado en la literatura científica Impellizzeri et al. (2008a), consistiendo en recorrer 6 veces una distancia de 40 metros (20+20 ida y vuelta), a la máxima velocidad posible, con 20 segundos de recuperación pasiva entre ellas. Con esta propuesta, se pretende acercar las exigencias del test a las características de la competición. Los autores evalúan las siguientes variables en el test: el mejor tiempo de los 6 intentos (RSAbest), la media de los 6 intentos (RSAmean) y porcentaje de disminución (RSAdecrement), calculado como el cociente RSAmean/RSAbest y expresado en porcentaje. De todas las variables mencionadas, parece ser que RSAmean es la que muestra una mayor fiabilidad. (Impellizzeri et al., 2008a). 


\section{RSA (ida y vuelta)}

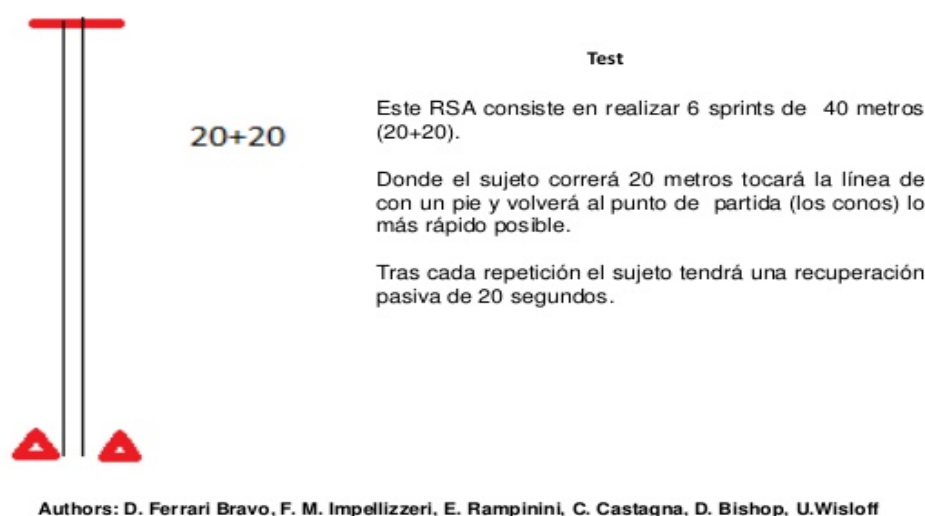

Figura 2. Test RSA Impellizzeri et al. (2008b), imagen extraída de http://image.slidesharecdn.com/testresistenciaalafatiga-121220052754phpapp01/95/test-resistencia-a-la-fatiga-13-638.jpg?cb=1355981368.

\section{E. Herramienta para evaluar la fuerza.}

La prescripción del trabajo de fuerza lo realizaremos a partir de la función de la curva fuerza-velocidad, la realización de la curva nos servirá para saber con que carga trabajar en cada zona del Spectrum de la Fuerza, la realizaremos con el enconder lineal Cronojump Boscosystem. El protocolo establecido para la realización de este test es el siguiente; se escoge un peso inicial, a partir de este peso subiremos $10 \mathrm{~kg}$ cada serie. Cada serie consta de 3 repeticiones con una micro pausa de 5 segundos entre cada una de ellas, y una macro pausa entre serie de 3 a 5 minutos. El test dará por concluido cuando la potencia baje un $10 \%$ respecto a la serie anterior. De esta forma podremos establecer y planificar el entrenamiento de fuerza en función de sus capacidades. El patrón inicial evaluado será el press de banca, debido a la poca estabilidad en la región lumbopelvica que muestra el sujeto, una vez avanzado el programa de intervención, y teniendo un control absoluto de la región mencionada se planteara la evaluación del patrón de la sentadilla.

Para la evaluación del salto vertical en contra movimiento (CMJ), utilizaremos una plataforma de contacto Cronojump Boscosystem, Din-A2 42*59,4 cm. De igual modo la medición del CMJ, nos servirá para valorar el índice de fatiga neuromuscular, autores como (Cormack, Newton, McGuigan, \& Cormie, 2008; Duffield, Murphy, Snape, Minett, \& Skein, 2012; Jiménez-Reyes \& González-Badillo, 2011; McLean, Coutts, Kelly, McGuigan, \& Cormack, 2010; Twist \& Highton, 2013; wist, Waldron, Highton, Burt, \& Daniels, 2012) exponen que la pérdida del $10 \%$ del CMJ sobre una medición basal, es un indicio de fatiga y mala recuperación, de esta forma lo podremos utilizar como marcador de asimilación de carga. Por otro lado el CMJ es un ejercicio utilizado habitualmente por profesionales en las Ciencia del Deporte para valorar la fuerza explosiva de miembros inferiores, su fácil implementación y escasa fatiga adicional generada aconsejan su uso de forma regular (Toscano \& Campos, 2015). Por los motivos anteriormente comentados esta herramienta será utilizada para la 
monitorización de la condición física durante el proceso de intervención. Igualmente el CMJ nos ofrecerá información de las mejoras en RSA, pues demostraron relación entre el CMJ e indicadores específicos de RSA en jugadores de baloncestos, (Stojanovic et al., 2012) (Balsalobre-Fernández, Nevado-Garrosa, del Campo-Vecino, \& Ganancias-Gómez, 2015). Realizaremos tres intentos con una recuperación completa entre ambos y nos quedaremos con el mejor.

Debido a los continuos cambios de direcciones que se producen en el baloncesto en un intervalo corto de tiempo, (Stojanovic et al., 2012), muchas investigaciones consideran un factor intrínseco modificable de lesión, la existencia de una déficit bilateral entre una pierna y otra, (Opar, Williams, \& Shield, 2012). Por este motivo, realizamos el test VJFT monopodal mediante un CMJ, para comprobar si verdaderamente existe o no un déficit bilateral entre la pierna izquierda y derecha, Impellizzeri, Rampinini, Maffiuletti, \& Marcora, 2007). El test VJFT (realización del CMJ de forma monopodal), es condiable para anilizar e interpretar factores de riesgo de lesiones asimétricas, así como la prevención de lesiones, (Contreras, Laguado, \& Hermoso, 2013; Impellizzeri et al., 2007), así que cuando una pierna es más débil que la otra una $10 \%$ nos encontramos ante un déficit bilateral, considerado un factor de riesgo. Al igual que en el $\mathrm{CMJ}$ realizamos tres intentos con una recuperación completa y nos quedamos con el mejor resultado del test.

\section{F. Test de estabilidad central.}

Para la valoración de la resistencia de la estabilidad central realizaremos el protocolo propuesto por S. M. McGill, Childs, and Liebenson (1999) consistiendo en mantener el máximo tiempo posible la posición de las tres siguientes pruebas que a continuación describimos.

Test modificado de Biering-Sorensen, el test comienza con los brazos cruzados por delante del pecho y en contacto con los hombros opuestos, el tronco perfectamente horizontal/paralelo al suelo, el test se da por finalizado cuando el sujeto el sujeto contacta con cualquier del tren superior en el suelo (Peña, Elvar, Moral, Donate, \& Mata, 2012).

Test de puente lateral derecho e izquierdo, el sujeto se coloca en decúbito lateral apoyando el peso corporal sobre uno de los codos y sobre la extremidad inferior del mismo lado. La extremidad inferior que no está en contacto con el suelo queda apoyada sobre la otra extremidad inferior, y ambas totalmente extendidas. El brazo contrario al que se apoya en el suelo queda flexionado por delante del tronco y contactando con la mano el hombro puesto. El sujeto debe mantener la posición suspendida con cero grados de flexión de cadera y el raquis en perfecta alineación lumbo-pélvica. El test concluye cuando el sujeto no sea capaza de mantener la postura derecha y la cadera caiga hacia el suelo o sea flexionada (Peña et al., 2012).

Test de resistencia de flexores del tronco, el sujeto se posiciona sentado con $60^{\circ}$ de flexión del tronco respecto al suelo, las caderas y las rodillas flexionadas a $90^{\circ}$, y los pies fijados al suelo por el propio evaluador. Los brazos deben estar cruzados por delante del pecho y en contacto con los hombros opuestos. Cualquier cambio en la angulación del tronco, las caderas o rodillas obliga a dar por finalizado el test (Peña et al., 2012). 


\section{G. Herramientas para evaluar la postura, longitudes y fuerza.}

Para la valoración de la postura, longitudes y fuerza, conté con la colaboración de un especialista en técnicas de activación muscular (MAT), terapia manual, utilizada para la valoración y el tratamiento de desequilibrios músculo-articulares. Utilizó diferentes test específicos para poder determinar que musculatura estaba inhibida y comprobó que posiciones y actividades son más vulnerables para el cliente. Esta evaluación nos puede ayudar a identificar en que lugar puede originarse tensiones y dolores musculares.

\section{H. Herramienta para evaluar los hábitos de nutrición.}

Para la evaluación de hábitos nutricionales utilizaremos recordatorios de 24 horas, Sabaté (1993), durante 3 días siendo estos 2 días no consecutivos laborales y uno no laboral. El análisis lo realizaremos con el software Dial.

\section{Herramienta para evaluar aspectos psicológicos.}

Debido a la información obtenida en la entrevista inicial con el entrenador del sujeto, donde comentaba una debilidad a nivel emocional durante el juego, le pasaremos al sujeto varios test Psicológicos: la escala de ansiedad CSAI - 2 Gutiérrez Calvo, García Pérez, Pérez Hernández, and Estévez (1997) y la de inteligencia emocional del sujeto, TTMS-24 (Weinberg, 2010) y (García, Melero, \& Salas, 2005)

\section{J. Herramientas para evaluar el movimiento.}

Para el estudio de los patrones motores básicos utilizamos una observación sistematizada cuyo propósito define por Pascal y Jenkins (1961) citada por Anguera. M.T (1997), el descubrir y precisar con exactitud determinados elementos de conducta que poseen cierto valor predictivo y heurístico. The functional Movement Screen (FMS) es un protocolo de valoración basado en 7 test, sentadilla profunda, paso de valla, tijera en línea, movilidad de hombro, elevación activa de pierna, fondos con estabilidad de tronco y estabilidad en rotación, que reciben una puntuación de 0 a 3 según la ejecución del mismo. El 0 se da cuando hay dolor en la ejecución, el 1 cuando no se puede hacer, el 2 cuando se realiza con algún tipo de compensación o modificación y el 3 cuando se ejecuta perfectamente (Beardsley \& Contreras, 2014; G. Cook et al., 2006a; G. Cook, L. Burton, \& B. Hoogenboom, 2006b) Concluyéndose que los sujetos que sumen una puntuación menor a 14 puntos tienen riesgo de sufrir algún tipo de lesión (Beardsley \& Contreras, 2014; G. Cook et al., 2006a; G. Cook et al., 2006b). Se requiere de otro tipo de test y evaluaciones más profunda y específica, cuando en cualquiera de los test se obtenga una puntuación baja, para reconocer los deterioros de los movimientos funcionales que pudieran provocar algún tipo de problema.

\section{K. Patrones motores propios del juego.}

La evaluación los patrones motores específicos del baloncesto durante el juego la realizaremos, mediante un análisis de video durante 5 partidos para ver sus déficits dentro de la lógica del juego. En el análisis de los patrones motores del juego utilizamos una observación no sistematizada definida por Young citado por Anguera. M.T (1997) como el escrutinio cuidadoso de las situaciones de la vida, en nuestro caso 
partidos de baloncesto, llegando a ser un medio útil para la búsqueda de una problemática que orienta hacia una investigación posterior, en este estudio sacar los déficit y fortaleza de nuestro sujeto, destaca también la el merito de no influir en absoluto sobre los hechos observado.

Tabla 2.2. Resumen métodos de evaluación.

\begin{tabular}{llll}
\hline \multicolumn{4}{c}{ Composición Corporal } \\
\hline Test & Referencia & Objetivo & Instrumento \\
\hline Impedancia & Heyward, V. H. (1996). & Evaluación de & Impedanciometro \\
bioeléctrica & & $\begin{array}{l}\text { composición } \\
\text { corporal. }\end{array}$ & Inbody 320 \\
& & Factor de riesgo & Cinta métrica \\
Perímetro & cintura- & Manual Isak & modificable. \\
cadera & & Indicador & \\
& posibles de \\
& enfermedades \\
& cardiovasculares. \\
\hline
\end{tabular}

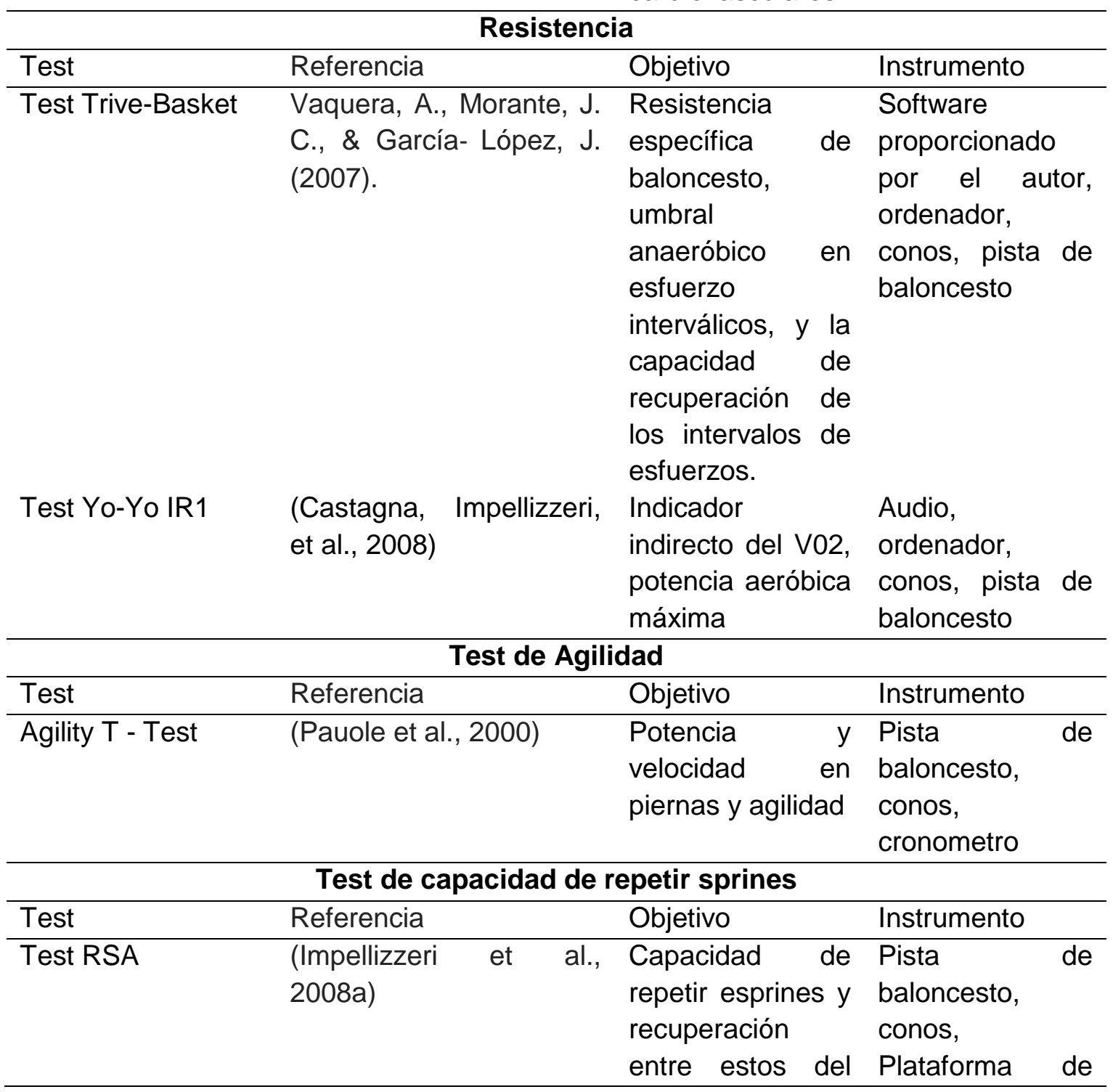




\begin{tabular}{|c|c|c|c|}
\hline & & sujeto & $\begin{array}{l}\text { contacto } \\
\text { Cronojump } \\
\text { Boscosystem, } \\
\text { Din-A2 } 42^{\star} 59,4 \\
\mathrm{~cm}, \text { hoja excel }\end{array}$ \\
\hline \multicolumn{4}{|c|}{ Fuerza } \\
\hline Test & Referencia & Objetivo & Instrumento \\
\hline $\mathrm{Rm}$ en press banca & (J. Tous, 1999) & $\begin{array}{l}\text { Determinar fuerza } \\
\text { máxima y la } \\
\text { carga de trabajo }\end{array}$ & $\begin{array}{l}\text { Pesas, y } \\
\text { enconder lineal } \\
\text { Cronojump } \\
\text { Boscosystem }\end{array}$ \\
\hline $\begin{array}{l}\text { Curva fuerza - } \\
\text { velocidad en press } \\
\text { banca }\end{array}$ & $\begin{array}{l}\text { (Badillo \& Ayestarán, } \\
\text { 2002) }\end{array}$ & $\begin{array}{l}\text { Determinar la } \\
\text { potencia, en cada } \\
\text { zona de trabajo } \\
\text { del sprectum de } \\
\text { la fuerza }\end{array}$ & $\begin{array}{l}\text { Pesas y } \\
\text { enconder lineal } \\
\text { Cronojump } \\
\text { Boscosystem }\end{array}$ \\
\hline CMJ & $\begin{array}{lr}\text { (Cormack et al., } & 2008 \text {; } \\
\text { Duffield et al., } & 2012 \text {; } \\
\text { Jiménez-Reyes } & \text { \& } \\
\text { González-Badillo, } & 2011 \text {; } \\
\text { McLean et al., } & 2010 \text {; } \\
\text { Twist \& Highton, } & 2013 \text {; } \\
\text { wist et al., 2012) }\end{array}$ & $\begin{array}{l}\text { Determinar RSA, } \\
\text { mejora de la } \\
\text { fuerza } \\
\text { adaptación a las } \\
\text { cargas de trabajo }\end{array}$ & $\begin{array}{l}\text { Plataforma de } \\
\text { contacto } \\
\text { Cronojump } \\
\text { Boscosystem, } \\
\text { Din-A2 42*59,4 } \\
\mathrm{cm}\end{array}$ \\
\hline Test VJFT & (Contreras et al., 2013) & $\begin{array}{l}\text { Comprobar si } \\
\text { existe un déficit } \\
\text { bilateral entre la } \\
\text { pierna izquierda y } \\
\text { derecha }\end{array}$ & $\begin{array}{l}\text { Plataforma de } \\
\text { contacto } \\
\text { Cronojump } \\
\text { Boscosystem, } \\
\text { Din-A2 42*59,4 } \\
\text { cm, hoja excels }\end{array}$ \\
\hline
\end{tabular}

\begin{tabular}{|c|c|c|c|}
\hline \multicolumn{4}{|c|}{ Valoración de la estabilidad central } \\
\hline Test & Referencia & Objetivo & Instrumento \\
\hline $\begin{array}{l}\text { Test modificado de } \\
\text { Biering-Sorense }\end{array}$ & $\begin{array}{l}\text { (S. M. McGill et al., } \\
\text { 1999) }\end{array}$ & $\begin{array}{l}\text { Resistencia de la } \\
\text { musculatura }\end{array}$ & $\begin{array}{l}\text { Cronómetro, } \\
\text { camilla, esterilla }\end{array}$ \\
\hline $\begin{array}{l}\text { Test de puente } \\
\text { lateral }\end{array}$ & & $\begin{array}{l}\text { posterior, anterior } \\
\text { y lateral de core }\end{array}$ & \\
\hline $\begin{array}{l}\text { Test de resistencia } \\
\text { de flexores del } \\
\text { tronco } 60^{\circ}\end{array}$ & & $\begin{array}{l}\text { en su función } \\
\text { estabilizadora }\end{array}$ & \\
\hline \multicolumn{4}{|c|}{ Pruebas Musculares; Postura, longitudes y fuerza } \\
\hline Test & Referencia & Objetivo & Instrumento \\
\hline $\begin{array}{l}\text { Pruebas } \\
\text { Postura } \\
\text { longitudes }\end{array}$ & $\begin{array}{l}\text { Kendall's, F. P., Kendall, } \\
\text { E., \& Geise, P. (2000). }\end{array}$ & $\begin{array}{ll}\text { Valoración de la } \\
\text { fuerza y la } \\
\text { función muscular }\end{array}$ & $\begin{array}{l}\text { Fotos, videos, y } \\
\text { plantilla } \\
\text { puntos con } \\
\end{array}$ \\
\hline
\end{tabular}




\begin{tabular}{|c|c|c|c|}
\hline & & \begin{tabular}{lr}
\multicolumn{2}{l}{ estructura } \\
componente del \\
movimiento, \\
postura \\
actividades y \\
sujetos
\end{tabular} & $\begin{array}{l}\text { referencia } \\
\text { observar }\end{array}$ \\
\hline Pruebas de fuerza & Técnica Mat & & Camilla \\
\hline \multicolumn{4}{|c|}{ Cuestionarios Nutrición } \\
\hline Test & Referencia & Objetivo & Instrumentos \\
\hline $\begin{array}{l}\text { Recordatorio } 24 \\
\text { horas }\end{array}$ & $\begin{array}{l}\text { (Mifflin et al., 1990; } \\
\text { Sabaté, 1993) }\end{array}$ & Hábito alimenticio & $\begin{array}{l}\text { Cuestionario, } \\
\text { hoja excels } \\
\text { software Dial }\end{array}$ \\
\hline \multicolumn{4}{|c|}{ Cuestionarios Psicológicos } \\
\hline Test & Referencia & Objetivo & Instrumentos \\
\hline $\begin{array}{l}\text { Escala de ansiedad } \\
\text { CSAI }\end{array}$ & $\begin{array}{l}\text { (Fernández, Río, \& } \\
\text { Fernández, 2007) }\end{array}$ & $\begin{array}{l}\text { Estado de ánimo } \\
\text { y ansiedad del } \\
\text { sujeto }\end{array}$ & Cuestionario \\
\hline $\begin{array}{l}\text { Test de inteligencia } \\
\text { emocional, TMMS- } \\
24\end{array}$ & $\begin{array}{l}\text { (Fernandez-Berrocal, } \\
\text { Extremera, \& Ramos, } \\
\text { 2004; Schutte et al., } \\
\text { 1998) }\end{array}$ & $\begin{array}{lr}\text { Medir } & \text { la } \\
\text { frecuencia } & \text { de } \\
\text { emociones } & \text { y } \\
\text { sentimientos } & \text { en } \\
\text { el sujeto } & \\
\end{array}$ & Cuestionario \\
\hline \multicolumn{4}{|c|}{ Análisis de videos de patrones motores básicos, del juego y en movimiento } \\
\hline Prueba & Referencia & Objetivo & Instrumentos \\
\hline $\begin{array}{lr}\text { Evaluación } & \text { de } \\
\text { patrones } & \text { motores } \\
\text { básicos. } & \text { The } \\
\text { functional } & \\
\text { Movement } & \text { Screen } \\
\text { (FMS) } & \end{array}$ & $\begin{array}{l}\text { Apuntes Master } \\
\text { entrenamiento personal } \\
\text { 2014, (Frost et al., 2012) } \\
\text { (Beardsley \& Contreras, } \\
\text { 2014; G. Cook et al., } \\
\text { 2006a; G. Cook et al., } \\
\text { 2006b) }\end{array}$ & $\begin{array}{l}\text { Evaluar control } \\
\text { motor del sujeto y } \\
\text { patrones motores } \\
\text { del sujeto } \\
\text { alterados, como } \\
\text { punto de partida } \\
\text { para la } \\
\text { planificación del } \\
\text { entrenamiento }\end{array}$ & $\begin{array}{l}\text { Videos, fotos y } \\
\text { planilla con } \\
\text { puntos } \\
\text { observar. Dos } \\
\text { picas con cinta } \\
\text { métrica, tabla de } \\
\text { madera con cinta } \\
\text { métrica, hoja } \\
\text { excels, escuadra }\end{array}$ \\
\hline $\begin{array}{l}\text { Patrones motores } \\
\text { propios del juego }\end{array}$ & (López et al., 2014) & Déficit en el juego & $\begin{array}{l}\text { Scouting de } \\
\text { partidos }\end{array}$ \\
\hline
\end{tabular}




\section{3. ¿Qué datos he obtenido? Resultado de la evaluación.}

A. Resultados evaluación Composición Corporal.

En la tabla 2.3 y figuras 3 y 4 podemos encontrar todos los datos obtenidos en la impedancia realizada al sujeto. Mientras en la tabla 2.4 se muestran la relación del ratio cintura - cadera.

Tabla 2.3. Resultados impedancia, en negritas destacamos los resultados que se salen de los parámetros normales.

\begin{tabular}{|c|c|c|}
\hline & Valor Normal & Sujeto \\
\hline Peso (kg) & $66.8-90.4$ & 103 \\
\hline Altura $(\mathrm{cm})$ & & 1.88 \\
\hline IMC & $18.5-24.9$ & 28.29 \\
\hline $\begin{array}{ll}\text { Masa } & \text { muscular } \\
\text { esquelética }(\mathrm{kg}) & \end{array}$ & $33.9-41.5$ & 48.5 \\
\hline Masa grasa corporal (kg) & $9.4-18.9$ & 19.4 \\
\hline Agua corporal total (kg) & $44.2-54.0$ & 61 \\
\hline Masa libre de grasa $(\mathrm{kg})$ & $57.4-71.5$ & 83.8 \\
\hline $\begin{array}{l}\text { Índice de masa corporal } \\
\text { (kg-metro cuadrado) }\end{array}$ & $18.5-25$ & \\
\hline $\begin{array}{l}\text { Porcentaje de grasa } \\
\text { corporal }\end{array}$ & $10 \%-20 \%$ & $18.8 \%$ \\
\hline $\begin{array}{l}\text { Relación cintura-cadera } \\
(\mathrm{cm})\end{array}$ & $.80-.90$ & .94 \\
\hline Metabolismo basal (Kcal) & $2075-2454$ & 2179 \\
\hline
\end{tabular}

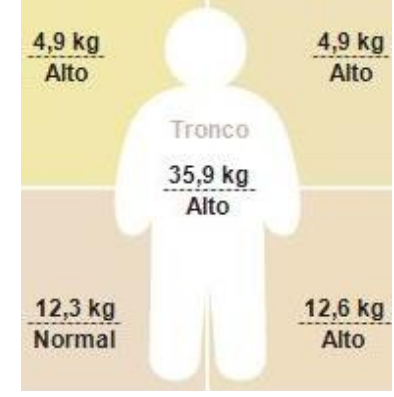

Figura 3. Resultados masa grasa segmental.

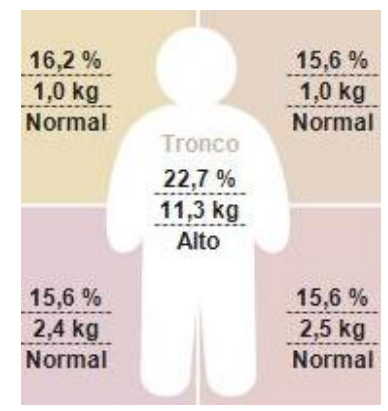

Figura 4. Resultado porcentajes de grasa corporal. 
Tabla 2.4. Resultados ratio cintura-cadera.

\begin{tabular}{lc}
\hline & Ratio cintura-cadera \\
\hline Cintura $(\mathrm{cm})$ & 93 \\
Cadera $(\mathrm{cm})$ & 113 \\
Ratio cintura/cadera & .82 \\
\hline
\end{tabular}

\section{B. Resultados evaluación de la resistencia.}

En la tabla 2.5 encontramos la estimación de la frecuencia cardiaca del sujeto la de reposo y la de reserva, a la misma vez se muestra los distintos porcentaje de la frecuencia cardiaca de entrenamiento.

Tabla 2.5. distintos valores de la frecuencia cardiaca del sujeto.

\begin{tabular}{|c|c|c|}
\hline Frecuencia Cardiaca & Fórmula & Resultado \\
\hline Fcmáxima (ppm) & $209-(0,7 x e d a d)$ & 193 \\
\hline FCreposo (ppm) & $\begin{array}{l}\text { Tomada decúbito supino } \\
\text { tras despertarse por la } \\
\text { mañana }\end{array}$ & 56 \\
\hline FCreserva (ppm) & FCmáx-Fcreposo & 137 \\
\hline \multirow[t]{11}{*}{ \% FCentrenamiento (ppm) } & (Intensidad de ejercicio $x$ & $40 \%-111$ \\
\hline & FCres) + Fcrep & $45 \%-118$ \\
\hline & & $50 \%-125$ \\
\hline & & $55 \%-131$ \\
\hline & & $60 \%-145$ \\
\hline & & $70 \%-152$ \\
\hline & & $75 \%-159$ \\
\hline & & $80 \%-166$ \\
\hline & & $85 \%-172$ \\
\hline & & $90 \%-179$ \\
\hline & & $95 \%-186$ \\
\hline
\end{tabular}

La tabla 2.6 se muestra los resultados obtenidos en el Yo-Yo test IR1, estos mismos resultados son comparados en la figura 4 , figura 5 y figura 6 , con la media de los valores de referencia de la investigación de Castagna, Impellizzeri, et al. (2008) con 22 jugadores junior Italianos de baloncesto.

Tabla 2.6 Resultados Yo-Yo test Ir1, valores de referencia extraído de (Castagna, Impellizzeri, et al., 2008).

\begin{tabular}{ccc}
\hline Ítems evaluados & Resultados & Valores de referencia \\
\hline VO2MAX $(\mathrm{mL} / \mathrm{min} / \mathrm{kg})$ & $\mathbf{5 0}$ & 60.4 \\
Distancia $($ metros $)$ & $\mathbf{1 5 9 9}$ & 1678 \\
Velocidad $(\mathrm{km} / \mathrm{h})$ & $\mathbf{1 4}$ & 15.7 \\
HRmáx $(\mathrm{ppm})$ & $\mathbf{1 9 7}$ & 187 \\
\hline
\end{tabular}




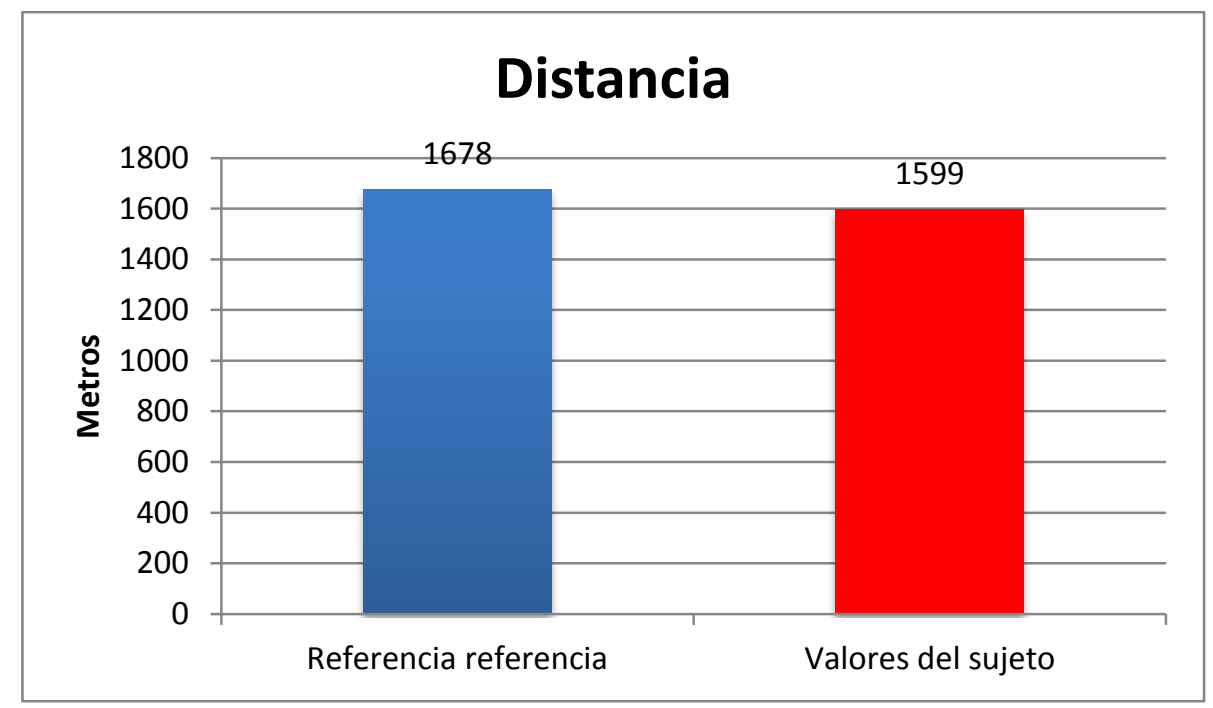

Figura 4. Valores de referencia Yo-Yo test IR1, (Castagna, Impellizzeri, et al., 2008).

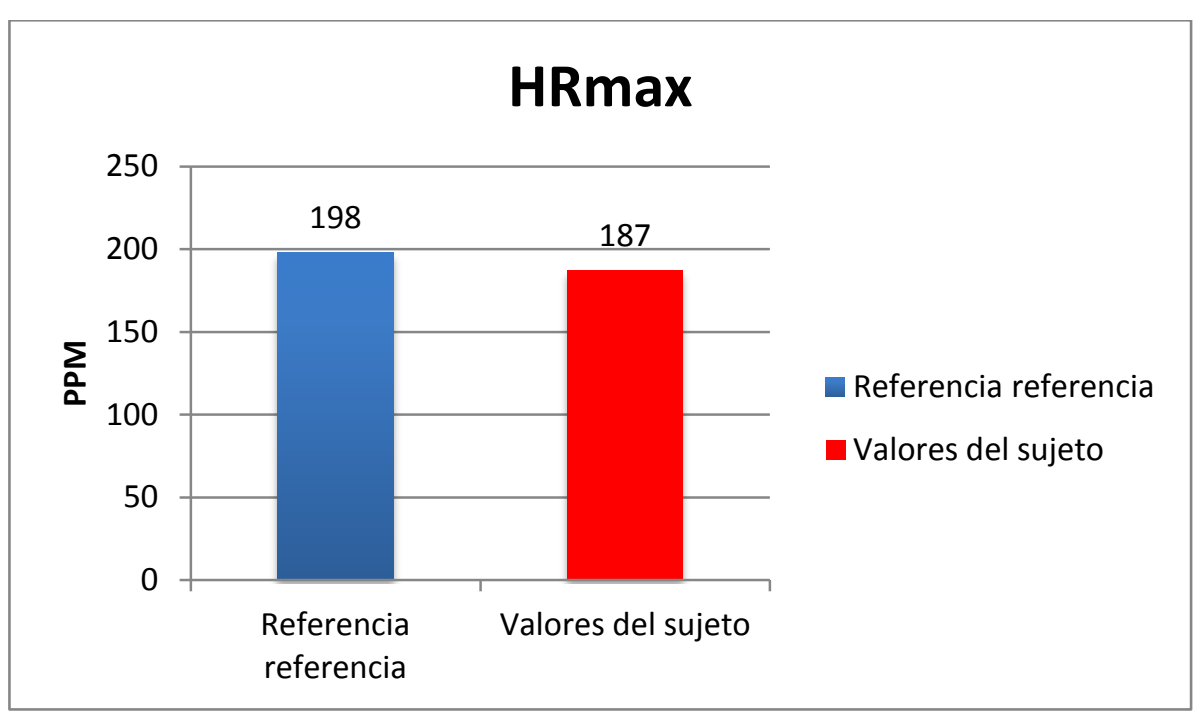

Figura 5. Valores de referencia Yo-Yo test IR1, (Castagna, Impellizzeri, et al., 2008).

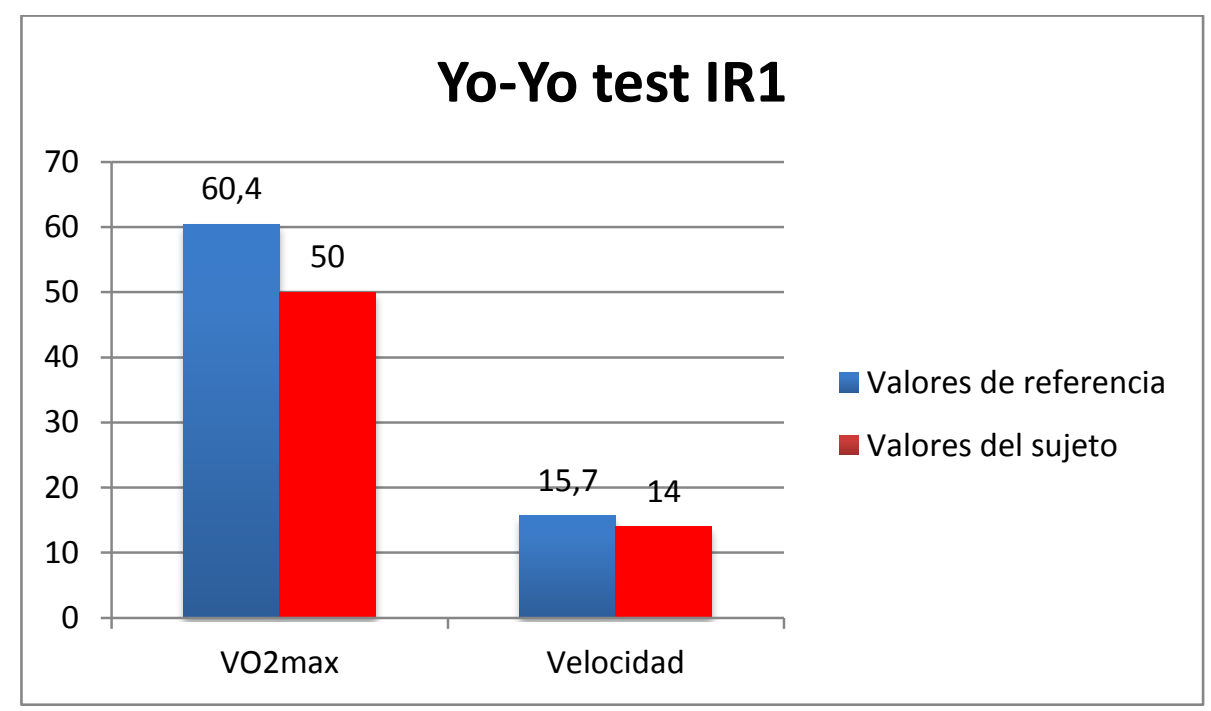

Figura 6. Valores de referencia Yo-Yo test IR1, (Castagna, Impellizzeri, et al., 2008). 
A continuación se muestra los valores del test de resistencia específica de baloncesto Test Trive-Basket tabla 2.7, y su comparación con valores de referencia, figura 7 y figura 8, que aporta (Vaquera et al., 2007).

Tabla 2.7 Resultados Test Trive-Basket.

\begin{tabular}{cc}
\hline Ítems evaluados & Resultados \\
\hline Tiempo total $($ min:s) & $\mathbf{1 1 : 7}$ \\
Velocidad $(\mathrm{km} / \mathrm{h})$ & $\mathbf{1 0 . 2}$ \\
Periodo $(\mathrm{n})$ & $\mathbf{5}$ \\
FCmáx $(\mathrm{ppm})$ & $\mathbf{1 9 8}$ \\
\hline
\end{tabular}

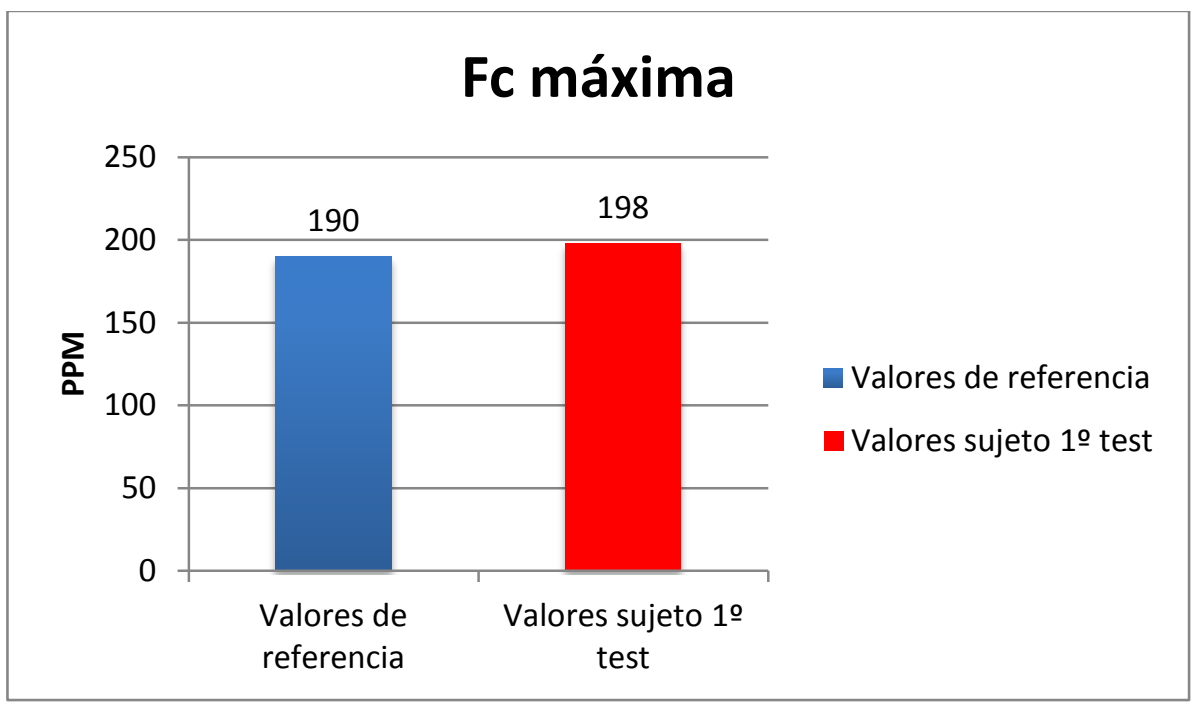

Figura 7. Valores de referencia del estudio Vaquera et al. (2007), en jugadores de liga EBA.

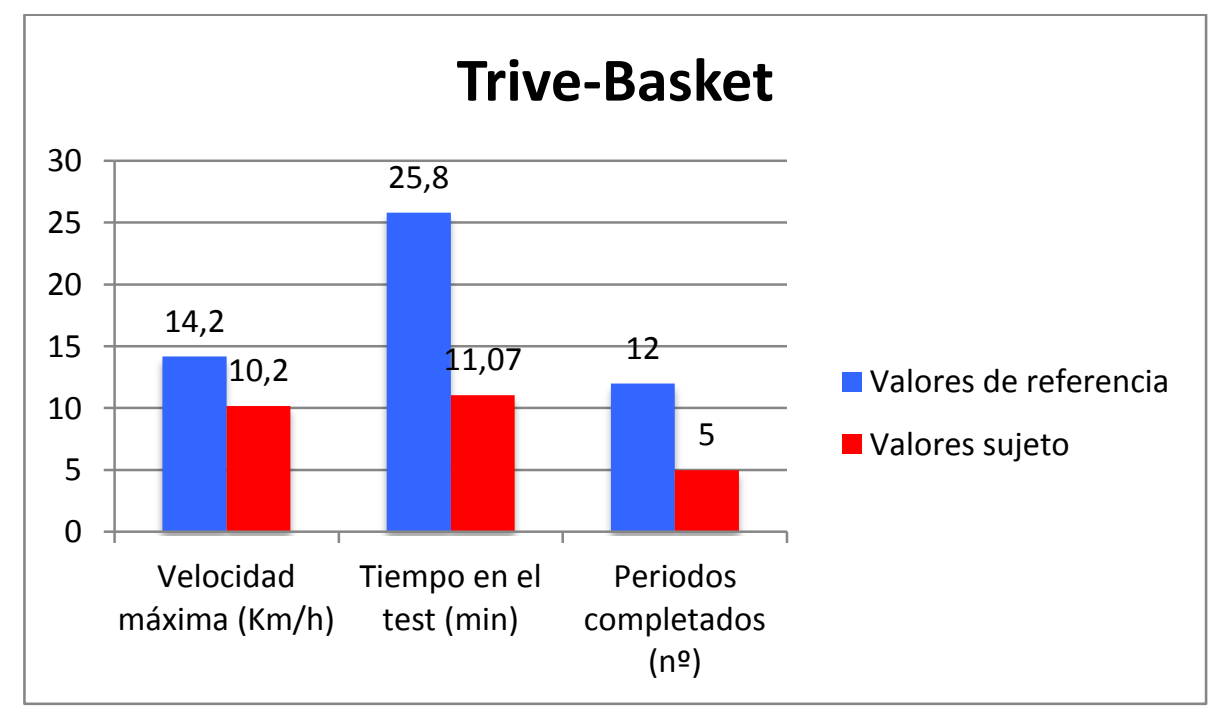

Figura 8. Valores de referencia del estudio Vaquera et al. (2007), en jugadores de liga EBA. 


\section{Resultado Test de agilidad.}

En la tabla 2.8, se muestran los resultados obtenidos en el Agility T-Test, en las tres series, a su vez en la figura 9 , podemos comparar los valores de referencia obtenidos en (Delextrat \& Cohen, 2008) con jugadores universitarios con los de nuestro sujeto.

Tabla 2.8. resultados del Agility T-Test.

\begin{tabular}{ll}
\hline & Tiempo $(\mathrm{s})$ \\
\hline Carrera 1 & 11.223 \\
Carrera 2 & 10.973 \\
Carrera 3 & $\mathbf{1 0 . 7 3 6}$ \\
\hline
\end{tabular}

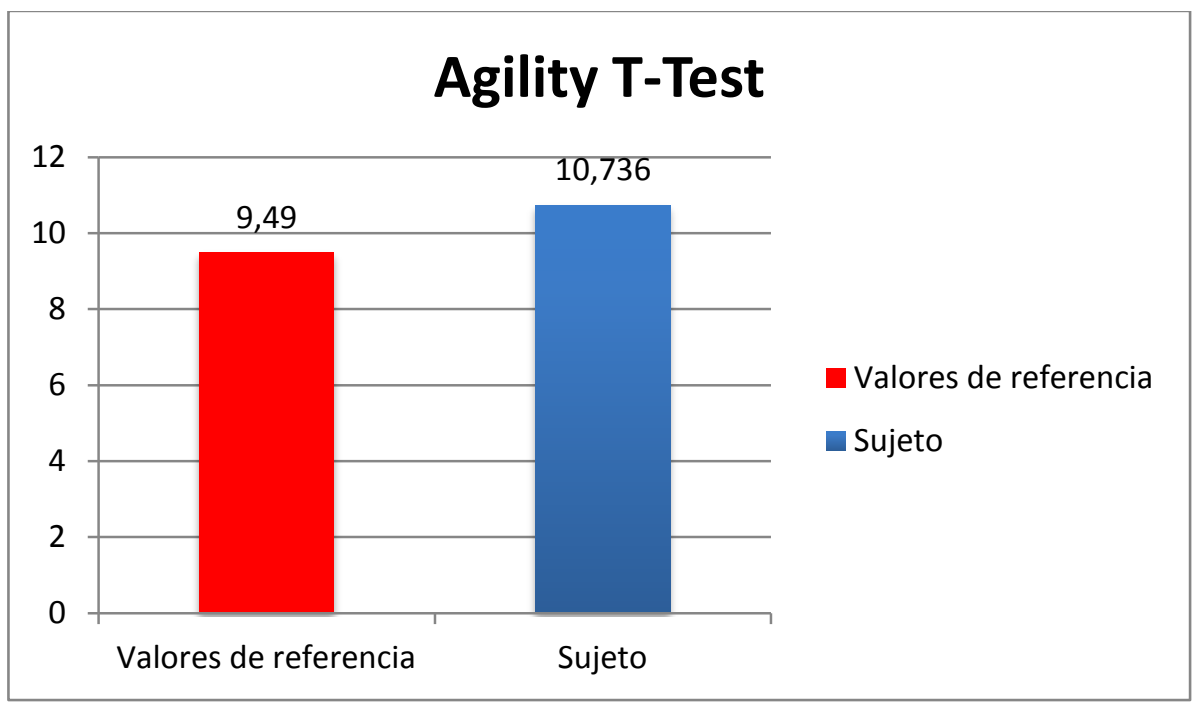

Figura 9. Valores de referencia del estudio Delextrat and Cohen (2008) en jugadores universitarios.

\section{Resultado Test de la capacidad de repetir sprines.}

La tabla 2.9 y figura 10 , se presentas los resultados obtenidos en el test RSA, tanto los tiempo y la velocidad, obtenidos en cada una de las seis carreras como los resultados finales. No encontramos valores de referencia de jugadores de baloncesto para la comparativa. 
Tabla 2.9. Resultados del test RSA.

\begin{tabular}{lll}
\hline & Tiempo $(\mathrm{s})$ & Velocidad $(\mathrm{m} / \mathrm{s})$ \\
\hline Carrera 1 & $\mathbf{8 . 1 3 6}$ & 4.916 \\
Carrera 2 & 8.532 & 4.688 \\
Carrera 3 & 8.541 & 4.683 \\
Carrera 4 & 8.833 & 4.528 \\
Carrera 5 & 8.599 & 4.652 \\
Carrera 6 & $\mathbf{8 . 2 4 8}$ Resultados finales \\
\hline \multicolumn{2}{c}{$\mathbf{4 . 8 5}$} \\
\hline RSAmean & $\mathbf{8 . 5 2 8 2}$ \\
RSAbest & 8.136 \\
Peor & \multicolumn{2}{c}{$\mathbf{8 . 8 8 3}$} \\
Diferencia & .697 \\
RSAdecrement \% & \multicolumn{1}{c}{.048205506 } \\
\hline
\end{tabular}

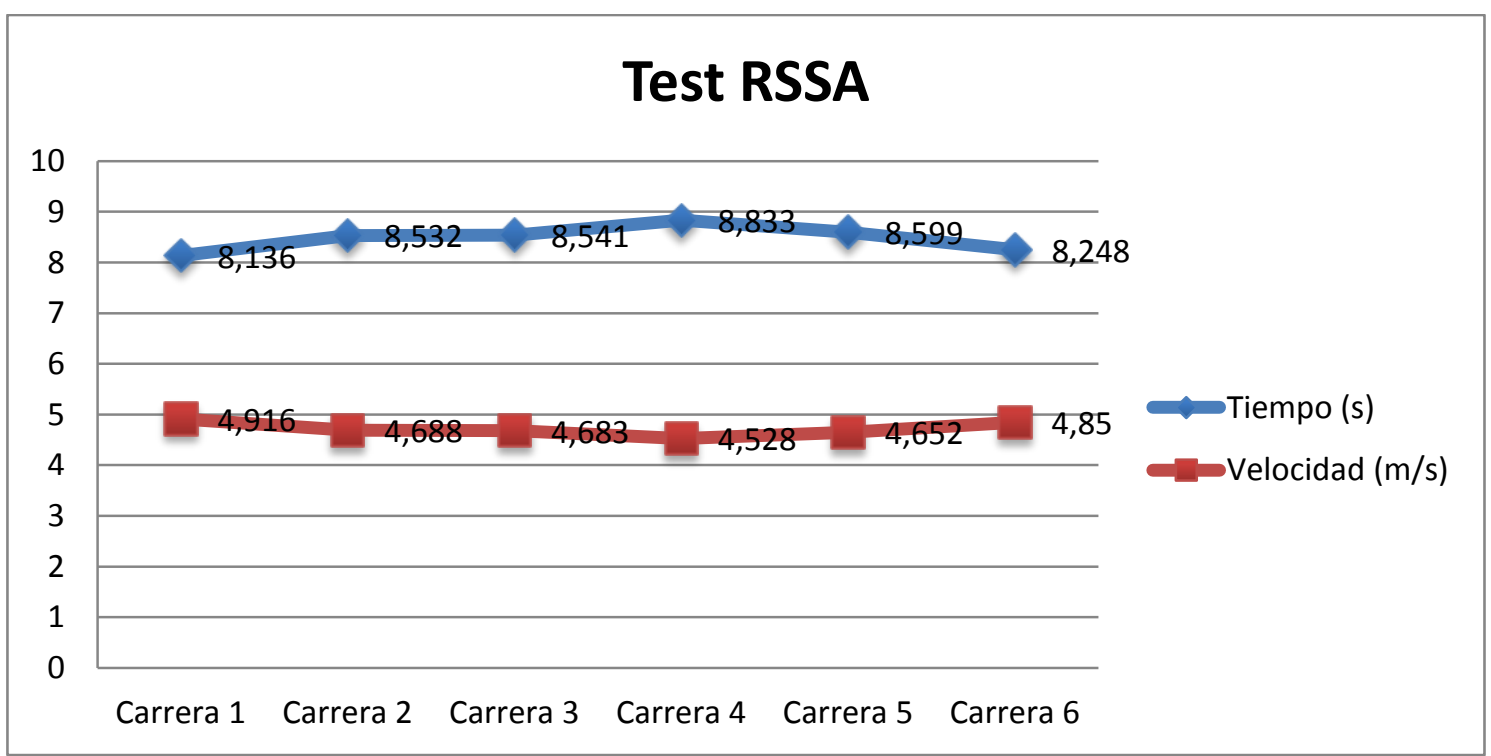

Figura 10. Resultados test RSA.

\section{E. Resultados evaluación de la Fuerza.}

La figura 11 muestra la predicción del Rm del sujeto en press banca realizada por el enconder lineal Cronojump Boscosystem, a su misma vez la figura 12 muestra la curva fuerza - velocidad realizada por este mismo dispositivo en este mismo patrón de movimiento, para terminar podemos observar las barras de potencia en la figura 13 en este mismo movimiento. 


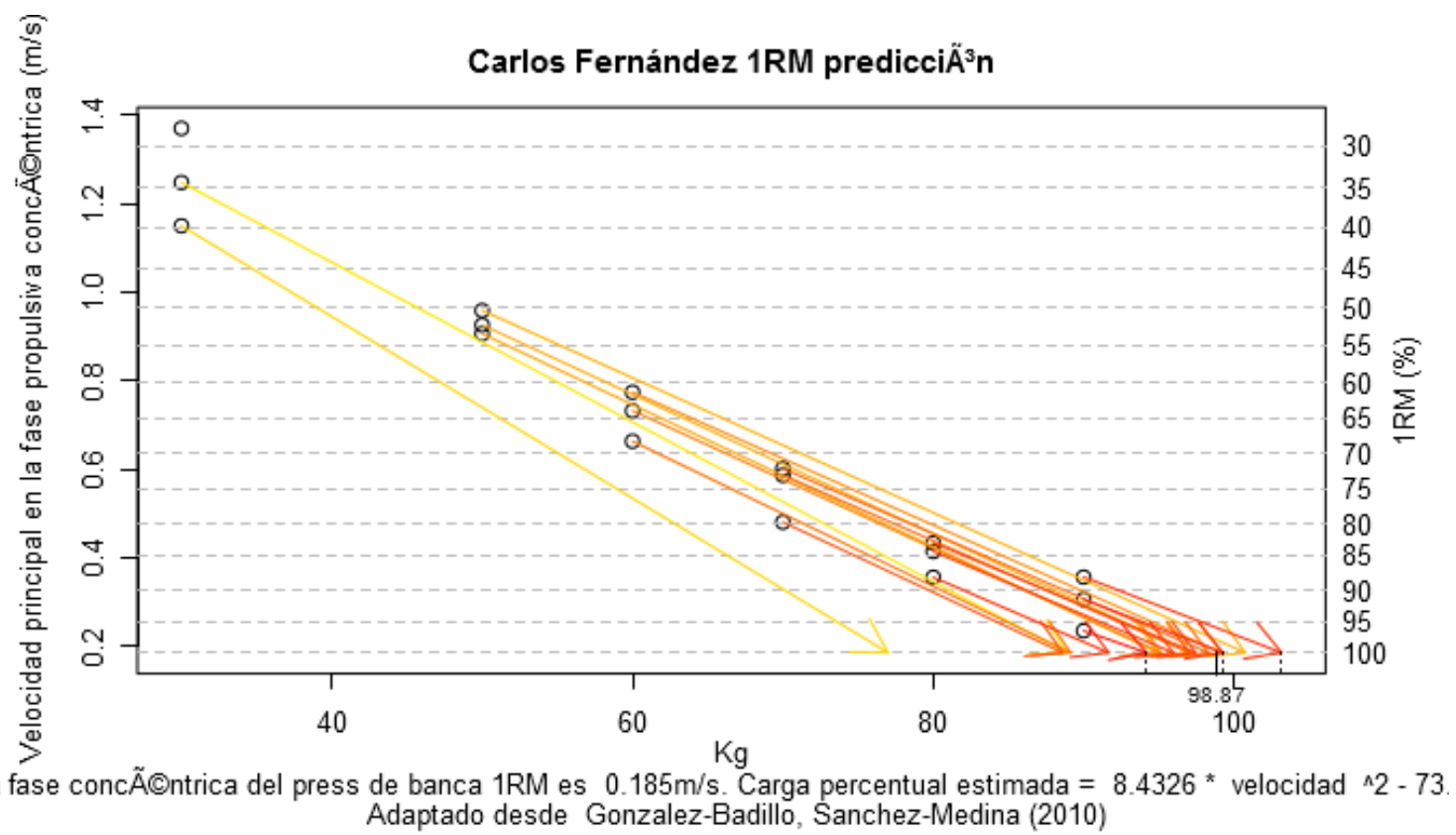

Figura 11. Predicción del RM en press de banca.

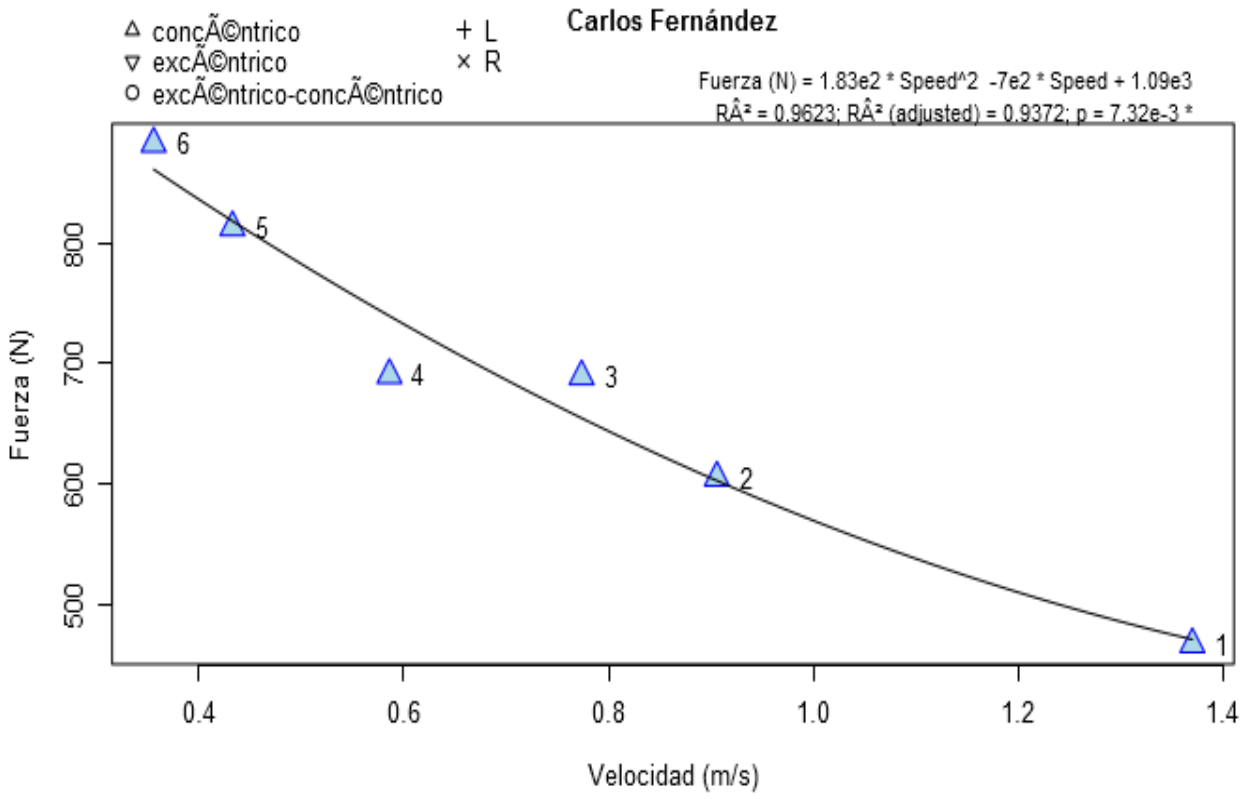

Figura 12. Curva fuerza - velocidad en press de banca. 


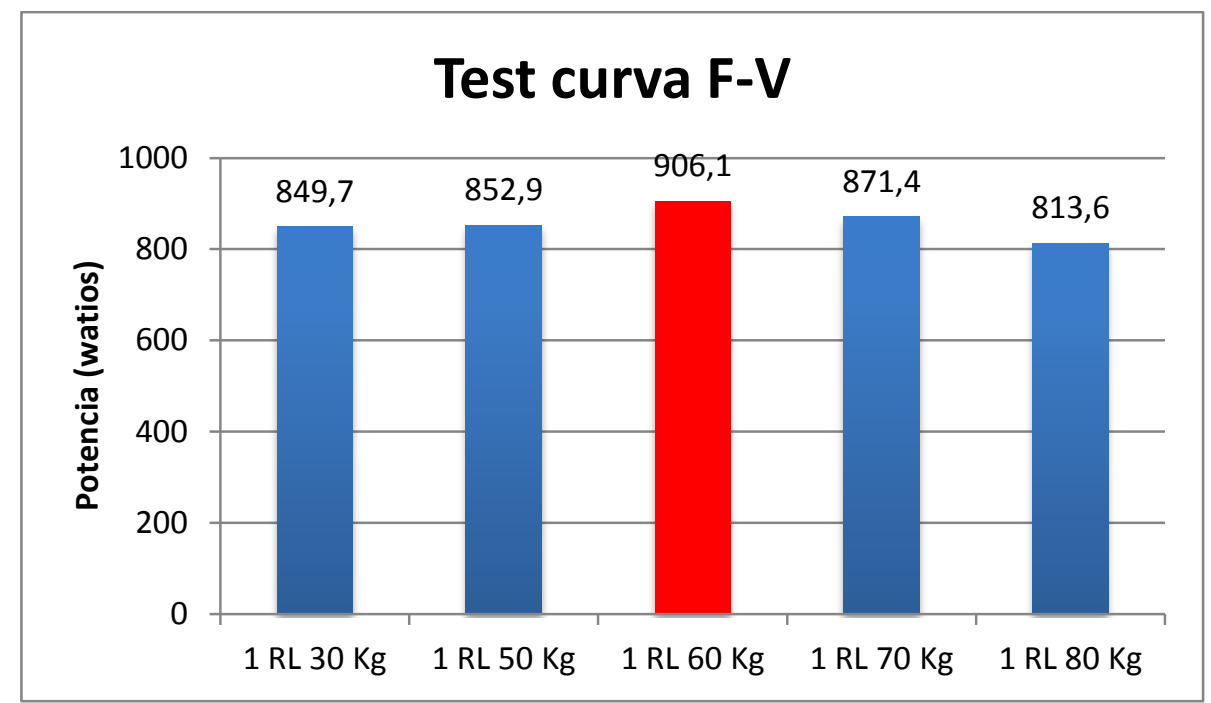

Figura 13. Potencia obtenida en la mejor repetición con cada una de las cargas evaluadas.

La tabla 2.10, muestra los resultados del test de salto CMJ, por otro lado en la tabla 2.11, se observa el test de salto monopodal VJFT, para examinar el déficit bilateral entre una pierna y otra.

Tabla 2.10. Resultado del CMJ.

\begin{tabular}{lllll}
\hline & $\begin{array}{l}\text { Tiempo de } \\
\text { vuelo }(\mathrm{sg})\end{array}$ & Altura $(\mathrm{cm})$ & Potencia $(\mathrm{w})$ & $\begin{array}{l}\text { Velocidad } \\
\text { inicial }(\mathrm{m} / \mathrm{s})\end{array}$ \\
\cline { 2 - 5 } 1ㅇ Intento $^{\circ}$ & .474 & 27.47 & 1114.24 & 2.322 \\
20 Intento $^{\text {o Intento }}$ & .472 & 27.281 & 1110.399 & 2.314 \\
\hline
\end{tabular}

Tabla 2.11. Resultados del test VJFT.

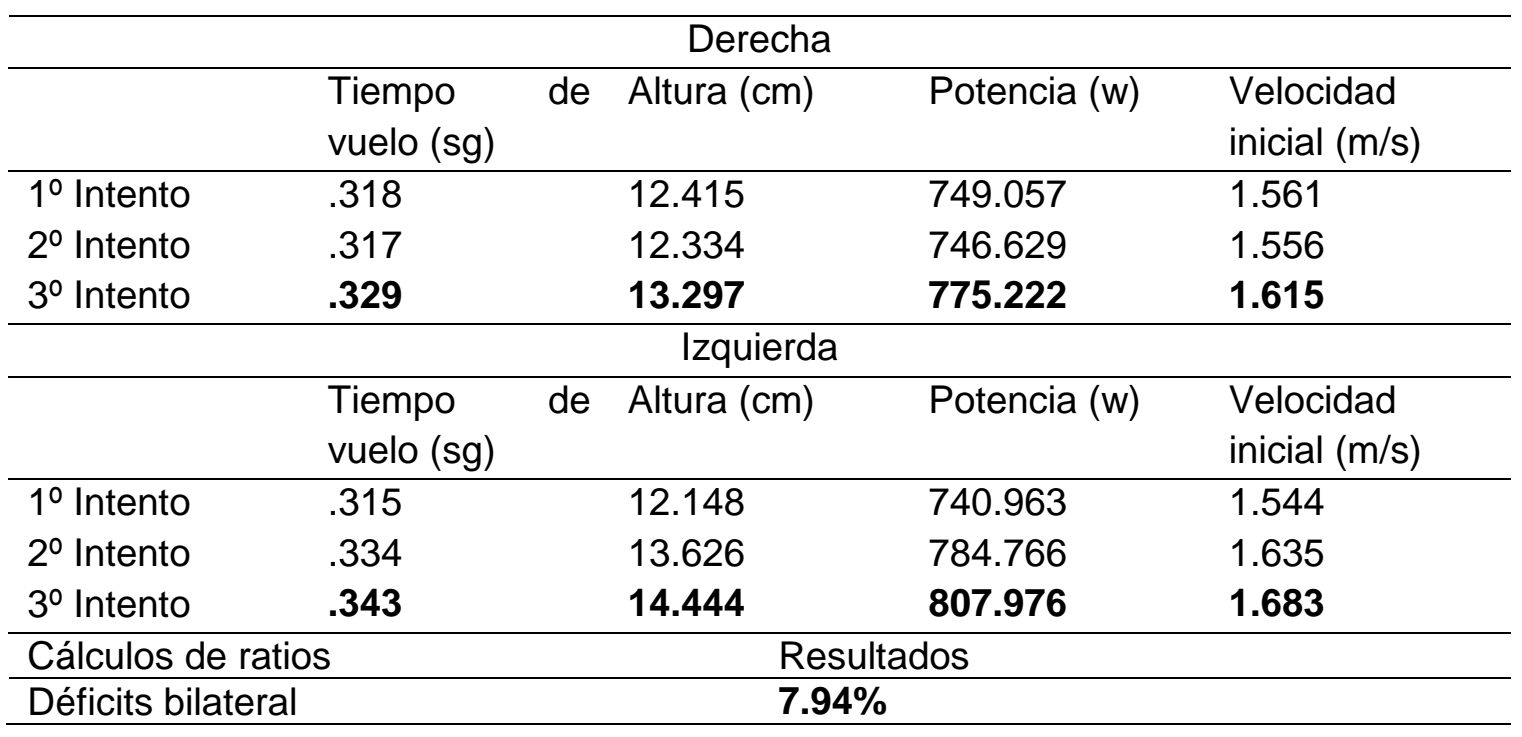




\section{F. Resultado valoración de la estabilidad central.}

La tabla 2.12 expone los datos obtenidos en la propuesta de McGuill 1999 para la valoración de la estabilidad central, los valores de referencia comparados en la figura 14 son los extraídos de la revisión (Peña et al., 2012).

Tabla 2.12. Resultados obtenidos en la prueba para valorar la estabilidad central.

\begin{tabular}{ll}
\hline Test & Tiempo $(\mathrm{s})$ \\
\hline Test modificado Biering-Sorensen & $\mathbf{1 4 0}$ \\
Puente lateral derecha & $\mathbf{8 9}$ \\
Puente lateral izquierda & $\mathbf{9 3}$ \\
Test resistencia flexores & $\mathbf{1 3 5}$ \\
\hline
\end{tabular}

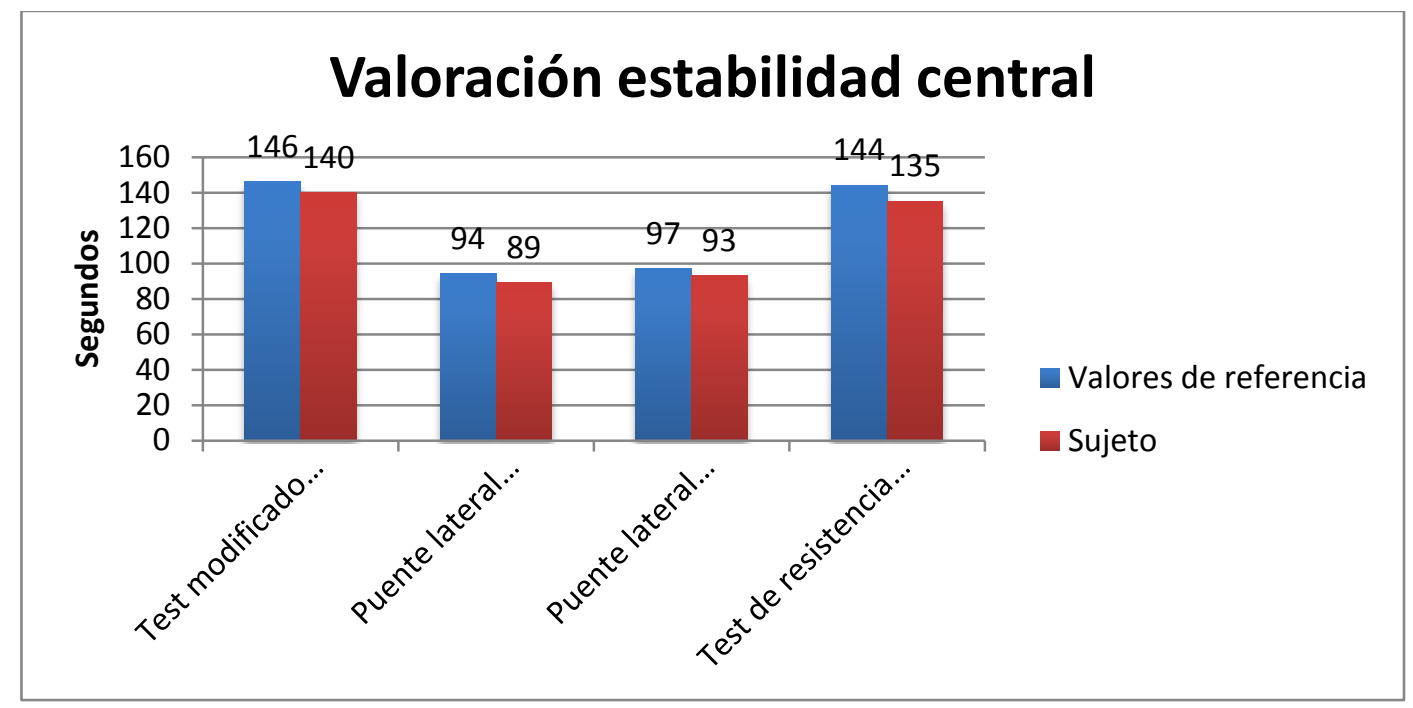

Figura 14. Valores de referencia para la valoración de la estabilidad central expuesto en (Peña et al., 2012).

G. Pruebas musculares; Postura, longitudes y fuerza.

Déficits detectados en longitudes y fuerza, por el activador muscular en su análisis:

- Protrusión cefálica.

- Rotación interna de hombro ambos por igual.

- Trapecio derecho acortado, medio superior e inferior, provocando problemas con el infraespinoso.

- Débiles rotadores externos de la cadera derecha e internos en la izquierda.

- Problemas en la flexión plantar pie derecho, peroneo largo inserción 1o metatarsiano.

- Problemas para activar transverso y oblicuo interno izquierdo. 


\section{H. Resultados cuestionarios de nutrición.}

El informe del análisis de las encuestas alimentarias se encuentran detallado en el anexo 7.

\section{Resultados cuestionarios psicológicos.}

Las tablas $\underline{2.13}$ y $\underline{2.14}$ enuncian los datos de los test psicológicos, no se han encontrado valores de referencia para poder realizar una comparación.

Tabla 2.13. Test de inteligencia emocial TTMS-24.

\begin{tabular}{ccc}
\hline & Test TTMS-24 & \\
\hline Atención & 29 \\
Claridad & 18 \\
Reparación & 27 \\
\hline
\end{tabular}

Tabla 2.14. Test de ansiedad CSAI-2.

\begin{tabular}{cc}
\hline \multicolumn{2}{c}{ Escala de ansiedad CSAI-2 } \\
\hline Ansiedad cognitiva & 18 \\
Ansiedad somática & 12 \\
Auto-estima & 30 \\
\hline
\end{tabular}

\section{J. Resultados análisis de patrones motores básicos y en movimiento}

En el anexo 6 muestran los resultados de los patrones motores básicos. Por otro lado en la tabla 2.15 se muestran los resultados del Test FMS.

Tabla 2.15. Test FMS.

\begin{tabular}{cc}
\hline Prueba & Puntuación \\
\hline Sentadilla profunda & $\mathbf{2}$ \\
Paso de valla & $\mathbf{2}$ \\
Fondos en línea & $\mathbf{3}$ \\
Movilidad del hombro & $\mathbf{3}$ \\
Elevación activa de piernas & $\mathbf{0}$ Aparece dolor \\
Estabilidad del tronco con fondos de & $\mathbf{2}$ \\
brazos & $\mathbf{1}$ \\
Estabilidad rotacional del tronco &
\end{tabular}




\section{4. ¿Cómo interpreto los datos obtenidos?}

\section{A. Resultados evaluación Composición Corporal}

Nos hallamos ante un sujeto con mucha masa muscular, si no es útil esa hipertrofia ante la que nos encontramos contribuye a hacerlo lento en el juego, ya que se produce un aumento tanto de la proteína no contráctil, como del plasma entre las fibras musculares, por el contrario se produce una disminución de las fibras musculares por unidad de superficie, por lo tanto no existe un aumento de nuestra fuerza.

Gran parte de su sobrepeso se explica por la masa magra, lo que pone menos en riesgo su salud en cuanto a enfermedades cardiovasculares y el porcentaje de masa grasa lo hace un valor deseablemente modificable pero no en tanta medida como se podía presuponer a la vista en la evaluación del IMC.

En la evaluación del ratio cintura - cadera nos encontramos con un ratio de 0,83185841 , por lo tanto y siguiendo con los valores de la tabla 2.4, nos encontramos ante un sujeto sin riesgo cardiovascular.

\section{B. Resultados evaluación de la resistencia}

En el test de resistencia Yo-Yo test IR1 para la estimación del $\mathrm{VO}_{2} \mathrm{MAX}$ el sujeto completó hasta el periodo 15,3, tasando su VO2MAX en $50 \mathrm{ml} / \mathrm{Kg} / \mathrm{min}$. Siguiendo los resultados expuestos en la tabla 3.7 de la revisión de Schelling (2012), los valores de VO2MAX del sujeto están por debajo de la media de jugadores de baloncesto, si bien como se ha mencionado antes el VO2MAX no es un factor limitante en el baloncesto(Stojanovic et al., 2012);(Terrados, N, \& Calleja-González, J. 2008)\&(Castagna et al., 2007). Todos los demás ítems evaluados Yo-Yo test IR1 como se muestra en la tabla 2.6, VO2MAX, distancia, velocidad y HRmax, están por debajo de los valores de referencia como se muestran en la figura 4 , figura 5 y figura 6 .

En el Test Trive-Basket el sujeto ha completado 5 periodos. En la figura 7 y figura $\underline{8}$ se muestra como el sujeto vuelve estar por debajo de los valores de referencia

\section{Resultado del agility Test $-\mathrm{T}$}

La figura 9 muestra como los valores de referencia aportado por Delextrat and Cohen (2008), están por encima de los resultado obtenido por nuestro sujeto.

\section{Resultado Test de Repeat Sprint Ability}

Para los test de RSA no tenemos valores de referencia para su comparación, de está manera compararemos los resultado durante y una vez terminada la intervención con los valores obtenidos.

\section{E. Resultados evaluación de la Fuerza}

El RM estimado del sujeto en el patrón de press de banca se halla en $98 \mathrm{Kg}$, teniendo su pico de potencia como podemos observar en la figura 13 en $60 \mathrm{Kg}$, por lo tanto esa será con la carga con la cual debemos trabajar con el. 
La medición basal del CMJ se encuentra en $28.848 \mathrm{~cm}$ como se muestra en la tabla 2.10, no encontramos valores de referencia de alguna muestra parecido a nuestro sujeto para ser comparado.

Los test de salto vertical son frecuentes utilizados para evaluar la potencia de la musculatura extensora de las extremidades inferiores, esta asimetría se refiere a la diferencia relativa en la fuerza máxima entre ambas piernas. (Impellizzeri et al., 2007). Más aún en deportes que impliquen saltos o cambio rápidos de posición, (Vandewalle y cols 1989) citado por Contreras et al. (2013), estos mismo autores exponen el test VJFT para detectar déficit bilaterales en extremidades inferiores mediante la formula (pierna más fuerte - pierna más débil)/pierna más fuerte*100). Según los resultados obtenidos mediante la formula mencionada anteriormente y los resultados que pueden ver en la tabla 2.11, el sujeto no muestra déficit bilateral en tren inferior.

\section{F. Resultado valoración de la estabilidad central}

La comparación de la valoración de la estabilidad central de las cuatro pruebas propuesta por S. McGill (2010), el sujeto se muestra en todas como se observa en la figura 14 por debajo de los valores de referencia aportado por (Peña et al., 2012).

\section{G. Resultado Pruebas musculares; Postura, longitudes y fuerza y patrones motores básicos.}

El análisis de la postura, longitudes y patrones motores básicos lo realizaremos de forma conjunta intentando comprender y establecer relaciones entre los resultados obtenidos.

Según el estudio de la postura y longitudes realizado el trapecio medio superior e inferior derecho se encuentra acortado, provocando problemas con el infraespinoso. El trapecio ayuda a sostener el movimiento de la parte superior del cuerpo entre ellos las escapulas, puede ser el motivo por las cuales, no realiza correctamente el movimiento de retracción como se puede comprobar en el patrón del remo, las escapulas no se aproximan en la fase concéntrica. De igual manera encontramos una rotación interna de los hombros, estos mismos no se mantienen estáticos en la fase final de los patrones motores de empujes verticales, ni en la fase concéntrica de los patrones motores de tracción vertical.

Hallamos una pequeña protrusión cefálica, como posible consecuencia de una disfunción tanto en estabilizadores como en movilizadores de la musculatura escápulotorácica, anexo 8 y anexo 9 , lo cual le impide mantener una alineación correcta de la columna en algunos patrones como en la sentadilla, el peso muerto, la plancha y la plancha lateral.

Encontramos problemas de activación zona CORE como se puede comprobar en la mayoría de los patrones motores, se acentúa en la activación del transverso y oblicuo interno izquierda, como muestra el informe del activador muscular.

Se observó debilidad en los rotadores externos de la cadera derecha e interno de la izquierda, que producen problemas en la rotación izquierda de la columna, y un valgo, anexo 10 y anexo 11 de rodilla en la flexión de esta y en la fase de aterrizaje con apoyo monopodal en ambas piernas. 
A su vez no disocia a nivel lumbo pélvico, como se percibió en el movimiento de caderas hacia atrás en los patrones de sentadilla, y empuje de caderas, realizando la extensión con el tronco y no con la cadera.

Se percibieron inconvenientes en la dorsi-flexión plantar, levanta talones en el patrón del squat, de igual modo se subrayo en la prueba de longitudes y postura que se le realizó problemas en la flexión plantar del pie derecho. Asimismo localizamos supinación en ambos pies como se muestra en las anexo 8, anexo 10 y anexo 11.

\section{H. Resultados cuestionarios de nutrición}

Como comentare en el aparatado 8.3 limitaciones y dificultades, no me encuentro capacitado según la formación recibida para emitir un juicio sobre los datos obtenidos. A su vez no encontré ningún profesional que pudiera ayudarme en este apartado.

\section{Resultados cuestionarios psicológicos}

En cuanto a los aspectos psicológicos hallamos a un sujeto con una alta autoestima una ansiedad somática baja y cognitiva moderada, tabla 2.13 , según estos resultados podríamos suponer que estamos ante un sujeto que no siente presión a la hora de la competición.

El sujeto es capaz de expresar, sentir y reparar sus sentimientos de forma adecuada, aunque en la puntación de compresión de sentimientos está por debajo obteniendo una puntuación de 18, siendo 25 el adecuado, tabla 2.14.

Después del análisis de los test psicológicos, en los cuales los resultados son bastante favorables, podemos interpretar las palabras del entrenador en la evaluación inicial acerca del estado emocional del sujeto y según lo observado en los videos, como acciones puntuales en los cuales el sujeto, se evade de las acciones de juego por falta de concentración.

\section{J. Resultados análisis de patrones en movimiento}

Después de la observación de 5 partidos del sujeto, siguiendo los patrones propuesto por (López, Arias et al. 2014) y evaluados de forma subjetiva, llego a la siguiente conclusión:

- Se siente incómodo a la hora de tirar, penetra más que tira.

- Ágil en el rebote más por posición que por salto, mejor de lo que tira, penetra y defiende.

- Le cuesta correr el contraataque.

- Lento en defensa, le cuesta cambiar de lado cuando le cambian el pie al que le atacan.

- En defensa a los exteriores es bastante lento en los desplazamientos.

- En defensa a exteriores le suelen sacar muchas personales.

- En defensa de interiores, le cuesta taponar tiros por su altura y poco salto

- Déficit en potencia para saltar y cambiar de ritmo. 


\section{Conclusiones generales}

Nos encontramos ante un sujeto con sobrepeso, y podemos suponer según los datos obtenidos en la evolución con una hipertrofia a nivel sarcoplasmica, lo cual hace al sujeto un jugador lento en todos los patrones de movimientos del juego, carencia que suple con ser un jugador rico a nivel táctico y gran resistente a los esfuerzo.

A su vez hallamos en él una protrusión cefálica que puede ser la consecuencia del acortamiento del trapecio, la poca movilidad en el movimiento de retracción de las escapulas y la excesiva de los hombros en los empujes y tracciones verticales, a su vez estos mismos encuentran rotados internamente en su misma medida.

El sujeto encuentra dificultad a la hora de realizar la tripe activación en el trabajo de CORE, a su vez tiene los rotadores externo de la cadera débiles, derivado en un valgo de rodilla.

Por último destacar la supinación en ambos pies y los problemas en la dorsi-flexión plantar. 


\section{EXPOSICIÓN Y ANÁLISIS DE LA CASUÍSTICA Y/O PATOLOGÍA.}

\subsection{Factores limitantes del deporte. Indicadores de carga externa.}

Para una correcta transferencia del trabajo que realicemos con nuestro sujeto a su modalidad y la orientación de las cargas de trabajo, debemos conocer los factores limitantes del baloncesto, como su carga interna y externa. Podemos definir la carga siguiendo a González-Badillo (2002) citado por Schelling (2012), como el conjunto de exigencias psicológicas y biológicas provocadas por las actividades de entrenamiento o competición.

Siguiendo Schelling (2012), los metros recorridos en una partido de baloncesto FIBA, oscila entre $925 \mathrm{~m}$ y $7558 \mathrm{~m}$, con un valor medio de $4486 \mathrm{~m}$. Tomando las publicaciones posteriores al año 2000 la media de metros en un partido asciende a $6679 \mathrm{~m}$, tabla 3.1.

Tabla 3.1. Principales publicaciones que analizan los metros recorridos en baloncesto. Min: Mínimo; Max; Máximo; AVG: Promedio. Revisión tomada de Schelling (2012).

\begin{tabular}{|c|c|c|c|c|c|}
\hline \multicolumn{6}{|c|}{ Metros recorridos } \\
\hline Año & Autor & Nivel & Mínimo & Máximo & Promedio \\
\hline 1941 & Blake & Universitario & 2000 & & 2000 \\
\hline \multirow[t]{2}{*}{1972} & Gradwska & Eq. Nacional & 3809 & & 3809 \\
\hline & & & $\mp 465$ & & \\
\hline \multirow[t]{2}{*}{1973} & Konzag\& & Eq. Nacional & 4480 & & 4480 \\
\hline & Frey & & & & \\
\hline \multirow[t]{2}{*}{1980} & Cohen & $1^{\circ} \quad$ Div. & 3890 & & 3890 \\
\hline & & Francesa & & & \\
\hline \multirow[t]{2}{*}{1985} & Colli & $1^{\circ} \quad$ Div. & 2775 & 3500 & 3137.5 \\
\hline & Faina & Italiana & & & \\
\hline \multirow[t]{2}{*}{1986} & Tiera & $1^{\circ} \quad$ Div. & 5675 & & 5675 \\
\hline & & Española & & & \\
\hline 1986 & Karger & $\begin{array}{l}\text { Femenino } \\
\text { (10 min.) }\end{array}$ & 925 & & 3700 \\
\hline 1987 & Galiano & & 5712 & & 5712 \\
\hline 1987 & Grosgeorge & & 5170 & & 5170 \\
\hline \multirow[t]{2}{*}{1988} & Hernández & $1^{0} \quad$ Div. & 5763 & & 5763 \\
\hline & Moreno & Española & & & \\
\hline \multirow[t]{2}{*}{1993} & Cañizares & Nacional e & 3755.22 & & 3755.55 \\
\hline & \&Sampedro & Internacional & & & \\
\hline \multirow[t]{2}{*}{1995} & Mclnnes y & 1ㅇ Div. & 1340 & 2430 & 1885 \\
\hline & Col. & Australiana & & & \\
\hline \multirow[t]{2}{*}{1998} & Janeira \& & $1^{0} \quad$ Div. & 4955 & & 4955 \\
\hline & Maia & Portuguesa & & & \\
\hline \multirow[t]{2}{*}{2002} & Sousa (en & & & & 5800 \\
\hline & $\begin{array}{l}\text { FEB, } \\
2007: 15)\end{array}$ & & & & \\
\hline \multirow[t]{2}{*}{2010} & Ben & Junior & 6338 & 8397 & 7558 \\
\hline & Abdelkrim y & Túnez & & & \\
\hline
\end{tabular}


Los deportes colectivos se caracterizan por la repetición de acciones de máxima intensidad y descansos de recuperaciones incompletas. El baloncesto, sigue dicho patrón, presentando muchas acciones de alta intensidad como aceleraciones, sprints, y cambios de dirección, además de requerir la capacidad de repetir varias veces dichos patrones. Schelling (2012).

El estudio de Mclnnes y col (1995), propuso diez patrones de movimientos distintos en función de la velocidad de desplazamiento tabla 3.2.

Tabla 3.2. Velocidades de desplazamiento. Adaptación de Mclnnes y col. (1995) en abdelkrinm y col. (2010).

\begin{tabular}{|c|c|c|}
\hline \multicolumn{3}{|c|}{ Velocidades de cada patrón del movimiento } \\
\hline Patrón & Velocidad (km/h) & \\
\hline Parado & 0 & $0 \mathrm{~m} / \mathrm{s}$ \\
\hline Caminar & $<6$ & $<1.69 \mathrm{~m} / \mathrm{s}$ \\
\hline Trotar & $6.1-12$ & $1.70-1.34 \mathrm{~m} / \mathrm{s}$ \\
\hline Carrera moderada & $12.1-18$ & $1.35-5.00 \mathrm{~m} / \mathrm{s}$ \\
\hline Carrera rápida & $18.1-24$ & $5.01-6.67 \mathrm{~m} / \mathrm{s}$ \\
\hline Sprint & $>24$ & $>6.67 \mathrm{~m} / \mathrm{s}$ \\
\hline $\begin{array}{l}\text { Desplazamiento lateral } \\
\text { lento }\end{array}$ & $<6$ & $<1.69 \mathrm{~m} / \mathrm{s}$ \\
\hline $\begin{array}{l}\text { Desplazamiento } \\
\text { moderado }\end{array}$ & $6.1-9$ & $1.70-2.50 \mathrm{~m} / \mathrm{s}$ \\
\hline $\begin{array}{l}\text { Desplazamiento lateral } \\
\text { rápido }\end{array}$ & $>9$ & $>2.50 \mathrm{~m} / \mathrm{s}$ \\
\hline Carrera laterales & $>12$ & $>1.34 \mathrm{~m} / \mathrm{s}$ \\
\hline
\end{tabular}

Investigaciones posteriores al año 2000, tabla 3.2, determinaron que el $34.6 \%$ del tiempo total de juego, se realiza mediante desplazamientos laterales, el $31.2 \%$ de carrera a leve intensidad, el $4.6 \%$ de saltos y el $29.6 \%$ andando.

Por otro lado el grupo de Ben abdelkrim y col, obtuvo que un $11,5 \%$ del tiempo de juego se realizan acciones de alta intensidad, un $11 \%$ de intensidad moderada, un $14 \%$ de baja intensidad y un $63 \%$ se está recuperando. Este mismo autor reporta diferencias significativas en función del momento del partido, destacando el aumento de los metros recorridos trotando y caminando y la reducción de sprint y aceleraciones en la segunda mitad. 
Tabla 3.3. Investigaciones posteriores al año 2000, debido al cambio de reglamento, analizan el tipo, el porcentaje del tiempo de juego y pausa de las acciones en baloncesto. Tiempo de juego (\%): Porcentaje del tiempo de juego. Revisión realizada por Schelling (2012).

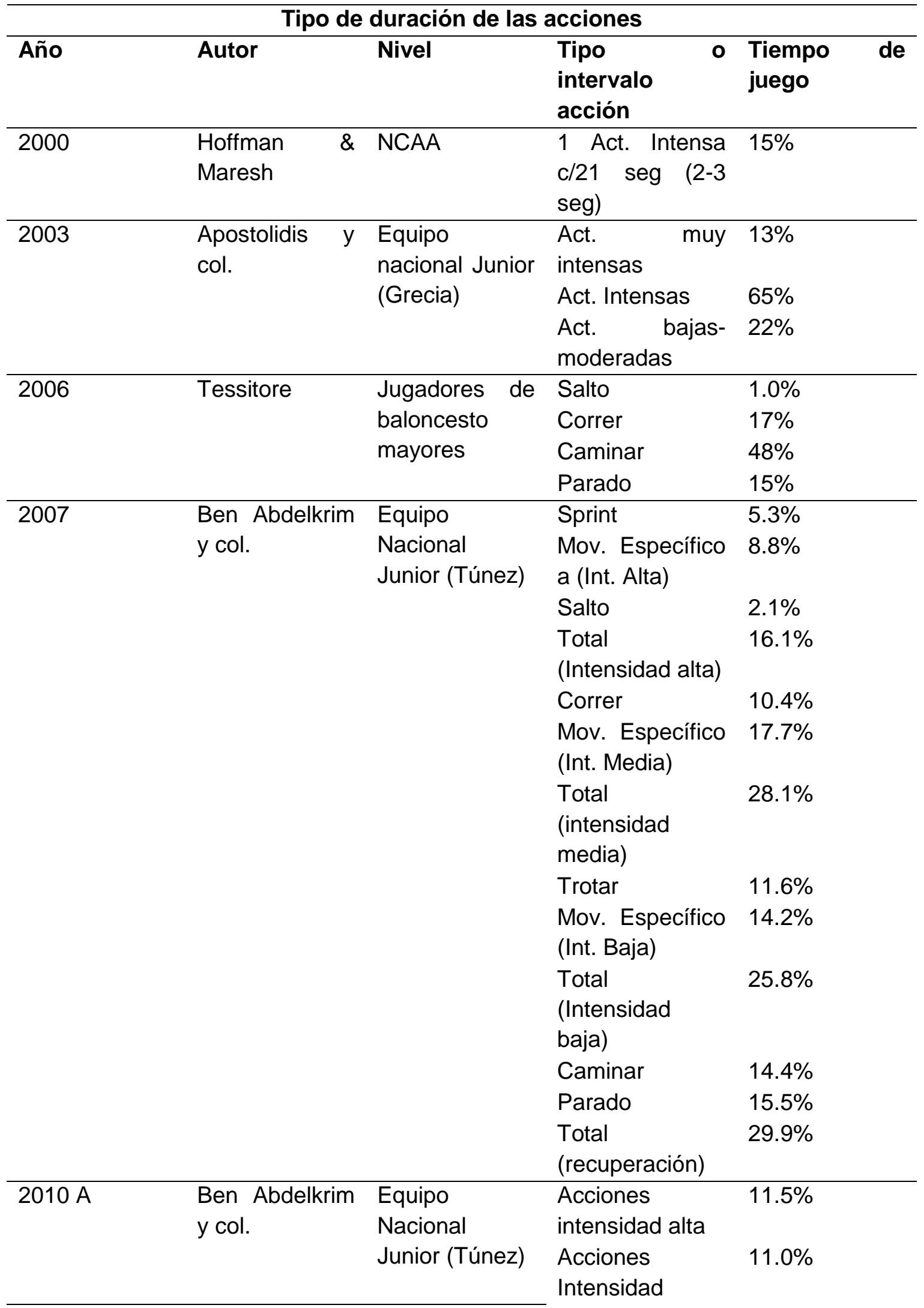




\begin{tabular}{|c|c|c|c|c|}
\hline & & & $\begin{array}{l}\text { media } \\
\text { Acciones } \\
\text { intensidad baja } \\
\text { Recuperación }\end{array}$ & $63.3 \%$ \\
\hline \multirow[t]{16}{*}{$2010 \mathrm{~B}$} & Ben Abdelkrim & Equipo & Sprint & $6.0 \%$ \\
\hline & y col. & $\begin{array}{l}\text { Nacional } \\
\text { Junior (Túnez) }\end{array}$ & $\begin{array}{l}\text { Mov. Específico } \\
\text { (Int. Alta) }\end{array}$ & $9.3 \%$ \\
\hline & & & Salto & $2.0 \%$ \\
\hline & & & Posicionamiento & $2.5 \%$ \\
\hline & & & Bloqueo & $1.6 \%$ \\
\hline & & & $\begin{array}{l}\text { Acciones } \\
\text { estáticas } \\
\text { intensas }\end{array}$ & $4.1 \%$ \\
\hline & & & $\begin{array}{l}\text { Total } \\
\text { (Intensidad alta) }\end{array}$ & $20.3 \%$ \\
\hline & & & Correr & $10.2 \%$ \\
\hline & & & $\begin{array}{l}\text { Mov. Específico } \\
\text { (Int. media) }\end{array}$ & $14.2 \%$ \\
\hline & & & $\begin{array}{l}\text { Total } \\
\text { (intensidad } \\
\text { moderada) }\end{array}$ & $24.4 \%$ \\
\hline & & & Trote & $11.3 \%$ \\
\hline & & & $\begin{array}{l}\text { Mov. Específico } \\
\text { (Intensidad } \\
\text { baja) }\end{array}$ & $13.6 \%$ \\
\hline & & & $\begin{array}{l}\text { Total } \\
\text { (intensidad } \\
\text { baja) }\end{array}$ & $24.8 \%$ \\
\hline & & & Caminar & $14.2 \%$ \\
\hline & & & Parado & $13.9 \%$ \\
\hline & & & $\begin{array}{l}\text { Total } \\
\text { (recuperación) }\end{array}$ & $28.1 \%$ \\
\hline
\end{tabular}

Los trabajos realizados en los años 80 y 90 , donde se estudiaron las acciones y densidades de trabajo de baloncesto, obtuvieron resultados muy similares. Los tiempos de trabajo eran superiores a los de descanso (densidad 2:1) y el $60-70 \%$ de las acciones de juego presentaban duraciones inferiores a 40 segundos. En estas publicaciones, ya se concluía que en situaciones de final de partido la densidad de juego se aumentaba un 1:1, tabla 3.4.

Los estudios posteriores al año 2000, se presentan un aumento en la densidad media de juego (1:1), con predominio de periodos de trabajo y descanso de 15 segundos cada uno, obtienen porcentajes más elevados de acciones de mayor intensidad y establecen que el tiempo de duración de las acciones intensas oscilan entre 2 y 5 segundos. En el estudio de Ben Abdelkrim y col. (2010), obtienen una densidad media de $1: 3$, siendo mayor la $1^{\circ}$ mitad del partido respecto a la $2^{\circ}$. Si solo 
consideramos las acciones muy intensas la densidad varia: acciones máximas de 2-3 segundos se dan cada 21 segundo (1:10), tabla 3.4 .

Tabla 3.4. Tipo y duración de las acciones en baloncesto. Revisión tomada de (Schelling, 2012).

\begin{tabular}{|c|c|c|c|c|c|}
\hline \multicolumn{6}{|c|}{ Duración de las acciones } \\
\hline Año & Autor & Nivel & Intervalo (sg) & $\begin{array}{l}\text { Tiempo de } \\
\text { juego (\%) }\end{array}$ & $\begin{array}{l}\text { Tiempo } \\
\text { de pausa } \\
(\%)\end{array}$ \\
\hline \multirow[t]{5}{*}{1985} & Colli \& Faina & $1^{\circ} \quad$ División & $0-20$ & $27.9 \%$ & $30.1 \%$ \\
\hline & & italiana & $21-40$ & $29.3 \%$ & $27.7 \%$ \\
\hline & & & $41-60$ & $13.9 \%$ & \\
\hline & & & $0-40$ & $57.2 \%$ & $54.4 \%$ \\
\hline & & & $11-40$ & $51.8 \%$ & \\
\hline \multirow[t]{3}{*}{1987} & Dalmonte & 1음 División & $<20 "$ & $16 \%$ & \\
\hline & col. & & $>1 "$ & Muy & \\
\hline & & & & escasas & \\
\hline \multirow[t]{4}{*}{1988} & Hernández & 1으 División & $0-20$ & $41.4 \%$ & $50.8 \%$ \\
\hline & Moreno & España & $21-40$ & $30.7 \%$ & $30.7 \%$ \\
\hline & & & $41-60$ & $14.8 \%$ & \\
\hline & & & $0-40$ & $72.1 \%$ & $81.5 \%$ \\
\hline \multirow[t]{4}{*}{1993} & Cañizares \& & Nacional e & $0-20$ & $26.56 \%$ & $44.82 \%$ \\
\hline & Sampedro & Internacional & $21-40$ & $37.5 \%$ & $36.2 \%$ \\
\hline & & & $41-60$ & $21.87 \%$ & \\
\hline & & & $0-40$ & $64.06 \%$ & $81.02 \%$ \\
\hline \multirow[t]{3}{*}{1993} & Buscató & NBA & $0-30$ & $67 \%$ & \\
\hline & & ACB & $20-40$ & $47 \%$ & \\
\hline & & FIBA & $10-50$ & $67.9 \%$ & \\
\hline \multirow[t]{9}{*}{1995} & Mclnnes y col. & $\begin{array}{l}\text { Australian } \\
\text { national }\end{array}$ & & $\begin{array}{l}\text { Duración } \\
\text { media (sg) }\end{array}$ & \\
\hline & & basketball & Salto & .9 & \\
\hline & & league & Sprint & 1.7 & \\
\hline & & (ANBL) & Corriendo & 2.3 & \\
\hline & & & Trotando & 2.5 & \\
\hline & & & $\begin{array}{l}\text { Dezplaz. lateral } \\
\text { (rápido) }\end{array}$ & 2 & \\
\hline & & & $\begin{array}{l}\text { Dezplaz. lateral } \\
\text { (moderado) }\end{array}$ & 1.9 & \\
\hline & & & $\begin{array}{l}\text { Dezplaz. lateral } \\
\text { (lento) }\end{array}$ & 1.8 & \\
\hline & & & Caminar/parado & 2.5 & \\
\hline \multirow[t]{2}{*}{2002} & Papadopoulos & 1으 División & $<1 "$ & $88 \%$ & 86 \\
\hline & y col. & $\begin{array}{l}\text { Alemania e } \\
\text { Int. }\end{array}$ & $16 "$ & & \\
\hline 2002 & Barrios & $\mathrm{ACB}$ & $\begin{array}{l}\text { Tiempo medio } \\
\text { de acción }\end{array}$ & $30.7 \mathrm{sg}$ & \\
\hline
\end{tabular}




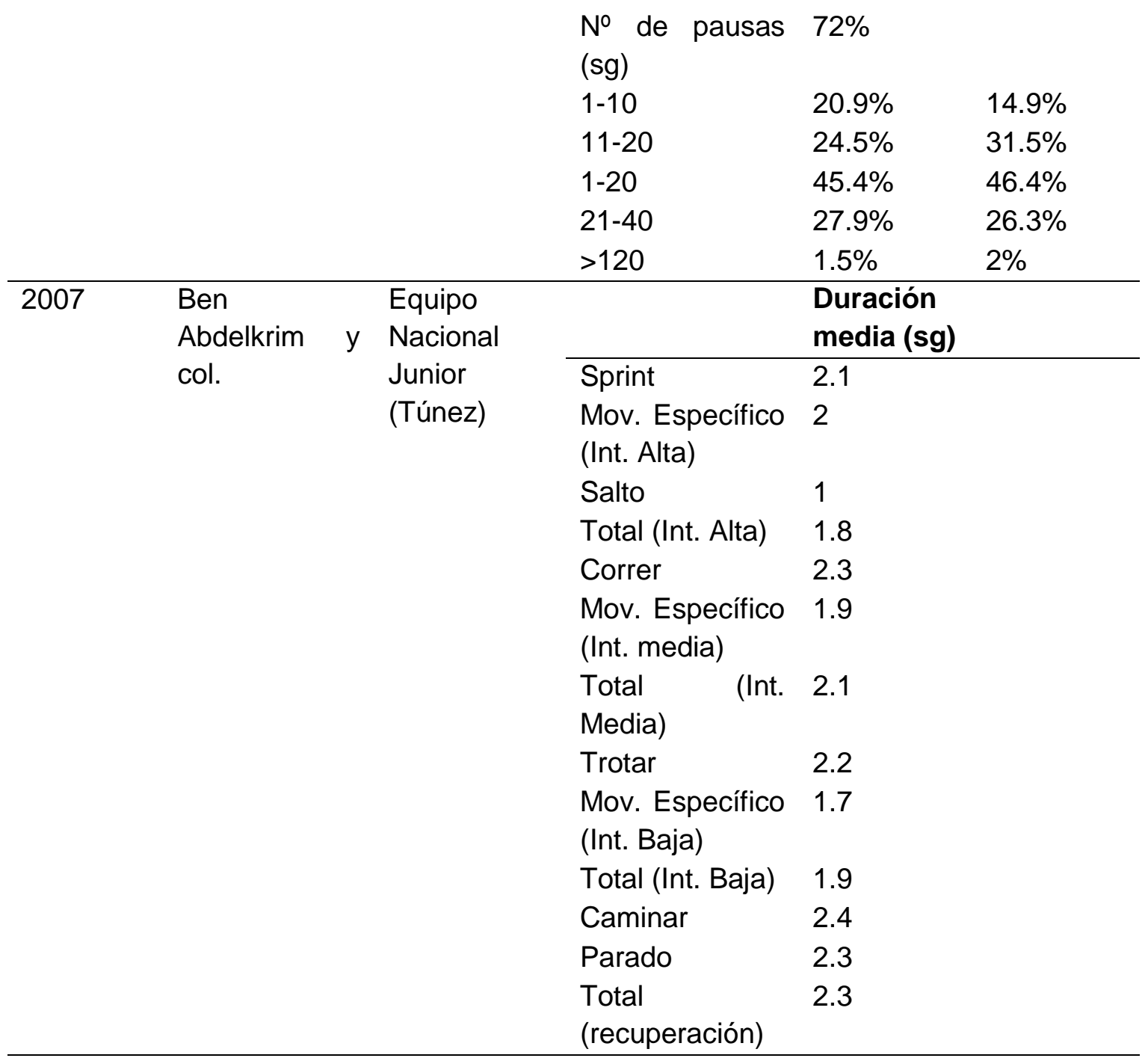

En el baloncesto actual se desarrollan alrededor de 1000 acciones por partido:44 saltos, 55 sprint, 97 carreras rápidas, 113 carreras moderadas, 276 acciones de recuperación o descanso, 175 desplazamientos laterales a ritmo lento, 197 desplazamientos laterales a ritmo medio, 94 desplazamientos a ritmo rápido; cambiando de patrón cada 2-3 segundos. Es importante destacar que no se encuentran patrones de movimientos periódicos ni estándar, lo que ha llevado a considerar el baloncesto como un deporte intermitente imprevisible. 
Tabla 3.5. Diferencia entre la frecuencia de acciones antes y después del año 2000. Revisión tomada en (Schelling, 2012).

\begin{tabular}{|c|c|c|c|c|}
\hline \multicolumn{5}{|c|}{ Frecuencia de acciones } \\
\hline & $\begin{array}{c}\text { Antes del } \\
\text { 2000Mclnnes } \\
(1995)\end{array}$ & & $\begin{array}{c}\text { Después del } \\
2000 \text { Ben } \\
\text { Abdelkrim } \\
(2007)\end{array}$ & Dif. \\
\hline Saltos & 46 & & 44 & $-4 \%$ \\
\hline Sprint & 105 & $>$ & 55 & $-48 \%$ \\
\hline Carrera rápida & 107 & $>$ & 97 & $-9 \%$ \\
\hline $\begin{array}{c}\text { Carrera } \\
\text { moderada }\end{array}$ & 99 & $<$ & 113 & $-14 \%$ \\
\hline $\begin{array}{l}\text { Acciones de } \\
\text { recuperación }\end{array}$ & 295 & $>$ & 276 & $-6 \%$ \\
\hline $\begin{array}{c}\text { Dezplaz. } \\
\text { Lateral (lento) }\end{array}$ & 168 & $<$ & 175 & $4 \%$ \\
\hline $\begin{array}{l}\text { Dezpla. Lateral } \\
\text { (moderado }\end{array}$ & 114 & $<$ & 197 & $73 \%$ \\
\hline $\begin{array}{l}\text { Dezpla. Lateral } \\
\text { (rápido) }\end{array}$ & 63 & $<$ & 94 & $49 \%$ \\
\hline Total & 997 & & 1051 & $5 \%$ \\
\hline
\end{tabular}




\subsection{Factores limitantes del deporte. Indicadores de carga interna.}

La frecuencia cardiaca media del tiempo de juego, en una competición de categoría sénior masculina, oscila entre 165 y 170 latidos por minuto tabla 3.6, presentando un rango entre 140-208 latidos por minutos. Los valores varían en función de las diferentes acciones y momentos del juego, de la posición y de la categoría. Jainera y Maia (1998), presentan valores medios de frecuencia cardiaca de $168+-9$ latidos por minutos. Dichos valores se sitúan entre el $80 \%$ y $90 \%$ de la frecuencia cardiaca máxima del jugador. Durante el $75 \%$ del tiempo total de juego los valores superan el $85 \%$ de la frecuencia cardiaca máxima y el $15 \%$ superan el $95 \%$ de la frecuencia cardiaca máxima.

Tabla 3.6. Promedio de frecuencia cardíaca en competición. FC promedio. Revisión tomada en (Schelling, 2012).

\begin{tabular}{|c|c|c|c|c|c|}
\hline \multicolumn{6}{|c|}{ Frecuencia cardíaca promedio } \\
\hline Año & Autor & & Nivel & & Avg. \\
\hline 1970 & Ramsey y col. & & Universi & & 170 \\
\hline 1985 & Colli\& Faina & & $1^{\circ}$ Div. It & iana & 170 \\
\hline 1992 & Sampedro & & $1^{\circ}$ Div. $E$ & pañola & 165 \\
\hline 1995 & Mclnnes y col. & & $1^{\circ}$ Div. $A$ & straliana & 168 \\
\hline 1997 & $\begin{array}{l}\text { López - Calbet } \\
\text { col. }\end{array}$ & $y$ & Cadetes & & 188 \\
\hline 1998 & Janeira \& Maia & & $1^{\circ}$ Div. $P$ & rtuguesa & 167 \\
\hline 2003 & Blanco \& De brito & & $\begin{array}{l}\text { Pre-ado } \\
\text { adolecel }\end{array}$ & $\begin{array}{l}\text { centes y } \\
\text { es }\end{array}$ & 169 \\
\hline 2007 & $\begin{array}{l}\text { Ben abdelkrim } \\
\text { col. }\end{array}$ & y & $\begin{array}{l}\text { Equipo } \\
\text { Junior }\end{array}$ & nacional & 171 \\
\hline 2008 & Vaquera y col. & & $\begin{array}{l}2^{\circ} \text { Div. } \\
\text { (LEB) }\end{array}$ & Española & 156 \\
\hline 2009 & $\begin{array}{l}\text { Ben abdelkrim } \\
\text { col. }\end{array}$ & $y$ & $\begin{array}{l}\text { Equipo } \\
\text { Junior }\end{array}$ & nacional & 175 \\
\hline 2010 & $\begin{array}{l}\text { Ben abdelkrim } \\
\text { col. }\end{array}$ & $y$ & $\begin{array}{l}\text { Equipo } \\
\text { Junior }\end{array}$ & nacional & 175 \\
\hline
\end{tabular}

En baloncesto, el valor medio de VO2MAX, mediante pruebas de laboratorios es de $53.3+-5.2 \mathrm{ml} / \mathrm{kg} / \mathrm{min}$ tabla 37 , pero se han llegado a obtener valores de hasta $74.4 \mathrm{ml} / \mathrm{kg} / \mathrm{min}$ en jugadores jóvenes. El trabajo de Narazaki y col (2008), probablemente sea la referencia sobre VO2MAX, obtenido durante un partido valores medios de 36.9 +- $2.6 \mathrm{ml} / \mathrm{kg} / \mathrm{min}$ en hombres, representando el $66.7+-7.5 \%$ del VO2MAX.

Según algunas investigaciones, existe relación positiva entre la capacidad de repetir esfuerzo de alta intensidad y los valores $\mathrm{VO}_{2} \mathrm{MAX}$ obtenidos en laboratorio. Esto podría justificarse porque una mejora del perfil aeróbico permite que esfuerzos anaeróbicos se vuelvan aeróbicos (retrasando así la aparición de fatiga), mejora la recuperación de los esfuerzos anaeróbicos y permite mantener una mejor eficiencia técnica durante más tiempo. 
Tabla 3.7. Consumo de oxígeno máximo en jugadores de baloncesto de competición. Revisión tomada en (Schelling, 2012).

\begin{tabular}{|c|c|c|c|}
\hline \multicolumn{4}{|c|}{ Consumo de oxígeno máximo (VO2 máximo) } \\
\hline Año & Autor & Nivel & $\mathrm{ml} / \mathrm{kg} / \mathrm{min}$ \\
\hline 1956 & Anstrand \& Rodahl & & 60 \\
\hline 1967 & Cumming y col. & & 53 \\
\hline 1974 & Coleman y col. & Universitarios & $51.1-50.3$ \\
\hline 1975 & Parnat y col. & Nacionales & $55.3 \mp 1.8$ \\
\hline 1977 & Cabrera & Senior & $50.4 \mp 5.68$ \\
\hline 1977 & Withers y col. & Nacionales & $58.5 \mp 6.68$ \\
\hline 1978 & Parr y col. & NBA & $41.9-50$ \\
\hline 1978 & Verma y col. & Nacionales & $53.4 \mp 54.2$ \\
\hline 1978 & Bergh y col. & & 52.3 \\
\hline 1979 & Bruce \&Maresh & Universitarios & 43.1 \\
\hline 1984 & Ecclache & & 50 \\
\hline 1987 & Dalmonte y col. & Nacionales & $54.8 \mp 5.2$ \\
\hline 1987 & Rosa y col. & & 59 \\
\hline 1987 & Rost & & 50 \\
\hline 1988 & Garl y col. & Universitarios & 55.2 \\
\hline 1989 & Aragonés & Senior & $55.9-57.2$ \\
\hline 1990 & Jousellin y col. & Selección & 57.5 \\
\hline 1990 & Layús y col. & Local & $57 \mp 5.41$ \\
\hline 1990 & González \& Rubio & & $49 \mp 5$ \\
\hline 1995 & Mclnnes y col. & NBL & $60.7 \mp 8.6$ \\
\hline 1995 & Tavino y col. & Universitarios & $61.8 \mp 65.2$ \\
\hline 2001 & Petrovic y col. & $\begin{array}{c}\text { Selección cadete } \\
\text { YUG }\end{array}$ & $43.3 \mp 8.82$ \\
\hline 2004 & Calleja y col. & $\begin{array}{c}\text { Selección Junior } \\
\text { XXI }\end{array}$ & $56.9 \mp 1.7$ \\
\hline 2008 & Narazaki y col. & Universitarios & $57.5 \mp 8.2$ \\
\hline 2010 & $\begin{array}{c}\text { Ben Abdelkikrim y } \\
\text { col. }\end{array}$ & Internacionales & $54.4 \mp 1.9$ \\
\hline 2010 & $\begin{array}{c}\text { Ben Abdelkikrim y } \\
\text { col. }\end{array}$ & Nacionales & $51.6 \mp 2.0$ \\
\hline
\end{tabular}

El baloncesto es un deporte que se caracteriza por una gran variedad de patrones de movimiento asociados a un proceso de toma de decisión, las tareas son muy abiertas y las acciones motrices muy dispares, representando gran complejidad para el jugador: gestos con o sin oposición, con o sin balón, en cadena cinética abierta o cerrada, monopodal, bipodal, etc. Para ello se utilizan un gran número de músculos en la ejecución de cada uno de los gestos técnicos. En este sentido, y basándonos en la clasificación propuesta por Zintl (1991), en la práctica del baloncesto se utiliza, simultáneamente, entre $1 / 6$ y $1 / 7$ parte de la musculatura total de deportista. Si además atendemos a la taxonomía de deportes dispuesta por Mitchell y col. (1994), 
consideramos el baloncesto un deporte dinámico en el que se movilizan una gran cantidad de musculatura con poco desarrollo de fuerza (máxima). 


\subsection{La Prevención de lesiones en el deporte}

Como exponen Romero Rodriguez and Tous Fajardo (2011), a la hora de realizar un plan preventivo, se debe tener en cuenta:

- La multilateralidad y polivalencia de la carga: cualidades físicas más importantes a trabajar con el objetivo de disminuir el riesgo de lesión, además de tener en cuenta las habilidades técnico-táctica del deporte en cuestión.

- La especialización: las cargas en un plan de prevención deben de estar orientadas de forma específicas a cada especialidad deportiva.

- La individualización, debe adaptarse de forma específica al deportista.

- La alteración cíclica o periodización. Distribuir multilateralmente las cargas en el tiempo. También es preciso repetir sistemáticamente dichas cargas y sus variaciones en intervalos de duración.

Estos principios intentan consolidar la base de la planificación del plan de prevención una vez se haya analizado el problema (Romero Rodriguez and Tous Fajardo (2011).

Para el correcto desarrollo de un plan preventivo, como exponen Romero Rodriguez and Tous Fajardo (2011), en su obra seguiremos los pasos marcado por Van Mechelen (1992), de este modo podremos satisfacer las necesidades específicas del problema que se nos presenta.

Fases del plan de prevención. Esquema inspirado en la idea de Van Mechelen (1992), citado por (Romero Rodriguez and Tous Fajardo (2011);

1ำ paso; estudio de la lesión:

- Incidencia.

- Localización corporal y severidad de la lesión.

- Repercusión social y económica.

Una vez terminado el primer paso se sacará una conclusión sobre la repercusión del problema.

$2^{\circ}$ paso; análisis sobre la etiología del problema:

- Estudio de los factores de riesgo.

- Estudio de los mecanismo de lesión.

3 ำ paso; preparación de un plan de prevención según el análisis previo realizado:

- Establecimiento de objetivos.

- Estimación del coste económico.

- Necesidades sobre equipamiento e instalaciones.

- Posibilidades de adaptación a la planificación deportiva de la temporada. 
4ํpaso; Evaluación del plan ejecutado:

- Análisis económico.

- Análisis lesivo.

- Análisis sobre la implantación real desarrollada. 


\subsubsection{Epidemiología en el Baloncesto.}

Como se expone en el primer paso, la puesta en marcha del plan preventivo consistirá en un estudio profundo, sobre la epidemiología del baloncesto.

Las partes lesionadas con más frecuencia en el baloncesto masculino como expone Dick, Hertel, Agel, Grossman, and Marshall (2007) y se observa en la tabla 3.8, son la cabeza/cuello, extremidades superiores, tronco/espalda, extremidades inferiores y otros.

Tabla 3.8. Porcentaje de las partes del cuerpo mas lesionadas, durante el juego y entrenamiento, en baloncesto masculino.

\begin{tabular}{ccc}
\hline Partes del cuerpo & Partido & Entrenamiento \\
\hline Cabeza/cuello & $13.9 \%$ & $11.2 \%$ \\
Extremidad superior & $14.1 \%$ & $11.1 \%$ \\
Tronco/espalda & $11.4 \%$ & $13.5 \%$ \\
Extremidad inferior & $57.9 \%$ & $60.6 \%$ \\
Otros & $2.7 \%$ & $3.6 \%$ \\
\hline
\end{tabular}

Profundizando una poco más en el contenido Dick et al. (2007), nos relaciona las partes del cuerpo con más frecuencia lesionadas en baloncesto masculino y el tipo de lesión que se produce tanto en partidos como en entrenamientos.

Tabla 3.9. Lesiones más frecuentes tanto en los partidos como en los entrenamientos en baloncesto masculino, en los años 2003-2004.

\begin{tabular}{cccc}
\hline Parte del cuerpo & Pesión & Frecuencia & $\begin{array}{c}\text { Porcentaje de } \\
\text { lesión }\end{array}$ \\
\hline Tobillo & Esguince & 1103 & 26 \\
Rodilla & Trastorno interno & 312 & 7.4 \\
Muslo & Contusión & 163 & 3.9 \\
Cabeza & Conmoción cerebral & 151 & 3.6 \\
Rotula & Lesión en el tendón & 99 & 2.4 \\
Sin especificar & rotuliano & & \\
Espalda & Sin especificar & 94 & 2.2 \\
& Distensión muscular- & 91 & 2.2 \\
Pelvi-cadera & tendón & & 2.1 \\
Pelvi-cadera & Contusión & 89 & 2.0 \\
& Distensión muscular- & 86 & \\
Muslo & tendón & & 1.9 \\
& Distensión muscular- & 79 & 1.7 \\
Nariz & tendón & & 1.6 \\
Muñeca & Fractura & 73 & 1.5 \\
Rodilla & Esguince & 69 & 1.3 \\
Pie & Contusión & 61 & 1.3 \\
Pie & Esguince & 55 &
\end{tabular}




\begin{tabular}{|c|c|c|c|}
\hline Espalda & Contusión & 52 & 1.2 \\
\hline Cara & & 47 & 1.1 \\
\hline Cabeza & & 43 & 1.0 \\
\hline Parte inferior pierna & Distensión muscular & 43 & 1.0 \\
\hline $\begin{array}{l}\text { Parte inferior de la } \\
\text { pierna }\end{array}$ & Contusión & 42 & 1.0 \\
\hline Pulgar & Esguince & 43 & 1.0 \\
\hline \multicolumn{4}{|c|}{ Entrenamiento } \\
\hline Parte del cuerpo & Tipo de lesión & Frecuencia & $\begin{array}{l}\text { Porcentaje de } \\
\text { lesión }\end{array}$ \\
\hline Tobillo & Esguince & 2012 & 26.8 \\
\hline Rodilla & Trastorno interno & 488 & 6.2 \\
\hline Pelvis, cadera & Distensión muscular & 348 & 4.4 \\
\hline Rotula & Conmoción celebrar & 292 & 3.7 \\
\hline Espalda & Distensión muscular & 283 & 3.6 \\
\hline Muslo & Distensión muscular & 283 & 3.6 \\
\hline Sin especificar & Sin especificar & 242 & 3.1 \\
\hline Cabeza & Contusión & 236 & 3.0 \\
\hline Muslo & Contusión & 187 & 2.4 \\
\hline Nariz & Fractura & 115 & 1.5 \\
\hline Pie & Esguince & 102 & 1.3 \\
\hline Pulgar & Esguince & 101 & 1.3 \\
\hline $\begin{array}{l}\text { Parte inferior de la } \\
\text { pierna }\end{array}$ & Distensión muscular & 93 & 1.2 \\
\hline Pie & Fractura por stress & 90 & 1.2 \\
\hline Pelvis, cadera & Contusión & 79 & 1.0 \\
\hline
\end{tabular}

Dos años después Flood and Harrison (2009), aportaron una nueva investigación en esta materia, haciendo en el mismo artículo una comparativa entre el baloncesto masculino y femenino en diagnostico de lesiones, el estudio mostro la asistencia a diversos centros de salud de Estados Unidos de jugadores y jugadoras de baloncesto y la parte del cuerpo dañada, tabla 3.10. 
Tabla 3.10. Datos aportado por el estudio de Flood and Harrison en el año (2009), sobre diagnostico y lesiones en baloncesto.

\begin{tabular}{|c|c|c|}
\hline $\begin{array}{l}\text { Lesión del cuerpo } \\
\text { dañada }\end{array}$ & Hombre & Mujeres \\
\hline Rodilla o pierna & $22.9 \%$ & $28.6 \%$ \\
\hline Codo o antebrazo & $19.5 \%$ & $17.4 \%$ \\
\hline Muñeca & $16.4 \%$ & $14.8 \%$ \\
\hline Cabeza & $13.3 \%$ & $13.2 \%$ \\
\hline Tobillo o pie & $12.8 \%$ & $9.3 \%$ \\
\hline Hombro o brazo & $4.9 \%$ & $2.2 \%$ \\
\hline Tronco & $2.4 \%$ & $2.5 \%$ \\
\hline Cadera o muslo & $1.6 \%$ & $1.0 \%$ \\
\hline Cuello & $0.7 \%$ & $2.4 \%$ \\
\hline Otros & $5.4 \%$ & $8.5 \%$ \\
\hline Diagnostico & Hombres & Mujeres \\
\hline Fractura & $49.9 \%$ & $40.3 \%$ \\
\hline Luxación & $10.9 \%$ & $10.1 \%$ \\
\hline Esguince & $10.6 \%$ & $19.4 \%$ \\
\hline Lesiones tendón & $10.0 \%$ & $7.3 \%$ \\
\hline Otras lesiones & $6.5 \%$ & $7.9 \%$ \\
\hline Sin lesión & $4.9 \%$ & $7.6 \%$ \\
\hline Lesión intracraneal & $3.2 \%$ & $5.0 \%$ \\
\hline Heridas & $2.7 \%$ & $0.6 \%$ \\
\hline Lesión superficial & $1.8 \%$ & $1.8 \%$ \\
\hline Principal diagnostico & Hombres & Mujeres \\
\hline Fractura de antebrazo & $18.6 \%$ & $17.0 \%$ \\
\hline $\begin{array}{l}\text { Luxación, esguince o } \\
\text { torcedura de ligamento o } \\
\text { articulación de la rodilla }\end{array}$ & $12.4 \%$ & $21.9 \%$ \\
\hline $\begin{array}{l}\text { Ruptura del ligamento } \\
\text { cruzado anterior }\end{array}$ & $5.3 \%$ & $11.0 \%$ \\
\hline Menisco & $2.8 \%$ & $4.1 \%$ \\
\hline Lesiones múltiples rodilla & $1.1 \%$ & $2.1 \%$ \\
\hline $\begin{array}{c}\text { Fracturas de la muñeca o } \\
\text { a nivel de la mano }\end{array}$ & $12.3 \%$ & $11.0 \%$ \\
\hline $\begin{array}{c}\text { Fracturas de pierna o } \\
\text { tobillo }\end{array}$ & $8.8 \%$ & $5.8 \%$ \\
\hline $\begin{array}{l}\text { Lesiones de los músculos } \\
\text { o tendones de la pierna }\end{array}$ & $8.8 \%$ & $5.9 \%$ \\
\hline Lesión tendón de Aquiles & $8.2 \%$ & $5.8 \%$ \\
\hline $\begin{array}{c}\text { Fractura del cráneo o } \\
\text { huesos faciales }\end{array}$ & $5.4 \%$ & $4.5 \%$ \\
\hline $\begin{array}{c}\text { Fracturas de los huesos } \\
\text { nasales }\end{array}$ & $4.0 \%$ & $3.7 \%$ \\
\hline Lesión intracraneal & $3.2 \%$ & $5.0 \%$ \\
\hline $\begin{array}{l}\text { Luxación, esguince o } \\
\text { torcedura de ligamento o }\end{array}$ & $2.2 \%$ & $2.2 \%$ \\
\hline
\end{tabular}


articulación del tobillo

Otros diagnostico

$28.3 \%$

$26.6 \%$

En las investigaciones estudiadas para este trabajo sacamos de conclusión que existe un mayor riesgo de lesión de rodilla en jugadoras que en jugadores de baloncesto, (Borowski, Yard, Fields, \& Comstock, 2008; Flood \& Harrison, 2009; Hamming, Yang, \& Bensema, 2007) en cambio Flood and Harrison (2009) localizan las lesiones más frecuentes en baloncesto masculino en la pierna, tobillo muñeca y dedos de la mano. Por otro lado paciente afroafricanos mostraron mayor incidencia lesiva que los blancos. Borowski et al. (2008) expresan en su estudio que los jugadores masculino son más propenso a sufrir una conmoción celebrar por ser mucho mas agresivos durante el juego.

En cuanto a la parte del cuerpo más afectada sacamos como conclusión que son la rodilla y tobillo, predominando los esguince y lesiones en los ligamentos (Agel et al., 2007; Borowski et al., 2008; Dick et al., 2007; Flood \& Harrison, 2009; Pappas, Zazulak, Yard, \& Hewett, 2011) .

Dick et al. (2007) nos exponen el mecanismo de lesión más común en baloncesto masculino durante su estudio siendo este en partidos 52,3\% contacto con otro jugador, otro tipo de contacto el $24,3 \%$, y sin ningún tipo de contacto $22,3 \%$. Durante entrenamientos contacto con jugador $43,6 \%$ otro tipo de contacto $17,9 \%$, y sin ningún tipo de contacto $36,3 \%$.

Borowski et al. (2008) encontraron que las lesiones en tendones y músculos se podrían producirse por sobreuso o programas inefectivos de acondicionamiento. Este mismo estudio presentó como mecanismo lesivo de los esguinces de tobillo el patrón de salto y aterrizaje.

(Borowski, Yard et al. 2008) Expone en su estudio que las diferencias entre géneros prodrian deberse a los diferentes programas de entrenamientos, a los factores extrensico de los atletas, las instalaciones, las formas de jugar y los diferentes entornos de competicion a los que son sometidos. Tambien podrian deberse a las diferencias fisiologicas entre géneros como la estructura anatomica las variaciones de fuerza, flexibilidad y hormonal. 


\subsection{2, Epidemiología de tendinitis.}

Las tendinopatías son una de las lesiones más frecuentes en las personas que practican deportes, ya sea a nivel mas o menos profesional como en aquellas que lo hacen de forma recreacional (Alfredson, 2005; Fredberg, Bolvig, \& Andersen, 2008; Langberg \& Kongsgaard, 2008), llegando a encontrar porcentajes de un $2 \%$ en la población trabajadora, $55 \%$ en los deportes de saltos Langberg and Kongsgaard (2008), un $11-24 \%$ en corredores, y llegando a un 32-45\% en jugadores de baloncesto Wasielewski and Kotsko (2007).

El tendón es un tejido altamente especializado, encargado de trasmitir las fuerzas producidas en el vientre muscular, hasta su inserción en el hueso, normalmente para que se produzca el movimiento deseado (Xu and Murrell (2008).

La tendiopatía hace referencia a aquellas lesiones o alteraciones tisulares que asistan a nivel de los tendones Xu and Murrell (2008). Estas alteraciones que se producen en el tendón la podemos encontrar por cambios degenerativos combinados con signos inflamatorios, existiendo afectación en distintas estruturas y con localización variada Xu and Murrell (2008). En el tendón normal, las fibras de colágenos, proteina principal de los tendones y en estado normal con gran resitencia a la tracción, estan orientas de forma lineal organizadas, en cambio en la tendinosis, encontramos una interrupción de las fibras de colágenos con orientación ondulada, con fragmentacion y los vasos sanguíneas entremezclados, sin existir inflamación Khan, Cook, Bonar, Harcourt, and Åstrom (1999). Es una patología que se caracteriza por que la aparición es tardía cuando en el tendón ya se han producido una serie de cambios tisulares que cronifican la lesión. (Fredberg et al., 2008; Khan et al., 1999; Maffulli, Sharma, \& Luscombe, 2004). (Fredberg et al., 2008) en su estudio encontró el $30 \%$ de tendones estudiados con alteraciones ecográficas sin sintomatología, lo que explica que lleguen a producirse roturas de tendones sin previo aviso,Langberg and Kongsgaard (2008).

Como exponen Khan et al. (1999) habria que diferenciar entre tendinosis, degeneración del tendón por sobregarga o ejercicio repetitito, tendiditis, rotura del tedón primero se dejenera "tendinosis" y después se rompe, paratendinitis, inflamación aislada en la capa mas aislada del tendón, y paratendinosis, se da todo lo mencionado con anterioridad.

Para poder prevenirla y tratarla correctamente deberemos conocer cuales son las causas que pueden provocarla. Investigaciones como las de (Maffulli et al., 2004; Sandmeier \& Renstrom, 1997), nos ofrecen una series de factores relacionados con la aparición de la tendiopatías.

Factores íntrinsecos relacionados con las tendiopatías crónicas en deporte:

- Desalineamento-desaxaciones.

- Discrepancia de longitud de las extremidades inferiores.

- Debilidad o desequilibrios musculares.

- Deterioro de la flexibilidad.

- Laxitud ligamentosa.

- Género. 
- Edad.

- Obesidad.

- Nutrición-hidratación.

- Predisposición a las lesiones-factores genéticos.

- Procesos patológicos anteriores-enfermedades sistématicas.

- Medicación hipertemia.

Factores de riesgo extrínsecos relacionados con las tendiopatías crónicas en deporte:

- Carga excesiva sobre el cuerpo:

- Tipo de movimiento

- Velocidad de movimiento

- Número de repeticiones

- Superficie

- Zapatillas deportivas

- Errores de entrenamiento:

- Largas distancias

- Progresiones rápidas

- Intensidades altas

- Técnica deficiente

- Fatiga-descanso insuficiente

- Cambios en el terreno

- Factores medioambientales:

- Oscuridad

- Calor-frio

- Humedad

- Viento

- Altitud

- Equipamiento inadecuado

- Reglas del juego erróneas 


\subsection{Adaptaciones fisiológicas al entrenamiento de fuerza.}

El entrenamiento de fuerza genera adaptaciones en los músculos, tendones y ligamentos Baechle (2004). La adaptación más evidente en el músculo es la hipertrofia, lo cual se traduce en un aumento de la capacidad de producción de fuerza y potencia Baechle (2004).

Aunque existen varias teorías sobre el motivo por el cual se produce la hipertrofia, según expone Tous (1999), parece que la teoría energética de la hipertrofia muscular es la aceptada (Siff y Verkhoshasky, 1996). Esta teoría propone que la hipertrofia ocurre como resultado de la supercompensación en la síntesis de proteínas después de un ejercicio de alta intensidad. Sería algo similar a la supercompensación de glucógeno muscular que acontece después de un ejercicio prolongado a baja intensidad (MacDougall 1986; op. cit. Cometti 1989, Kraemer et al., 1998)

El engrosamiento de las fibras musculares se produce como consecuencia de un incremento en el número y la talla de las miofibrillas musculares, acompañado de un aumento de tejido conectivo, ligamento, tendones y cartílagos (McDonagh y Davies, 1984). Según Zatsiorsky (1995) y Siff y Verkhosanky (1996) podemos distinguir dos tipos fundamentales de hipertrofia:

- Hipertrofia sarcoplásmica: donde se incrementa el volumen de las proteínas no contráctiles y del sarcoplasma (sustancia semifluida que se encuentra entre las fibras musculares). A pesar de que el área de sección transversal del músculo aumenta, la densidad de fibras musculares por unidad motora disminuye, por lo que no ocurre el deseado incremento en la fuerza del músculo.

- Hipertrofia sarcomérica o miofibrilla: por medio de la cual se incrementa el tamaño y el número de sarcómeros, la unidad básica y fundamental de las miofibrillas, además de las propias miofibrillas, por lo que aumenta el número de filamentos de actina y miosina disponibles. Al sintetizarse proteínas contráctiles y aumentar la densidad de los filamentos, este tipo de hipertrofia se acompaña de un incremento de la fuerza muscular, de ahí que también se le denomine hipertrofia funcional o útil.

El mencionado aumento en el número de sarcómeros puede acontecer de dos maneras (Edgerton 1986, Tihanyi, 1989, Cometti, 1989):

- En paralelo (transversalmente): como consecuencia de un entrenamiento que busca un aumento de la masa muscular. Este tipo de disposición multiplica la tensión muscular por dos y provoca un incremento de la sección transversal del músculo.

- En serie (longitudinalmente): se ha observado que un músculo inmovilizado en posición de estiramiento es susceptible a aumentar el número de sarcómeros dispuesto en serie Goldspink (1985). La disposición de los sarcómeros en serie aumenta la velocidad de contracción Edgerton (1986), provocando un aumento en la longitud del músculo. 
Por otro lado, Wilmore y Costill (1999) distinguen una hipertrofia de carácter inmediato a la que denominan hipertrofia transitoria. Está ocurre como consecuencia de la acumulación de fluidos en los espacios intracelulares del músculo, que vuelven al torrente sanguíneo al cabo de unas horas.

Tihanyi (1988) y García Manso (1996) proponen una aproximación distinta a la hora de distinguir los tipos de hipertrofia, diferenciando entre una hipertrofia general y otra selectiva:

- Hipertrofia general: provocada por un trabajo que implica el aumento del área de sección transversal de tanto las fibras lentas como las rápidas, sin tener en cuenta el porcentaje en que se desarrollan unas $u$ otras.

- Hipertrofia selectiva: en el caso de que se produzca una mayor hipertrofia en un tipo de fibras que en otro, pudiéndose distinguir entre:

- Hipertrofia confirmativa: al hipertrofiarse las fibras que predominan en un músculo.

- Hipertrofia compensatoria: al hipertrofiarse las fibras que se hallan en un mejor porcentaje.

Otro aspecto importante es el ángulo de pennación, el diseño en que están dispuestas las fibras musculares en el complejo músculo-tendón. Las fibras musculares terminan en los tendones formando un determinado ángulo con respecto a la línea de acción o tirón del músculo; cuanto mayor sea este ángulo, mayor será la cantidad de material contráctil que pueda insertarse en el tendón, lo cual provocará un aumento del área fisiológico de sección trasversal del músculo y de, en principio, la fuerza. Sin embargo, se ha observado cómo un aumento de dicho ángulo perjudica a la transmisión de fuerza desde las fibras musculares hacia el tendón, debido a la disminución del componente de fuerza de las fibras con respecto a la línea de acción del músculo (Kawakami et al., 1995). Parece ser que la tensión específica del músculo, es decir, la capacidad de los músculos de generar fuerza es menor en músculos muy hipertrofiados, al tener mayores ángulos de pennación, que en músculos menos hipertrofiados (Kawakami et al, 1993, 1995, Funato y Fukunaga, 1998).

Durante las fases iniciales de un programa de entrenamiento, los factores neuronales como la mejora de la ejecución, el reclutamiento motor y el ritmo de activación, son la razón primaria de los incrementos de fuerza. En adelante, los aumento de la fuerza están causados sobre todo por la hipertrofia. (Baechle, 2004)

Según exponen Badillo and Ayestarán (2002), la manifestación de fuerza depende de la tensión, la velocidad, el tipo de activación o contracción producida y otros factores.

En la manifestación de la fuerza se producen dos relaciones que son de vital importancia para comprender el significado de la propia fuerza y de su entrenamiento. Se trata de la relación entre la producción de fuerza y el tiempo necesario para ello, y de la relación entre las manifestaciones de fuerza y la velocidad del movimiento (Badillo \& Ayestarán, 2002). 


\subsubsection{Curva fuerza-tiempo.}

Toda manifestación de fuerza se produce de acuerdo con unas características determinadas, que evolucionan en el tiempo de forma diferente, pero pasando por las mismas fases hasta llegar a su máxima expresión. La relación entre la fuerza manifestada y el tiempo necesario para ello se conoce como la curva fuerza tiempo (C.F - t), (Badillo \& Ayestarán, 2002).

Toda acción o todo movimiento puede representarse con la curva fuerza-tiempo. Ante una resistencia a vencer, el efecto del esfuerzo viene determinado por la relación entre esa resistencia y la magnitud de la fuerza manifestada para superarla (Badillo \& Ayestarán, 2002).

Dentro de la curva fuerza-tiempo se han distinguido tradicionalmente tres fases: la fuerza inicial, relativamente independiente de la resistencia a vencer, y que se entiende como la habilidad para manifestar fuerza en el inicio de la tensión o contracción muscular; la zona en la que se establece una mejor relación entre el incremento de la fuerza aplicada y el tiempo empleado para ello; y la fuerza máxima expresada, que puede ser la isométrica, si la resistencia es insuperable, o la máxima dinámica, si existe desplazamiento del punto de aplicación de la fuerza.

Los datos más relevante que se pueden obtener de la cueva fuerza-tiempo siguiendo a (Badillo \& Ayestarán, 2002) son los siguientes:

- Fuerza máxima

- Fuerza máxima aplicada ante resistencia superable

- Tiempo necesario para alcanzar cualquier nivel o porcentaje de la fuerza máxima isométrica o dinámica.

- Tiempo total de acción de la fuerza

- Impulso de fuerza (fuerza por tiempo)

- Fuerza media: relación entre el impulso y el tiempo total de acción.

- Índice de manifestación de fuerza: relación entre la fuerza alcanzada y el tiempo necesario para ello. Este índice se puede medir desde el inicio de la tensión muscular o en cualquier punto de la curva fuerza tiempo.

- Tiempo de relajación después de una contracción isométrica máxima 


\subsubsection{Curva fuerza-velocidad.}

La fuerza y la velocidad mantienen una relación inversa en su manifestación, cuanto mayor sea la velocidad con la que se realiza un gesto deportivo, menor será la fuerza aplicada. La mejora de la velocidad vendrá dada por un aumento de la fuerza hasta alcanzar el nivel óptimo en cada caso y etapa de trabajo, realizado en el momento oportuno, y a través de las cargas y ejercicios adecuado a las necesidades del gesto específico (Badillo \& Ayestarán, 2002)

Siguiendo a estos autores, la curva fuerza-velocidad no tiene la misma características en todos los deportistas y en todas las especialidades. Las cualidades del sujeto y el tipo de entrenamiento realizado dan lugar a curvas diferenciadas.

Estas diferencias que se dan entre especialidades también ocurren dentro de las mismas. Es decir, un deportistas va modificando su curva fuerza-velocidad a través de los años de entrenamiento, e incluso entre las distintas fases de una temporada (Badillo \& Ayestarán, 2002).

Un concepto importante para el entrenamiento, que viene asociado a la curva fuerza-velocidad es el de potencia. La potencia sería el producto de la fuerza por la velocidad en cada instante del movimiento(Badillo \& Ayestarán, 2002).

Siguiendo a (Badillo \& Ayestarán, 2002), el potencial de fuerza, su desarrollo y manifestación depende de una serie de factores:

- Composición del musculo:

- Sección transversal muscular: número y grosor de fibras; La fuerza máxima generada por una sola fibra muscular es directamente proporcional a su CSA, con independencia del tipo de fibra. Debido a el hecho de que la potencia está fuertemente influenciada por la fuerza máxima, una fibra muscular con mayor CSA puede por tanto generar mayor Pma. Mientras la Vmax de un sarcómero difiere de forma significativa entre los diversos tipos de fibras, la Vmax de una fibra muscular es proporcional a su longitud, suponiendo un nivel constante de activación.

- Tipos de fibras: proporción de fibras rápidas y lentes. Debido a las características únicas de cada fibra, las propiedades de la velocidad de la fuerza de un músculo son determinadas por la contribución de fibras del área muscular. Las fibras tipos II tienen una capacidad mayor para generar el poder por unidad el área .

- Ángulo de inserción del músculo: A medida que aumenta el ángulo de pennación, mas sarcómeros pueden ser dispuestos en paralelo, es decir más tejido contráctil se puede unir en un área determinada, por lo tanto el músculo puede producir más fuerza. 
- Utilización de las unidades motoras:

- Reclutamiento. La fuerza producida por un músculo está relacionada con el número y tipo de unidades motoras reclutadas. Las unidades motoras se reclutan en un orden sistemático. Las fibras de tipo Ila y IIlx se activan después que las unidades motoras de contracción lenta.

- Frecuencia de impulso. La frecuencia de disparo de cada unidad motora representa a la tasas de impulso neurales trasmitidos desde la mononeuronas alfa a las fibras musculares.

- Sincronización. La sincronización de unidades motoras se produce cuando dos o más unidades motoras se activan simultáneamente con más frecuencia de los esperado para procesos independiente aleatorios.

- Coordinación intermuscular. La coordinación intermuscular, describe la adecuada activación, tanto en magnitud y momento, de los músculos agonistas, sinergistas y antagonistas durante el movimiento. Los sigernistas juegan un papel importante en la producción de la potencia máxima. La mejora de la activación y coordinación de los músculos sinergistas pueden contribuir a una mejor rendimiento. La magnitud la co-activación de antagonista depende de varios factores, tales como el tipo de contracción, la carga, la velocidad, la precisión y el rango de movimiento.

- Factores coadyuante a la contracción:

- Reflejo de estiramiento.

- Elasticidad muscular.

- Reducción de la actividad de células.

- Órganos de Golgi

- Factores mecánicos:

- Número de puentes cruzados activos, según el estado de estiramiento del músculo con respecto a su longitud de reposo 


\subsubsection{Factores morfológicos.}

\section{A. Área de la sección.}

La fuerza máxima generada por una sola fibra muscular es directamente proporcional a su CSA, con independencia del tipo de fibra. Debido a el hecho de que la potencia está fuertemente influenciada por la fuerza máxima, una fibra muscular con mayor CSA puede por tanto generar mayor Pma (Badillo \& Ayestarán, 2002).

\section{B. Longitud del fascículo.}

Mientras la Vmax de un sarcómero difiere de forma significativa entre los diversos tipos de fibras, la Vmax de una fibra muscular es proporcional a su longitud, suponiendo un nivel constante de activación (Badillo \& Ayestarán, 2002)

\section{Propiedades del tendón.}

El comportamiento de los fascículo se ve afectado entre los elementos contráctiles y elásticos, la conformidad intrínseco del tendón afecta a estas interacciones (Badillo \& Ayestarán, 2002)

A modo de conclusión podemos decir que la potencia muscular esta influenciada por una series de factores neuromusculares como son la composición de la fibras musculares, la sección trasversal, la longitud y área de los fascículos, el ángulo de pennación, las propiedades del tendón, el reclutamiento de unidades motoras, la frecuencia de disparo y la coordinación y sincronización intermuscular. La potencia máxima también se ve afectada por el tipo de acción muscular, y en particular por el tiempo disponible para desarrollar la fuerza, el almacenamiento y la utilización de energía elástica, y las interacciones contráctiles y elementos elásticos (Badillo \& Ayestarán, 2002).

Por otro parte los cambios agudos en el músculo, afecta a la capacidad de generar el máximo de potencia. 


\section{JUSTIFICACIÓN DEL PROGRAMA DE INTERVENCIÓN.}

El fin de todo deportista con fines competitivos, no es más que la optimización del rendimiento para mejorar sus prestaciones durante el juego, es por esto que el objetivo general de este trabajo, y teniendo en cuenta el periodo de la temporada en el cual nos encontramos, periodo transitorio, es el aumento de las capacidades básicas para hacer al jugador más fuerte dentro de la lógica interna del juego.

\section{A. Justificación del trabajo de control motor.}

El estudio de la causa y la naturaleza del movimiento resulta esencial para la práctica en la ciencias del deporte (Cano de la Cuerda et al., 2012).

La neurofisiología del movimiento y del aprendizaje motor cubre un terreno científico muy amplio (Chéron, 2011). Las bases fundamentales de la elaboración central del movimiento están inscritas en unas estructuras cerebrales muy específicas en plano anatómico y funcional, pero están también muy ricamente interconectadas formando conjuntos neuronales jerarquizados y dinámicos (Chéron, 2011).

En los mecanismo de aprendizaje de las actividades motoras el ser humano debe tener en cuenta los diferentes niveles de organización, estructurados de forma jerárquica y en iteración dinámica (Chéron, 2011). Siguiendo con este autor en cada uno de estos niveles, las uniones sinápticas entre neuronas pueden modificarse por la experiencia consciente o inconsciente Chéron (2011), y por lo tanto, pueden intervenir los mecanismo de aprendizaje en diferentes circuitos neuronales y dirigir el comportamiento motor final (Chéron, 2011).

Por todo lo comentado hasta el momento y siguiendo con los objetivos de la neuro-rehabilitación expuesto por Cano de la Cuerda et al. (2012) trabajaremos con nuestro sujeto el mantenimiento de las habilidades existentes, la readquisición de habilidades perdidas y el aprendizaje de nuevas destrezas (Cano de la Cuerda et al., 2012).

Existen diversos factores que tendremos que tener en cuenta a la hora de la intervención con nuestro sujeto desde el punto de vista de la neuro-rehabilitación, y que pueden influir en su aprendizaje motor, como son los feedback verbales que realicemos, la participación activa y motivación del sujeto, la transferencia negativa y positiva de su aprendizaje, el control postural, la memoria y la retroalimentación (Cano de la Cuerda et al., 2012).

\section{B. Justificación del trabajo preventivo y correctivo.}

Antes del diseño de cualquier tipo de programas para potenciar las cualidades básicas de nuestros jugadores debemos de retroceder a la base de todo y retornar a la ciencia como hicimos en el apartado anterior para analizar los factores limitantes en nuestro deporte en este caso el baloncesto.

Como expone Baechle (2004), según el principio de individualidad, cada persona debe seguir un entrenamiento adaptado, no adaptarse a un entrenamiento común, por este motivo no contemplamos un entrenamiento tratando por igual a todos nuestros jugadores/as. 
Pero no debemos de obviar que nuestra modalidad deportiva, el baloncesto, es un deporte de invasión donde nuestros jugadores/as están en continuo movimiento, cambiando constantemente de planos y ejes. Por este motivo debemos maximizar el movimiento tanto de manera eficaz como eficiente de nuestros deportistas en primer lugar a nivel preventivo para que no se produzcan lesiones por sobreuso y en segundo lugar buscando la eficiencia de ese patrón de movimiento específico en la situación real de juego, que haga a nuestro jugador/a mejor en la lógica interna del juego.

Siguiendo en esta línea Bennasar (2015), expone el modelo cinesiopatológico como instrumento para evaluar el movimiento, pues nos aporta las herramientas de análisis necesarias para poder analizar como los movimientos repetidos y las posiciones mantenidas pueden ser fuente de excesivo estrés tisular que puede llegar a desencadenar en una lesión.

Este mismo autor marca como objetivos generales del enfoque cinesiopatolólgico:

- Valorar las influencias biomecánicas dinámicas y posturales entre segmentos corporales que pueden llegar a ser causa de un exceso de estrés estructural provocando así un estado de vulnerabilidad de los tejidos por causa de microtraumas repetidos que con el tiempo desencadenará en lesiones, (Bennasar, 2015).

- Poder individualizar los entrenamientos gracias a los criterios de subclasificación en función de las alteraciones de movimiento encontradas durante la exploración física, (Bennasar, 2015).

Una vez analizadas las alteraciones musculares y el movimiento de nuestros sujetos, los programas de optimización partirán de la propuesta de J. Tous (1999) donde la fuerza es la cualidad física principal, donde otras como la resistencia ayudan a mantener los niveles de fuerza, la velocidad es una derivada directamente del trabajo de esta y la flexibilidad-amplitud de movimiento-elasticidad y coordinación son facilitadoras de la primera.

Antes de desarrollar cualquier programa de fuerza y siguiendo con los principios del modelo cinesiopatológico propuesto por Sahrmann (2002), tendremos en cuentas las dos propuesta que a continuación se desarrollan.

- Joint by Joint de Gray Cook, donde evaluaremos la estabilidad y movilidad de ciertas estructuras de nuestro cuerpo:

- Región glenohumeral móvil

- Región escapulo torácica estable

- Vertebras dorsales móviles

- Vértebras lumbares estables

- Cadera, móvil

- Rodilla estable

- Tobillo móvil 
- A la teoría de Gray Cook anteriormente mencionada le uniremos las diferentes leyes de (Bompa, 2006):

- Ley número 1: Antes del desarrollo de la fuerza muscular desarrollar la ADM de las articulaciones.

- Ley número 2: Antes del desarrollo de la fuerza muscular, desarrollar la unión músculo-hueso (tendones)

- Ley número 3: Antes del desarrollo de la fuerza muscular de los miembros, desarrollar el centro del cuerpo

- Ley número 4: Antes del desarrollo de los músculos de la primera fuerza motriz, consolidad los estabilizadores

\section{Justificación del trabajo de fuerza.}

Como base de nuestro trabajo hemos establecido la fuerza como promotor de todo (véase figura 15), cualidad como expone J. Tous (1999) básica a través de la cual se desarrollan todas las demás.

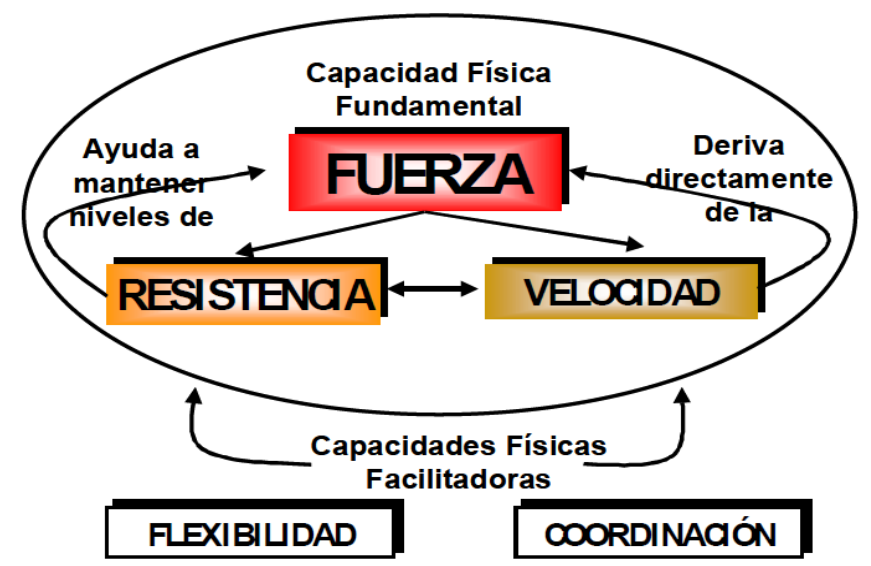

Figura 15. Propuesta de estructuración de las características físicas entorno a la fuerza como capacidad física fundamental, extraído de Tous (1999).

El trabajo de fuerza puede ser trabajado a lo largo de todo un spectrum, desde exigencias coordinativas hasta factor de carga, en todo ese spectrum pasaremos por las diferentes manifestaciones que presenta la fuerza, y según nuestro objetivo pretendido incidiremos más en un rango u en otro de este spectrum.

Pero dentro del spectrum, debemos encontrar la zona de trabajo donde el sujeto obtendrá una mejora.

Según (Cormie \& Flanagan, 2008) y (J. Tous, 1999), el entrenamiento de potencia utilizando diferentes cargas, causas cambios específicos en la relación fuerza velocidad, lo que hace establecer variabilidad en el grado de mejora de la potencia externa generada.

El entrenamiento con cargas donde se genera la máxima potencia externa es más efectivo para mejorar la potencia máxima y el rendimiento del deportista que utilizan 
cargas más ligeras o más pesadas como se ha venido realizando tradicionalmente (Cormie and Flanagan (2008).

Siguiendo con esta creencia estos mismos autores exponen que la expresión de la máxima potencia no concierne ni con la máxima velocidad ni con la fuerza máxima, sin embargo es una interacción optima entre ambas (Cormie \& Flanagan, 2008).

Por lo tanto, los mejores beneficios en la relación fuerza - velocidad, es aquella carga con la que se genera más potencia, esto a su vez incrementa la máxima velocidad y la máxima fuerza que se puede generar, lo que se traduce en una gran aumento de la potencia que puede producir.

Como punto de partida para este tipo de trabajo, entre las múltiples opciones que nos ofrece la ciencia, lo que hemos tenido que hacer es saber cuál es la zona donde nuestro sujeto genera la máxima potencia figura 13 y trabajar en ese rango .

En nuestro caso, el baloncesto, como expone J. Tous (2014) tendríamos que orientar este trabajo de mejora de potencia en dos sentidos:

- Capacidad de mejorar la máxima potencia que puedo generar y mantener en una serie.

- Repeated power ability: capacidad de repetir esa máxima potencia generada.

Se cree que todas las mejoras obtenidas en la potencia cuando se trabaja con la potencia óptima con respecto a las demás se deben a una serie de adaptaciones específicas que se originan en el organismo al trabajar con dichas cargas y que crean una serie de patrones de activación neural que nos llevan al incremento del rendimiento (Cormie \& Flanagan, 2008).

Estos entrenamiento deben medirse por el carácter del esfuerzo, que son las repeticiones que nuestros deportistas son capaces de realizar dentro de los margenres establecidos Cormie and Flanagan (2008), (carácter del esfuerzo máximo y niveles de tolerancia), (Moras, 2014b).

En este apartado estructuraremos el entrenamiento por áreas y contenidos (Moras, 2014a). Este autor define las áreas como las cualidades y capacidades físicas y/o técnica asociadas a una capacidad como por ejemplo; el salto, golpeo, lanzamiento, desplazamiento (aceleración y deceleración), lucha, etc (Moras, 2014a).

Los contenidos será la especialización de estas áreas y los determinará la posición del jugador.

En base a este planteamiento podremos enfatizar nuestro trabajo desde el gesto específico hasta acciones complementarias, a partir de los niveles de aproximación tabla 4.1 de Moras (2014a), de esta forma conseguimos una transferencia al trabajo efectuado. Cuando combinamos niveles, el nivel más fuerte es el que está controlado el carácter del esfuerzo, (Moras 2014). 
Tabla 4.1. Niveles de aproximación extraído (Moras 2014).

\begin{tabular}{cc}
\hline $\begin{array}{c}\text { Nivel de } \\
\text { aproximación }\end{array}$ & Metodología \\
\hline $\begin{array}{c}\text { Nivel V } \\
\text { Juego Real } \\
\text { Nivel IV } \\
\text { Espacio reducido }\end{array}$ & Juego real \\
Nivel III & Elemento técnico + toma de decisión \\
Técnica & Determinar las decisiones posibles previamente \\
Nivel II & Sesión técnica (con/sin balón) \\
Físico-técnico & Sin toma de decisión o sencillas \\
Nivel I & Similar al gesto técnico con pequeñas sobrecarga \\
Condicional- & Similar al gesto técnico. Carga alta \\
estructural & \\
Nivel 0 Orientado & Musculatura implicada en el gesto técnico \\
Nivel 0 no & Sin similitud al movimiento \\
orientado & Musculatura no implicada en el gesto \\
& Complementarios y compensatorio \\
\hline
\end{tabular}

En la tabla 4.1, se ha descrito los niveles de aproximación siendo los más bajo los más lejos de la especificad y los más altos los que más se asemeja al modelo de juego, por este motivo nosotros en la propuesta de intervención de esta segunda fase solo incidiremos hasta el nivel II.

La fuerza que tiene un jugador es la que puede aplicar en cada momento (Moras, 2015). Aunque en el gimnasio podamos aplicar mucha fuerza al realizar un determinado ejercicio debemos ser conscientes de que esto no nos garantiza poderla aplicar en otros ejercicios y en contexto (Moras, 2015). Por eso la construcción muscular en el gimnasio debería realizarse en base a una preparación amplia de los deportistas que les permita adaptarse continuamente a las exigencias del juego, para ello probamente será imprescindible abordar el desarrollo tridimensional (3D) y cuadrimensional (4D) de la fuerza (Moras, 2015).

Las ganancias de fuerza son, en parte, específicas de acción muscular y al movimiento (Moras, 2015). La realización de una extensión de piernas en una prensa describe un determinado patrón de reclutamiento muscular que solamente podrá ser modificado notablemente variando el plano de trabajo o cambiando de ejercicio (Moras, 2015). Por eso es lógico pensar que no será posible alcanzar un desarrollo adecuado y equilibrado de la fuerza muscular sin proponer, para cada ejercicio, sensibles modificaciones del mismo que persigan un desarrollo armónico de la fuerza en una visión tridimensional (Moras, 2015). Pero esta visión tridimensional del trabajo de fuerza puede ser complementada por una visión cuatridimensional (Moras 2015). 
Sabemos que cada repetición de un mismo movimiento presenta una cierta cantidad de cambio independientemente del nivel o del grado de familiarización de la tarea (Moras 2015). La variedad del movimiento está presente de forma inherente en el rendimiento motor y podría estar asociada con la complejidad del sistema neuromuscular (Moras 2015). No obstante, cada deportista dispone de unas características morfológicas y funcionales que determinan un perfil exclusivo de rendimiento conocido como huella (Moras 2015; (Dias, Martens, Couceiro, Clemente, \& Mendes, 2014). En este sentido, si focalizamos nuestra atención en las tareas realizadas en un gimnasio observaremos que obedecen normalmente a movimientos muy regulares, que a pesar de estar inevitablemente sometidos a la variabilidad humana, presentan una parte invariable muy importante en cada movimiento que puede ser observada repetición a repetición (Moras 2015). Esta parte invariable del movimiento es la que se considerará estable y presenta la huella identificativa del deportista (Moras 2015). Modificar la intensidad, el volumen o el carácter del esfuerzo de uno de estos ejercicios no supondrá grandes cambios en el porcentaje de la parte invariable o estable de la señal (Moras 2015). Entonces, para aumentar el nivel de variabilidad durante la ejecución de un ejercicio será necesario introducir ciertos constreñimientos como pueden ser la realización de ejercicios a través de movimientos oscilatorios progresivos, incorporar el estímulo vibratorio o incluir retos de diversa índole (Moras, Rodriguez-Jimenez, Tous-Fajardo, Ranz, \& Mujika, 2010). Además será relevante poder determinar el alcance del aumento de complejidad con la finalidad de identificar los constreñimientos más apropiados para aumentar el rendimiento de los deportistas (Moras 2015). Así, el deportista deberá aprender a resolver cada uno de los ejercicios de fuerza en múltiples condiciones de variabilidad (Moras 2015). Con este planteamiento pretendemos alterar el patrón de gestión de la fuerza de cada uno de los ejercicios y de sus variantes que complemente la visión tridimensional de la fuerza (Moras, 2015).

\section{Justificación del trabajo de estabilización Coxolumbopélvica}

Se concibe el entrenamiento coxolumbopélvico o del CORE como base fundamental de los programas de entrenamiento saludable y su desarrollo será necesario para realizar tareas de manera eficaz y con el riesgo de lesión menos acentuado (S. McGill, 2010). Esto supone garantizar un óptimo estado y funcional del sistema pasivo, del sistema muscular y del sistema de control motor con la finalidad de satisfacer los requisitos del equilibrio postural (estático y dinámico), crear movimientos específicos, soportar fuerzas externas inesperadas o generar presión con la que ayudar a la respiración dificultosa. (S. McGill, 2010).

Este tipo de entrenamiento incluye diferentes propósitos, la activación de la musculatura implicada, la corrección de la disfunción, aumentando los diferentes tipos de estabilidad y el desarrollo de la fuerza, potencia y resistencia (Schoenfeld, 2013).

Siguiendo en esta línea Vera-García et al. (2015) exponen que en el deporte profesional y amateur son habituales los programas de ejercicios para el acondicionamiento de la región coxolumbopélvica. Los objetivos de estos programas suelen ser la mejora del rendimiento deportivo y la prevención de lesiones, mediante el desarrollo de las diferentes cualidades de los músculos del tronco, especialmente, la resistencia, la fuerza y la capacidad de estabilización de sus estructuras. 
El trabajo coxolumbopélvico es de mera importancia ya que como expone Panjabi (1992) desarrolla tres funciones fundamentales:

- trasmisor de fuerza a todas las extremidades.

- trabaja como centro de gravedad.

- Punto de inicio de todos los movimientos.

Consideraciones que tendremos en cuenta a la hora del diseño de estímulos siguiendo a (Schoenfeld, 2013):

- Acciones conjuntas: el entrenamiento coxolumbopélvico gira en torno a los músculos que une la columna vertebral, la pelvis y la cadera por lo tanto las acciones y contracciones se deben ver implicado de forma conjunta los núcleos anteriormente mencionados.

- Fuerza desde diferentes vectores: creación de fuerza desde múltiples vectores con el fin de maximizar o aumentar el rendimiento del sujeto.

- Acciones seguras: Se plantearan progresiones seguras y graduales, para evitar todo tipo de lesión. Este autor recomienda entre 2-4 series de 8-15 repeticiones tanto de ejercicios básicos como dinámicos.

- Progresiones y regresiones: Dominando los conceptos básicos, triple activación y realización de ejercicios sin perturbación del sujeto para progresar en dificultad.

- Acciones con trasferencia al deporte: cumpliendo así el principio de especificad y llevando al sujeto a ejercicios y movimientos reales que puedan encontrar en el juego.

Podríamos dividir el trabajo de dicha región como expone Reed, Ford, Myer, and Hewett (2012) en dos grandes bloque:

- Core Strength: capacidad de los músculos del core para producir y mantener la producción de fuerza.

- Core Stability: Control del core durante la generación de fuerza muscular o en respuesta a una perturbación.

\section{E. Justificación del trabajo de resistencia a los esprines (RSA).}

A la misma vez que el trabajo de fuerza tendremos que tener en cuenta la capacidad de repetir esprines (RSA) de nuestros sujeto, varios estudios han informado que durante un partido de baloncesto los jugadores suelen realizar unas 105 acciones de alta intensidad de corto intervalos de tiempo (2-6 segundos) con un intervalo de 21 segundos entre una acción y otra. (Mclnnes et al. (1995). Esto sugiere que la capacidad de repetir esprines en un periodo determinado de tiempo con un tiempo determinado de recuperación es de suma importancia en el baloncesto (Castagna, Abt, et al., 2008; Spencer et al., 2005)

Para la planificación de los patrones de RSA tomaremos como punto de inicio la investigación de López et al. (2014) donde desarrollan los patrones de movimientos específico del baloncesto (Véase tabla 4.2), y partiendo de la metodología observacional, analizando varios partidos, diseñaremos tareas a nivel individual con los patrones de movimientos más comunes de nuestro sujeto. 
Tabla 4.2. Patrones motores específicos de baloncesto, modificado de (López et al., 2014).

\begin{tabular}{cc}
\hline Sin balón & Con balón \\
\hline Parado & Parado \\
Andando & Andando \\
Trote & Trote \\
Carrera & Carrera \\
Sprint & Sprint \\
Baja intensidad carrera hacia atrás & Baja intensidad carrera hacia atrás \\
Media intensidad carrera hacia atrás & Media intensidad carrera hacia atrás \\
Alta intensidad carrera hacia atrás & Alta intensidad carrera hacia atrás \\
Baja intensidad carrera lateral o & Baja intensidad carrera lateral o \\
movimiento defensivo & movimiento defensivo \\
Media intensidad carrera lateral o & Media intensidad carrera lateral o \\
movimiento defensivo & movimiento defensivo \\
Alta intensidad carrera lateral o & Alta intensidad carrera lateral o \\
movimiento defensivo & movimiento defensivo \\
Saltos & Saltos \\
Cambio de ritmo & Tiro a canasta \\
& Entrada a canasta \\
& Cambio de ritmo
\end{tabular}




\section{OBJETIVOS DEL PROGRAMA DE INTERVENCIÓN.}

\subsection{Objetivo Generales.}

El objetivo principal es optimizar el rendimiento del sujeto en el juego del Baloncesto, a partir principalmente de, cómo se ha mencionado en el aparto anterior, un programa de fuerza y la reeducación de patrones alterados, por este motivo se consideran objetivos que tendremos que tener siempre presentes en nuestras sesiones, como son:

A. Readaptar aquellos patrones de movimientos tantos básicos como específicos, que puedan hacer sufrir al sujeto algún tipo de lesión, y a su vez una vez modificados hacerlos útil tanto en su vida deportiva como diaria.

B. Desarrollar el control y estabilidad de la región coxolumbopélvica, con el fin de trasferir dicha estabilidad y fuerza al juego.

C. Modificar el entrenamiento clásico de pesas en gimnasio que venía realizando el sujeto hasta el comienzo del programa de intervención y orientarlo a mejorar su potencia máxima y la habilidad de repetir esta potencia (RPA), en patrones lineales como el press banca y la sentadilla, y multidireccionales como una salida frontal, lateral, de espalda y un desplazamiento defensivo en polea cónica, intentando de esta manera transferir el entrenamiento de fuerza a los patrones propios del juego.

A su vez tendremos una serie de objetivos secundarios, que al igual que los anteriores serán una referencia durante todo el programa de intervención, pero que en divergencia con los tres nombrados con anterioridad no tienen por qué estar presente en todas las sesiones de intervención. Estos son:

D. Implantar programas preventivos, según las lesiones anteriores del mismo y la incidencia lesiva en el baloncesto y hacer consiente al sujeto de la importancia de este tipo de trabajo.

E. Mejorar la capacidad tanto de repetir acciones de velocidad, cambios de dirección y saltos, como la recuperación entre estas acciones.

F. Mantener niveles de VO2max. del sujeto.

G. Mejorar la tendinosis rotuliana del sujeto. 


\subsection{Objetivos específicos.}

En cuanto al objetivo A, que se abordara principalmente en la primera fase del programa de intervención trabajaremos la normalización en el movimiento de retracción escapular y la flexión plantar de ambos pies, a su vez nos centraremos en la rotación interna de los hombros, la protacción cefálica y el aprendizaje de la disociación lumbopélvica.

En el objetivo B centrado en la región coxolumbopelvica, trabajaremos sobre los músculos flexores, extensores, inclinadores y rotadores, de dicha región, teniendo siempre en cuenta el concepto de triple activación.

Incidir en la higiene postural del sujeto, objetivo A, objetivo B y objetivo $\mathrm{C}$ en ejercicios predominantes de rodilla, manteniendo la columna neutra en la transmisión de fuerza, y en los ejercicios de empujes y tracciones, no haciendo el esfuerzo solo con los brazos, realizándolo con todo el cuerpo, implicando también a extremidades inferiores y manteniendo la columna neutra.

Iniciar al sujeto al entrenamiento sensoriomotor sin que se produzcan perdidas de fuerza, este tipo de trabajo estará presente en el programa preventivo que se realizara con el sujeto, objetivo $\mathrm{D}$, y en las últimas fases del entrenamiento de fuerza objetivo $\mathrm{C}$ en 4 dimensiones cuando estén presentes las fluctuaciones, (Moras, 2015).

Preparar al sujeto para un trabajo de fuerza de carácter excéntrica, objetivo $\mathrm{C}$, objetivo D y objetivo $G$ teniendo presente el concepto de la fuerza en 3 y 4 dimensiones (Moras, 2015).

Trabajo de capacidad anaeróbica, a partir de patrones de movimientos específicos del baloncesto tabla 4.2, objetivo $\mathrm{E}$.

Trabajo de potencia aeróbica, para mantener los niveles de VO2MAX, objetivo F. 


\section{PROGRAMA DE INTERVENCIÓN.}

\subsection{Secuencias de las fases de entrenamiento del programa de intervención.}

Las dos semanas previas al comienzo del programa de intervención, las dedicamos a realizar unas evaluaciones iniciales para conocer mejor las aptitudes y características de nuestro sujeto, (véase figura 16). Aquellas pruebas de mayor exigencia físicas, test de fuerza para realizar la cuerva fuerza velocidad tabla 2.2, test de resistencia Yo-Yo IR1 tabla 2.2 y Trive-Basket tabla 2.2, y test de RSA tabla 2.2, fueron separadas por un periodo de 48 a 72 horas para que se produjera una recuperación completa y la prueba no se realizara en condiciones de fatiga.

\begin{tabular}{|l|}
\hline \multicolumn{1}{|c|}{ Evaluaciones iniciales } \\
\hline 15 de Mayo; Entrevista inicial, Test curva fuerza-velocidad \\
\hline 18 de Mayo; Test composición corporal, Pruebas Mat \\
\hline 19 Mayo; Yo-Yo IR1, Recordatorio 24 Horas \\
\hline 21 de Mayo: FMS, recordatorio 24 horas \\
\hline 22 de Mayo: Agility T - Test \\
\hline 23 de Mayo: Recordatorio24 Horas \\
\hline 25 de Mayo: Test Trive-Basket \\
\hline 27 de Mayo: Core, CMJ, VJFT \\
\hline 28 de Mayo: Patrones motores básicos, Test psicológicos \\
\hline 29 de Mayo: Test RSA
\end{tabular}

Figura 16. Periodización de las evaluaciones iniciales.

El programa de intervención fue dividido en tres períodos (véase figura 19), una primera fase encaminada al aprendizaje y control motor (objetivo A), los primeros pasos del trabajo coxolumbopélvico (objetivo B) y la readaptación de una tendinosis rotuliana (objetivo D) a su vez lo combinaremos con sesiones de RSA (objetivo E) y de mantenimiento $\mathrm{VO}_{2} \mathrm{MAX}$, (objetivo $\mathrm{F}$ ), realizaremos también sesiones en momento puntuales de recuperación en la piscina.

Como punto de partida está fase durará un mes, aunque el final de la misma se verá condicionada por el progreso del sujeto. Estas mejoras según los objetivos planteados para la primera fase del programa de intervención, serán evaluados mediante los test de Trive-basket (Objetivo F) test de RSA, (objetivo E) Test de Core, (Objetivo B $)$ y por último T-Test, (Objetivo A) y (Objetivo C). La monitorización del CMJ durante toda esta fase nos servirá para ver las mejoras en relación a fuerza, (objetivo C). Por último las mejoras y reeducación de patrones motores básico serán evaluadas mediante una observación sistemática durante todas las sesiones dedicadas a las misma, para no aburrir al sujeto con la realización de tantos test durante el proceso de intervención. La realización del test Trive-Basket y test de RSA se realizara con un margen entre una y otra de 72 horas, figura 17 para que existe una recuperación completa entra una y otra. Los días anteriores a estas dos pruebas serán sesiones que no condicione la realización de esto test, para realizarlo sin fatiga, figura 19. 


\section{Evaluación primera fase}

\section{4 de Junio: Test Trive-Basket}

\section{Junio: Test RSA}

\section{0 de Junio: T-Test, Test de Core}

Figura 17. Evaluación de la primera fase del programa de intervención.

En el segundo periodo los contenidos girarán alrededor de la optimización del rendimiento del sujeto, principalmente con un trabajo de fuerza de carácter excéntrico, (objetivo $\mathrm{C}$ ) seguiremos realizando sesiones de RSA, (objetivo E) y mantenimiento VO2MAX, (objetivo $F$ ) combinándolas con sesiones regenerativas en la piscina, en momentos concretos de algunas sesiones seguiremos realizando ejercicios correctivo utilizados en la primera fase en el periodo de aprendizaje y control motor.

Como ocurrió en la primera fase del programa de intervención está fase concluirá con una serie de evaluaciones para poder evaluar las mejoras en el sujeto, estas pruebas serán test de Trive-basket, (Objetivo F), test de RSA (objetivo E), Test de Core (Objetivo B), y por último T-Test (Objetivo A) y (Objetivo C). La monitorización del CMJ al igual que en la primera fase, nos servirá para ver las mejoras en relación a fuerza, (objetivo C). La realización del test Trive-Basket y test de RSA se realizara con un margen entre una y otra de 48 horas, figura 18, para que existe una recuperación completa entra una y otra. Los días anteriores a estas dos pruebas serán sesiones que no condicione la realización de esto test, para realizarlo sin fatiga, figura 19.

\section{Evaluación segunda fase}

\section{3 de Agosto:Test Trive-Basket \\ 5 de Agosto: T-Test, Test Core \\ 6 de Agosto:Test RSA}

Figura 18. Evaluación de la segunda fase del programa de intervención.

La tercera y última parte del programa de intervención será una parte no presencial, ya que el sujeto una vez empezado el programa de intervención en Junio, nos comunicó que desde la segunda semana de agosto hasta principio de Septiembre se marcharía de vacaciones a otra provincia Andaluza. En consecuencia, y después de haber entrenado con él durante 9 semanas de forma presencial, casi en su totalidad de Lunes a Viernes, le mandaremos un plan de trabajo con tareas ya planteadas en las 2 fases anteriores, para que pueda ser realizada por el sujeto durante el mes de Agosto, y pueda llegar en las condiciones más adecuadas a la Pretemporada. 


\subsection{FASE 1 DEL PROGRAMA DE INTERVENCIÓN.}

\subsubsection{Objetivos específicos.}

A. Aprendizaje y control motor de patrones motores básicos, tracciones y ejercicios dominante de rodilla.

B. Aprender el concepto de triple activación en patrones básicos del trabajo Coxolumbopélvico, Core Stability.

C. Readaptación de la tendinosis rotuliana

D. Concienciación del sujeto de la importancia del trabajo preventivo

E. Mejorar la recuperación ante los esfuerzo de alta intensidad requerido en el baloncesto.

F. Mantener niveles de $\mathrm{VO}_{2} \mathrm{MAX}$ del sujeto. 


\subsubsection{Contenidos secuenciados.}

- Estabilidad del raquis. Objetivo específico A.

- Trabajo de estabilización escapulo torácica. Objetivo específico A.

- Trabajo de retracción y aproximación. Objetivo específico A.

- Trabajo de activación de glúteo medio. Objetivo específico A.

- Disociación lumbopélvica. Objetivo específico A.

- Mejorar de la dorsiflexión plantar de tobillo. Objetivo específico A.

- Estabilidad coxolumbopélvica. Objetivo específico B.

- Conciencia de la importancia de la triple activación en el juego. Objetivo específico B.

- Trabajo isométrico en la primeras fases de la readaptación de la tendinosis rotuliana. Objetivo específico $\mathrm{C}$.

- Trabajo excéntrico, en la últimas fases de la readaptación de la tendinosis rotuliana. Objetivo específico $\mathrm{C}$.

- Trabajo preventivo tobillo. Objetivo específico D.

- Repeat sprint Ability. Objetivo específico E.

- Potencia aérobica. Objetivo específico F.

Los contenidos se han ido alterando a lo largo de la fase, teniendo presente que la recuperación del trabajo de RSA constaba de 48 horas y el estímulo de VO2MAX, se introducía cada 10-12 días, (véase anexo 12). 


\subsubsection{Metodología.}

A. Metodología utilizada en la primera fase en las sesiones de control motor, tabla 6.3 , tabla 6.4 , tabla 6.5 .

El calentamiento que utilizaremos en las sesiones de control motor, estará dividido en tres parte. Una primera parte de liberación miosfacial autores como MacDonald et al. (2013) ha demostrado que la utilización de esta técnica, pasando un foam roller de forma lenta por diversas parte del cuerpo para aumentar la amplitud de movimiento del sujeto. La segunda parte del calentamiento consistirá en una activación vegetativa del entrenado para de esta forma romper la homeóstasis y preparar al cuerpo para la actividad posterior. Para concluir el calentamiento utilizaremos ejercicios de movilidad para aquellas articulaciones que según propone G. Cook (2010) deben ser móviles como el tobillo movilidad sagital, la cadera debe tener movilidad multiplanar pero a la vez estable, la región glenohumeral y la columna toráxica o vértebras dorsales.

La parte principal de las sesiones orientadas a control motor estará divida en dos, una primera en la cual se realizarán ejercicios orientados a la tendinosis rotuliana del sujeto, (Objetivo específico C.), para ellos utilizaremos la propuesta de Mascaró (2014), Tabla 6.1, esta propuesta está basada en múltiples investigaciones (Alfredson, 2005; Fredberg et al., 2008; Kannus, 1997; Khan et al., 1999; Langberg \& Kongsgaard, 2008; Maffulli et al., 2004; Mafi, Lorentzon, \& Alfredson, 2001; Sandmeier \& Renstrom, 1997; Wasielewski \& Kotsko, 2007; Xu \& Murrell, 2008). La segunda parte de este tipo de sesiones irá orientada al trabajo correctivo de aquellos eslabones débiles encontrados en la evaluación inicial, (Objetivo específico A), será un trabajo de 1 a 3 series y de 8 a 10 repeticiones sin llegar a fatigar las estructuras implicadas y el sistema nervioso central, el descanso entre series será el suficiente para asimilar el trabajo planteado, ya que estamos en fase de aprendizaje. 
Tabla 6.1. Protocolo recuperación tendiopatías rotuliana propuesto por (Mascaró (2014).

\section{1ํㅜ Fase: Suave}

3 isométricos mantener entre 30

y 50 segundos. Reposos entre isométricos de 30 segundos. Repetir 3 veces al día. Todo los días.

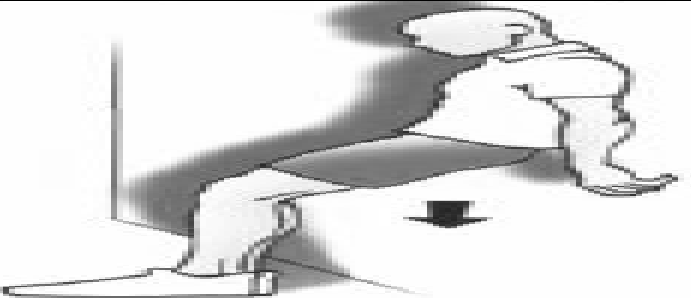

\section{Criterios para pasar de fase}

Inicialmente mantener (isométrico) "Suave" diario.

¿Me duele más al día siguiente?

$\mathrm{Si}$, disminuir carga o tiempo de mantenimiento.

No, progresar a dinámicos lentos 2 o 3 días estoy en un valor de 4 de escala EVA

\begin{tabular}{l}
\hline series de concéntrico- \\
excéntrico lento, 6 a 8 \\
repeticiones de 4 segundos \\
concéntrico +4 segundos \\
excéntrico. \\
Progresar en carga $(2 \mathrm{~kg}, 4 \mathrm{~kg}$, \\
$6 \mathrm{~kg} . . .12 \mathrm{~kg})$ \\
Después progresar a velocidad \\
2 segundos \\
Volver progresar en carga (2kg, \\
$4 \mathrm{~kg}, 6 \mathrm{~kg} . . .12 \mathrm{~kg})$ \\
Reposo entre series de 30 \\
segundos \\
1 vez al día, días alternos
\end{tabular}

\section{Criterios para pasar de fase}

Dinámicos lentos a días alternos "Medio". Alternar con mantener isométricos "Suave". (Un día isométrico, al día siguiente dinámico lento, al día siguiente isométrico...) ¿Me duele mas al día siguiente?

$\mathrm{Si}$, disminuir carga o velocidad

No, progresar en velocidad o carga cuando 2 o 3 días estoy en un valor 4 de escala EVA

\begin{tabular}{l} 
30 Fase: Fuerte \\
\hline excéntrico reries de concéntrico- \\
necesario el trabajo explosivo?) \\
¿lo necesita? \\
6 a 8 repeticiones. Progresar en \\
carga o altura. \\
Reposo entre series de 2 \\
minutos. \\
1 vez al día, cada tercer día
\end{tabular}


La vuelta a la calma de las sesiones de aprendizaje motor constará de una primera parte en la cual se volverá hacer hincapié en el trabajo de liberación miosfacial pues investigaciones como la de Torres, Ribeiro, Duarte, and Cabri (2012) exponen que puede ser beneficioso después de un ejercicio intenso que produce daño muscular, y una última parte que consistirá en estiramiento de (SGA), Streching Global Activo, esta técnica como expone Souchard (2008) son estiramientos basados en autoposturas que compromete y ponen en tensión las diferentes cadenas musculares, estas posturas mantenidas irán acompañada de un adecuada y controlada respiración. Está técnica nos ayudará a recuperar alteraciones del aparato locomotor encontradas en las evaluaciones iniciales. A continuación detallamos las posturas utilizadas y la implicación de cada una de ellas sobre las diferentes cadenas musculares:

- Postura mantenida de la rana con diferentes variantes: Cadena posterior, músculos paravertebrales, músculos profundo de la pelvis, músculos isquiotibiales, gemelos, músculos aductores y músculos tensor de la fascia lata.

- Postura mantenida sentado, con insistencia sobre los músculos espinosos, y los miembros inferiores: Cadena posterior, músculos paravertebrales, músculos inspiratorios, músculos aductores, tensor de la fascia lata, músculos profundo de la pelvis, músculos isquiotibiales y gemelos.

- Postura mantenida en pie inclinado hacia delante con insistencia sobre los músculos espinosos, la pelvis y los miembros inferiores: Cadena posterior, músculos paravertebrales, músculos profundo de la pelvis, músculos isquiotibiales y gemelos

- Postura mantenida de pie contra la pared, con insistencia sobre los hombros y los miembros superiores: Cadena anterior, músculos inspiradores, músculos superiores de la cintura escapular, músculos del cuello, psoas iliaco, músculos anteriores del brazo, el antebrazo y la mano.

\section{B. Metodología utilizada en la primera fase en las sesiones de VO2MAX.}

Para la mantener los niveles de Vo2Max, (Objetivo específico F) utilizaremos la propuesta de Schelling and Torres-Ronda (2013), tabla 6.2, los cuales sugieren una carrera continua extensiva con una duración comprendida entre 30 y 40 minutos. Esté tipo de entrenamiento realizará en el periodo transitorio cada 12 días.

Vuelta a la calma de las sesiones de VO2MAX será idénticas que las de control motor, constando de una primera parte de liberación miosfacial y una segunda de SGA.

\section{Metodología utilizada en la primera fase en el trabajo de RSA, tabla 6.6.}

El calentamiento de este tipo de sesiones consistirá en una primera parte de liberación miosfacial con los beneficios nombrado anteriormente en la investigación de (MacDonald et al., 2013), una segunda de ejercicios de movilidad articular de las siguientes estructuras, el tobillo movilidad sagital, la cadera debe tener movilidad multiplanar pero a la vez estable, la región glenohumeral y la columnatoráxica o vértebras dorsales. 
Habrá una tercera parte encaminada a la readaptación y prevención de lesiones del tobillo, (Objetivo específico D) para ello nos guiaremos por la propuesta(V. J. Sammarco, 2003a, 2003b; V. J. Sammarco \& Sammarco, 2003), en esta primera fase incidiremos en estiramientos para intentar normalizar el ROM de la articulación perdido por las múltiples inmovilizaciones, esto lo combinaremos con ejercicios en cadena cinética cerradas para implicar la contracción de múltiples grupos musculares y ejercicios de cadena cinética abierta con resistencias manuales, o con banda elásticas para incidir en musculatura mas concreta.

Para terminar realizaremos ejercicios de técnica individual de juego para preparar al sujeto al esfuerzo que realizara posteriormente.

La parte principal la dividiremos en dos fases, una primera fase donde el contenido principal girara alrededor del trabajo coxolumbopélvico, (Objetivo específico B $)$. La metodología utilizada en este contenido será la propuesta por (S. McGill, 2010):

- Primer paso, ejercicios correctivos, en relación con el Objetivo específico A.

- Segundo paso, perfeccionar patrones de movimientos, en relación con el (Objetivo específico A) en este apartado tendremos presenta los patrones básicos en este tipo de trabajo que proponen Akuthota, Ferreiro, Moore, and Fredericson (2008) que son el bracing, bird dog, glute brigde, y la plancha lateral.

- Tercer paso, construir todo el cuerpo y movilidad de algunas articulaciones y estabilidad de otras. Objetivo específico A y Objetivo específico B.

- Cuarto paso, aumentar la resistencia. Objetivo específico A y_Objetivo específico B. Hasta esta fase hemos planificado el trabajo en esta fase.

- Quinto paso, construir la fuerza.

- Sexto paso, desarrollar velocidad, potencia y agilidad.

Intentaremos incluir la triple activación durante todo el proceso de aprendizaje del sujeto en este contenido (Objetivo específico B).

La segunda parte de la sesión la dedicaremos al trabajo de RSA (Objetivo específico E), la metodología utilizada será la expuesta por Castagna, Abt, et al. (2008) 5 series de 6 repeticiones de 20 segundos, con una micro pausa de 20 segundos, y una macro pausa de 2 minutos 50 segundos. Tanto la micro como la macro pausa la recuperación será pasiva. Los patrones de movimientos utilizados serán sacado de la investigación de López et al. (2014), tabla 4.2.

Vuelta a la calma de las sesiones de las RSA será idénticas que las de V02MAX y control motor, constando de una primera parte de liberación miosfacial y una segunda de SGA.

\section{Metodología utilizada en la primera fase en las sesiones de piscina, tabla 6.7.}

Investigaciones como las de (Sola \& Valdivieso, 2013; Torres-Ronda \& Schelling i del Alcázar, 2014) exponen en sus trabajos los beneficios del trabajo en el medio acuático entre los cuales destacamos que es un medio optimo para mantener el estado de forma del sujeto a la vez que poco lesivo, siendo a su vez un entorno ideal para recuperar a deportistas después de esfuerzo y por ultimo se considera un 
contexto ideal en las primeras partes de la readaptación de deportistas. Por este motivo hemos decidió meter aproximadamente cada 14 días una sesión en piscina para recuperar al sujeto de los esfuerza realizado.

Las sesiones en piscina constará de 3 partes una primera parte de calentamiento que empezará con una liberación miosfacial al igual que en las demás sesiones, acompañada de una activación vegetativa de 5 minutos de nado libre del sujeto. La parte principal constará de 40 minutos de running-pool, y terminaremos con una vuelta a la calma con dos ejercicios de relajación. 
Tabla 6.2. Propuesta trabajo de la resistencia en baloncesto extraído de (Schelling \& Torres-Ronda, 2013).

\begin{tabular}{|c|c|c|c|c|c|c|c|c|c|c|c|}
\hline Orientación & Nivel & Similitud & $\begin{array}{c}\text { Método de } \\
\text { entrenamiento }\end{array}$ & Lugar & Balón & $\begin{array}{l}\text { Toma de } \\
\text { decisión }\end{array}$ & $\begin{array}{c}\text { Formato de } \\
\text { enfrentamiento }\end{array}$ & Intensidad & $\begin{array}{c}\text { Exigencia } \\
\text { metabólica principal }\end{array}$ & Duración & Densidad \\
\hline Competitiva & v & Baloncesto & $\begin{array}{l}\text { Juego real; similitud en } \\
\text { el juego }\end{array}$ & $\begin{array}{c}\text { En } \\
\text { cancha }\end{array}$ & Con & $\begin{array}{c}\text { Complejidad } \\
\text { real }\end{array}$ & $4 v 4,5 v X$ & $\begin{array}{c}\text { Óptima modificando } \\
\text { reglas }\end{array}$ & Toda & Requerido & Requerida \\
\hline Especial & IV & Baloncesto & $\begin{array}{l}\text { Juegos en espacios } \\
\text { reducidos }\end{array}$ & $\begin{array}{c}\text { En } \\
\text { cancha }\end{array}$ & Con & Complejo & $\begin{array}{l}1 \mathrm{v} 1,2 \mathrm{vX}, 2 \mathrm{v} 2 \\
3 \mathrm{vX}, 3 \mathrm{v} 3,4 \mathrm{v} 4 \mathrm{X}\end{array}$ & $\begin{array}{l}\text { Óptima pero la } \\
\text { complejidad no debe } \\
\text { reducir la intensidad } \\
\text { ¿modificación de } \\
\text { reglas? }\end{array}$ & $\begin{array}{c}\text { Manejable } \\
\text { dependiendo del } \\
\text { formato y las reglas }\end{array}$ & $\begin{array}{l}\text { En función } \\
\text { del objetivo }\end{array}$ & $\begin{array}{c}\text { Manejable, } \\
\text { dependiendo, } \\
\text { del formato y } \\
\text { reglas }\end{array}$ \\
\hline \multirow[t]{2}{*}{ Dirigido } & III & $\begin{array}{l}\text { Baloncesto- } \\
\text { base }\end{array}$ & $\begin{array}{l}\text { Cortos a intensidad } \\
\text { alta, con patrones de } \\
\text { movimientos } \\
\text { específicos, con } \\
\text { cambios de dirección }\end{array}$ & $\begin{array}{c}\text { En } \\
\text { cancha }\end{array}$ & $\begin{array}{l}\text { Con } y \\
\sin \end{array}$ & $\begin{array}{l}\text { Ninguna o } \\
\text { simple }\end{array}$ & $1 \mathrm{v} 0,2 \mathrm{v} 0,3 \mathrm{v} 0$ & Máxima & $\begin{array}{l}\text { Agotamiento del } \\
\text { almacenamiento del } \\
\text { fosfágeno (ATP y } \\
\text { PCr) }\end{array}$ & $2-5 \mathrm{~s}(<60 \mathrm{~s})$ & $1: 5-10$ \\
\hline & II & $\begin{array}{l}\text { Carrera de } \\
\text { base y } \\
\text { baloncesto } \\
\text { base }\end{array}$ & $\begin{array}{l}\text { Cortos a intensidad } \\
\text { alta, patrones de } \\
\text { movimientos } \\
\text { específicos con } \\
\text { cambios de dirección }\end{array}$ & $\begin{array}{c}\text { En } \\
\text { cancha }\end{array}$ & $\begin{array}{l}\text { Con } y \\
\sin \end{array}$ & $\begin{array}{l}\text { Ninguna o } \\
\text { simple }\end{array}$ & $1 \mathrm{v} 0,2 \mathrm{v} 0,3 \mathrm{v} 0$ & Máxima & $\begin{array}{l}\text { Anaeróbica glucolisis } \\
\text { (metabolismo del } \\
\text { ácido láctico) }\end{array}$ & $\begin{array}{c}15-40 s(<60 \\
\text { s) }\end{array}$ & $1: 3-6$ \\
\hline \multirow[t]{4}{*}{ General } & $I$ & $\begin{array}{l}\text { Carrera de } \\
\text { base y } \\
\text { baloncesto } \\
\text { base }\end{array}$ & $\begin{array}{l}\text { Cortos a intensidad } \\
\text { alta, acciones y } \\
\text { patrones de } \\
\text { movimiento } \\
\text { deben ser similares a } \\
\text { los de } \\
\text { baloncesto }\end{array}$ & $\begin{array}{c}\text { Dentro y } \\
\text { fuera de } \\
\text { la } \\
\text { cancha }\end{array}$ & $\begin{array}{l}\text { Con } y \\
\sin \end{array}$ & $\begin{array}{l}\text { Ninguna o } \\
\text { simple }\end{array}$ & $\begin{array}{l}\text { Ninguno, 1v0, } \\
2 \mathrm{v} 0, \mathrm{Xv0}\end{array}$ & $>$ vo2 Max & $\begin{array}{c}\text { Zona de transición } \\
\text { aeróbica-anaeróbica }\end{array}$ & $\begin{array}{c}40-60 \mathrm{~s}(<60 \\
\text { s) }\end{array}$ & $1-2: 1$ \\
\hline & & $\begin{array}{l}\text { Carrera de } \\
\text { base y } \\
\text { baloncesto } \\
\text { base }\end{array}$ & Intensidad larga & $\begin{array}{l}\text { Dentro y } \\
\text { fuera de } \\
\text { la } \\
\text { cancha }\end{array}$ & $\begin{array}{l}\text { Con } y \\
\sin \end{array}$ & $\begin{array}{l}\text { Ninguna o } \\
\text { simple }\end{array}$ & $\begin{array}{l}\text { Ninguno, 1v0, } \\
2 \mathrm{v} 0, \mathrm{Xv0}\end{array}$ & $>90 \%$ vo2 Max & $\begin{array}{c}\text { Sistema aeróbico } \\
\text { (potencia/vo2 Max) }\end{array}$ & $\begin{array}{l}3-5 \min \\
(>60 \mathrm{~s})\end{array}$ & $1-2: 1$ \\
\hline & $\begin{array}{c}0 \\
\text { orientado }\end{array}$ & $\begin{array}{l}\text { Inespecífica, } \\
\text { carrera base }\end{array}$ & $\begin{array}{c}\text { Continuos y } \\
\text { entrenamiento } \\
\text { interválicos }\end{array}$ & $\begin{array}{c}\text { Fuera de } \\
\text { la } \\
\text { cancha }\end{array}$ & $\begin{array}{l}\text { Con } y \\
\sin \end{array}$ & Ninguna & Ninguno & $<85 \%$ vo2 Max & $\begin{array}{l}\text { Sistema aeróbico, } \\
\text { capacidad }\end{array}$ & $\begin{array}{c}30-40 \mathrm{~min} \\
\text { (6-10 min } \\
\text { interval) }\end{array}$ & $2-4: 1$ \\
\hline & $\begin{array}{c}0 \text { no } \\
\text { orientado }\end{array}$ & Inespecífica & $\begin{array}{l}\text { Continuos y } \\
\text { entrenamiento } \\
\text { interválicos }\end{array}$ & $\begin{array}{l}\text { Fuera de } \\
\text { la } \\
\text { cancha }\end{array}$ & $\begin{array}{l}\text { Con } y \\
\sin \end{array}$ & Ninguna & Ninguno & $<70 \%$ vo2 Max & $\begin{array}{l}\text { Sistema aeróbico, } \\
\text { eficiencia }\end{array}$ & $30-40 \mathrm{~min}$ & $1: 0$ \\
\hline
\end{tabular}




\subsubsection{Sesiones.}

Tabla 6.3. Sesión primera de muestra de control motor.

Fecha: Jueves 4 de Junio

Lugar: Polideportivo Andrés Estrada "Sala de Entrenamiento"

Objetivo de la sesión:

Aprendizaje y control motor del patrones básico Glute Brigde y de desplazamientos específicos en baloncesto, carrera hacia delante, atrás, desplazamientos laterales y defensivos.

\section{Contenidos:}

Estabilidad del lumbo pélvica

Trabajo coxolumbopélvico

Fuerza glúteo medio

Trabajo preventivo, tendinosis rotuliana

\begin{tabular}{lcc}
\hline & Desarrollo de la sesión \\
\hline & Calentamiento \\
\hline Ejercicios & Normativa de Carga & Representación gráfica \\
\hline Liberación miosfacial & con 10 pasadas lentas por \\
foam roller: & cada zona \\
Abductores & \\
Cuádriceps & \\
Femoral \\
Flexores de la cadera \\
Gemelos \\
Glúteo \\
Dorsal \\
Trapecio \\
Romboide \\
Fascias torocolumbar
\end{tabular}

Activación vegetativa: bicicleta estática 3 minutos

\begin{tabular}{ll}
\hline Movilidad de: \\
Tobillo \\
Cadera \\
Glenohumeral \\
Columna toráxica o vértebras \\
dorsales. \\
\hline Normativa de Carga \\
\hline Ejercicios & P series mantener el \\
\hline Sentadilla Isométrica & patrón 60 segundos. \\
& Reposos \\
& isométricos de \\
& segundos.
\end{tabular}




\begin{tabular}{|c|c|}
\hline $\begin{array}{l}\text { Glute Brigde Isométrico, } \\
\text { concepto de triple activación }\end{array}$ & 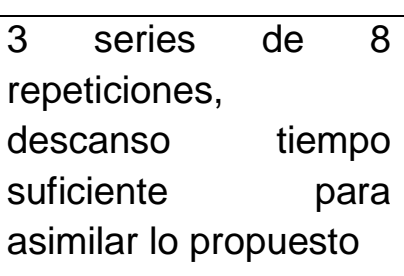 \\
\hline $\begin{array}{l}\text { Glute Brigde, dinámico, } \\
\text { bajando y subiendo con el } \\
\text { rango total y hasta la mitad } \\
\text { según la información del } \\
\text { entrenador, concepto de triple } \\
\text { activación }\end{array}$ & 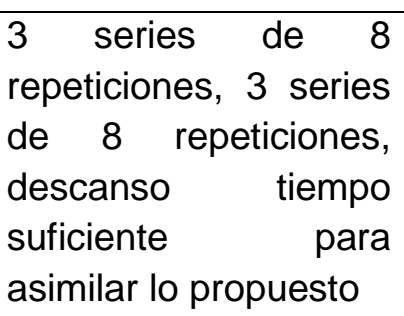 \\
\hline $\begin{array}{l}\text { Standing Lineal Wall, primero } \\
\text { con brazos en cruz haciendo } \\
\text { consiente al sujeto del } \\
\text { movimiento (especial énfasis } \\
\text { en los apoyos y rodilla), } \\
\text { realiza desplazamientos en } \\
\text { línea rectas, en segundo lugar } \\
\text { los brazos acompañaran el } \\
\text { movimiento }\end{array}$ & 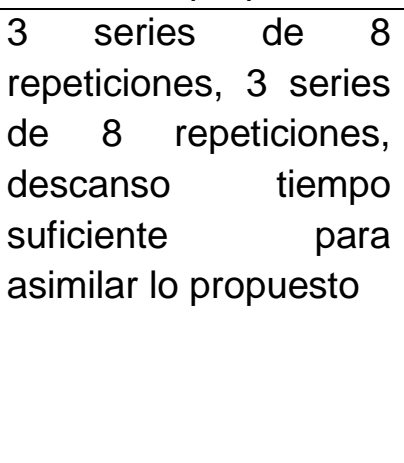 \\
\hline $\begin{array}{l}\text { Base Lineal Wall, en posición } \\
\text { defensiva, primero con brazos } \\
\text { en cruz haciendo consiente al } \\
\text { sujeto del movimiento } \\
\text { (especial énfasis en los } \\
\text { apoyos y rodilla), realiza } \\
\text { desplazamientos en línea } \\
\text { rectas, en segundo lugar los } \\
\text { brazos acompañaran el } \\
\text { movimiento }\end{array}$ & $\begin{array}{lrr}3 & \text { series } & \text { de } \\
\text { repeticiones, } & 3 & \text { series } \\
\text { de } 8 & \text { repeticiones, } \\
\text { descanso } & \text { tiempo } \\
\text { suficiente } & \text { para } \\
\text { asimilar lo propuesto }\end{array}$ \\
\hline
\end{tabular}




\begin{tabular}{ll}
\hline & \multicolumn{1}{c}{ Vuelta a la calma } \\
\hline Ejercicios & Normativa de Carga \\
\hline Liberación miosfacial: & 10 pasadas lentas por \\
Liberación en clavícula fascia & cada zona \\
apendicular + Trabajo fascia & \\
axial del brazo. & \\
Palma de la mano. & pierna \\
Fascias extensores del brazo. & \\
Fascia plantar. & \\
Liberación \\
flexoextensión de tobillo. \\
Fascia peronéos. \\
Fascias toracolumbar. \\
Liberación fascia lateral. \\
Extensión torácica. \\
\end{tabular}


Tabla 6.4. Sesión segunda de muestra de control motor.

Fecha: Miércoles 17 de Junio

Lugar: Polideportivo Andrés Estradas "Sala de Entrenamiento"

Objetivo de la sesión:

Aprendizaje y control motor del patrón básico de ejercicios dominantes de rodilla.

Contenidos:

Disociación lumbo pélvica

Dorsiflexión de tobillo

Estabilidad lumbar y del raquis

Trabajo preventivo, tendinosis rotuliana

\begin{tabular}{ll}
\hline & Desarrollo de la sesión \\
\hline & $\begin{array}{l}\text { Calentamiento } \\
\text { Cormativa de Representación gráfica }\end{array}$ \\
\hline Ejercicios & miosfacial \\
\hline $\begin{array}{l}\text { Liberación pasadas } \\
\text { con foam roller: }\end{array}$ & lentas por cada \\
$\begin{array}{l}\text { Abductores } \\
\text { Cuádriceps }\end{array}$ & zona \\
Femoral & \\
Flexores de la cadera & \\
Gemelos & \\
Glúteo \\
Dorsal \\
Trapecio \\
Romboide \\
Fascias torocolumbar
\end{tabular}

Activación vegetativa: bicicleta estática 3 minutos

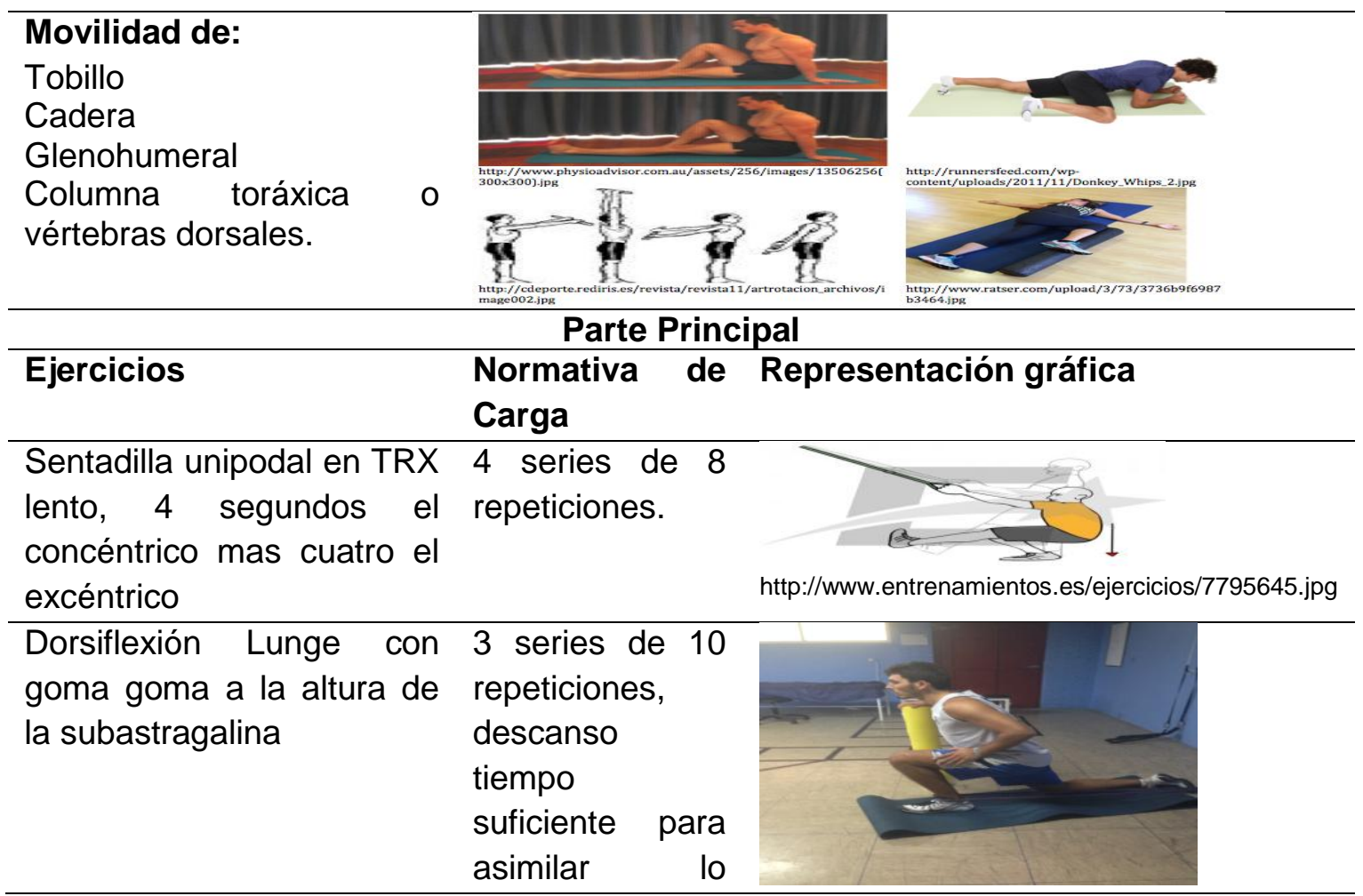




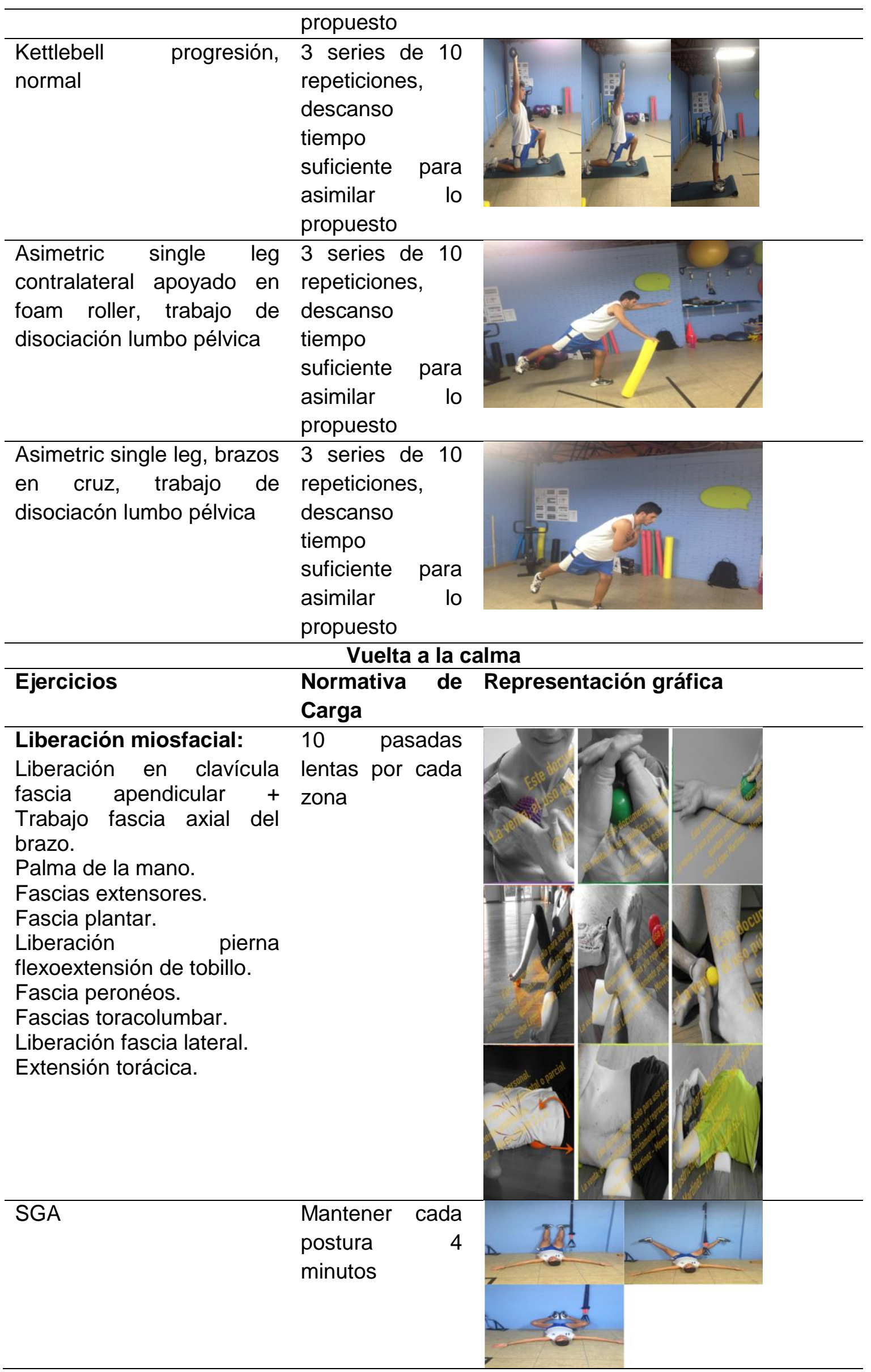


Tabla 6.5. Sesión tercera de muestra de control motor.

Fecha: Martes 25 de Junio

Lugar: Polideportivo Andrés Estradas "Sala de Entrenamiento"

Objetivo de la sesión:

Aprendizaje y control motor del patrón básico de tracción

Contenidos:

Trabajo de estabilización escapulo toráxica

Trabajo de retracción y aproximación escapular

Trabajo preventivo, tendinosis rotuliana "fuerza excéntrica"

\begin{tabular}{ll}
\hline & \multicolumn{1}{c}{ Calentamiento } \\
\hline Ejercicios & $\begin{array}{l}\text { Normativa } \\
\text { de Carga }\end{array}$ \\
\hline $\begin{array}{l}\text { Liberación miosfacial } \\
\text { con foam roller: }\end{array}$ & $\begin{array}{l}10 \text { pasadas } \\
\text { lentas por } \\
\text { cada zona } \\
\text { Abductores }\end{array}$ \\
$\begin{array}{l}\text { Cuádriceps } \\
\text { Femoral } \\
\text { Flexores de la cadera }\end{array}$ \\
Gemelos \\
Glúteo \\
Dorsal \\
Trapecio \\
Romboide \\
Fascias torocolumbar
\end{tabular}

Activación vegetativa: bicicleta estática 3 minutos

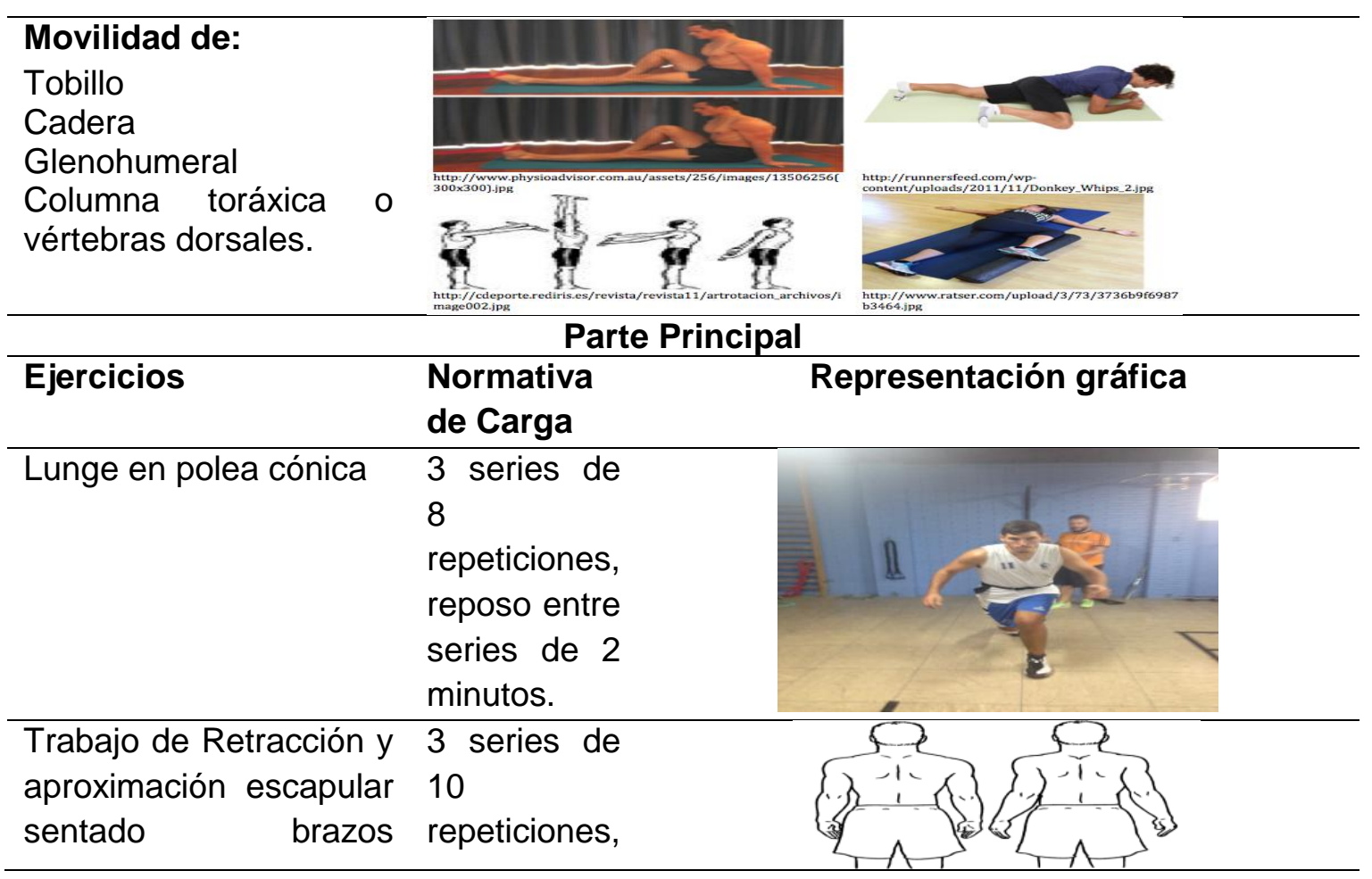




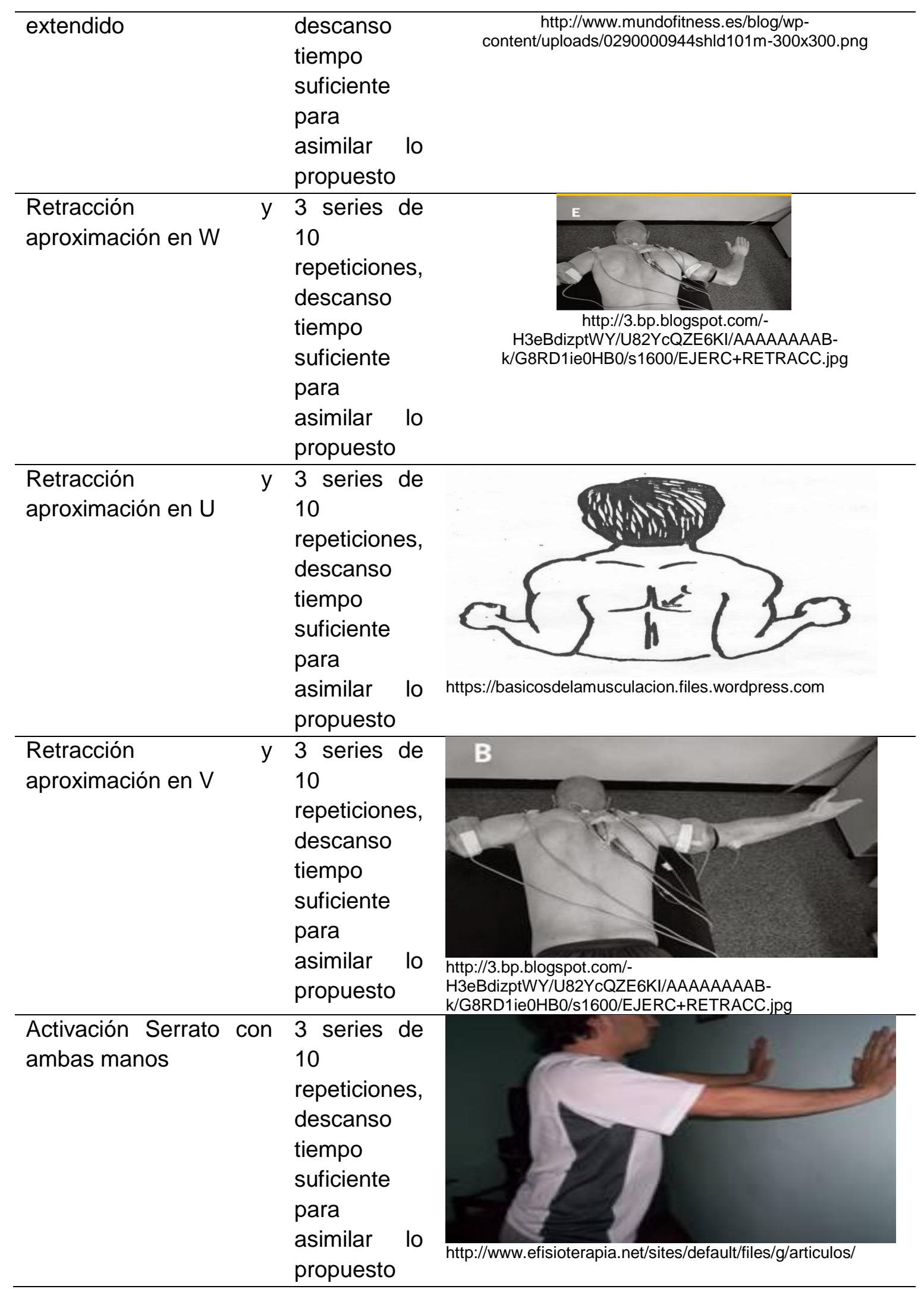




\begin{tabular}{|c|c|c|}
\hline $\begin{array}{l}\text { Rotación externa con } \\
\text { ambas manos }\end{array}$ & $\begin{array}{l}3 \text { series de } \\
10 \\
\text { repeticiones, } \\
\text { descanso } \\
\text { tiempo } \\
\text { suficiente } \\
\text { para } \\
\text { asimilar lo } \\
\text { propuesto }\end{array}$ & http://es.fitness.com/exercises/uploaded/1292325274_0190.gif \\
\hline $\begin{array}{l}\text { Con gomas Postura de } \\
\text { la A }\end{array}$ & $\begin{array}{l}3 \text { series de } \\
10 \\
\text { repeticiones, } \\
\text { descanso } \\
\text { tiempo } \\
\text { suficiente } \\
\text { para } \\
\text { asimilar lo } \\
\text { propuesto }\end{array}$ & 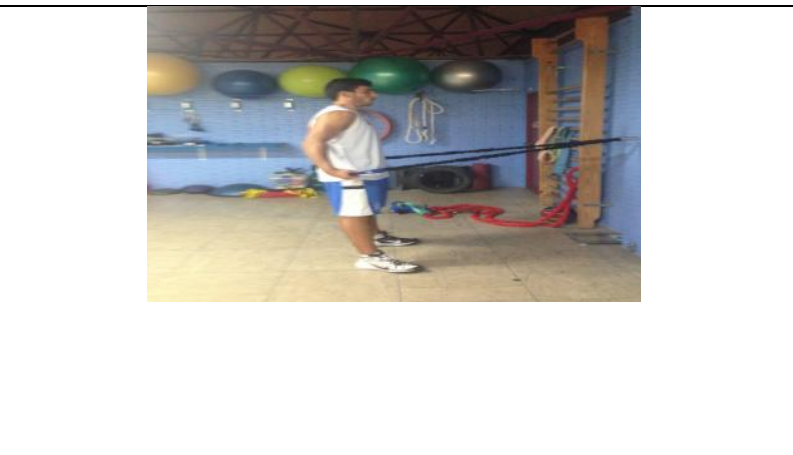 \\
\hline \multicolumn{3}{|c|}{ Vuelta a la calma } \\
\hline Ejercicios & $\begin{array}{l}\text { Normativa } \\
\text { de Carga }\end{array}$ & Representación gráfica \\
\hline $\begin{array}{l}\text { Liberación miosfacial: } \\
\text { Liberación en clavícula } \\
\text { fascia apendicular + } \\
\text { Trabajo fascia axial del } \\
\text { brazo. } \\
\text { Palma de la mano. } \\
\text { Fascias extensores del } \\
\text { brazo. } \\
\text { Fascia plantar. } \\
\text { Liberación } \\
\text { flexoextensión pierna } \\
\text { tobillo. } \\
\text { Fascia peronéos. } \\
\text { Fascias toracolumbar. } \\
\text { Liberación fascia lateral. } \\
\text { Extensión torácica. }\end{array}$ & $\begin{array}{l}10 \text { pasadas } \\
\text { lentas por } \\
\text { cada zona }\end{array}$ & (1) \\
\hline SGA & $\begin{array}{l}\text { Mantener } \\
\text { cada } \\
\text { postura } \\
\text { minutos }\end{array}$ & 2 \\
\hline
\end{tabular}


Tabla 6.6. Cuarta sesión de muestra RSA.

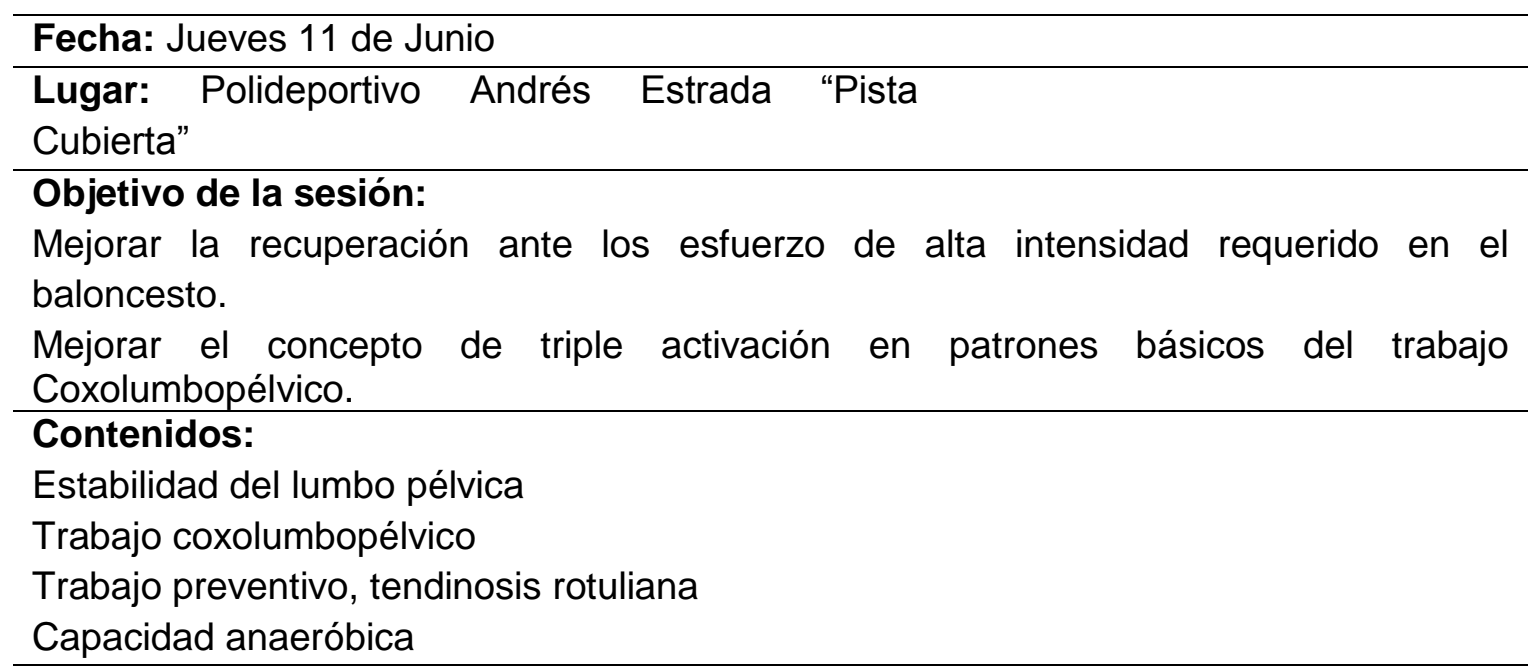

\begin{tabular}{ll}
\hline \multicolumn{3}{c}{ Desarrollo de la sesión } \\
\hline Calentamiento \\
\hline Libercicios & Normativa de Carga \\
miosfacial & 10 pasadas lentas por cada zona \\
con foam \\
roller: \\
Abductores \\
Cuádriceps \\
Femoral \\
Flexores de \\
la cadera \\
Gemelos \\
Glúteo \\
Dorsal \\
Trapecio \\
Romboide \\
Fascias \\
torocolumbar \\
Movilidad de: \\
Tobillo \\
Cadera \\
Glenohumer \\
al \\
Columna \\
toráxica \\
vértebras \\
dorsales.
\end{tabular}




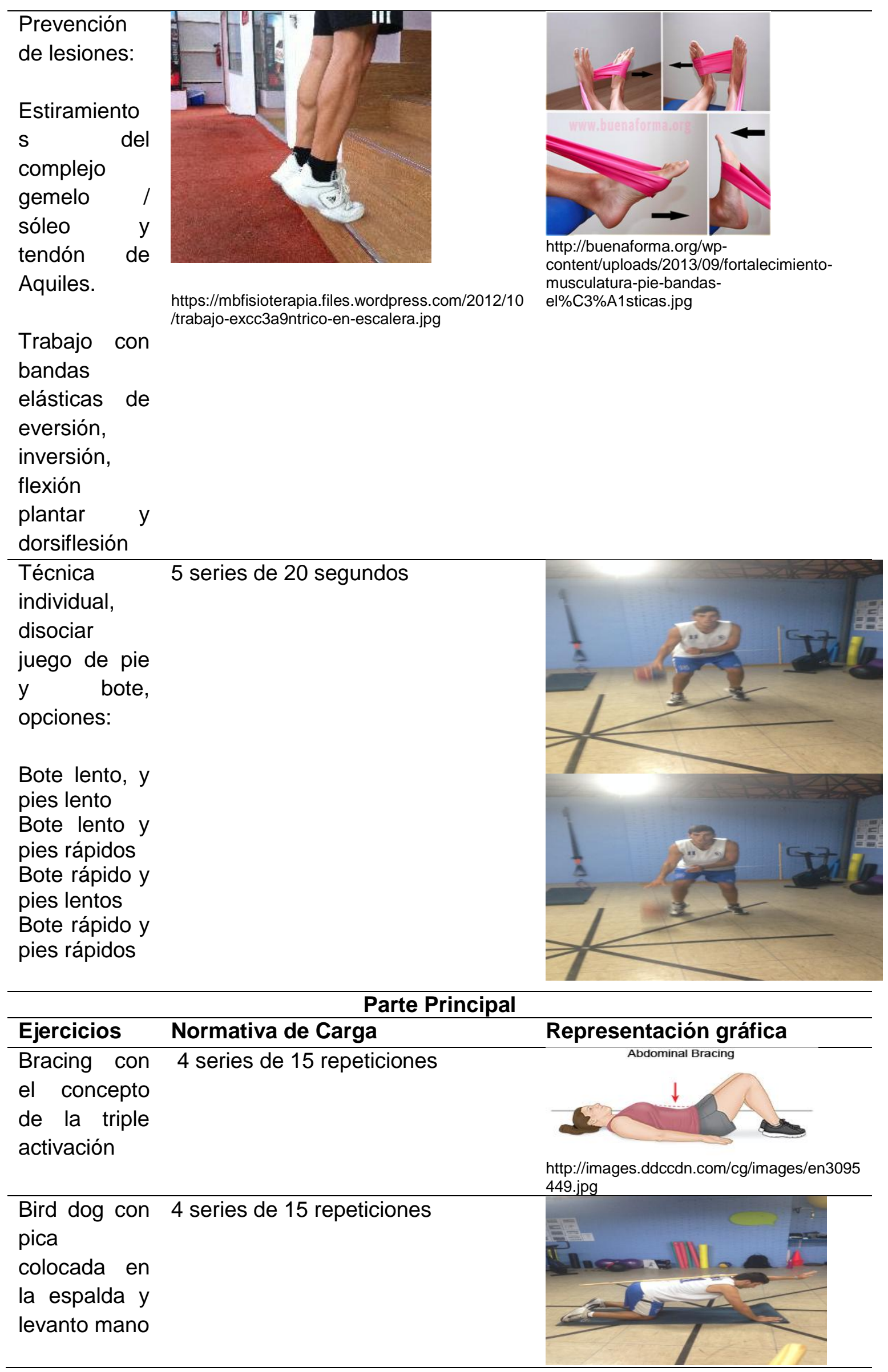




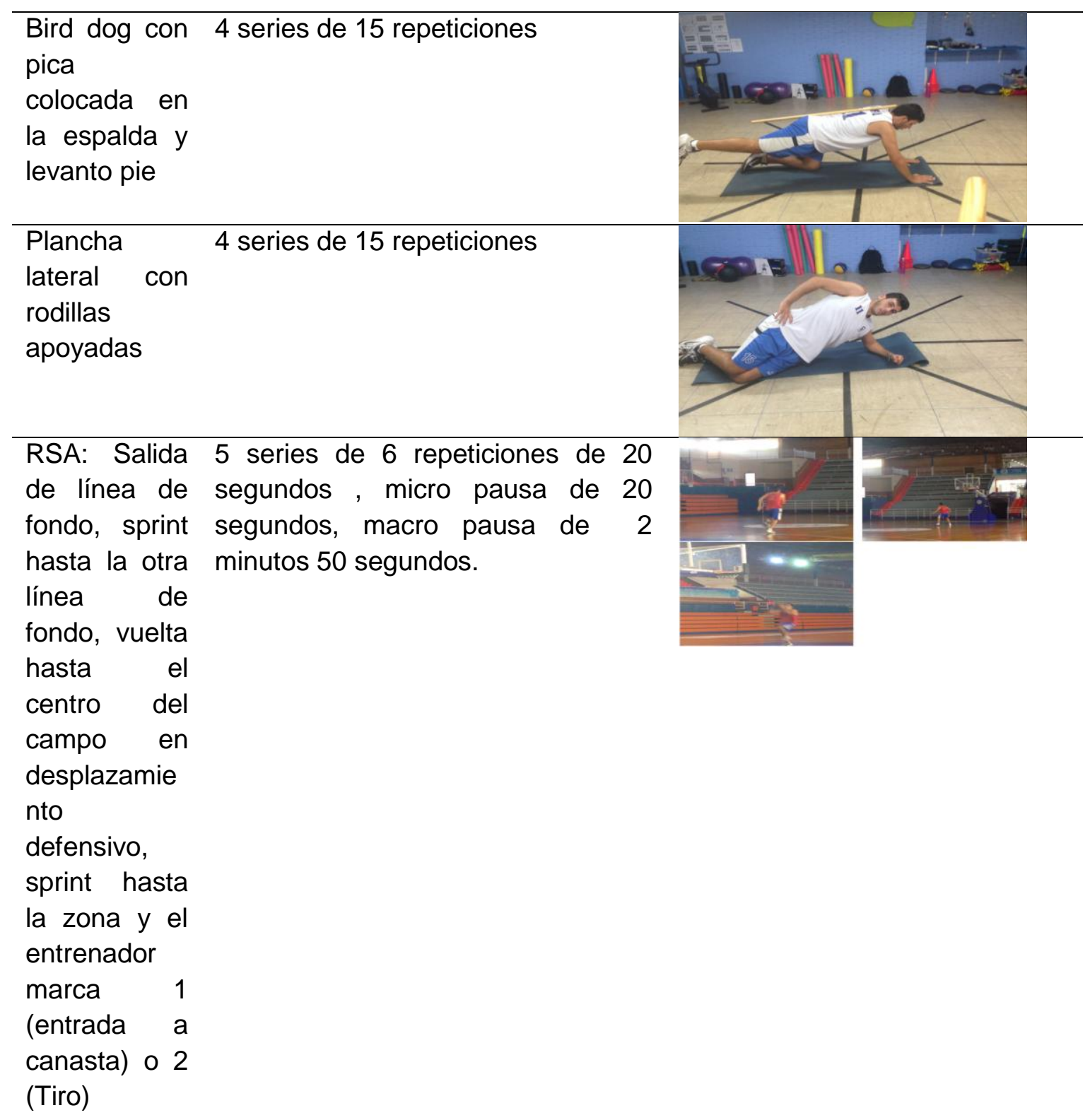




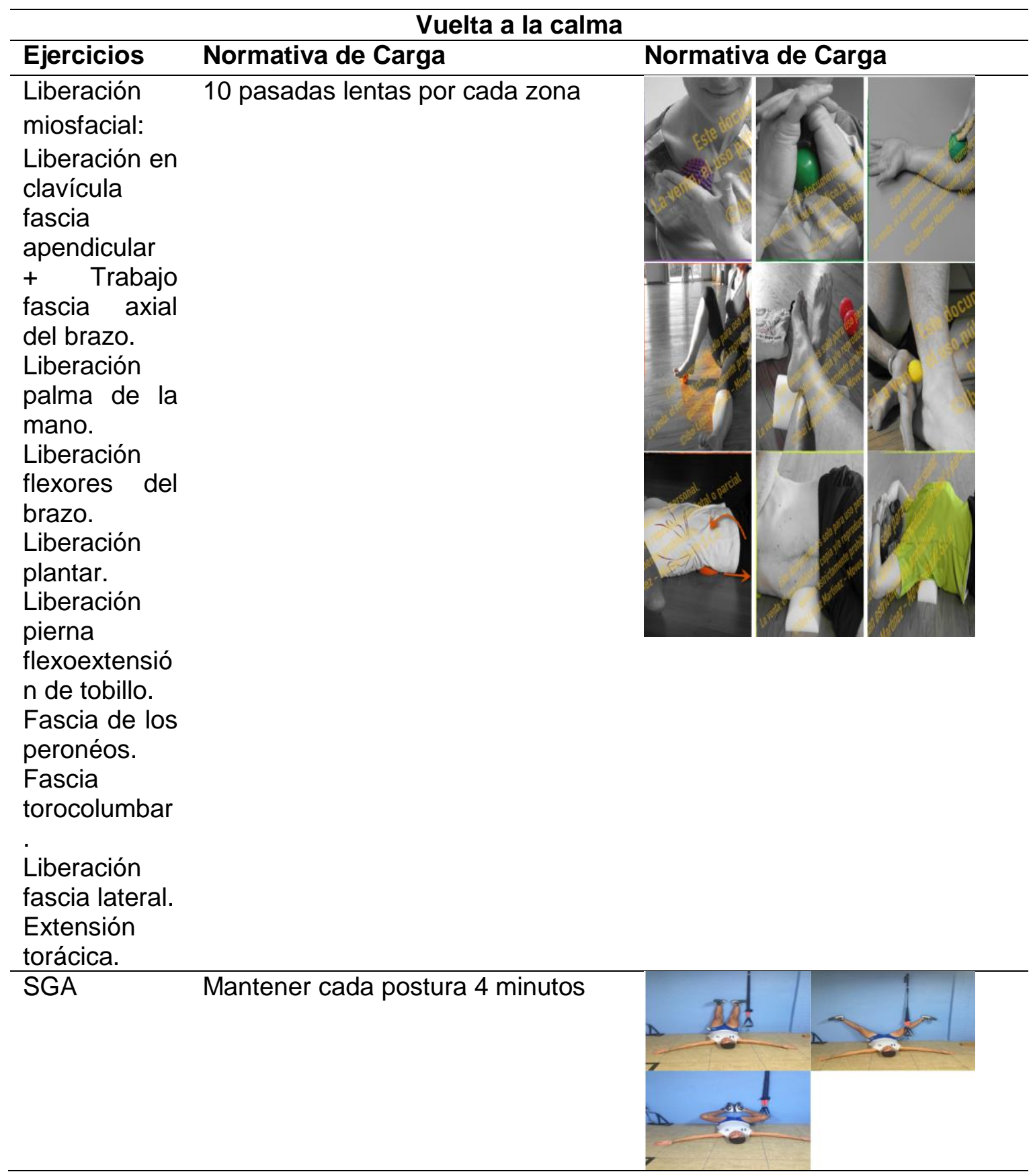


Tabla 6.7. Quinta sesión de muestra en piscina

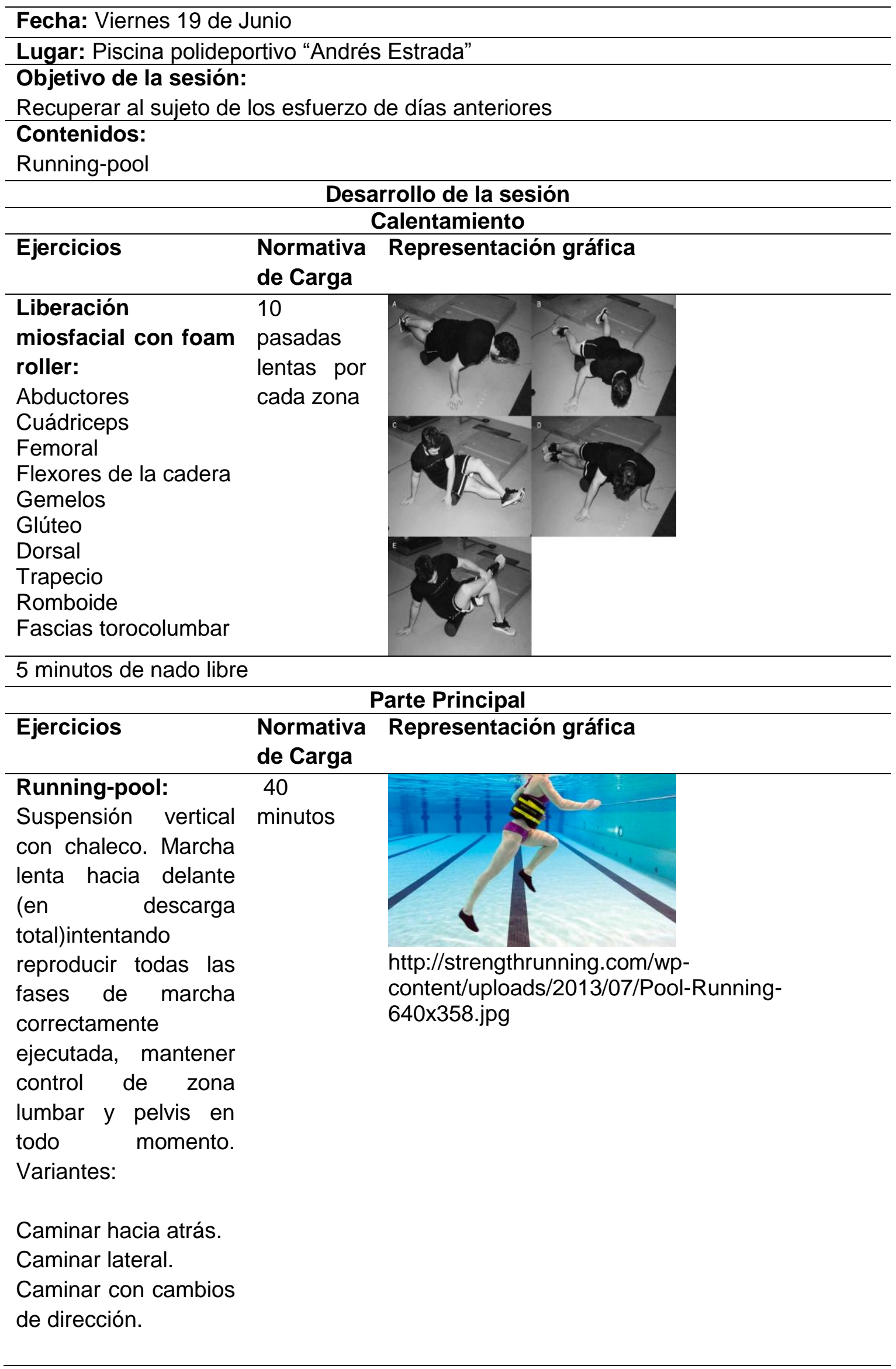




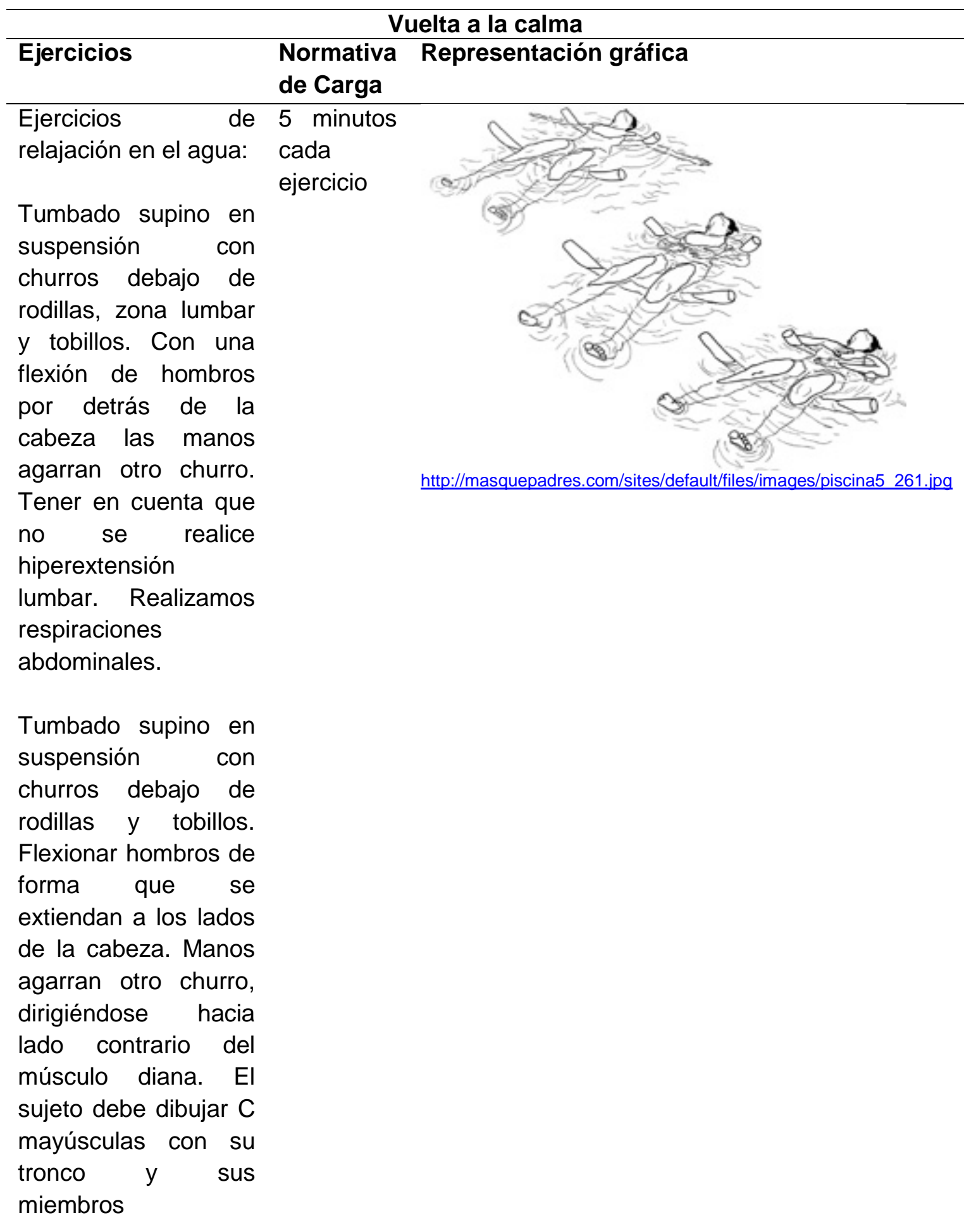




\subsubsection{Evaluación y control del proceso.}

\section{A. Medios de control y seguimiento de la primera fase del programa de intervención.}

Siguiendo la propuesta de Toscano and Campos (2015), hemos diferenciado entre la monitorización de las cargas de entrenamiento, monitorización de la condición física, y monitorización de la fatiga.

La monitorización de las cargas de entrenamiento la realizaremos a través de RPE TL propuesto por Foster et al. (2001), se basa en el uso de la escala de Borg 10, tabla $\underline{6.8}$, mediante la cual el jugador determina como de intenso ha sido el entrenamiento al finalizar el mismo, este valor se multiplica por el volumen de la sesión en minutos y el resultado es la carga de entrenamiento, Toscano and Campos (2015), figura 19, la unidad de mediad expresada son unidades arbitrarias.

Tabla 6.8. Escala de Borg 10 extraído de (Foster et al., 2001).

\begin{tabular}{cc}
\hline Valor & Descriptor \\
\hline 0 & Descanso \\
\hline 1 & Muy, muy fácil \\
\hline 2 & Fácil \\
\hline 3 & Moderado \\
\hline 4 & Algo duro \\
\hline 5 & Duro \\
\hline 6 & Muy duro \\
\hline 7 & \\
\hline 8 & \\
\hline 9 & Máximo
\end{tabular}

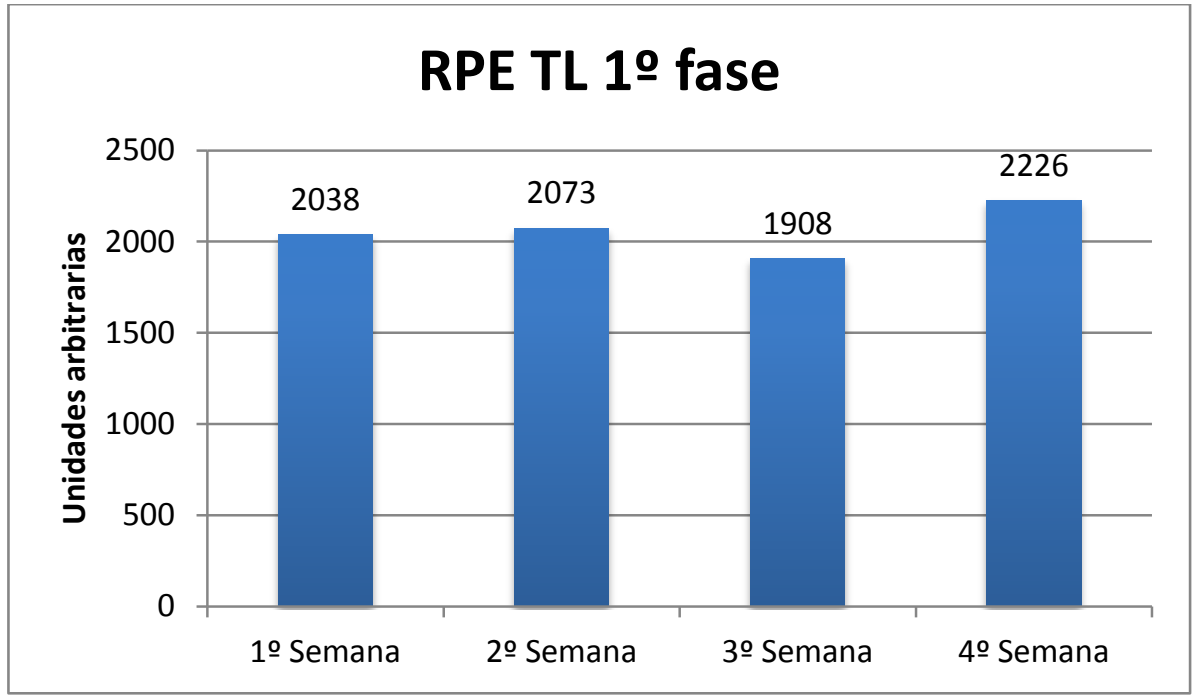

Figura 19. RPE TL de la primera fase del programa de intervención. 
También utilizaremos para la monitorización de las cargas de entrenamientos un método basado en el análisis de la frecuencia cardiaca como es el TRIMP individualizado (Manzi, Bovenzi, Impellizzeri, Carminati, \& Castagna, 2013), este índice es el resultado de la multiplicación de la FC media del entrenamiento por el volumen de trabajo. En la figura 20 podemos observar la progresión de los índices TRIMP en la primera fase del programa de intervención.

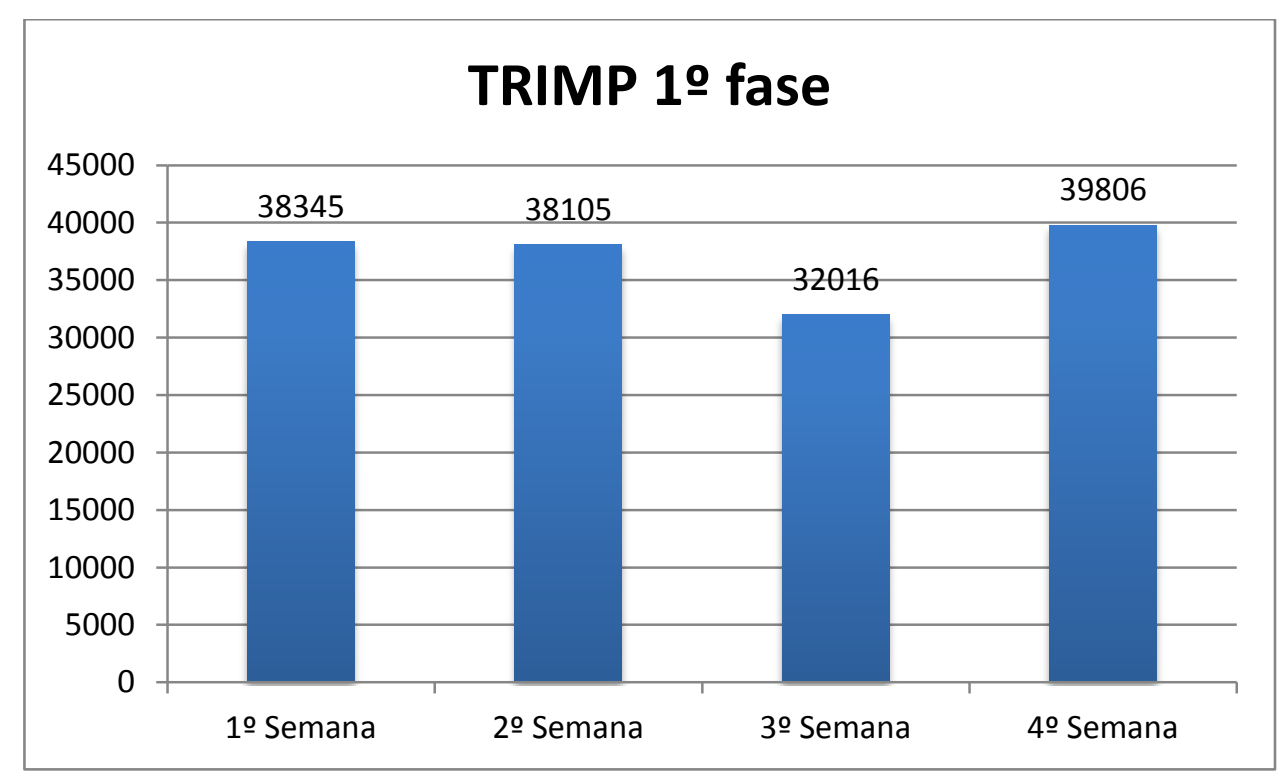

Figura 20. TRIMP individualizados en la primera fase del programa de intervención.

La monitorización de la condición física la llevaremos a cabo a través del CMJ, utilizado para medir en los miembros inferiores la fuerza explosiva (Cormack et al., 2008; Duffield et al., 2012; Jiménez-Reyes \& González-Badillo, 2011; McLean et al., 2010; Twist \& Highton, 2013; wist et al., 2012). Su fácil aplicación y la escasa fatiga que produce a los jugadores aconsejan su uso Toscano and Campos (2015), no solo nos servirá para monitorizar la condición física si no una perdida de altura en $10 \%$ sobre una medición basal, tabla 2.10, nos indica un índice de fatiga neuromuscular (Cormack et al., 2008; Duffield et al., 2012; Jiménez-Reyes \& González-Badillo, 2011; McLean et al., 2010; Twist \& Highton, 2013; wist et al., 2012). Los resultados obtenidos en esta fase los podemos observar en la figura 21. 


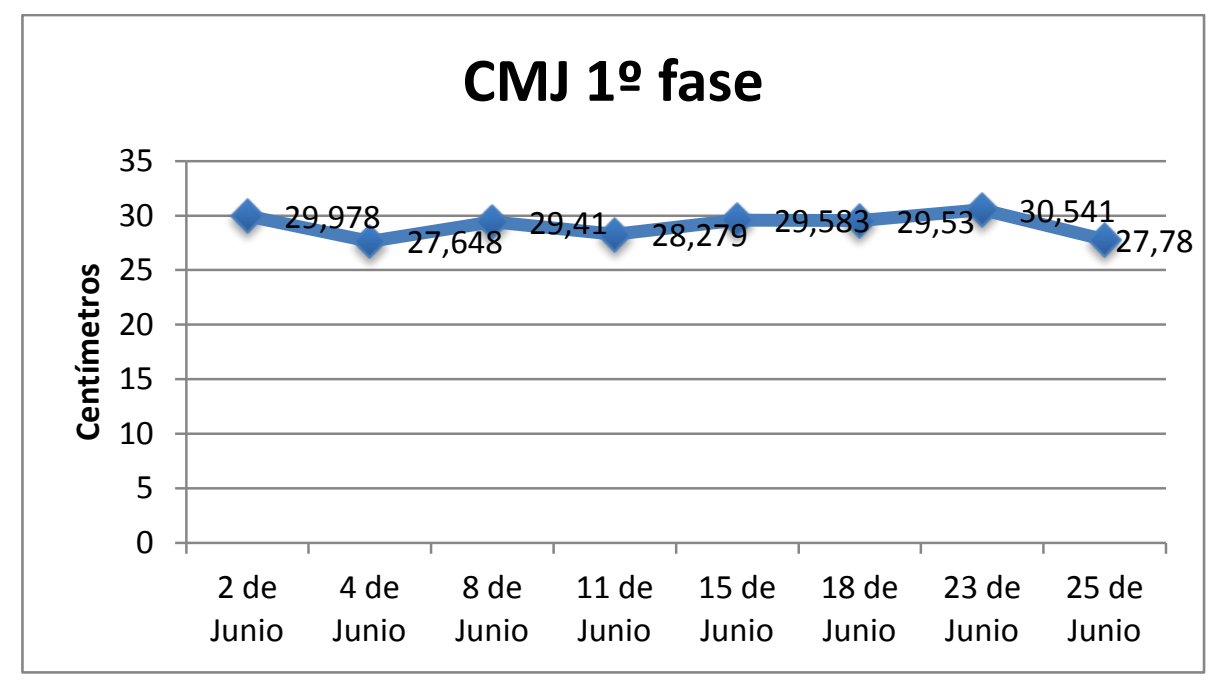

Figura 21. Monitorización del CMJ durante la 1ำ fase del programa de intervención.

Para terminar la monitorización de la fatiga se llevara a cabo por medio del cuestionario de Bienestar de McLean et al. (2010), se trata de 5 preguntas relacionadas con la fatiga percibida, la calidad del sueño, el daño muscular, los niveles de estrés y el humor (véase anexo12) (Toscano \& Campos, 2015). Cada pregunta se puntúa entre 1-5, con 1 y 5 representando niveles pobres y muy buenos de bienestar respectivamente, y con incremento de 0.5 puntos (Toscano \& Campos, 2015). El grado de bienestar se determina sumando las 5 puntuaciones, debe ser rellenado antes de cada entrenamiento (Toscano \& Campos, 2015). En la figura 22 podemos observar los valores obtenido cada uno de los días de enteramiento en cada uno de los ítems valorados en el cuestionario de Bienestar, durante la 1ํ fase del programa de intervención, en cambio en la figura 23 podemos observar la progresión según cada semana. Como se ha comentado anteriormente el CMJ también se tendrá en cuenta como índice de fatiga neuromuscular (Cormack et al., 2008; Duffield et al., 2012; Jiménez-Reyes \& González-Badillo, 2011; McLean et al., 2010; Twist \& Highton, 2013; wist et al., 2012).

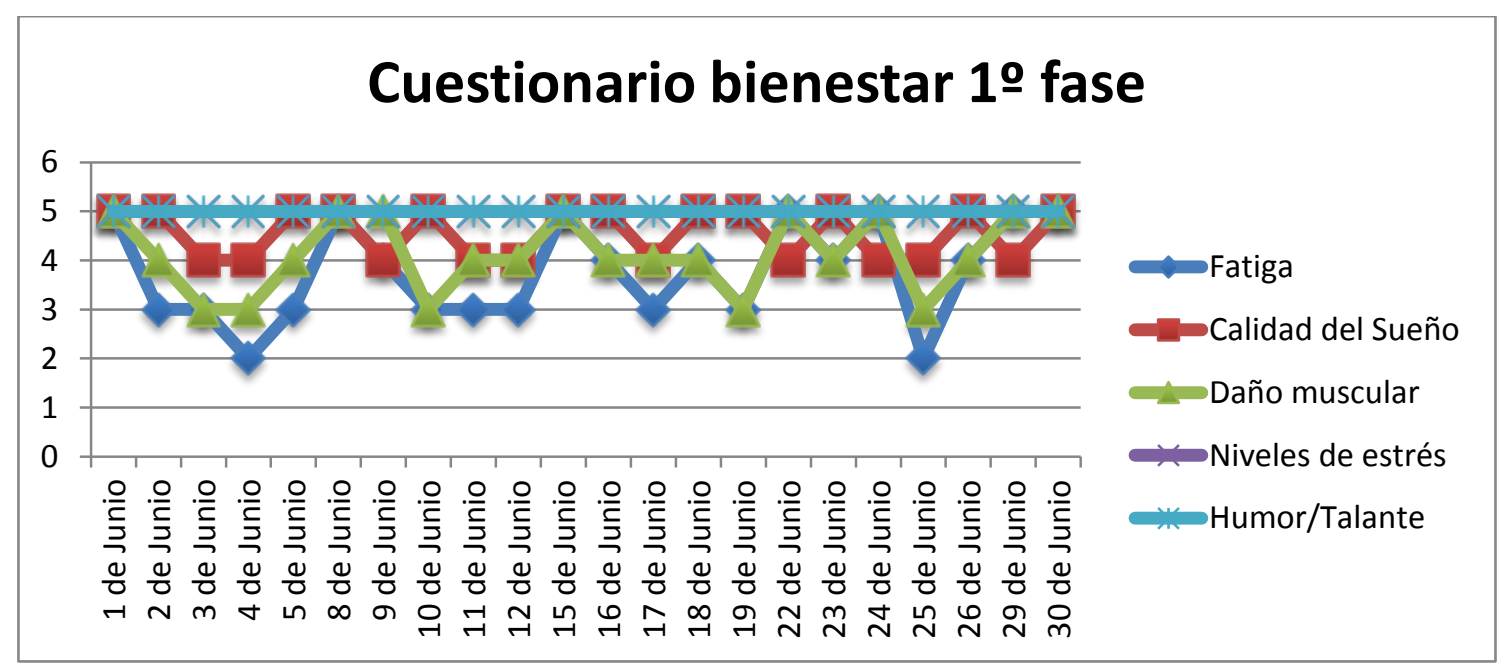

Figura 22. Monitorización por días del cuestionario de bienestar (McLean et al., 2010). 


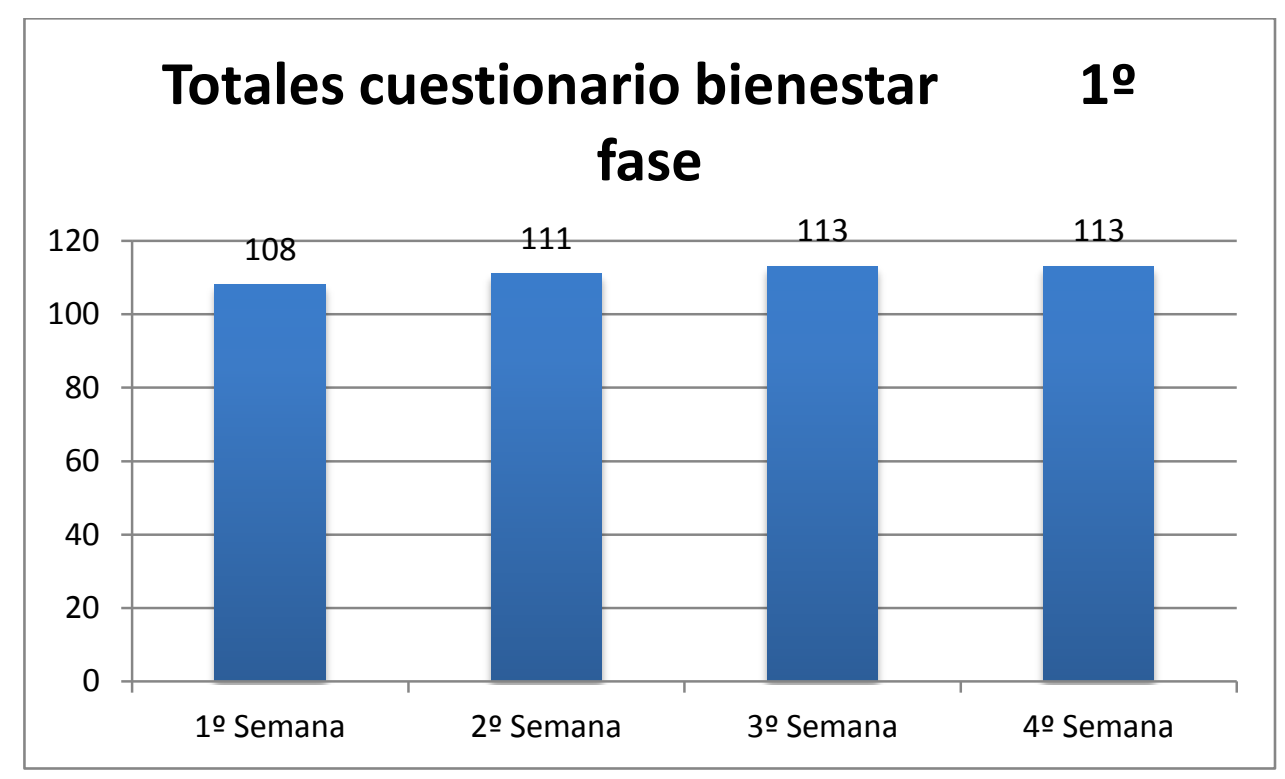

Figura 23. Monitorización por semanas del cuestionario de bienestar (McLean et al., 2010).

Los días 4 y 25 de Junio encontramos un descenso sobre el estado basal del CMJ, sin llegar a estar por debajo del 10\% como valor alarmante como índice de fatiga neuromuscular. Estas dos días venían precedidos de dos esfuerzo máximos, 3 de Junio primer día de trabajo de RSA 3 y 25 de Junio Test Trive-Basket (véase anexo 12), los descansos tanto intra series como inter series fueron aumentados, para realizar el trabajo en ausencia de fatiga e intentar recuperar los esfuerzo realizados, a su vez al final de la sesión realizamos ejercicios de retorno venoso y aconsejamos al sujeto realizar crioterapia en su casa, al no disponer ni de bañeras ni hielos en la instalación.

\section{B. Evaluación de la primera fase del programa de intervención.}

El objetivo específico A, aprendizaje y control motor de patrones motores básicos, haciendo especial énfasis en las tracciones y ejercicios dominante de rodilla, fue evaluado a lo largo de todas las sesiones de la $1^{\circ}$ fase del programa de intervención, teniendo como guía la planilla que se puede observar en el anexo 6. A lo largo de esta fase el normalizo todo los movimientos que en la evaluación inicial realizaba incorrectamente. Trabajar en la consecución de este objetivo nos ayudo a regularizar los movimiento de retracción escapular y la flexión plantar de ambos pies, la rotación interna de los hombros, la protucción cefálica y el aprendizaje en la disociación lumbopélvica planteados en el (objetivo general A) del programa de intervención.

La evaluación de patrones específicos la realizamos mediante el Agility T-Test, tabla 6.9, donde vemos que el sujeto sigue estando por debajo de los valores de referencia, y bajo con respecto al primer test realizado figura 24. 
Tabla 6.9. Resultados del Agility T-Test.

\begin{tabular}{ll}
\hline & Tiempo (s) \\
\hline Carrera 1 & 11,642 \\
Carrera 2 & 10,939 \\
Carrera 3 & $\mathbf{1 0 , 8 4 4}$ \\
\hline
\end{tabular}

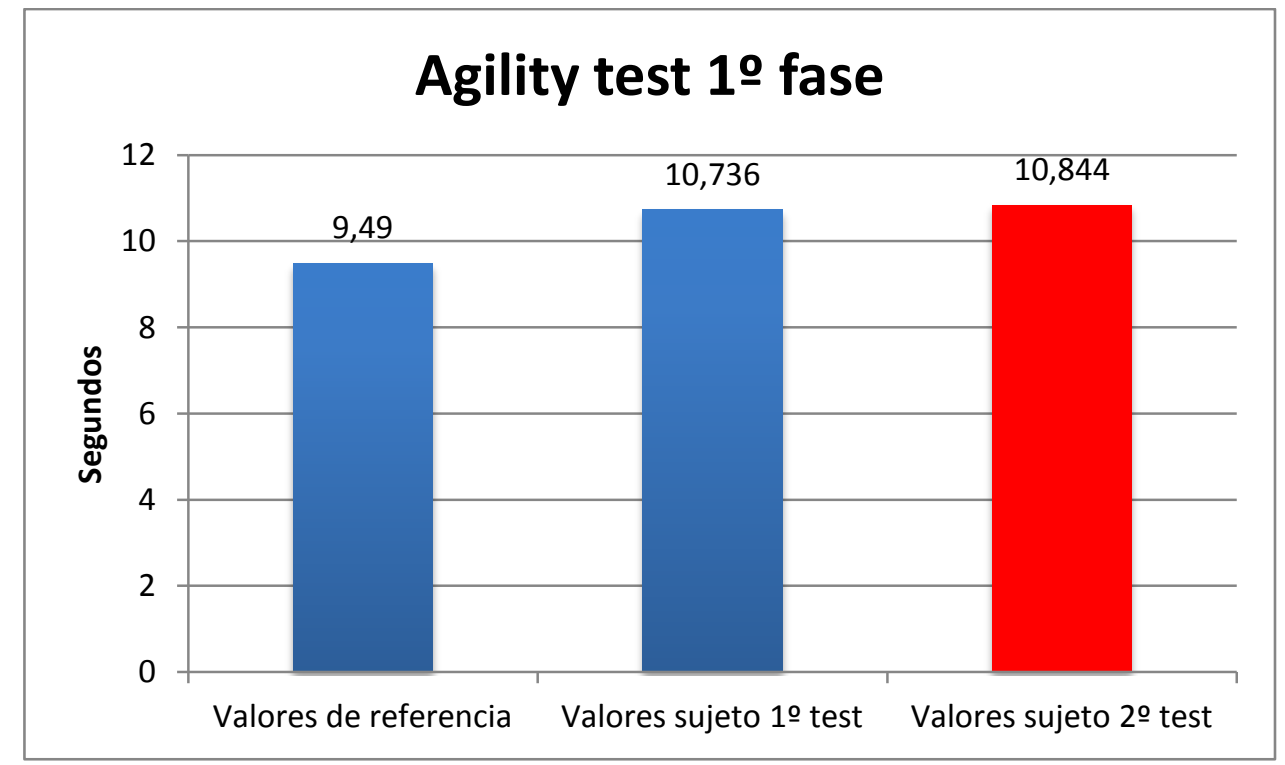

Figura 24. Valores de referencia del estudio Delextrat and Cohen (2008) en jugadores universitarios y valores del sujeto en la evaluación inicial y final de la $1^{\circ}$ fase.

Para la evaluación del objetivo específico $\mathrm{B}_{\text {, }}$ evaluaremos la región del core y su progresión en esta primera fase a partir la propuesta presentada en los apartados anteriores de McGuill (1999), tabla 6.10. Podemos observar en la figura 25, una mejora en todas las pruebas, menos en el test modificado Biering-Sorensen, que tiene una disminución considerable con respecto a los resultados obtenidos en la primera evaluación. Podemos presumir que al ser el primero y el sujeto no tener valores de referencia no se esforzó al máximo, ya que en los otros resultados fueron mejorados. Esta hipótesis será contrastada en la evaluación de la segunda fase. A pesar de la mejora en todos los demás test el sujeto sigue estando por debajo de los valores de referencia, figura 25, expuesto por Peña et al. (2012), exceptuando en el test de resistencia de flexores, que supera estos valores, figura 25.

Tabla 6.10. Resultados obtenidos en la prueba para valorar la estabilidad central.

\begin{tabular}{ll}
\hline Test & Tiempo (s) \\
\hline Test modificado Biering-Sorensen & 35 \\
Puente lateral derecha & 95 \\
Puente lateral izquierda & 100 \\
Test resistencia flexores & 146 \\
\hline
\end{tabular}




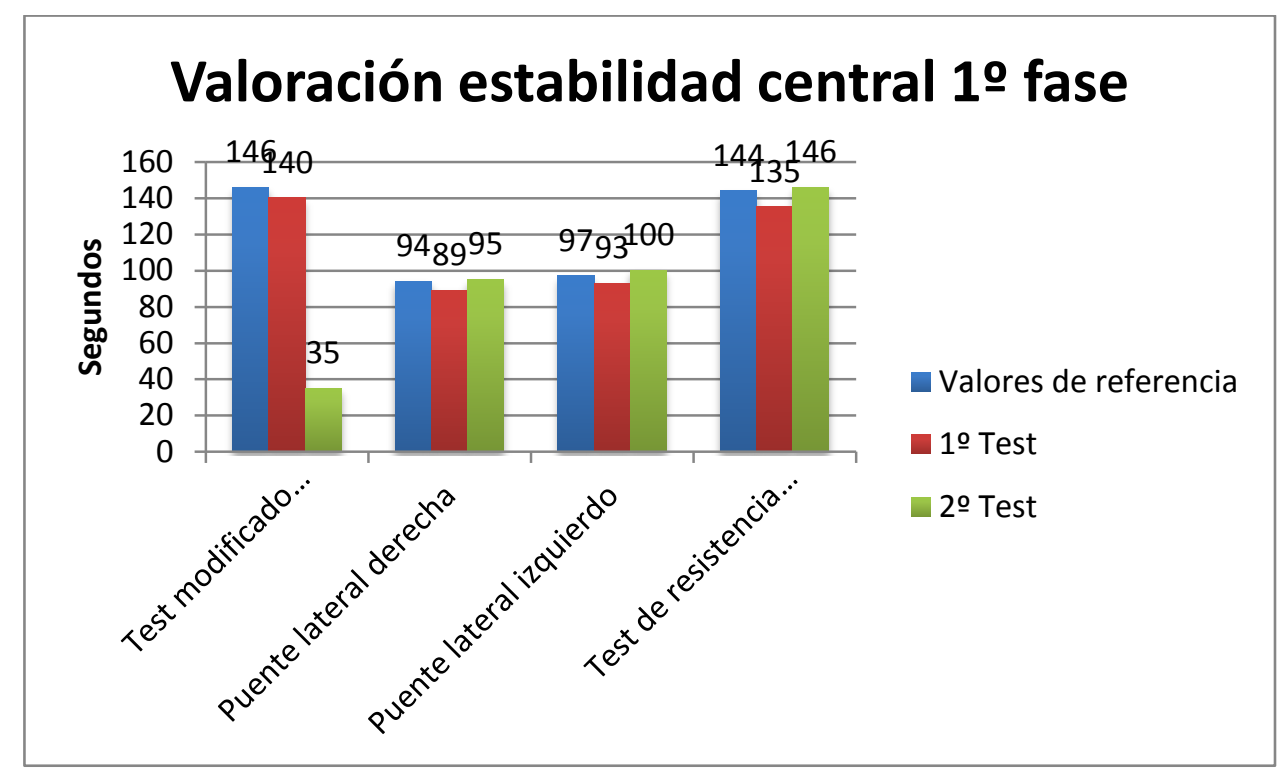

Figura 25. Valores de referencia para la valoración de la estabilidad central expuesto en (Peña et al., 2012).

El objetivo específico $\mathrm{C}$, referido a la readaptación de la tendinosis rotuliana, se implanto el programa de readaptación planteado en la tabla 6.1, propuesto por (Mascaró (2014). La evaluación y progresión de cada fase como se proyecta en la tabla 6.1, es estar en un valor de 4 en la escala de dolor (anexo 13) para superar cada fase. En la figura 26, mostramos la evolución del sujeto para la consecución de este objetivo, los días donde aparecen tres medidas son días como se expone en la tabla $\underline{6.1}$, son días donde el sujeto tenía que realizar el ejercicio planteado tres veces a lo largo del día. En la segunda semana conseguimos que desaparecieran las molestias planteadas, y este objetivo paso a ser uno más del programa preventivo.

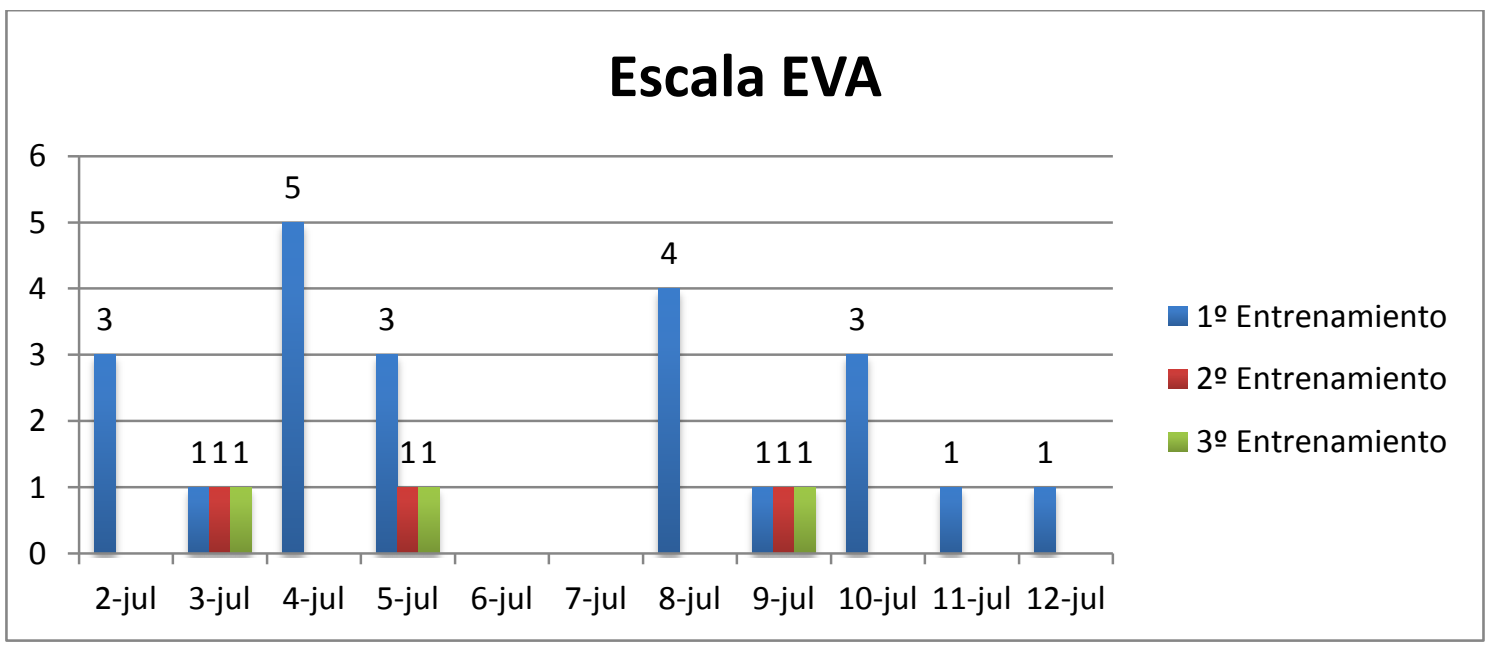

Figura 26. Monitorización de la escala de dolor en la readaptación de la tendinosis rotuliana. 
El objetivo específico E, donde se cita la mejora de la recuperación ante los esfuerzo de alta intensidad requerido en el baloncesto, fue evaluado por el test de RSA (Impellizzeri et al., 2008a) tabla 6.11. Como podemos observar en la figura 27 el sujeto siempre muestra sus mejores resultados tanto en la primera carrera como en la últimas, esto podría ser que el sujeto sabiendo que aún le quedan carreras por realizar no dé el máximo hasta la última. En este medición el sujeto no supero los valores obtenidos en la primera medición.

Tabla 6.11. Resultados del test RSA 1ㅇase.

\begin{tabular}{|c|c|c|}
\hline & Tiempo (s) & Velocidad $(\mathrm{m} / \mathrm{s})$ \\
\hline Carrera 1 & 8,2 & 4,878 \\
\hline Carrera 2 & 8,574 & 4,66 \\
\hline Carrera 3 & 8,979 & 4,454 \\
\hline Carrera 4 & 8,677 & 4,609 \\
\hline Carrera 5 & 8,406 & 4,758 \\
\hline Carrera 6 & 8,272 & 4,833 \\
\hline \multicolumn{3}{|c|}{ Resultados finales } \\
\hline RSAmean & \multicolumn{2}{|c|}{8,5672} \\
\hline RSAbest & \multicolumn{2}{|c|}{8,2} \\
\hline Peor & \multicolumn{2}{|c|}{8,979} \\
\hline Diferencia & \multicolumn{2}{|c|}{0,779} \\
\hline RSAdecrement \% & \multicolumn{2}{|c|}{1,044780488} \\
\hline
\end{tabular}

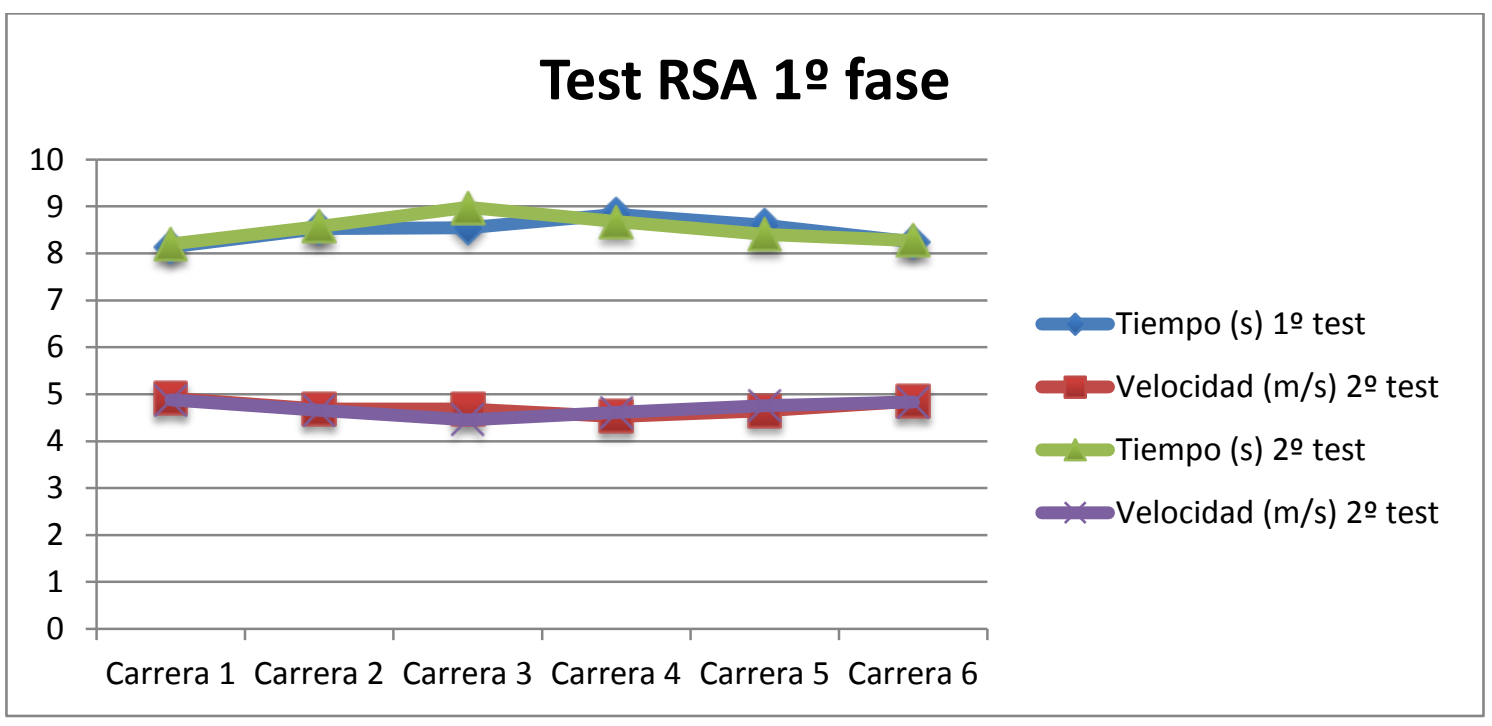

Figura 27. Comparación resultados test RSA $1^{\circ}$ fase e iniciales.

El objetivo específico F, mantener niveles de VO2MAX del sujeto, fue evaluado por medio del Test Trive-Basket, (Vaquera et al., 2007), tabla 6.12. Podemos observar en la figura 28 como el sujeto mejore con respecto al test inicial pero sigue estando muy por debajo de los valores de referencia presentado por (Vaquera et al., 2007). 
Tabla 6.12. Resultados Test Trive-Basket.

\begin{tabular}{ll}
\hline Ítems evaluados & Resultados \\
\hline Tiempo total $(\min : \mathrm{s})$ & $\mathbf{1 4 : 1 5}$ \\
Velocidad $(\mathrm{km} / \mathrm{h})$ & $\mathbf{1 0 , 8}$ \\
Periodo $(\mathrm{n})$ & $\mathbf{6}$ \\
FCmáx $(\mathrm{ppm})$ & $\mathbf{1 9 8}$ \\
\hline
\end{tabular}

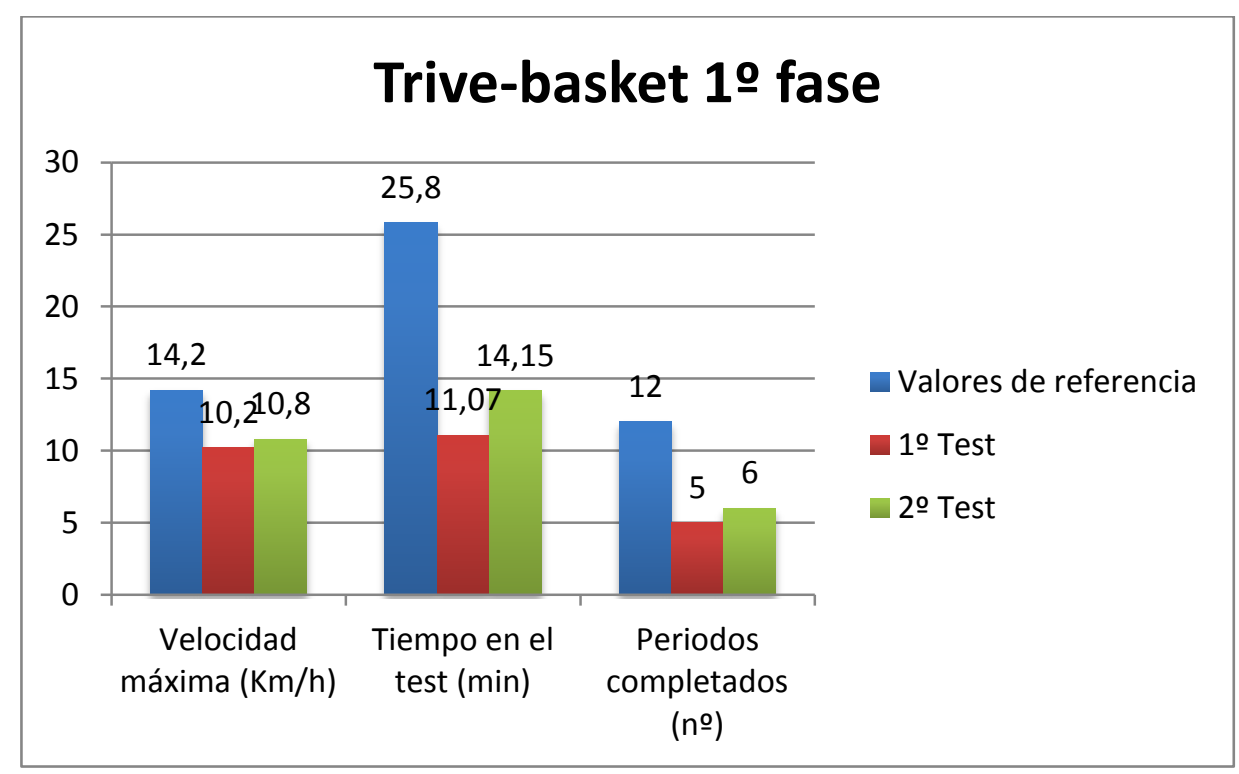

Figura 28. Valores de referencia del estudio Vaquera et al. (2007), en jugadores de liga EBA, comparados con la primera y la segunda medición. 


\subsection{FASE 2 DEL PROGRAMA DE INTERVENCIÓN.}

\subsubsection{Objetivos específicos.}

A. Implantar un programa de fuerza a partir de sobrecargas excéntricas, siendo la fase concéntrica fundamental para intentar mejorar los niveles de potencia.

B. Progresar con el trabajo coxolumbopélvico.

C. Implantar programa preventivo según la epidemiología del baloncesto y del historial de lesiones del sujeto. Trabajo preventivo en tobillo y rodilla.

D. Mejorar la recuperación ante los esfuerzo de alta intensidad requeridos en el baloncesto.

E. Mantener niveles de $\mathrm{V} 0_{2} \mathrm{MAX}$. 


\subsubsection{Contenidos secuenciados.}

- Trabajo de RPA, en patrones motores básicos como el press banca y la sentadilla, y en patrones específicos como salida frontal, lateral, de espaldas, el desplazamiento defensivo y el cambio de dirección. Objetivo específico A.

- Trabajo potencia máxima, en patrones motores básicos como el press banca y la sentadilla, y en patrones específicos como salida frontal, lateral, de espalda, el desplazamiento defensivo y el cambio de dirección en polea cónica. Objetivo específico A.

- Core stability. Objetivo específico B.

- Core strenght. Objetivo específico B

- Concienciar de la importancia en el juego y automatizar la triple activación. Objetivo específico B

- Trabajar sobre mecanismo de lesión, valgo de rodilla. Objetivo específico C.

- Trabajar sobre movimientos específicos de baloncesto más lesivos, aceleraciones, deceleraciones y cambios de planos en el eje z. Objetivo específico C.

- Trabajar sobre la flexión plantar y dorsal del pie. Objetivo específico C.

- Trabajo sensoriomotor. Objetivo específico C.

- Trabajo de la musculatura de la cadera, flexores, extensores, y rotadores externo e internos. Objetivo específico C.

- Ejercicios multiarticulares focalizando en una buena postura del miembro inferior. Objetivo específico C.

- Repeat sprint Ability. Objetivo específico D.

- Potencia aérobica. Objetivo específico E.

Los contenidos se han ido alterando a lo largo de la fase, teniendo presente que la recuperación del trabajo de RSA y de fuerza constaba de 48 horas y el estímulo de VO2MAX, se introducía cada 10-12 días, (véase anexo 12). 


\subsubsection{Metodología.}

Esta segunda fase del programa de intervención se centrará principalmente en el trabajo de fuerza, figura 15 , acentuándose en el trabajo excéntrico con tecnología isoinercial más concretamente con una polea cónica, autores como (FernandezGonzalo, Lundberg, Alvarez-Alvarez, \& de Paz, 2014; Norrbrand, Fluckey, Pozzo, \& Tesch, 2008) han demostrado su beneficio en las estructuras músculos esqueléticas. Al no disponer de encoder rotatorio nos guiaremos por estudios como los de (Alkner \& Tesch, 2004; Chiu \& Salem, 2006; Fernandez-Gonzalo et al., 2014; Norrbrand et al., 2008; Onambele et al., 2008; Romero-Rodriguez, Gual, \& Tesch, 2011) los cuales marcan un trabajo entre 3 y 4 series de 6 a 8 repeticiones, aunque tendremos presenta la percepción subjetiva de la velocidad, Bautista, Chirosa, Robinson, Chirosa, and Martín (2015) tanto por el sujeto como por el entrenador. Para este contenido empezaremos por una fase de adaptación al entrenamiento excéntrico, una segunda en las que se realizará este tipo de entrenamiento específicamente y una tercera en la que entrarán en acción las fluctuaciones y toma de decisión, simulando de esta forma un poco más las exigencia e incertidumbre que se dan durante el juego (Moras, 2015). Este mismo autor expone que no debe darse más de dos repeticiones idénticas pues en el juego no se da, por esta afirmación le pediremos a nuestro sujeto que cambie de rango en cada repetición, y como hemos comentado anteriormente meteremos fluctuaciones en las repeticiones. A la hora de planificar y estructuras los ejercicios utilizados en esta fase del programa de intervención utilizaremos la propuesta de (Moras, 2014a) de los niveles de aproximación, tabla 4.1.

Aunando mas en esta planificación del entrenamiento presentamos una propuesta de trabajo de nuestro deporte el baloncesto, dividida según Moreas (2014a), en áreas cualidad o capacidad física, y en contenidos habilidad técnica, tabla 6.13.

Después de una primera fase de aprendizaje del trabajo coxolumbopélvico donde nos hemos centrado en los cuatro primeros paso propuesto por (S. McGill, 2010), enfatizado el trabajo en patrones básicos (Akuthota et al., 2008) como el bracing, bird dog, glute brigde y la plancha lateral, y acentuando la realización de estos patrones con la triple activación, daremos un pasito más en este contenido incluyendo el quinto paso, construir la fuerza y Sexto paso, desarrollar velocidad, potencia y agilidad, buscando de esta forma la especificad al gesto deportivo.

Para desarrollar los pasos anteriormente mencionados seguiremos la propuesta por Conde (2014), el cual plantea una primera fase la cual correspondía con el primer periodo de nuestro programa de intervención, con ejercicios isométricos de cuerpo entero, una segunda fase con isométricos del Core + movimientos de las extremidades y una tercera con ejercicios dinámicos generadores de vectores rotacionales. 
Asimismo tuvimos en cuenta los diferentes movimientos clasificándolos según Conde (2014) en:

- Cadera:

- Movimientos de anti-flexión de cadera

- Movimientos de anti-extensión de cadera

- Movimientos anti ABD-ADD de cadera

- Movimientos de rotación de cadera

- Movimientos dinámicos de cadera

- Isométricos

- Columna:

- Movimientos anti-flexión de columna

- Movimientos anti-extensión de columna

- Movimientos de anti-extensión lateral de columna

- Movimientos anti-rotación de columna

- Movimientos dinámicos de columna.

- Isométricos

En cuanto a la propuesta de trabajo metabólico en esta segunda fase seguiremos con el planteamiento realizado en la primera en cuanto al contenido de VO2MAX, en el trabajo de RSA en esta fase meteremos fluctuaciones en las acciones para asemejar mas estas situaciones al juego.

\section{A. Metodología utilizada en la segunda fase del programa de intervención en las sesiones de adaptación al trabajo excéntrico.}

Este periodo de la segunda fase del programa de intervención consto de tres sesiones que se realizaron los días 3,7 y 9 de julio y sirvió de adaptación al trabajo que se realizaría las semanas posteriores. Estas sesiones de ajuste tuvieron un carácter del esfuerzo bajo.

El calentamiento al igual que en la primera fase del programa del programa de intervención estará dividido en tres partes una de liberación miosfacial, una de activación vegetativa y una última de movilidad. En esta última parte utilizaremos la propuesta de movilidad en el calentamiento de (Hauschildt, McQueen, \& Stanford, 2014), los cuales plantean patrones fundamentales teniendo en cuenta el control motor, la estabilidad y movilidad dirigidas a las principales articulaciones del cuerpo a través de los siguientes movimientos. 
Primera secuencia de movilidad, figura 29: $1^{\circ}$ Single-leg stance position, $2^{\circ}$ Pull leg across body, $3^{\circ}$ Pull leg away from body y $4^{\circ}$ Standing quadriceps stretch.

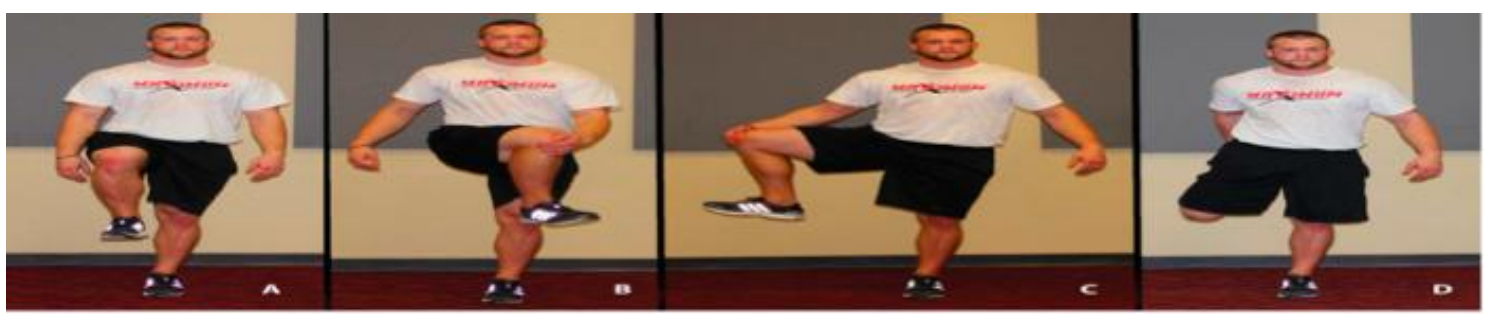

Figura 29. Primera secuencia de movilidad.

Segunda secuencia de movimiento, figura 30: Single-leg hip hinge of the stance leg.

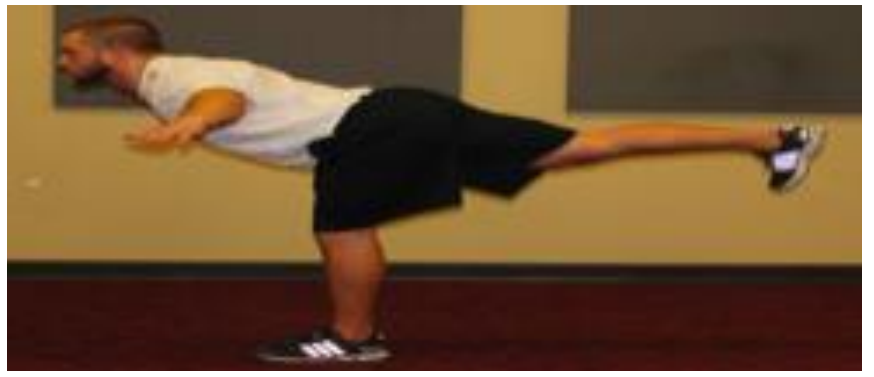

Figura 30. Segunda secuencia de movilidad.

Tercera secuencia de movimiento, figura 31: $1^{\circ}$ Overhead squat stance position, $2^{\circ}$ Hip hinge into a toe touch position, $3^{\circ}$ Deep squat position y $4^{\circ}$ Rotate with one hand toward the celling.

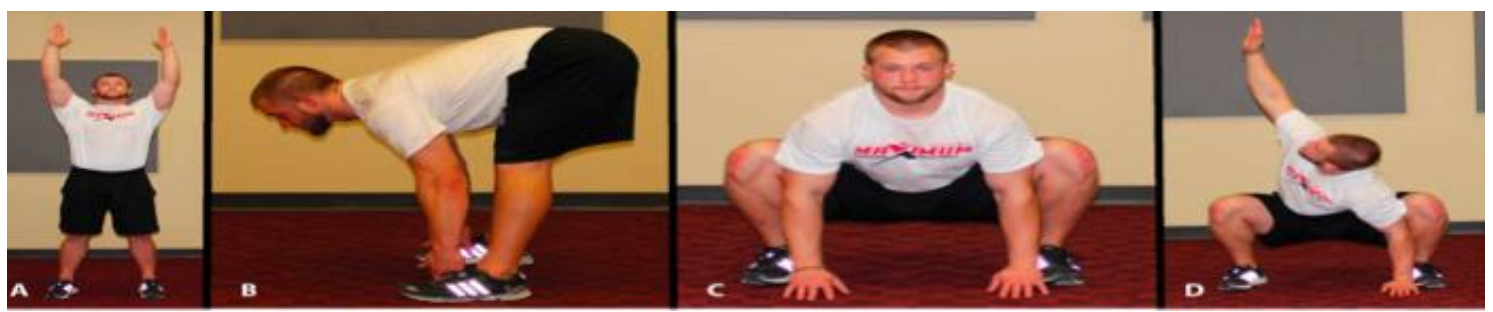

Figura 31. Tercera secuencia de movilidad.

Cuarta secuencia de movimiento, figura 32: 1ํㅡㄹ toward celling y $3^{\circ}$ Rotate left arm toward celling.

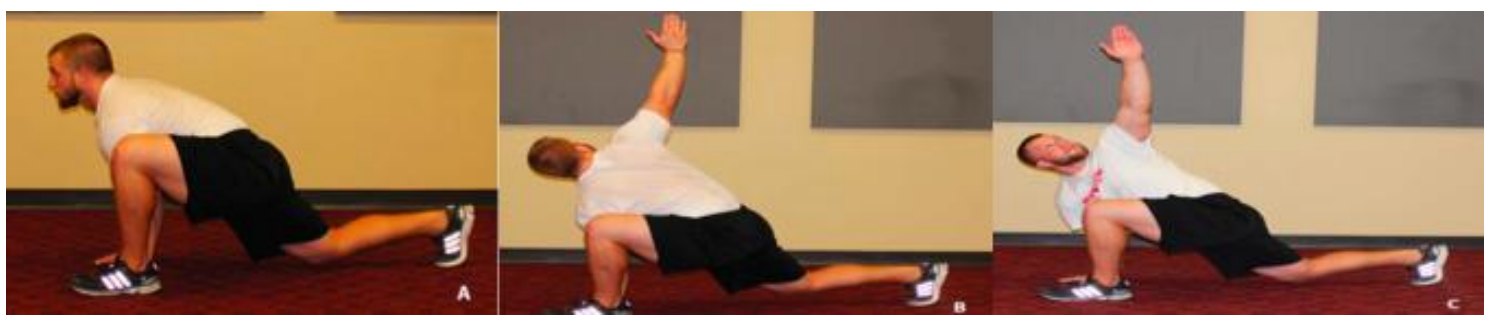

Figura 32. Cuarta secuencia de movilidad. 
Quinta secuencia de movimiento, figura 33: 1은 Straight-arm plank, 느 T-rotation with left arm up, 3ำ Trasition to T-rotation with right arm up y $4^{\circ}$ T-rotation with right arm up.

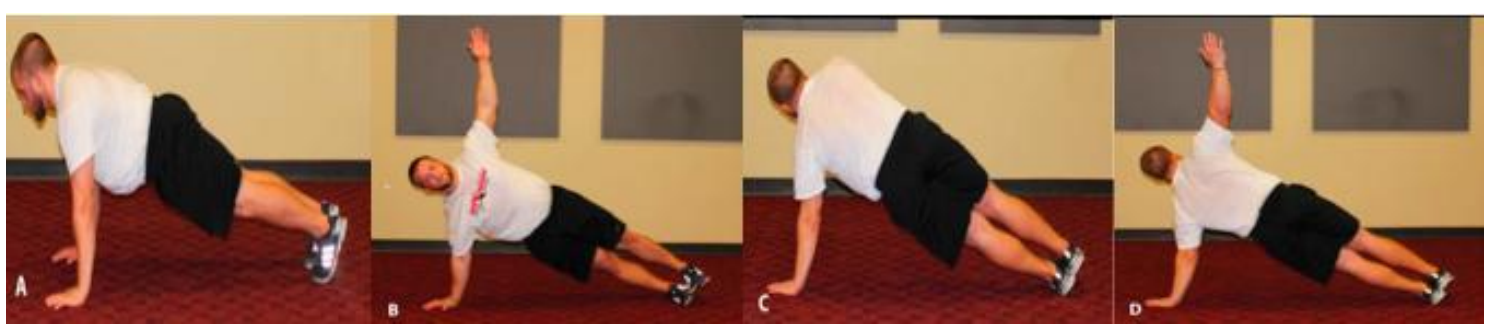

Figura 33. Quinta secuencia de movilidad.

Sexta secuencia de movimiento, figura 34: $1^{\circ}$ Quadruped with over head reach, $2^{\circ}$ Quadruped with $90^{\circ}$ lateral reach, 3ํ. Quadruped with straight leg raise y $4^{\circ}$ Q Quadruped with lateral leg raise.

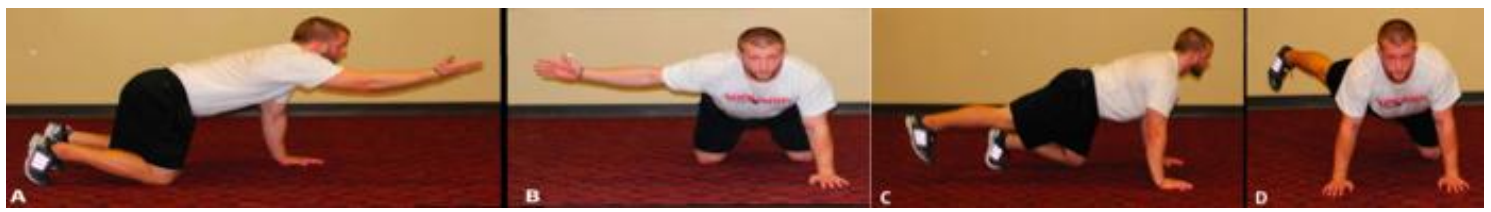

Figura 34. Sexta secuencia de movilidad.

Séptima secuencia de movimiento, figura 35: $1^{\circ}$ Talk Kneeling position, $2^{\circ}$ Kneeling with hips sitting on heles, $3^{\circ}$ Hands cupping the heles y $4^{\circ}$ Kneeling with hips forward for stretch.

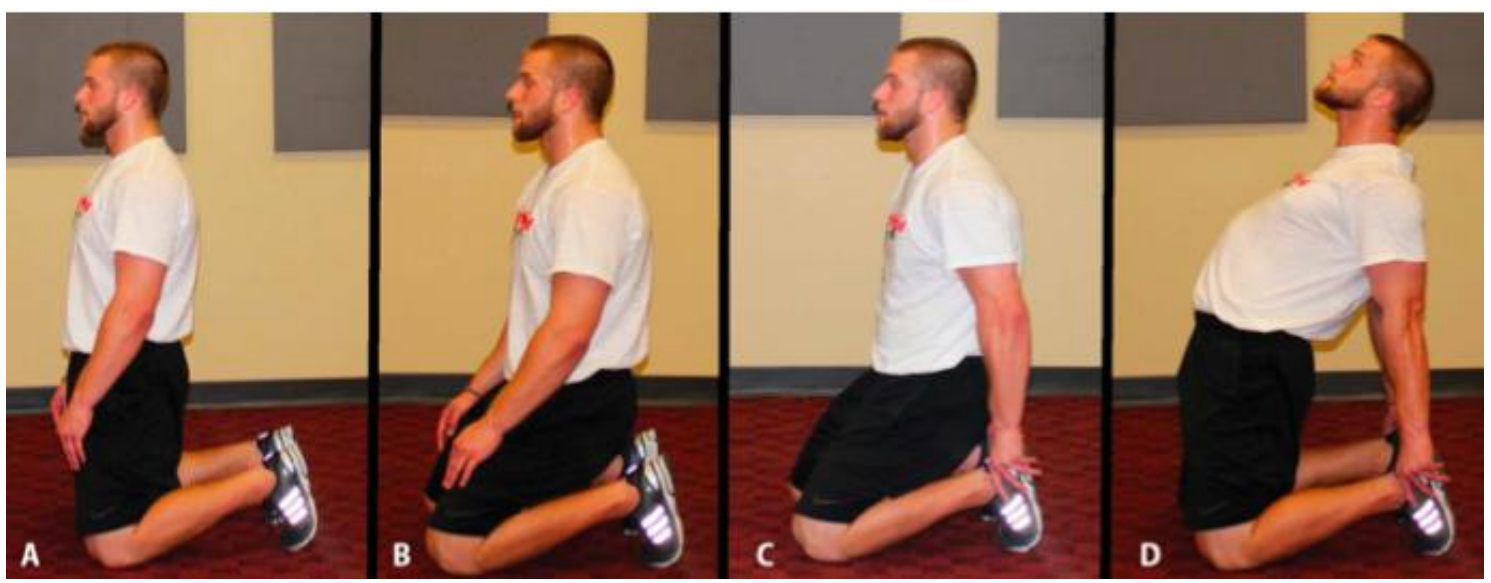

Figura 35. Septima secuencia de movilidad.

Octava secuencia de movimiento, figura 36: $1^{\circ}$ Top push-up position, $2^{\circ}$ Right foot on the outside of the right hand, $3^{\circ}$ Deep squat position y $4^{\circ}$ Deep over head squat position. 


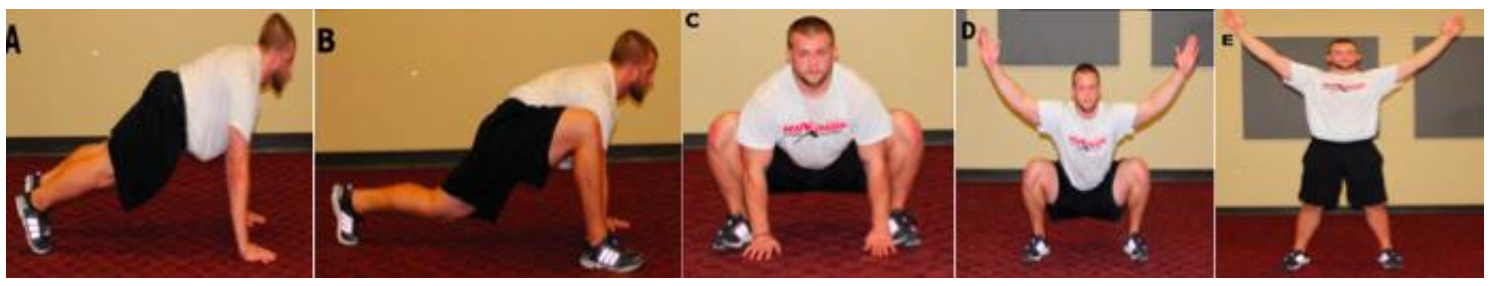

Figura 36. Octava secuencia de movilidad.

La parte principal consto de 2 segmentos, Un primer segmento de la parte principal estará encaminado al trabajo coxolumbopélvico con la metodología del mismo anteriormente mencionada (Objetivo específico B) y un último segmento que fue encaminado a los ejercicio para mejorar la potencia de nuestro sujeto, Objetivo específico A.

Para terminar la vuelta a la calma estará compuesta por los mismo contenidos que en la primera fase del programa de intervención, una primera de liberación miosfacial y una segunda de SGA.

\section{B. Metodología utilizada en la segunda fase del programa de intervención en las sesiones de trabajo excéntrico.}

Este periodo de la segunda fase del programa de intervención consto de tres sesiones que se realizaron los días 13,15 y 20 de julio y el cual nos centramos en el trabajo de potencia, Objetivo específico A.

En el calentamiento al igual que en las sesiones de adaptación al trabajo excéntrico, se centro en un trabajo la liberación miosfacial, una segunda parte de activación vegetativa y una última de movilidad con la propuesta de Hauschildt, McQueen et al. (2014) anteriormente planteada.

En la parte principal seguiremos con el trabajo de CORE (Objetivo específico B), orientado al baloncesto, y una segunda parte en el cual nos centraremos en el trabajo de fuerza excéntrica (Objetivo específico A), con un carácter del esfuerzo alto.

La vuelta a la calma constará de nuevo de una parte de liberación miosfacial y otra de SGA.

\section{Metodología utilizada en la segunda fase del programa de intervención en las sesiones de fuerza en 3 y 4 dimensiones.}

Este periodo de la segunda fase del programa de intervención consto de tres sesiones que se realizaron los días 22, 27 y 30 de julio y el cual nos centramos en el trabajo de potencia, Objetivo específico A.

En el calentamiento al igual que en las sesiones de anteriores de fuerza, se centro en un trabajo la liberación miosfacial, una segunda parte de activación vegetativa y una última de movilidad con la propuesta de Hauschildt, McQueen et al. (2014) anteriormente planteada.

En la parte principal seguiremos con el trabajo de CORE (Objetivo específico B), orientado al baloncesto, y una segunda parte en el cual nos centraremos en el trabajo 
de fuerza excéntrica, (Objetivo específico A), con un carácter del esfuerzo alto. A su vez el sujeto estará tomando decisiones, según indicaciones del entrenador modificando constantemente la repeticiones del sujeto.

La vuelta a la calma constará de nuevo de una parte de liberación miosfacial y otra de SGA.

\section{Metodología utilizada en la sesiones de trabajo compensatorio y VO2MAX.}

En el calentamiento al igual que en las sesiones de trabajo excéntrico, se centró en un trabajo la liberación miosfacial, una segunda parte de activación vegetativa y una última de movilidad con la propuesta de Hauschildt, McQueen et al. (2014), anteriormente planteada.

La parte principal la dividiremos en 2 partes una primera orientada a la compensación del trabajo de fuerza excéntrica el cual constara de empujes horizontal y vertical, tracciones horizontal y vertical, ejercicios predominantes de cadera y rodilla. Este tipo de trabajo dentro de nuestra planificación en los niveles de aproximación Moras (2014), estará encuadrada en un Nivel 0 no orientado, por eso la denominación de trabajo compensatorio

La segunda parte estará centrada en el trabajo de VO2MAX, (Objetivo específico E), en el cual se realizará una carrera continua extensiva durante 40 minutos.

La vuelta a la calma constará de nuevo de una parte de liberación miosfacial y otra de SGA.

\section{E. Metodología utilizada en la sesiones de RSA y prevención de lesiones}

El calentamiento de este tipo de sesiones constará de una parte de liberación miosfacial y otra de movilidad.

La parte principal estará dividida en tres partes. Una primera donde el trabajo irá orientado a la prevención (Objetivo específico C), dado la incidencia lesiva de este jugador en zonas como en el tobillo o rodilla y coincidiendo con estudios realizados por Dick et al. (2007), tabla 3.9 y Flood and Harrison (2009) tabla 3.10, nos ajustaremos principalmente en ambas.

Para la propuesta de trabajo en el tobillo seguiremos con la propuesta que empezamos en la fase anterior de (V. J. Sammarco, 2003a, 2003b; V. J. Sammarco \& Sammarco, 2003), aunque en esta fase los contenidos varia y nos centraremos en:

- Trabajo sobre los mecanismo de lesión

- $\quad$ Trabajo de tiempo de reacción

- Trabajo de control motor

- Trabajo sensoriomotor

- Movimientos de patrones específicos del baloncesto 
Por otro lado el trabajo de prevención de rodilla ira encaminado en tres tipos de ejercicios;

A. Ejercicios de la musculatura de la cadera, para el fortalecimiento de los rotadores externos de cadera y su correcta activación en tiempo e intensidad durante el apoyo del pie en el suelo, ya que es un punto clave para evitar la falta de control sobre la rotación interna, estos ejercicios pueden ser ejercicios.

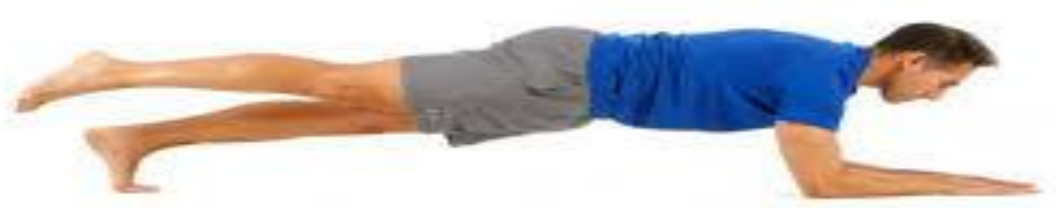

Figura 39. Plancha frontal con extensión de cadera, extraído de http://estaticosv2.sportlife.es/rcs/galerias/4888/imagenes/thumb/plancha-abd-frontal thumb e.jpg

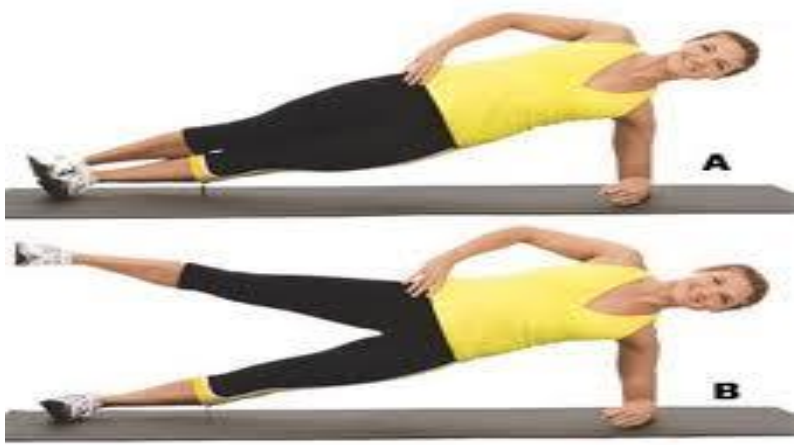

Figura 40. Abducción de cadera en plancha lateral, extraído de http://gse.com/uploads/imagen/2013-02-27-19-16-36_plancha-lateral2-jpg.jpeg 


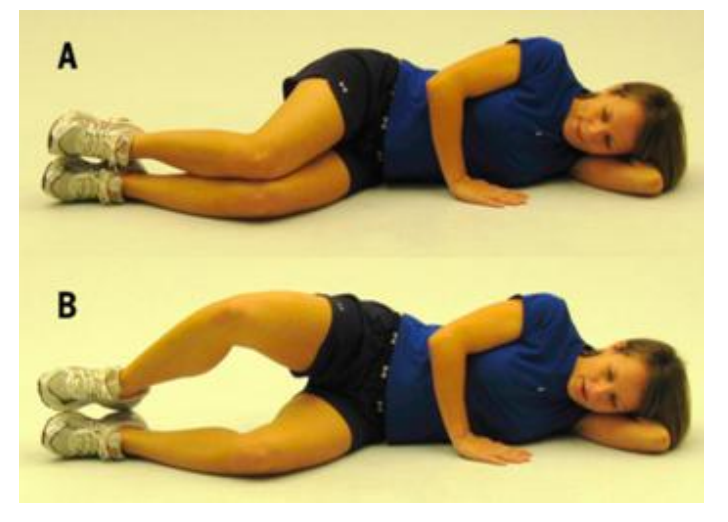

Figura 41. Clamshell, extraído de http://lesserevillife.com/wpcontent/uploads/2013/02/clamshell.png

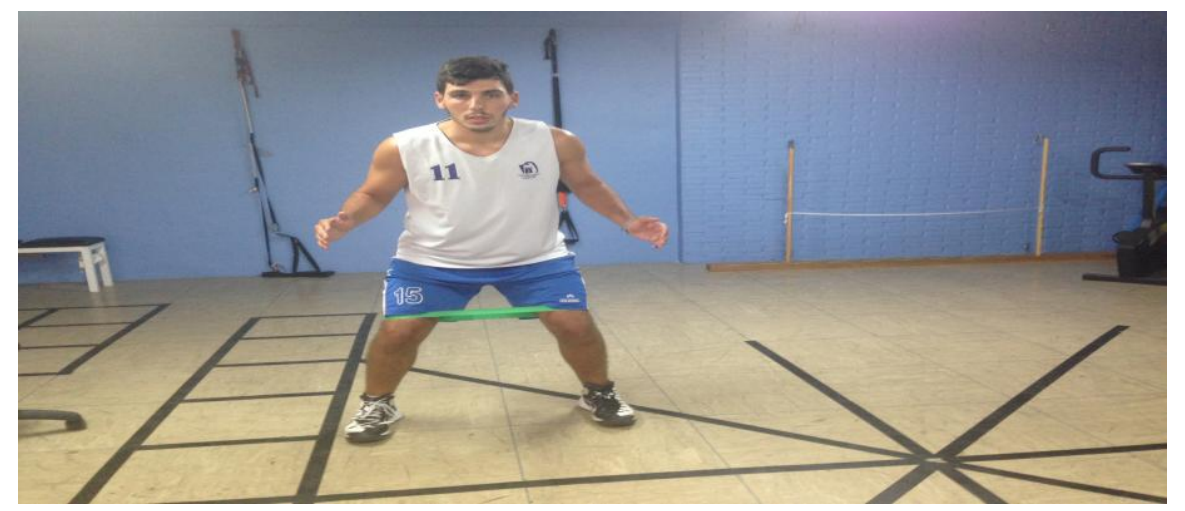

Figura 42. Lateral band walk

B. Ejercicios multiarticulares de fuerza con focalización en una buena postura del miembro inferior:

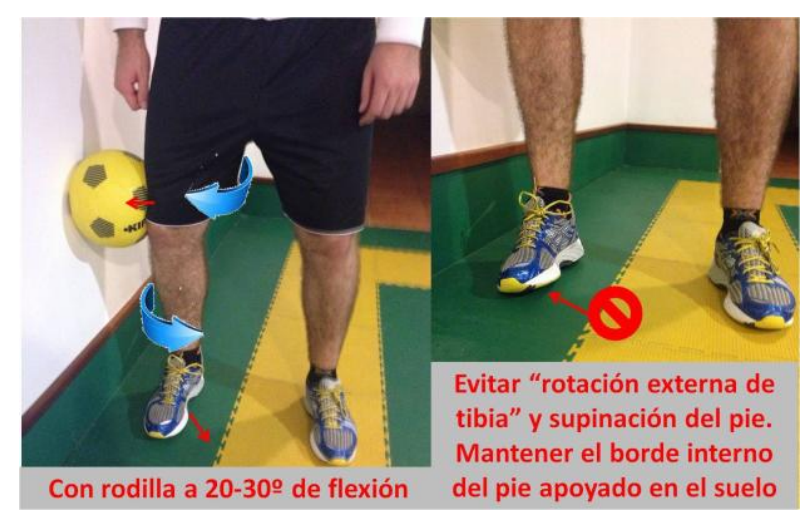

Figura 43. Wall-press contra balón en rotación en carga con pie fijo, extraído de http://2.bp.blogspot.com/hMhxtaG34Ns/VH2Us6DIsTI/AAAAAAAACXs/e1XshRsUYR0/s1600/press\%2Bba \%C3\%B3n\%2Bpared.jpg 


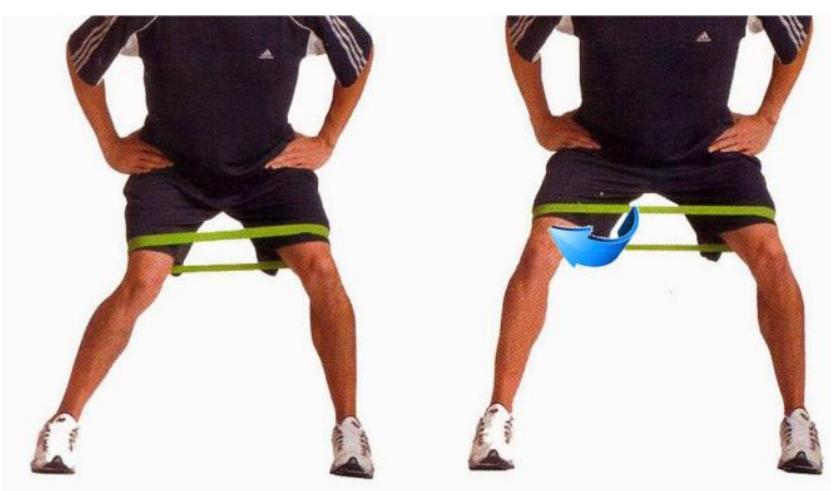

Figura 44. Rotación externa de cadera en carga contra elástico y pie fijo, extraído de http://4.bp.blogspot.com/- DbvglmIYDo/VH2WbOYUuWl/AAAAAAAACX4/g-

yl4CIURKg/s1600/rot\%2Bext\%2Bcadera\%2Bgoma.jpg

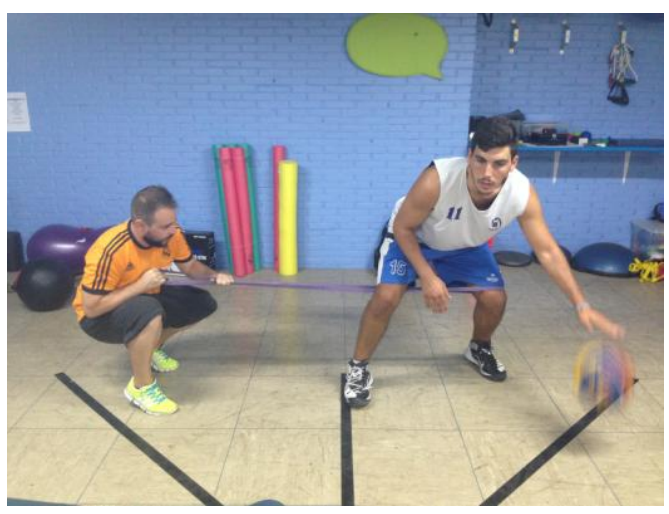

Figura 44. Control postural rodilla, goma altura de la rodilla resistencia externa intenta provocar una valgo.

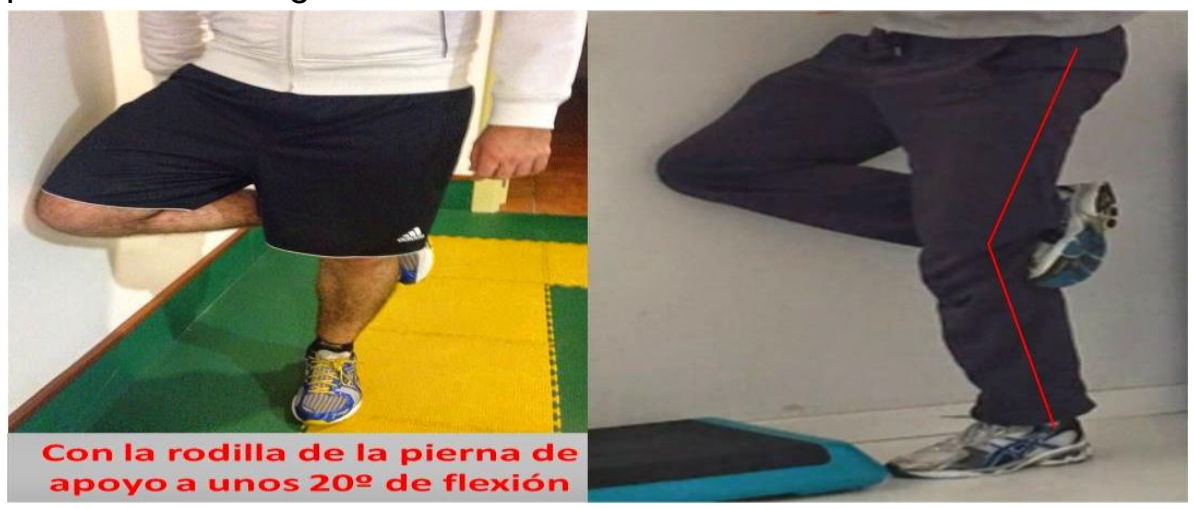

Figura 45. Wall press de rodilla contra pared en rotación de cadera, extraído de http://1.bp.blogspot.com/-QDQMXgWntWs/VH8sj-OcJwl/AAAAAAAACY4/ctz2SWJ-

EkE/s1600/press\%2Bwall\%2Brot.jpg 
C. Para terminar ejercicios de propiocepción orientado a gestos técnicos o situaciones que puedan producirse durante el juego:

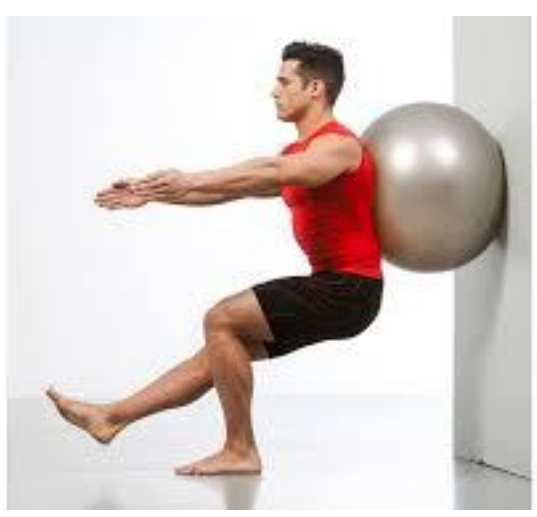

Figura 46. Fitball en la espalda y apoyado en pared, con apoyo monopodal realizar sentadillas a la vez que se le lanza pelotas de diferentes tamaños. Extraído de http://www.triatlonweb.es/upload/images/imagegallery/69/imagenes/imagegallery-69536b7d4ade223.jpg

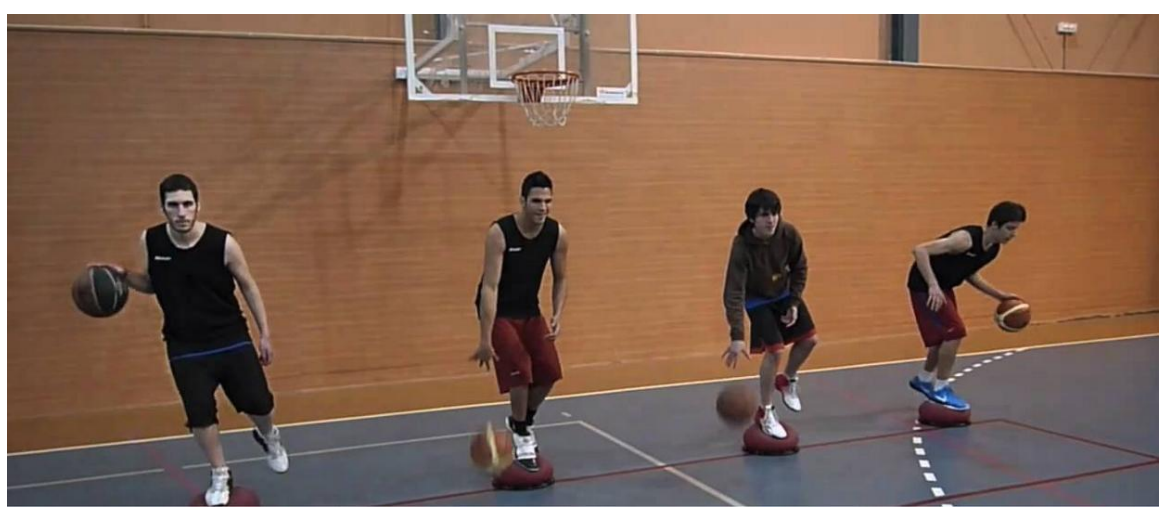

Figura 47. Propiocepción en bosu, botar el balón, hacer ochos alrededor de la pierna, pasar por alrededor de cintura, o cuello. Extraído de http://i.ytimg.com/vi/GzWsyELBhk/maxresdefault.jpg

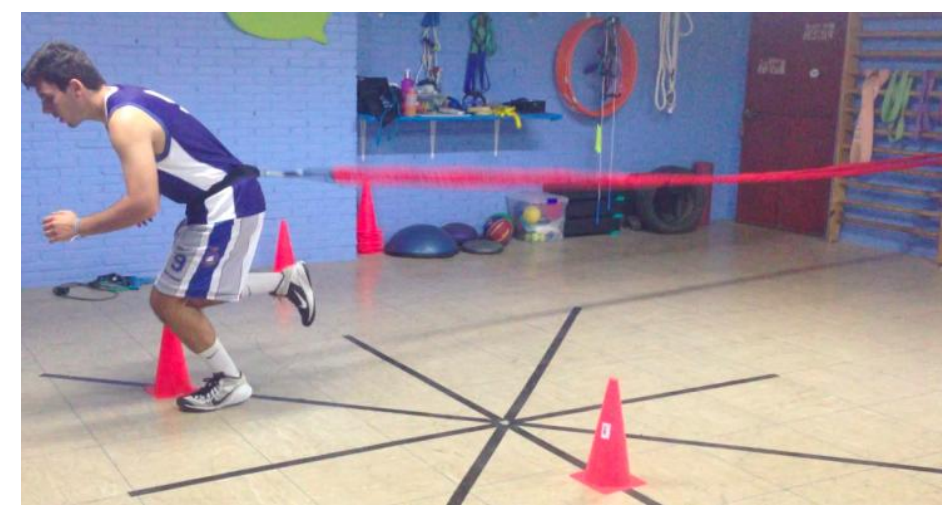

Figura 48. Se colocan tres conos en forma de triángulo cada cono recibirá un número, uno, dos y tres. El sujeto llevará una goma lastrada que le realizará resistencia hacía atrás cada vez que corra o salte. El sujeto debe esprintar hacia el cono con el número 
que diga el entrenador y deberá saltar y caer de forma monopodal en el cono mencionado.

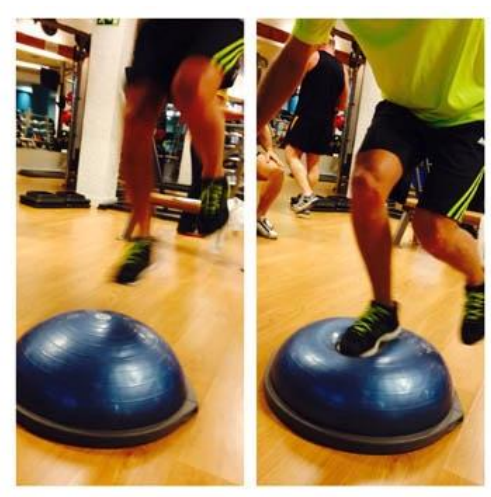

Figura 49. Carrera hasta el bosu, saltar en el aire realizar un giro de 90 grados, una vez que caiga al bosu recibe pase de pecho. Extraído de http://www.correryfitness.com/clipping/2014/12/03/00523/31.jpg

La segunda parte de la parte principal trabajaremos técnica individual, para preparar al sujeto a los esfuerzo que se realizará en la tercera parte de la sesión.

La tercera parte de la parte principal la dedicaremos al trabajo de RSA, Objetivo específico E, la metodología utilizada será la expuesta por (Castagna, Abt, et al., 2008) 5 series de 6 repeticiones de 20 segundos, con una micro pausa de 20 segundos, y una macro pausa de 2 minutos 50 segundos. La micro pausa al contrario que la primera fase del programa de intervención será activa, en la macro pausa la recuperación seguirá siendo pasiva. Los patrones de movimientos utilizados serán sacado de la investigación (López et al., 2014).

La vuelta a la calma seguirá siendo igual que en las sesiones anteriores, una primera parte de liberación miofascial y una segunda de SGA. 
Tabla 6.13. Propuesta de áreas y contenidos baloncesto extraído de Schelling (2012).

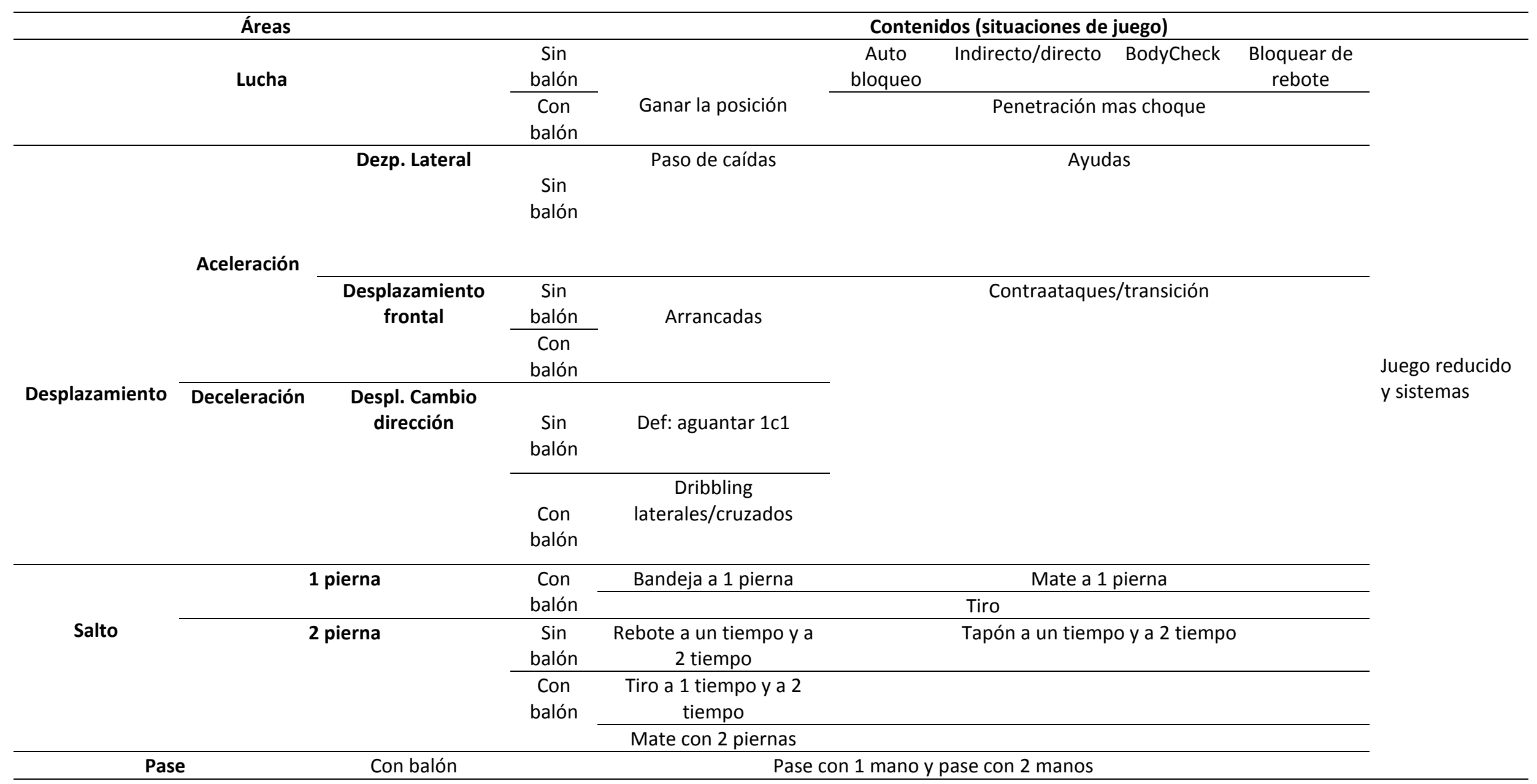




\subsubsection{Sesiones}

Tabla 6.14. Sexta sesión de muestra, adaptación al trabajo excéntrico.

\begin{tabular}{l} 
Fecha: Martes 7 de Julio \\
\hline Lugar: Polideportivo Andrés Estrada "Sala de entrenamiento" \\
\hline Objetivo de la sesión: \\
Adaptación al trabajo de potencia y fuerza excéntrica \\
Orientar el trabajo coxolumbopélvico a patrones de \\
movimientos específicos del baloncesto
\end{tabular} Contenidos:

Trabajo del CORE

Trabajo potencia máxima

\begin{tabular}{|c|c|c|}
\hline \multirow{2}{*}{\multicolumn{3}{|c|}{$\begin{array}{c}\text { Desarrollo de la sesión } \\
\text { Calentamiento }\end{array}$}} \\
\hline & & \\
\hline Ejercicios & Normativa de Carga & Representación gráfica \\
\hline $\begin{array}{ll}\text { Liberación miosfacial: } \\
\text { - } & \text { Abductores } \\
\text { - } & \text { Cuádriceps } \\
\text { - } & \text { Femoral } \\
\text { - } & \text { Flexores de la cadera } \\
\text { - } & \text { Gemelos } \\
\text { - } & \text { Glúteo } \\
\text { - } & \text { Dorsal } \\
\text { - } & \text { Trapecio } \\
\text { - } & \text { Romboide } \\
\text { - } & \text { Fascias torocolumbar }\end{array}$ & $\begin{array}{l}10 \text { pasadas lentas por } \\
\text { cada zona }\end{array}$ & \\
\hline
\end{tabular}

Activación vegetativa: bicicleta estática 3 minutos

Propuesta de movilidad de (Hauschildt, McQueen et al. 2014) compuesta por 8 secuencias de ejercicios

\begin{tabular}{|c|c|c|}
\hline & Parte Principal & \\
\hline Ejercicios & Normativa de Carga & Representación gráfica \\
\hline $\begin{array}{l}\text { Brigde con balón de } \\
\text { baloncesto en las manos. } \\
\text { Ejercicio en posición tumbado } \\
\text { con carga externa. }\end{array}$ & 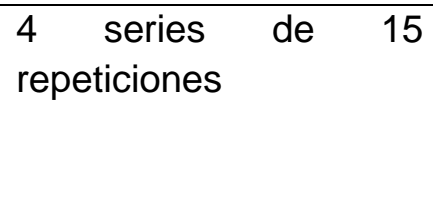 & \\
\hline $\begin{array}{l}\text { Brigde con balón de } \\
\text { baloncesto en las manos, } \\
\text { mas entrenador que realiza } \\
\text { perturbación. }\end{array}$ & 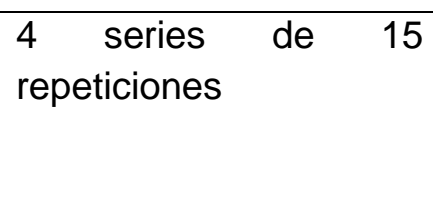 & \\
\hline
\end{tabular}




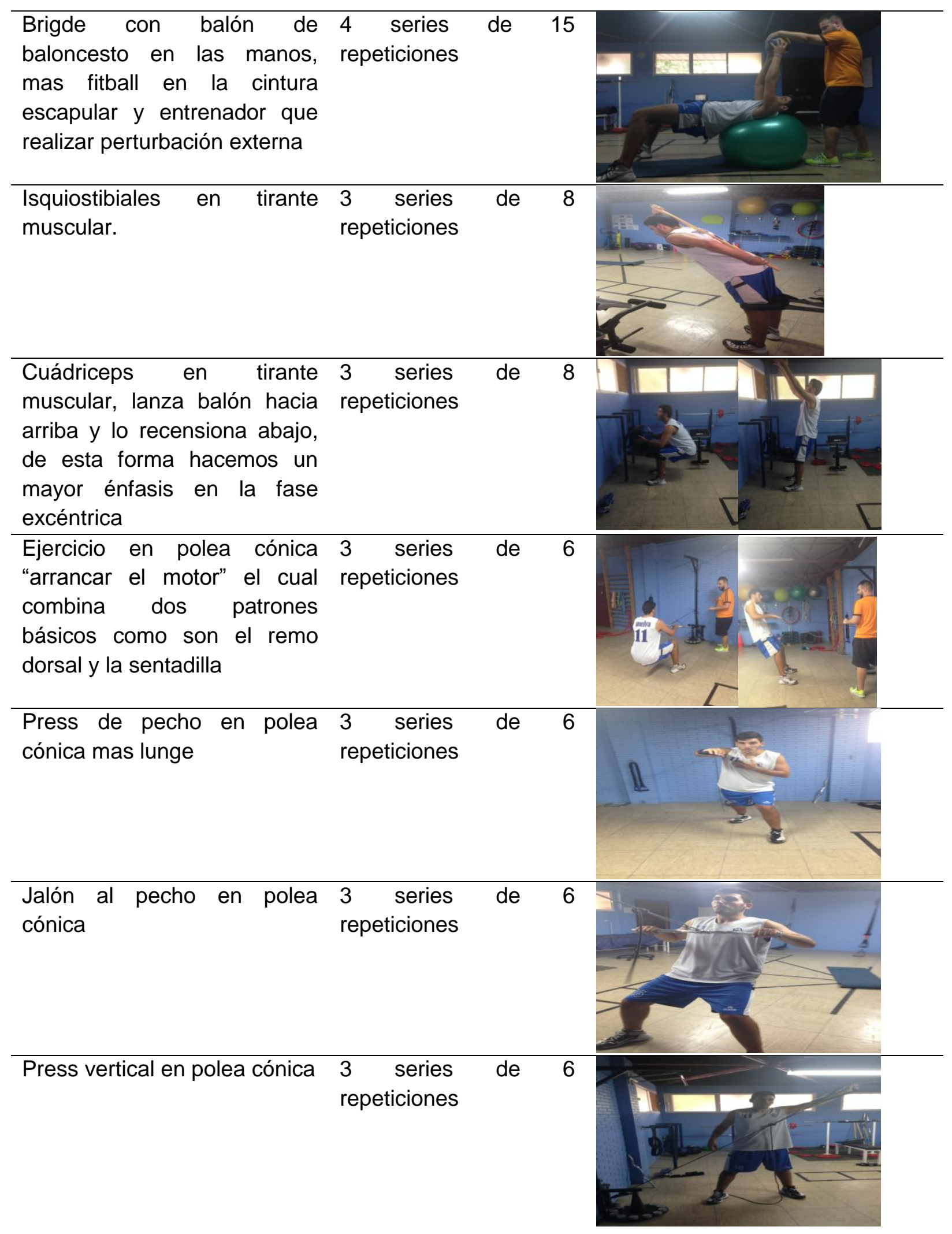




\begin{tabular}{ll}
\hline & Normativa de Carga \\
\hline Ejercicios & Norma calma \\
\hline Liberación miosfacial: & 10 pasadas lentas por \\
Liberación en clavícula fascia & cada zona \\
apendicular + Trabajo fascia & \\
axial del brazo. & \\
Palma de la mano. & pierna \\
Fascias extensores del brazo. \\
Fascia plantar. \\
Liberación \\
flexoextensión de tobillo. \\
Fascia peronéos. \\
Fascias toracolumbar. \\
Liberación fascia lateral. \\
Extensión torácica. \\
\end{tabular}


Tabla 6.15. Séptima sesión de muestra, fuerza excéntrica.

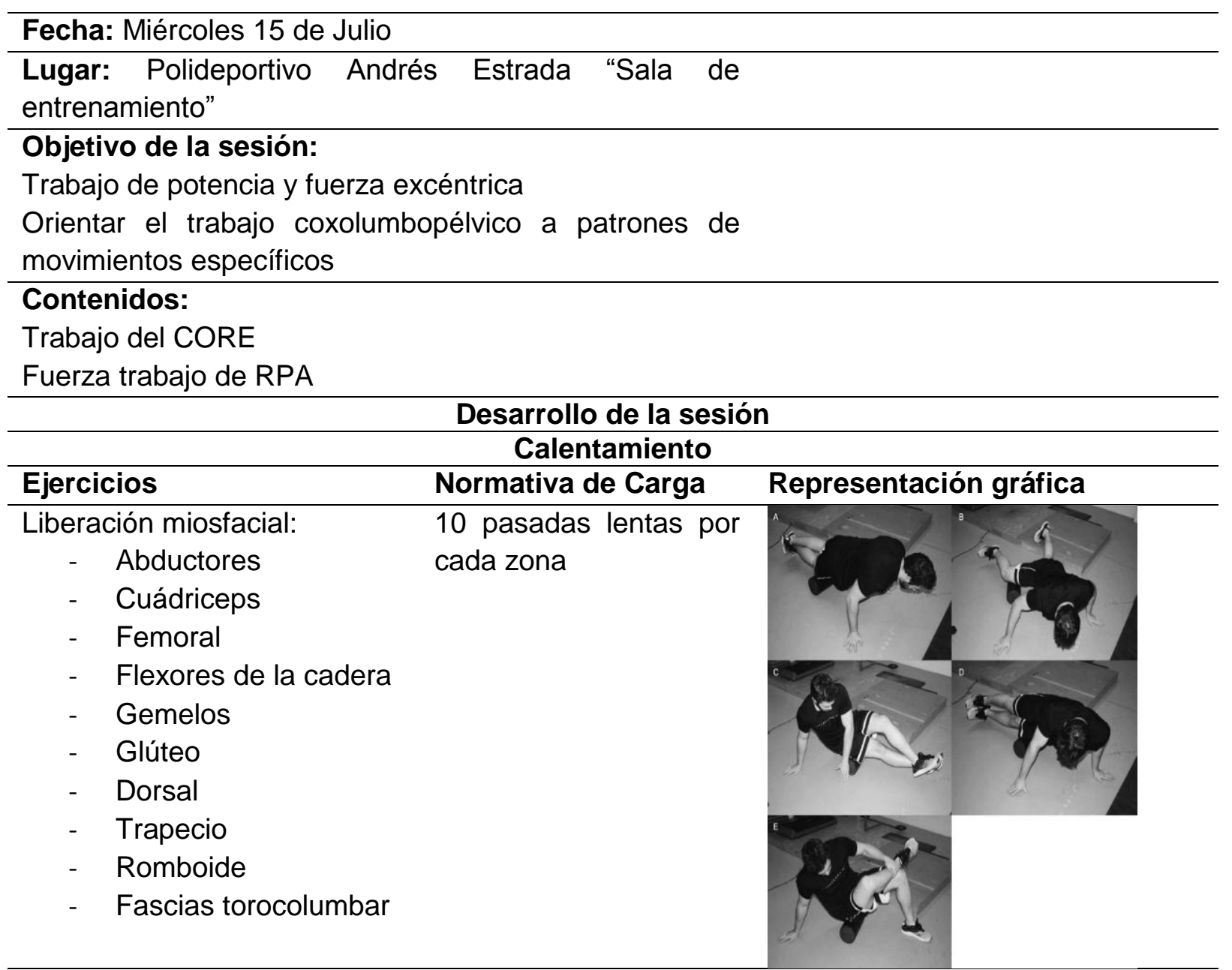

Activación vegetativa: bicicleta estática 3 minutos

Propuesta de movilidad de (Hauschildt, McQueen et al. 2014) compuesta por 8 secuencias de ejercicios

\begin{tabular}{|c|c|c|}
\hline 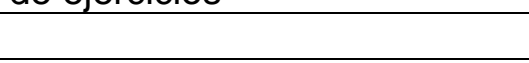 & Parte Principal & \\
\hline Ejercicios & Normativa de Carga & Representación gráfica \\
\hline 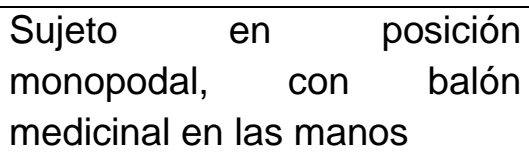 & 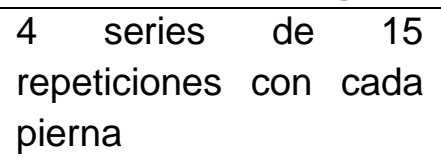 & \\
\hline $\begin{array}{l}\text { Sujeto en posición monopodal } \\
\text { bota balón y entrenador } \\
\text { desequilibra }\end{array}$ & 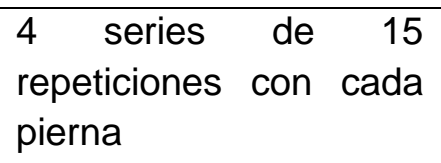 & \\
\hline
\end{tabular}




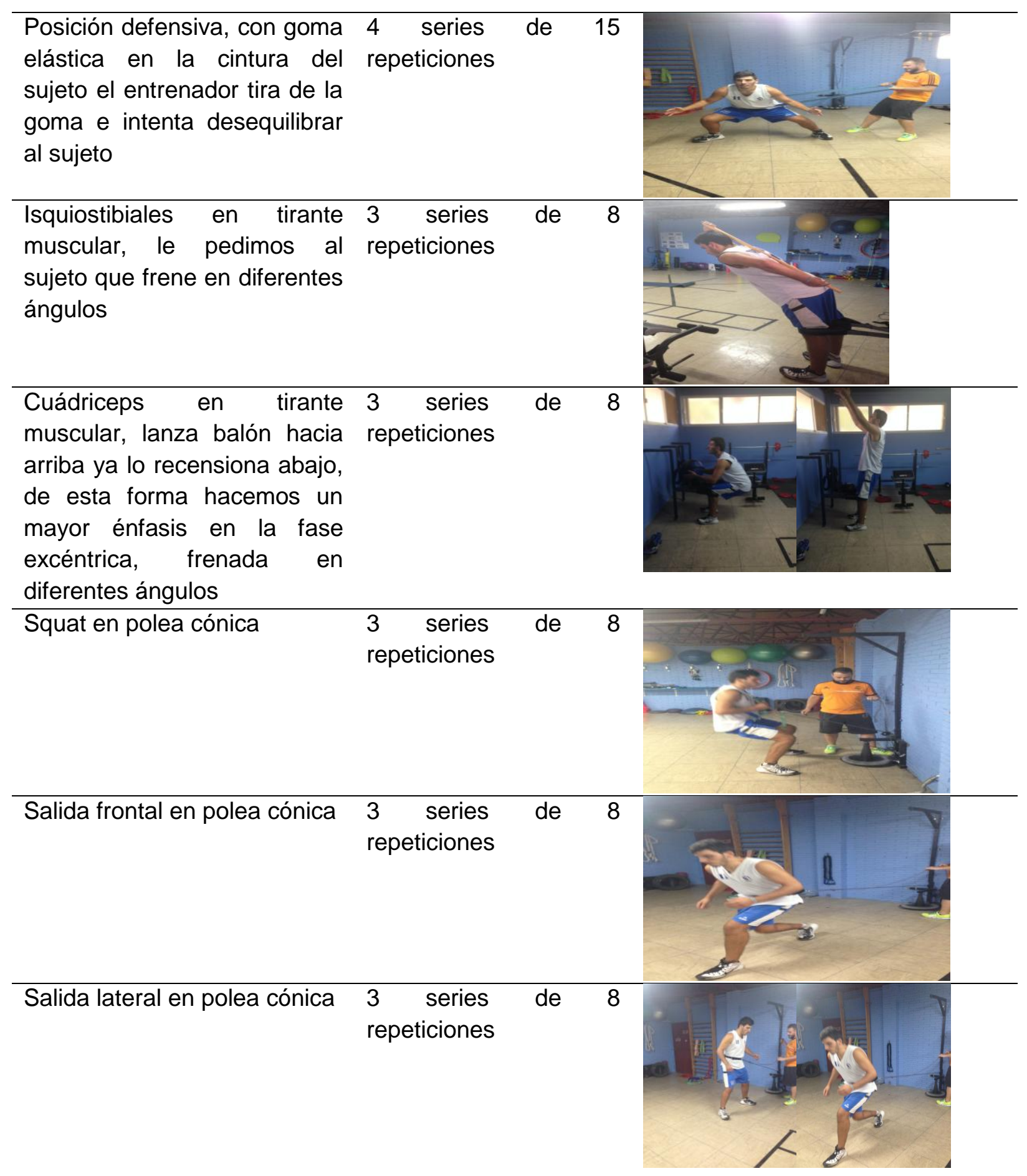




\begin{tabular}{|c|c|c|}
\hline \multicolumn{3}{|c|}{ Vuelta a la calma } \\
\hline Ejercicios & Normativa de Carga & Normativa de carga \\
\hline $\begin{array}{l}\text { Liberación miosfacial: } \\
\text { Liberación en clavícula fascia } \\
\text { apendicular + Trabajo fascia } \\
\text { axial del brazo. } \\
\text { Palma de la mano. } \\
\text { Fascias extensores del brazo. } \\
\text { Fascia plantar. } \\
\text { Liberación pierna } \\
\text { flexoextensión de tobillo. } \\
\text { Fascia peronéos. } \\
\text { Fascias toracolumbar. } \\
\text { Liberación fascia lateral. } \\
\text { Extensión torácica. }\end{array}$ & $\begin{array}{l}10 \text { pasadas lentas por } \\
\text { cada zona }\end{array}$ & \\
\hline SGA & $\begin{array}{l}\text { Mantener cada postura } \\
4 \text { minutos }\end{array}$ & \\
\hline
\end{tabular}


Tabla 6.16. Octava sesión de muestra, fuerza excéntrica.

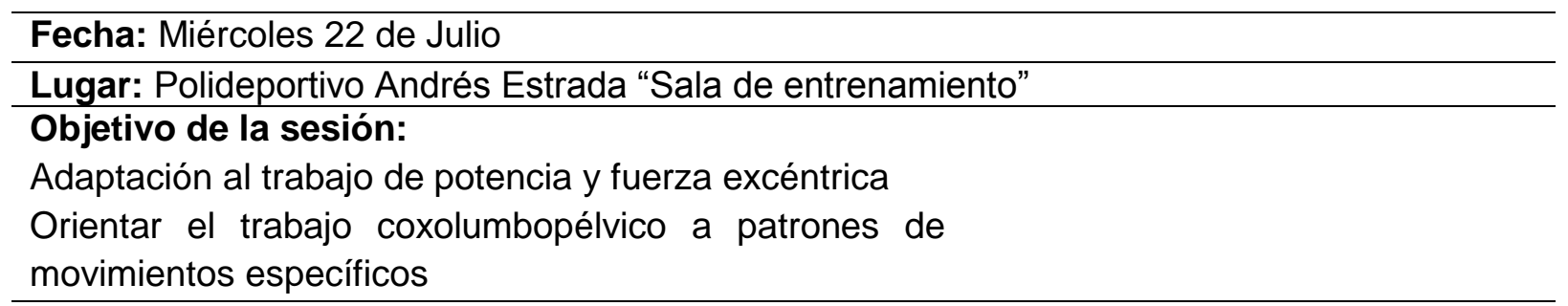

\section{Contenidos:}

Trabajo sensoriomotor

Trabajo del CORE

Fuerza, trabajo de RPA

\begin{tabular}{|c|c|c|}
\hline \multicolumn{3}{|c|}{$\begin{array}{c}\text { Desarrollo de la sesión } \\
\text { Calentamiento }\end{array}$} \\
\hline Ejercicios & Normativa de Carga & Representación gráfica \\
\hline 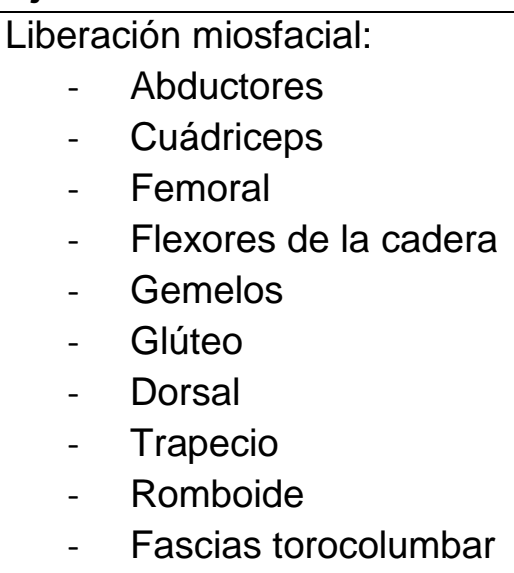 & $\begin{array}{l}10 \text { pasadas lentas por } \\
\text { cada zona }\end{array}$ & \\
\hline
\end{tabular}

Activación vegetativa: bicicleta estática 3 minutos

Propuesta de movilidad de (Hauschildt, McQueen et al. 2014) compuesta por 8 secuencias de ejercicios

\begin{tabular}{ll}
\hline & Parte Principal \\
\hline Ejercicios & Normativa de Carga \\
\hline $\begin{array}{l}\text { Sujeto de rodilla en un fitball } \\
\text { intenta mantener el equilibrio }\end{array}$ & sujeto aguante \\
Sujeto de rodilla en un fitball 4 series de & de \\
intenta mantener el equilibrio, repeticiones \\
tiene en una mano una goma \\
y el otro extremo de la goma \\
lo tiene el entrenador, este \\
realiza jalones de la gomas \\
intentando desequilibrar al
\end{tabular}




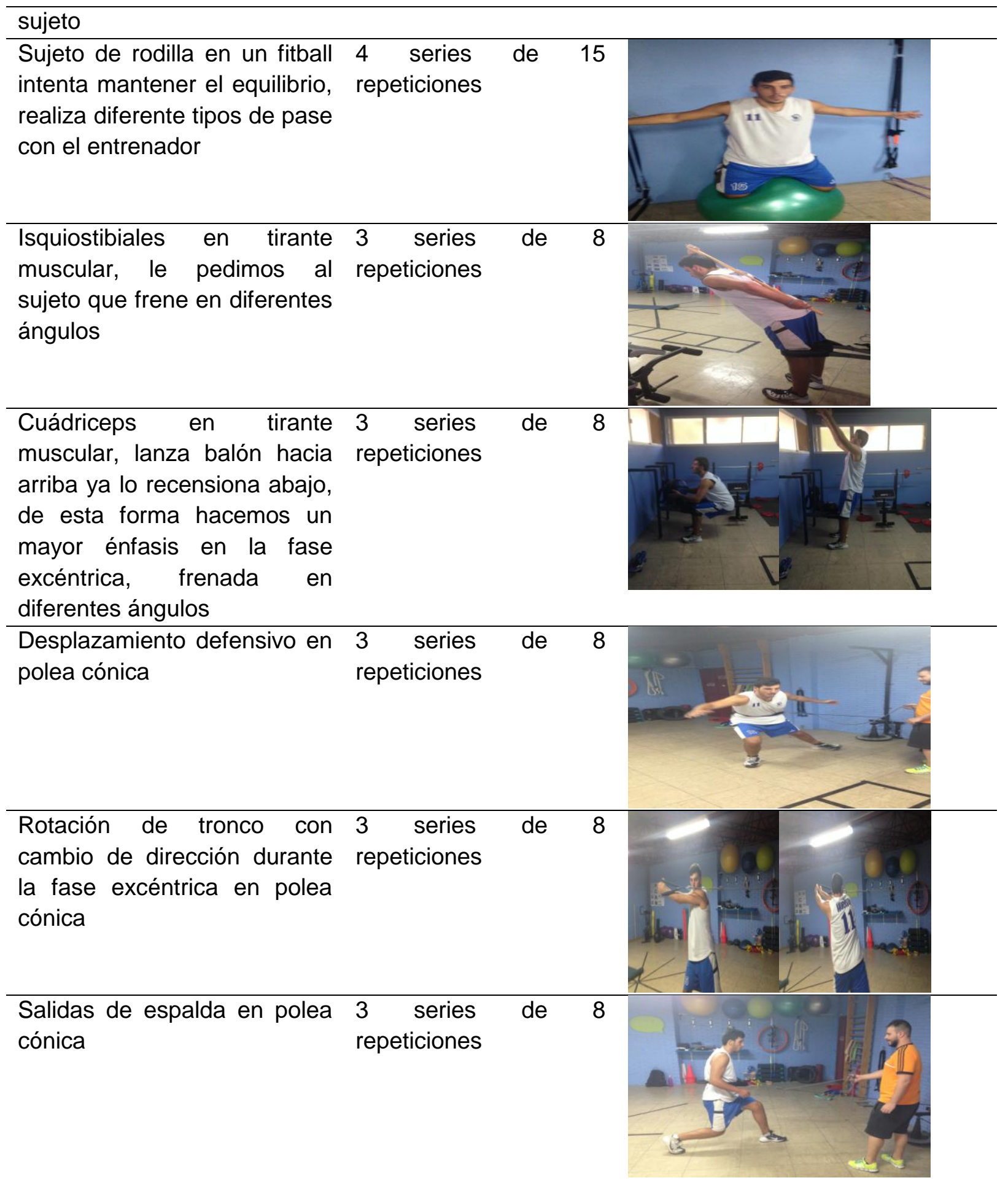




\begin{tabular}{ll}
\hline & Normativa de Carga \\
\hline Ejercicios & 10 pasadas lentas por \\
\hline Liberación miosfacial: & Representación gráfica \\
Liberación en clavícula fascia & cada zona \\
apendicular + Trabajo fascia \\
axial del brazo \\
$\begin{array}{l}\text { Palma de la mano } \\
\text { Fascias extensores del brazo } \\
\text { Fascia plantar } \\
\text { Liberación } \\
\text { flexoextensión de tobillo }\end{array}$ \\
$\begin{array}{l}\text { Fascia peronéos } \\
\text { Fascias toracolumbar } \\
\text { Liberación fascia lateral } \\
\text { Extensión torácica }\end{array}$ \\
\end{tabular}


Tabla 6.17. Novena sesión de muestra, fuerza compensatoria y VO2MAX.

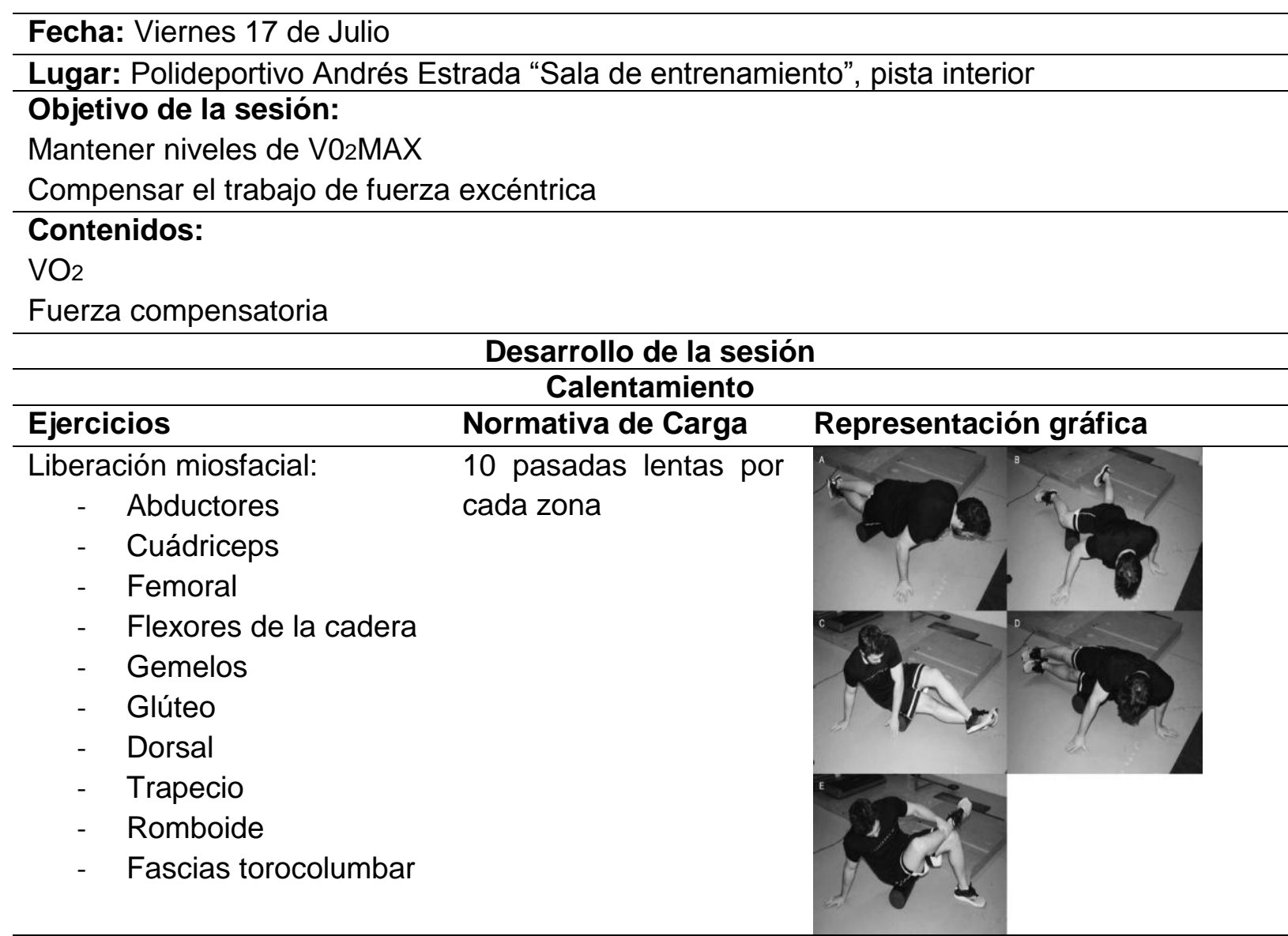

Activación vegetativa: bicicleta estática 3 minutos

Propuesta de movilidad de (Hauschildt, McQueen et al. 2014) compuesta por 8 secuencias de ejercicios

\begin{tabular}{|c|c|c|}
\hline & Parte Principal & \\
\hline Ejercicios & Normativa de Carga & Representación gráfica \\
\hline Hip thrust & $\begin{array}{lccc}3 & \text { series } & \text { de } & 6 \\
\text { repeticiones } & & \end{array}$ & \\
\hline $\begin{array}{l}\text { Abductores en patín mas } \\
\text { remo }\end{array}$ & 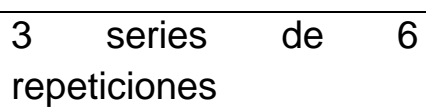 & \\
\hline
\end{tabular}




\begin{tabular}{|c|c|c|}
\hline $\begin{array}{l}\text { Concepto de triple activación } \\
\text { lanzar balón medicinal hacia } \\
\text { el suelo }\end{array}$ & $\begin{array}{lrll}3 & \text { series } & \text { de } & 6 \\
\text { repeticiones } & & & \end{array}$ & \\
\hline Dorsal TRX & $\begin{array}{lccc}3 & \text { series } & \text { de } & 6 \\
\text { repeticiones } & & \end{array}$ & 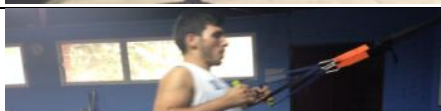 \\
\hline $\begin{array}{l}\text { Kettlebell progresión mas } \\
\text { press vertical }\end{array}$ & $\begin{array}{lccc}3 & \text { series } & \text { de } & 6 \\
\text { repeticiones } & & \end{array}$ & \\
\hline Lunge mas press & 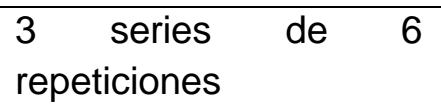 & \\
\hline Carrera continua extensiva & 40 minutos & \\
\hline & Vuelta a la calma & \\
\hline Ejercicios & Normativa de Carga & Representación gráfica \\
\hline $\begin{array}{l}\text { Liberación miosfacial: } \\
\text { Liberación en clavícula fascia } \\
\text { apendicular + Trabajo fascia } \\
\text { axial del brazo. } \\
\text { Palma de la mano } \\
\text { Fascias extensores del brazo. } \\
\text { Fascia plantar. } \\
\text { Liberación pierna } \\
\text { flexoextensión de tobillo. } \\
\text { Fascia peronéos. } \\
\text { Fascias toracolumbar. } \\
\text { Liberación fascia lateral. } \\
\text { Extensión torácica. }\end{array}$ & $\begin{array}{l}10 \text { pasadas lentas por } \\
\text { cada zona }\end{array}$ & 1 \\
\hline
\end{tabular}




SGA 4 minuten cada postura
4 mater


Tabla 6.18. Décima sesión de muestra, trabajo preventivo y de RSA.

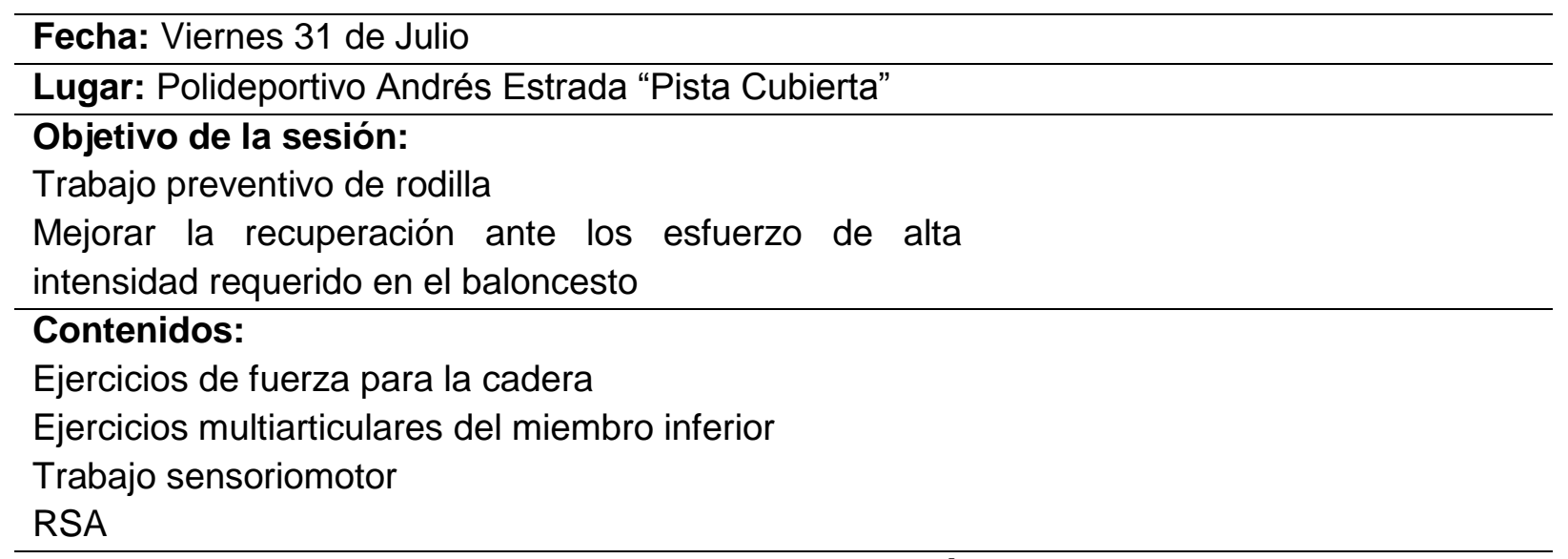

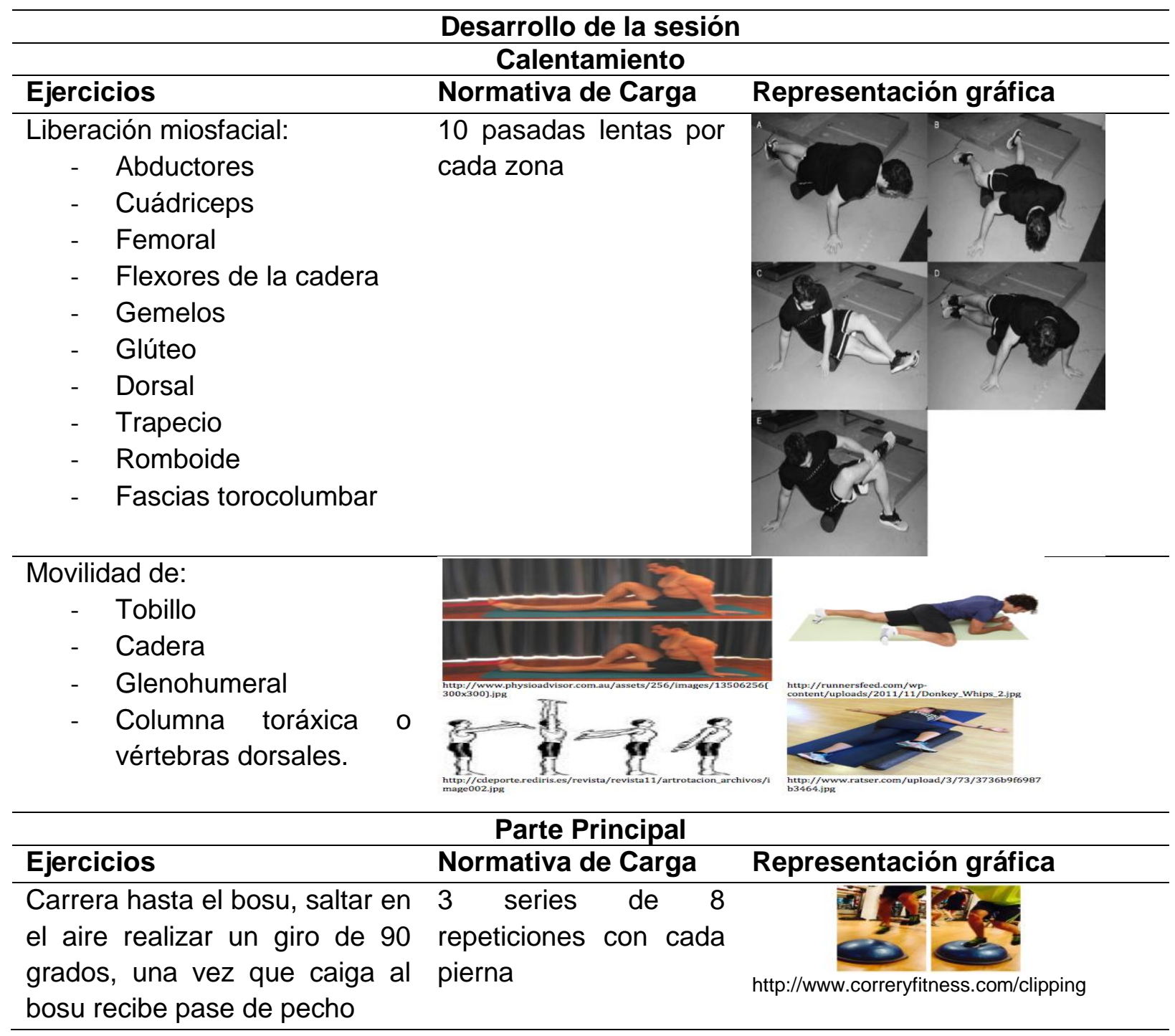




Control postural rodilla, goma 3 series de
altura de la rodilla resistencia repeticiones con cada
externa intenta provocar una
palgrna, jugador botando
valgo
Sujeto corre hacia los conos, 3 series de
salta, y cae con la pierna que repeticiones con cada
le diga el entrenador, a su vez pierna
tiene una resistencia externa
de una goma
Técnica individual, disociar 4 series de
juego de pie y bote, opciones: segundos
Bote lento, y pies lento.
Bote lento y pies rápidos
Bote rápido y pies lentos
Bote rápido y pies rápidos

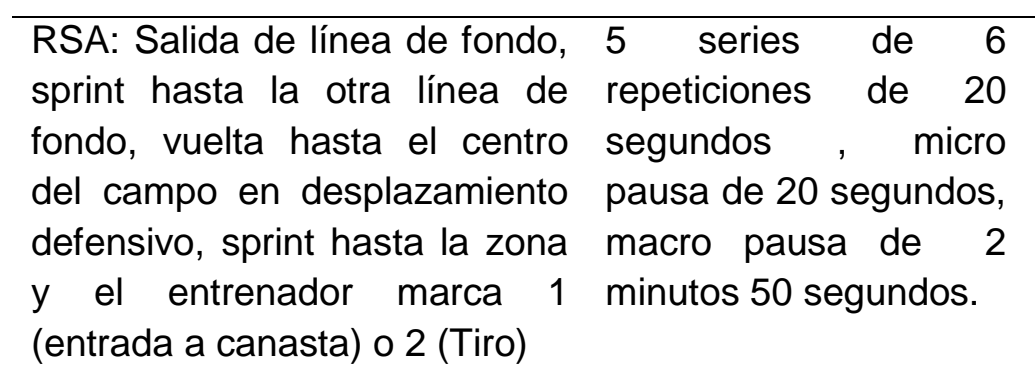

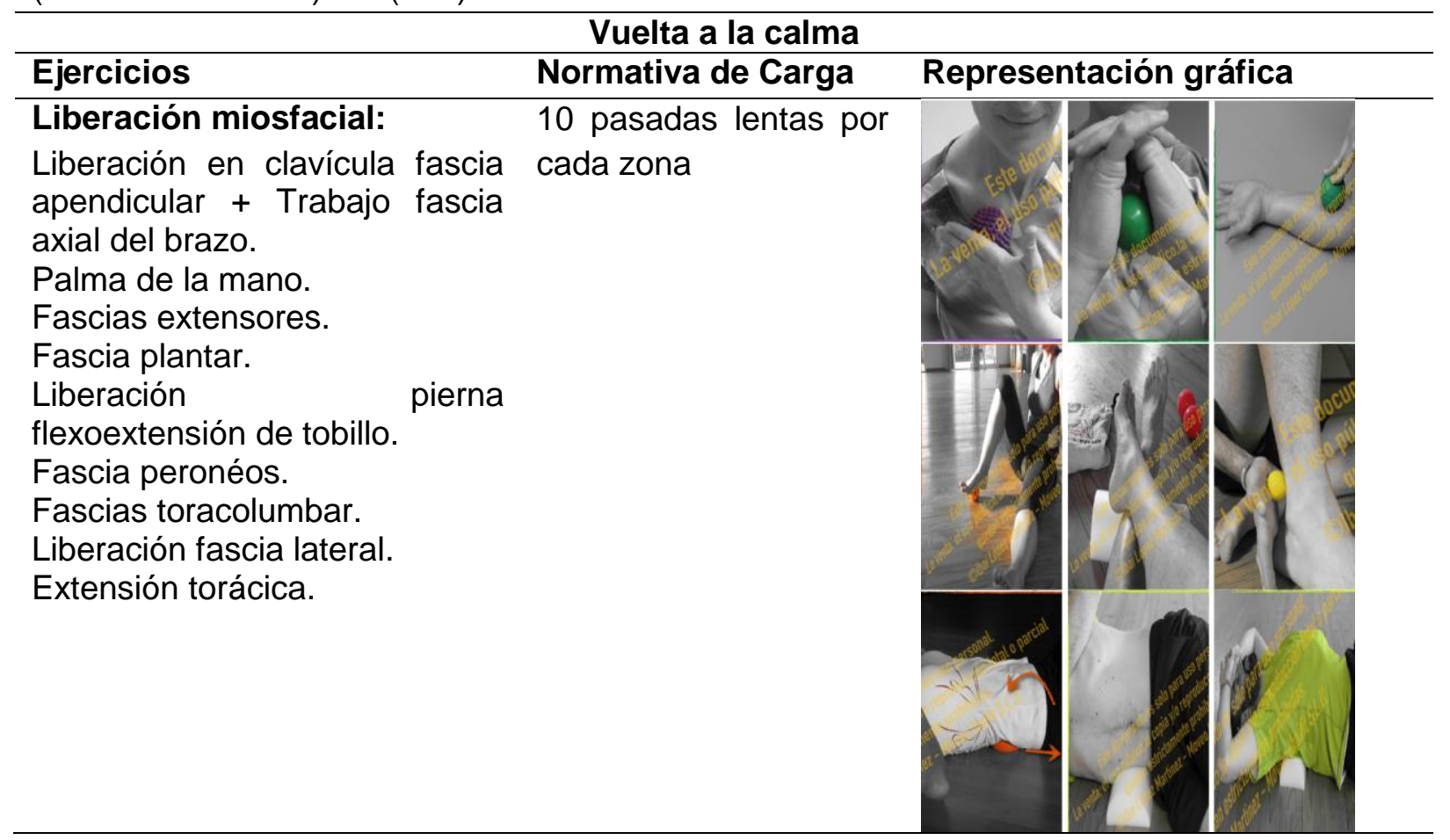




\begin{tabular}{lll}
\hline SGA & Mantener cada postura \\
4 minutos &
\end{tabular}




\subsubsection{Evaluación y control del proceso.}

\section{A. Medios de control y seguimiento de la primera fase del programa de intervención.}

Al igual que en la fase uno seguiremos la propuesta Toscano and Campos (2015), con la monitorización de las cargas de entrenamiento, la monitorización de la condición física, y la monitorización de la fatiga.

La monitorización de las cargas de entrenamiento a través de RPE TL propuesto por Foster et al. (2001), de esta segunda fase de intervención la podemos observar en la figura $\underline{43}$, la semana quinta y octava donde se observa un bajada considerable de la carga de entrenamiento con respecto a las otras semanas, fue porque se entrenaron 3 días en la semana quinta ya que los dos primemos días de la semana se utilizaron para evaluar y no fue monitorizada la carga de entrenamiento. En la semana octava podemos suponer esa bajada en la carga de entrenamiento por la sesión de descarga utilizada al final de la semana en piscina. A parte del RPE TL, utilizamos también TRIMP individualizado, (Manzi et al., 2013), figura 44.

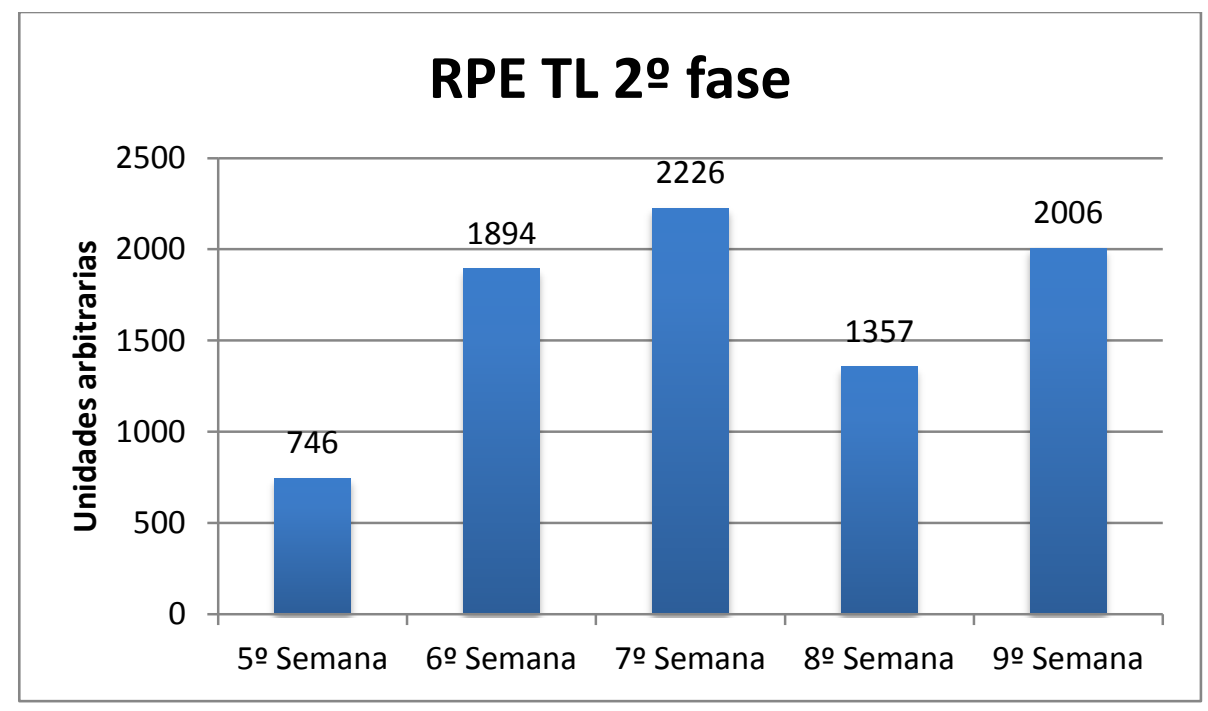

Figura 43. RPE TL de la segunda fase del programa de intervención.

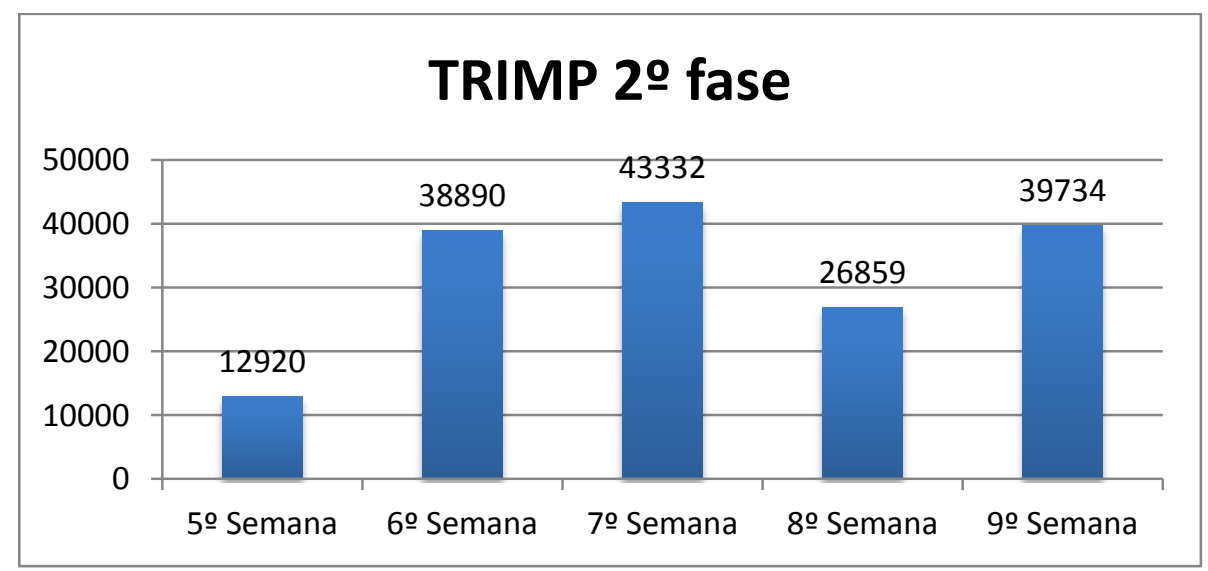

Figura 44. TRIMP individualizados en la segunda fase del programa de intervención. 
La monitorización de la condición física se llevó a cabo a través del CMJ, utilizado para medir en los miembros inferiores la fuerza explosiva (Cormack et al., 2008; Duffield et al., 2012; Jiménez-Reyes \& González-Badillo, 2011; McLean et al., 2010; Twist \& Highton, 2013; wist et al., 2012) y monitorizar la fatiga neuromucular con una pérdida de altura en $10 \%$ sobre una medición basal, tabla 2.10, (Cormack et al., 2008; Duffield et al., 2012; JiménezReyes \& González-Badillo, 2011; McLean et al., 2010; Twist \& Highton, 2013; wist et al., 2012). Los resultados obtenidos en esta fase lo podemos observar en la figura 45.

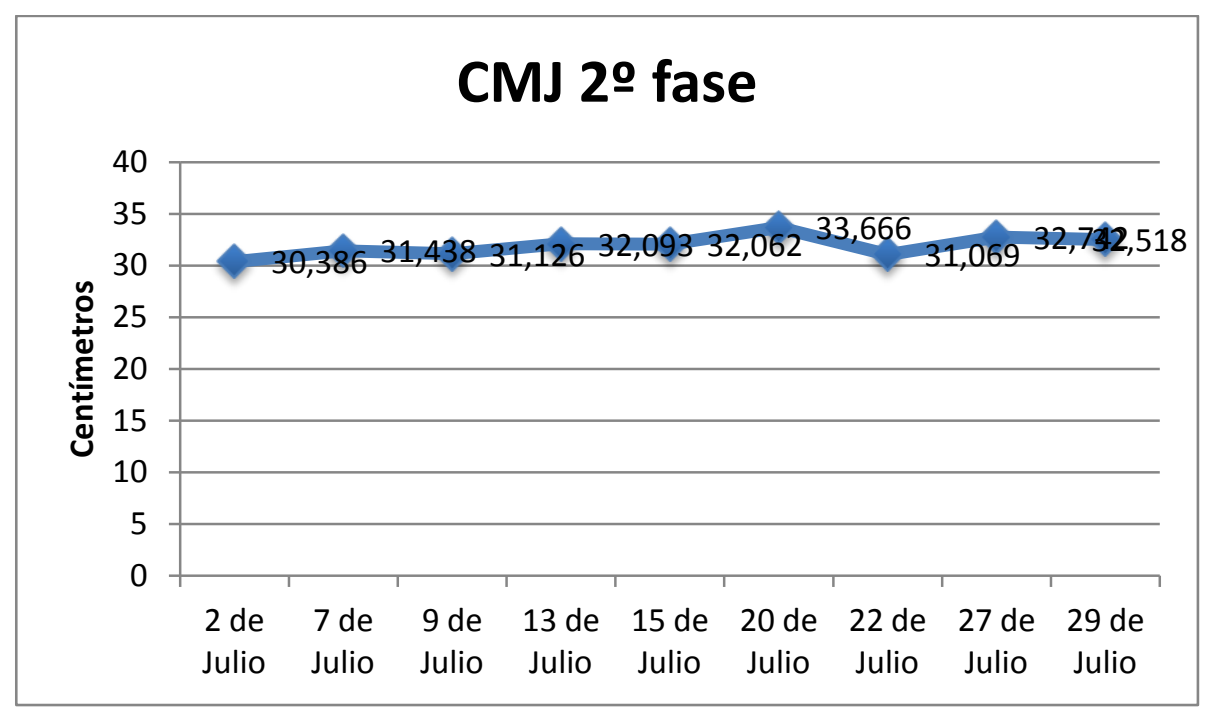

Figura 45. Monitorización del CMJ durante la segunda fase del programa de intervención.

Para terminar la monitorización de la fatiga se llevara a cabo por medio del cuestionario de Bienestar de McLean et al. (2010), En la figura 46 podemos observar los valores obtenido cada uno de los días de enteramiento en cada uno de los ítems valorados en el cuestionario de Bienestar, durante la $1^{\circ}$ fase del programa de intervención, en cambio en la figura 47 podemos observar la progresión según cada semana.

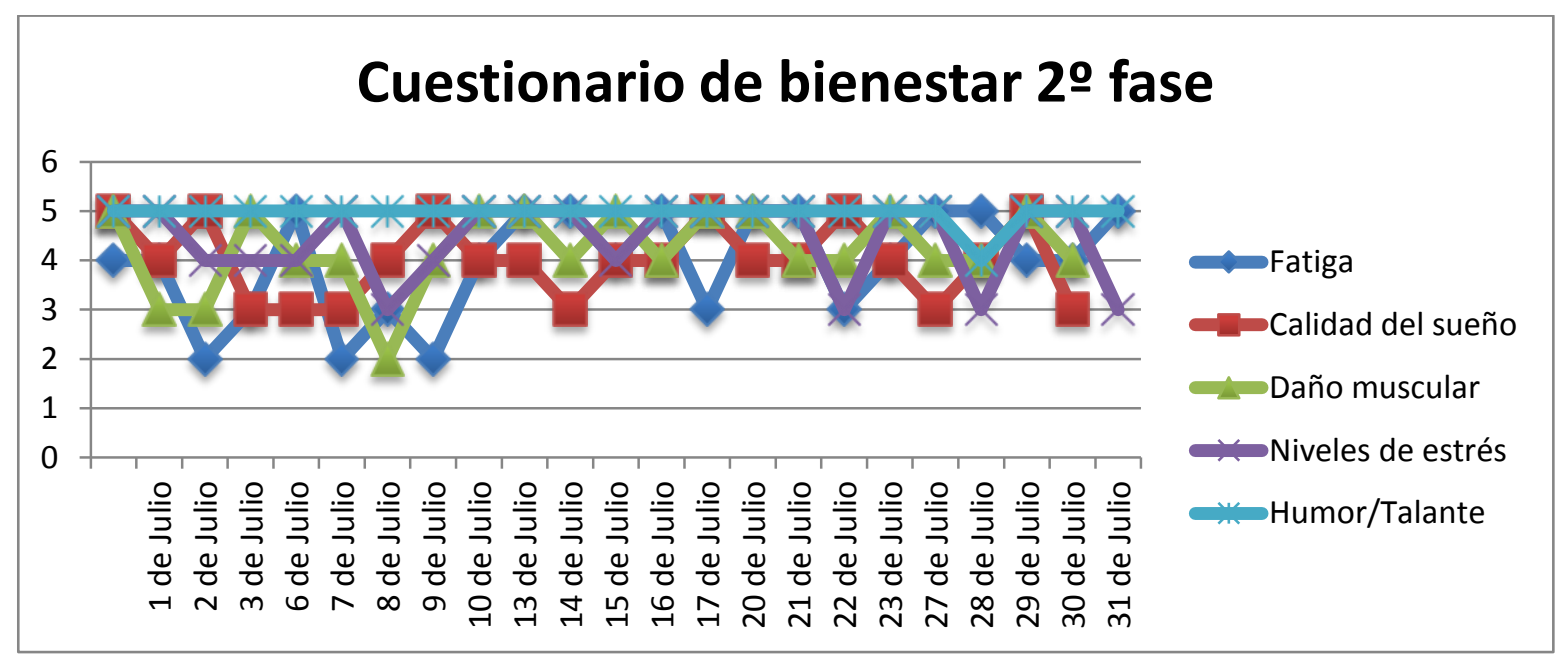

Figura 46. Monitorización por días del cuestionario de bienestar en la segunda fase del programa de intervención (McLean et al., 2010). 


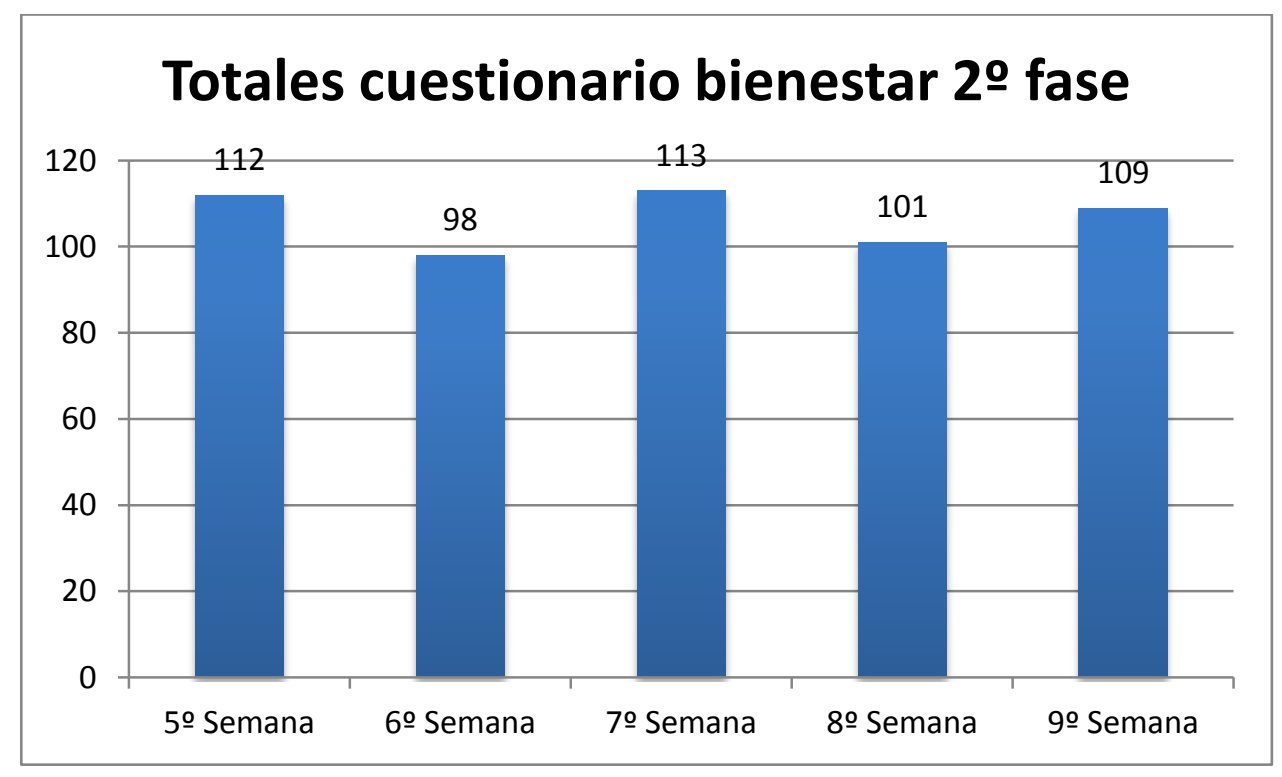

Figura 47. Monitorización por semanas del cuestionario de bienestar (McLean et al., 2010).

En la figura 47, podemos observar unos valores en la primera semana de trabajo que contradicen con los obtenidos en el RPE TL figura 43, y los TRIMPS individualizado figura $\underline{44}$, el cuestionario del cuestionario de bienestar de (McLean et al., 2010), el sujeto hubo un día que punto bajo el ítems referido al humor, por motivos personales, también cabe destacar que esa semana hizo demasiado calor y los ítems de calidad del sueño también obtuvieron puntuaciones bajas.

El día 8 de Julio se obtuvo unos valores muy por debajo en el cuestionario de bienestar de los que se estaban obteniendo usualmente en la monitorización del entrenamiento, en los ítems de fatiga, daño muscular y estrés. Al tocar ese día trabajo de RSA, (véase anexo 12), ampliamos a 5 minutos mínimos la recuperación entre series. Al día siguiente seguía saliendo valores por debajo de la medía de las semana anteriores en el ítems de fatiga, se corroboro esos resultados obtenidos en el cuestionario con el CMJ, obteniendo un resultado el 9 de Julio normal e incluso mejorando la evaluación del día 7 de Julio, el sujeto nos comento que por motivo de las altas temperaturas producidas durante esos días le constaba recuperar algo mas y no tenia mucho apetito, siendo una posible causa esto en el ítems de fatiga en el cuestionario de bienestar.

\section{B. Evaluación de la primera fase del programa de intervención.}

El objetivo específico A referidos a la mejora de la potencia del sujeto en el patrón básico de la sentadilla, y en patrones específicos como salida frontal, lateral, de espalda, el desplazamiento defensivo, ha sido medido a través del CMJ utilizado para medir la fuerza explosiva en miembros inferiores (Cormack et al., 2008; Duffield et al., 2012; Jiménez-Reyes \& González-Badillo, 2011; McLean et al., 2010; Twist \& Highton, 2013; wist et al., 2012). Podemos observar en la figura 45 una tendencia ascendente, a lo largo de esta segunda fase. 
Este objetivo también se evaluó con mediante la prueba de patrones específicos con el Agility T-Test, tabla 6.18.

Tabla 6.18. Resultados del Agility T-Test.

\begin{tabular}{ll}
\hline & Tiempo (s) \\
\hline Carrera 1 & 10,982 \\
Carrera 2 & 11,268 \\
Carrera 3 & $\mathbf{1 0 , 7 9 7}$ \\
\hline
\end{tabular}

Como se puede observar en la figura 48 , el sujeto obtuvo mejores resultados que en la evaluación de la primera fase, pero no mejoro con respecto a los valores de referencia expuesto por Delextrat and Cohen (2008), ni con la primera evaluación.

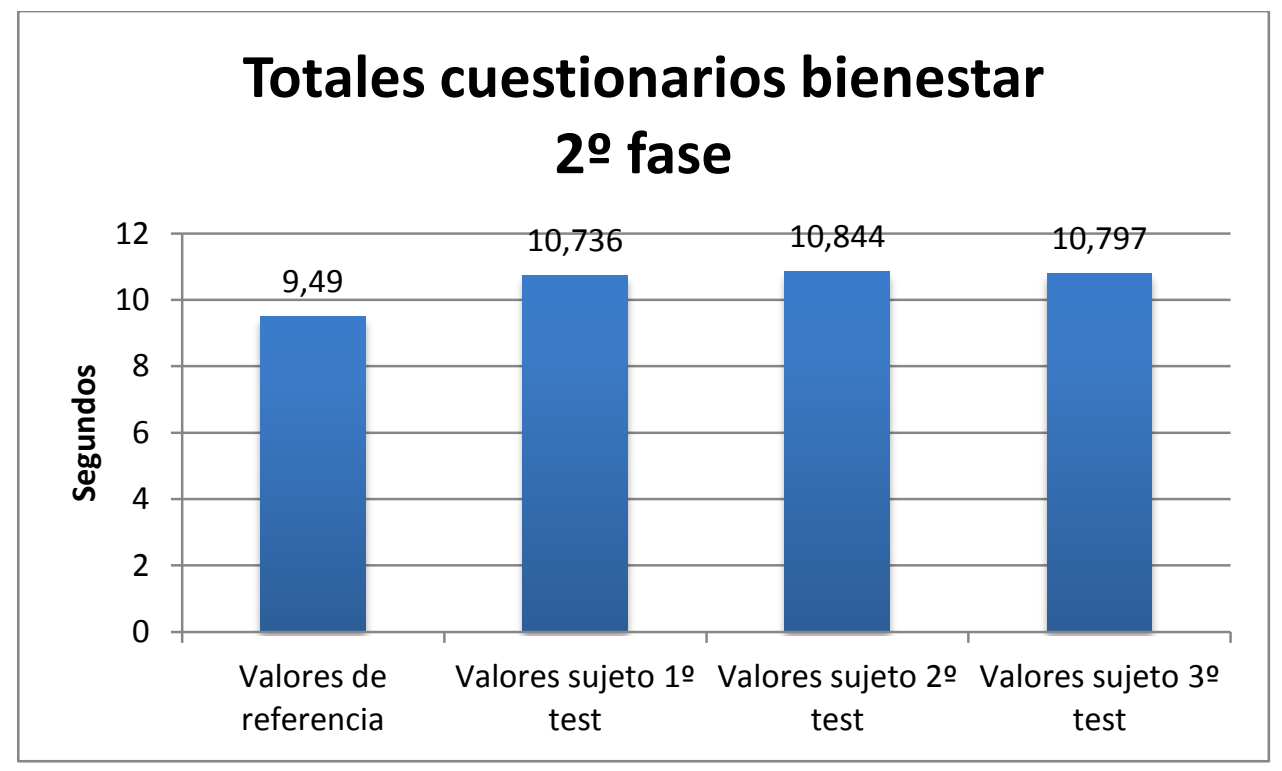

Figura 48. Valores de referencia del estudio Delextrat and Cohen (2008) en jugadores universitarios.

El objetivo específico B el cual hace mención al trabajo coxolumbopélvico. Tabla $\underline{6.19}$, muestra mejoras respecto a los test evaluados con anterioridad, figura 49, como superando en todos menos en el test de modificado Biering-Sorensen los valores de referencia (Peña et al., 2012), hay que recordad que en la evaluación de la primera fase fue el test donde obtuvo unos valores muy por debajo con respecto a la evaluación inicial.

Tabla 6.19. Resultados obtenidos en la prueba para valorar la estabilidad central, en la segunda fase del programa de intervención.

\begin{tabular}{cc}
\hline Test & Tiempo (s) \\
\hline Test modificado Biering-Sorensen & 145 \\
Puente lateral derecha & 101 \\
Puente lateral izquierda & 103 \\
Test resistencia flexores & 149 \\
\hline
\end{tabular}




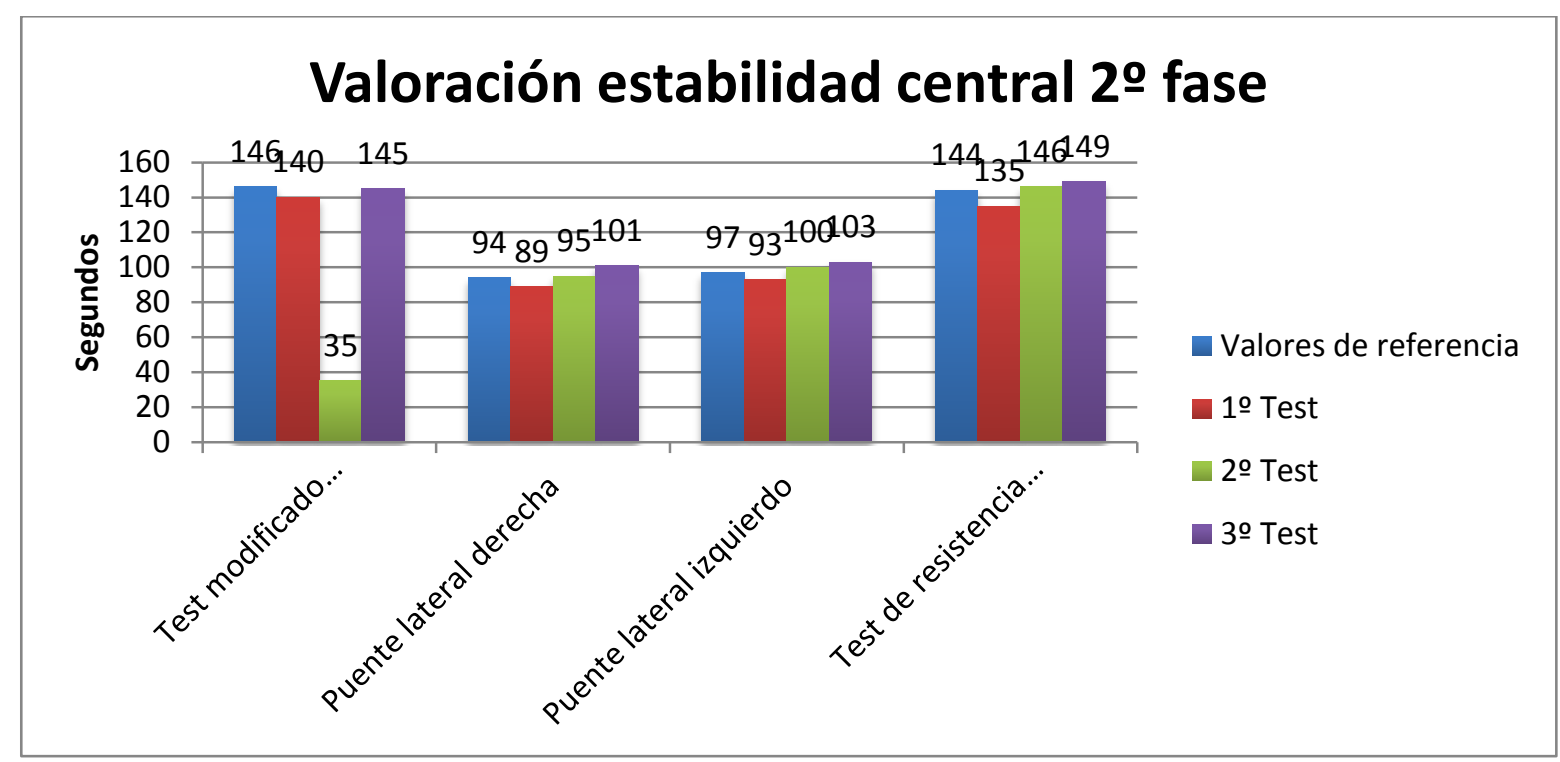

Figura 49. Comparación de los distintos test con los valores de referencia para la valoración de la estabilidad central expuesto en (Peña et al., 2012).

El objetivo D, el cual menciona la mejora de recuperación antes los esfuerzo de alta intensidad que se dan en el baloncesto, se evaluó mediante el test de RSA Impellizzeri et al., (2008a), tabla 6.20.

Tabla 6.20. Resultados del test RSA $2^{2}$ fase.

\begin{tabular}{lll}
\hline & Tiempo $(\mathrm{s})$ & Velocidad $(\mathrm{m} / \mathrm{s})$ \\
\hline Carrera 1 & $\mathbf{8 , 3 8 1}$ & $\mathbf{4 , 7 7 2}$ \\
Carrera 2 & $\mathbf{8 , 1 8 2}$ & $\mathbf{4 , 8 8}$ \\
Carrera 3 & $\mathbf{8 , 8 5 2}$ & $\mathbf{4 , 5 1 8}$ \\
Carrera 4 & $\mathbf{8 , 7 1 8}$ & $\mathbf{4 , 5 8 8}$ \\
Carrera 5 & $\mathbf{8 , 8 5 4}$ & $\mathbf{4 , 5 1 7}$ \\
Carrera 6 & $\mathbf{8 , 9 2 2}$ Resultados finales \\
\hline \multicolumn{2}{c}{$\mathbf{4 , 4 8 3}$} \\
\hline RSAmean & $\mathbf{8 , 5 9 7 4}$ \\
RSAbest & \multicolumn{2}{c}{$\mathbf{1 8 2}$} \\
Peor & \multicolumn{8}{c}{$\mathbf{8 5 4}$} \\
Diferencia & $\mathbf{0 , 6 7 2}$ \\
RSAdecrement \% & $\mathbf{1 , 0 5 0 7 6 9 9 8 3}$ \\
\hline
\end{tabular}

En este test nos encontramos ante la misma situación que el del Agility T-Test, el sujeto mejora resultado con respecto a la evaluación anterior pero sigue esta por debajo que los valores de referencia mostrado por Impellizzeri et al., (2008a), y aunque muy parejo por debajo que la evaluación inicial, figura 50. 


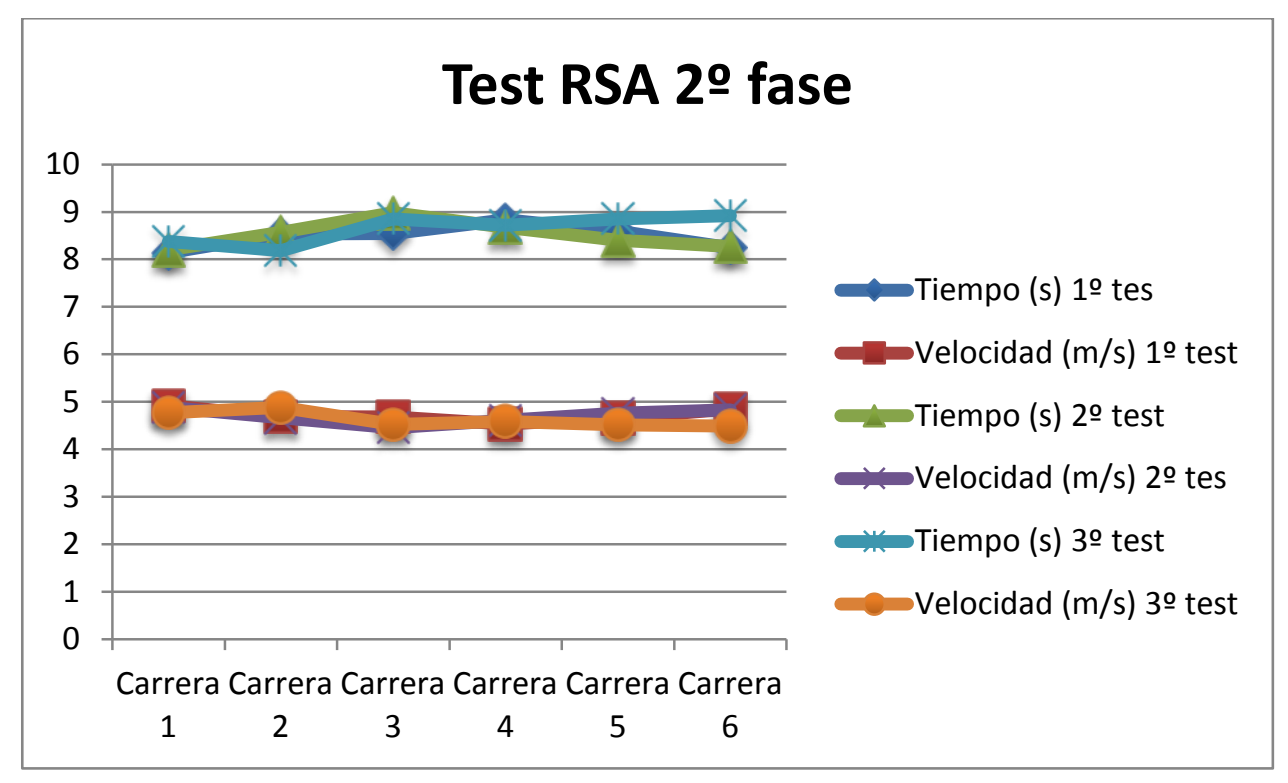

Figura 50. Comparación resultados de todos los test realizado de RSA.

El objetivo $E$, en el cual se menciona mantener los niveles de V02MAX, fue evaluado mediante Test Trive-Basket, (Vaquera et al., 2007), tabla 6.21.

Tabla 6.21. Resultados Test Trive-Basket segunda fase.

\begin{tabular}{cc}
\hline Ítems evaluados & Resultados \\
\hline Tiempo total $(\mathrm{min}: \mathrm{s})$ & $\mathbf{1 8 : 1 1}$ \\
Velocidad $(\mathrm{km} / \mathrm{h})$ & $\mathbf{1 2}$ \\
Periodo $(\mathrm{n})$ & $\mathbf{8}$ \\
FCmáx $(\mathrm{ppm})$ & $\mathbf{1 9 8}$ \\
\hline
\end{tabular}

En este test a pesar de no estar por encima de los valores de referencia que muestra, Vaquera et al., (2007), figura 51, el sujeto mejoro los test realizado con anterioridad. 


\section{Trive-basket 2 - fase}

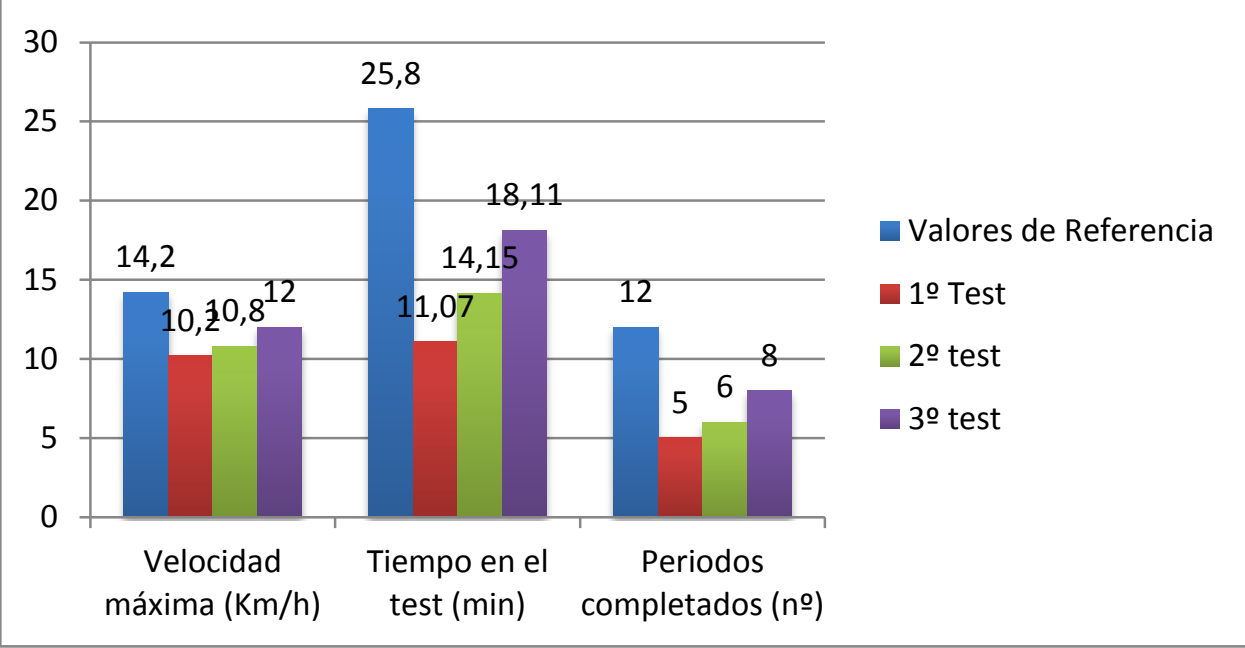

Figura 51. Valores de referencia del estudio Vaquera et al. (2007), en jugadores de liga EBA, comparados con la primera y la segunda medición. 


\subsection{Fase 3 del programa de intervención}

El objetivo principal de esta fase es que el sujeto de forma autónoma, ya que se marcha de vacaciones y con los materiales que dispone, le dé continuidad al trabajo que hemos empezado con él de forma guiada durante los dos meses anteriores.

Materiales que dispone el sujeto para esta fase del programa de intervención:

- $\operatorname{TRX}$

- Goma elástica

- Tirante muscular

- Pelota de tenis (lo utilizaremos para realizar ejercicios propioceptivo)

- Foam roller

Para ello se le preparó al sujeto un documento exel, figura 52, el cual contenida la planificación del contenido que debía trabajar cada día, figura 53, los ejercicios puntos clave de cada uno y la metodología a utilizar, anexo 15, y una hoja de control que nos serviría para monitorizar la carga de entrenamiento.
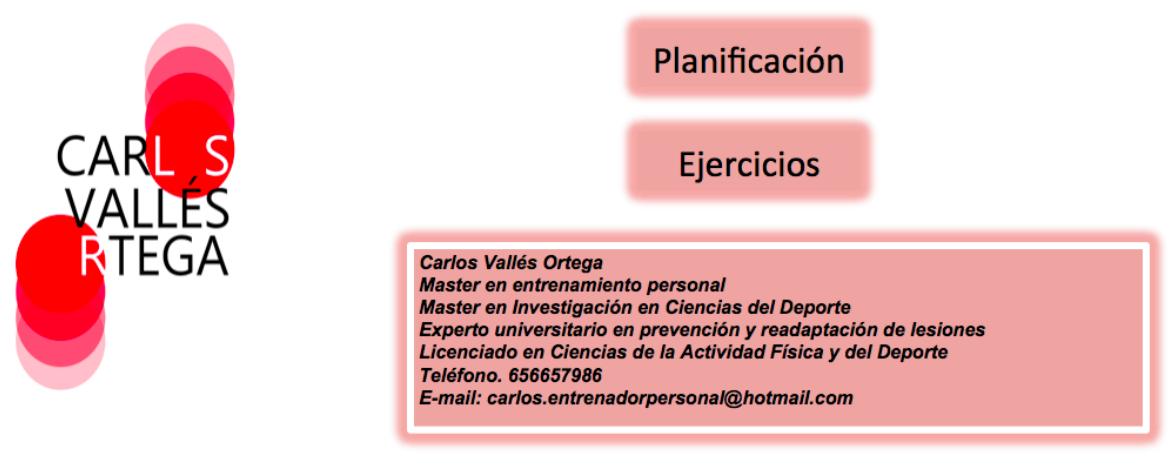

Figura 52. Portada Excel preparado para el sujeto con la planificación de agosto. 


\subsubsection{Objetivos específicos}

A. Dar continuidad al trabajo de fuerza, coxolumbopélvico, y programas preventivos impuesto al sujeto.

B. Mejorar la recuperación ante los esfuerzo de alta intensidad requerido en el baloncesto.

C. Mantener niveles de V02max. 


\subsubsection{Contenidos secuenciados}

- Fuerza estructural, mejorando factores neurales y coordinativos para luego transferirlo a la práctica deportiva de forma útil. Objetivo $\mathrm{A}$.

- Core stability. Objetivo A.

- Core strenght. Objetivo A.

- Trabajar sobre mecanismo de lesión, valgo de rodilla. Objetivo A.

- Trabajar sobre la flexión plantar y dorsal del pie. Objetivo A.

- Trabajo sensoriomotor. Objetivo A.

- Trabajo de la musculatura de la cadera. Objetivo A.

- Ejercicios multiarticulares focalizando en una buena postura del miembro inferior. Objetivo A.

- Repeat sprint Ability. Objetivo B.

- Potencia aérobica. Objetivo C.
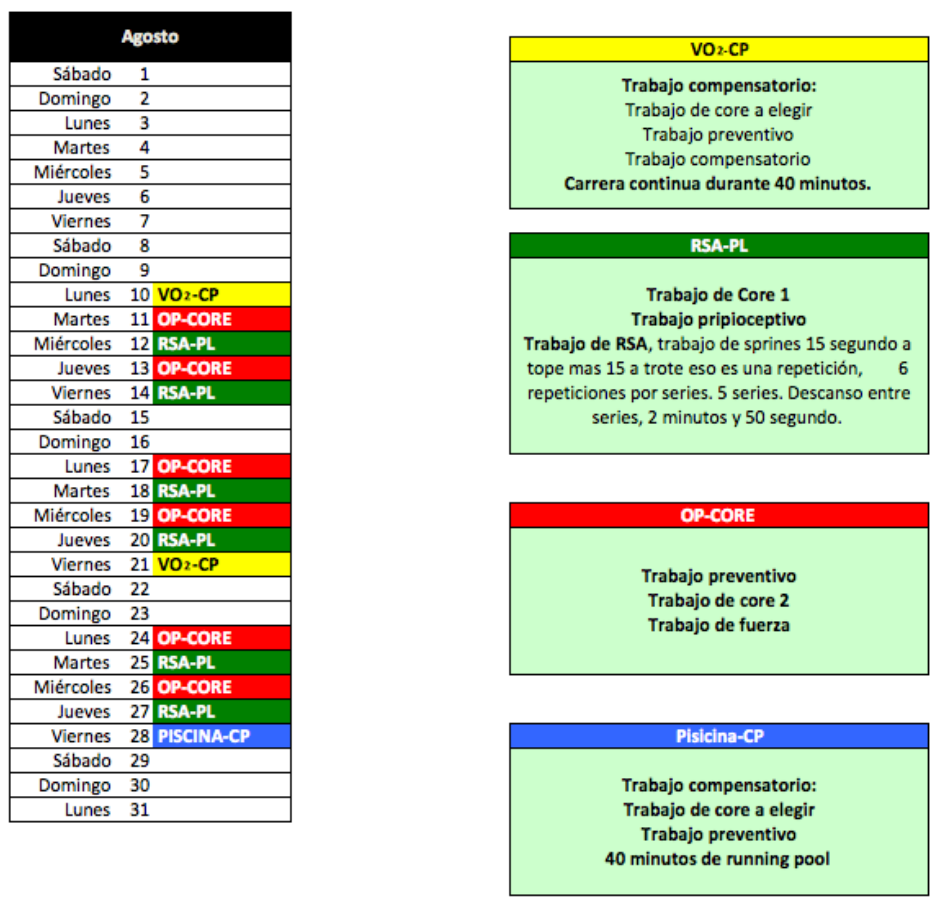

Figura 53. Planificación parte no presencial agosto. 


\subsubsection{Metodología}

\section{A. Metodología utilizada en la sesiones de trabajo compensatorio y VO2MAX.}

El calentamiento al igual que en las fases anteriores, se centró en un trabajo la liberación miosfacial, y otra de movilidad con la propuesta de Hauschildt, McQueen et al. (2014), anteriormente planteada.

La parte principal la dividiremos en 2 partes una primera orientada a la compensación del trabajo de fuerza.

La segunda parte estará centrada en el trabajo de VO2MAX (Objetivo específico C), en el cual se realizará una carrera continua extensiva durante 40 minutos.

La vuelta a la calma dado que la carrera se realiza por el paseo marítimo donde se encuentra de vacaciones el sujeto, aprovecharemos la cercanía del mar para introducirlo como medio de recuperación ya que muchos autores han demostrado sus propiedades como medio de recuperación (Sola \& Valdivieso, 2013; Torres-Ronda \& Schelling i del Alcázar, 2014). Seguiremos la propuesta establecida por Sola and Valdivieso (2013) con una primera parte como hemos venido realizado hasta ahora de trabajo de SGA, y una segunda de inmersión en el medio acuático hasta las crestas iliacas de 15 minutos (Sola \& Valdivieso, 2013; Torres-Ronda \& Schelling i del Alcázar, 2014).

\section{B. Metodología utilizada en la sesiones de RSA y prevención de lesiones}

Al igual que en las sesiones de VO2MAX el calentamiento constará de dos partes una de liberación miosfacial y otra de movilidad.

La parte principal estará dividida también en dos partes. Una primera donde el trabajo irá orientado a la prevención (Objetivo A), dando continuidad a los programas preventivos individuales empezado en la fase primera y segunda del programa de intervención de tobillo y rodilla.

La segunda parte estará dedicada al trabajo de RSA (Objetivo específico B), la metodología utilizada será la expuesta por (Castagna, Abt, et al., 2008) 5 series de 6 repeticiones de 20 segundos, con una micro pausa de 20 segundos, y una macro pausa de 2 minutos 50 segundos. Al no disponer de pista polideportiva como en las dos fases anteriores para realizar patrones de movimientos específicos del baloncesto (López et al., 2014), el sujeto realizaba esta trabajo intermitente por el paseo marítimo del lugar donde estaba de vacaciones.

Para la vuelta a la calma utilizaremos la misma metodología del día del trabajo de VO2MAX dado la cercanía al mar, con una primera parte de trabajo de SGA, y una segunda de inmersión en el medio acuático hasta las crestas iliacas de 15 minutos (Sola \& Valdivieso, 2013; Torres-Ronda \& Schelling i del Alcázar, 2014).

\section{Metodología utilizada en las sesiones de Fuerza y Core}

De la misma manera que en las dos sesiones anteriores el calentamiento estará dividido en dos partes una de liberación miosfacial y otra de movilidad. 
La primera parte le daremos continuidad al trabajo de la región coxolumbopélvica empezado en las fases anteriores.

La segunda parte ira encaminado a un trabajo de fuerza nivel sarcomérico, con una intensidad en torno a 10RM, un volumen por grupo muscular no excesivamente elevado (10 series) con progresión vertical en la ejecución de los ejercicios, no pasando de uno a otro hasta que se hayan completado todas las series (J. Tous, 1999). Los ejercicios utilizados son empujes verticales y horizontales, tracciones verticales y horizontales, ejercicios predominantes de caderas y ejercicios predominantes de rodilla. Para controlar la perdida de velocidad como indicador de fatiga durante el entrenamiento de fuerza (Gonzalez-Badillo \& Sanchez-Medina, 2010; Sanchez-Medina \& Gonzalez-Badillo, 2011), se utilizó la percepción subjetiva de la velocidad Bautista et al. (2015), aplicada con anterioridad en la fase anterior.

La vuelta a la calma la realizaremos como la hemos llevado a cabo hasta el momento con un primera parte de SGA y una segunda de liberación miosfacial. 
6.4.4.Sesiones.

Todas los ejercicios y sesiones realizado por el sujeto en esta fase del programa de intervención, la cual no fue presencial se pueden observar en el anexo 15. 


\subsubsection{Evaluación y control del proceso.}

Para el control y evaluación en esta fase del programa de intervención contamos con el inconveniente que el sujeto lo debía realizar de forma autónoma y enviarnos los resultados para poder monitorizar el entrenamiento. Al igual que en las fases anteriores controlaremos el entrenamiento en tres ámbitos, la monitorización de la carga de entrenamiento, monitorización de la condición física y la monitorización de la fatiga, (Toscano \& Campos, 2015).

La monitorización de la carga de entrenamiento la hemos seguido realizando a partir de la RPE TL, (Foster et al., 2001). En la figura 54 podemos observar los resultados obtenidos en esta 3 fase del programa de intervención, la bajada de la carga de entrenamiento de la tercera semana con respecto a las otras dos se debe por que se realizo un día menos de entrenamientos.

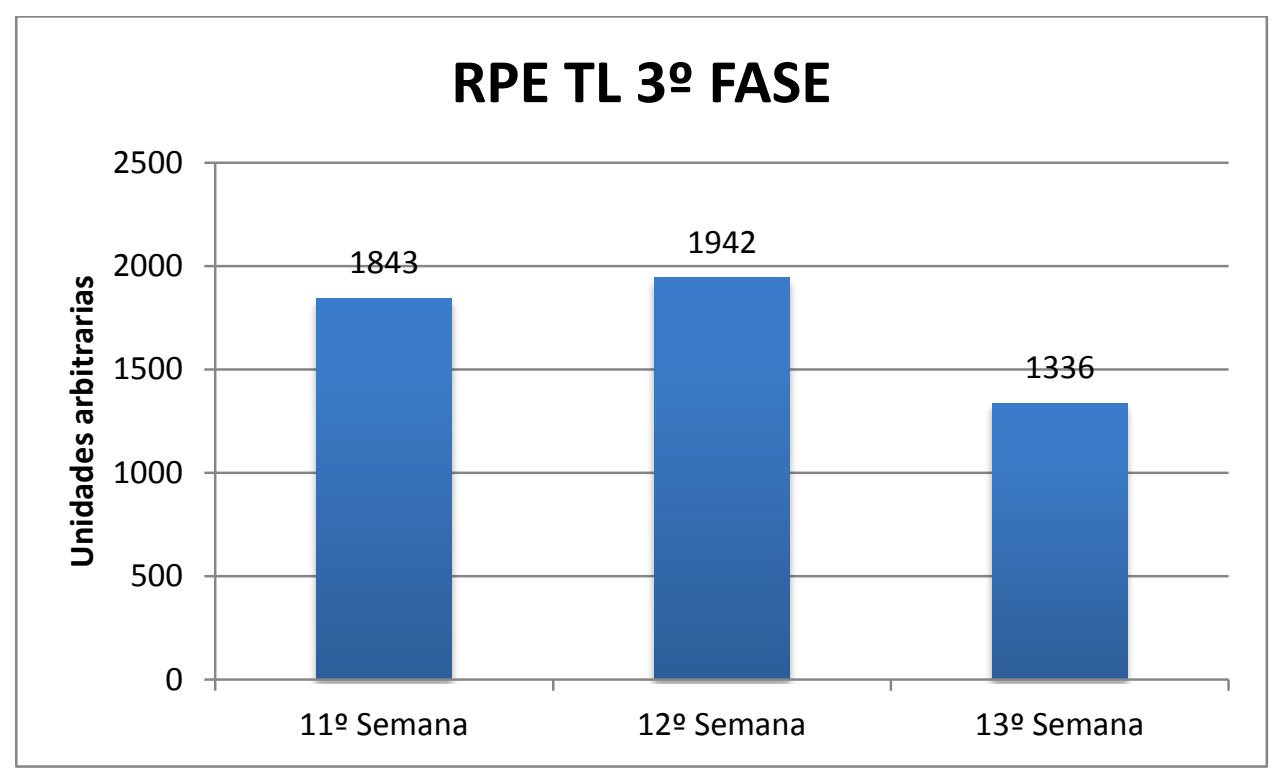

Figura 54. RPE TL Foster et al., (2001) de la tercera fase del programa de intervención.

Para la monitorización de la condición física seguiremos utilizando el CMJ (Cormack et al., 2008; Duffield et al., 2012; Jiménez-Reyes \& González-Badillo, 2011; McLean et al., 2010; Twist \& Highton, 2013; wist et al., 2012). El sujeto a no disponer de plataforma de salto, utilizaremos la aplicación My Jump para Iphone para la medición del CMJ, en la siguiente investigación Balsalobre-Fernandez, Glaister, and Lockey (2015), se muestra su validez, y el protocolo que utilizaron para la medición, con el Iphone 5s (es el que tiene el sujeto), se grabó en horizontal a un distancia de 1,5 metros del sujeto, los resultados finales muestran una $r=0,0995$ y una diferencia de 1 centímetro con respecto a una plataforma de salto de fuerza profesional, (Balsalobre-Fernandez et al., 2015).

El sujeto realizo la medición ayudado por un familiar, los lunes antes de empezar los entrenamientos, los resultados obtenidos se muestran en la figura 55, siendo el salto realizado el 17 de agosto el mejor en toda el programa de intervención. 


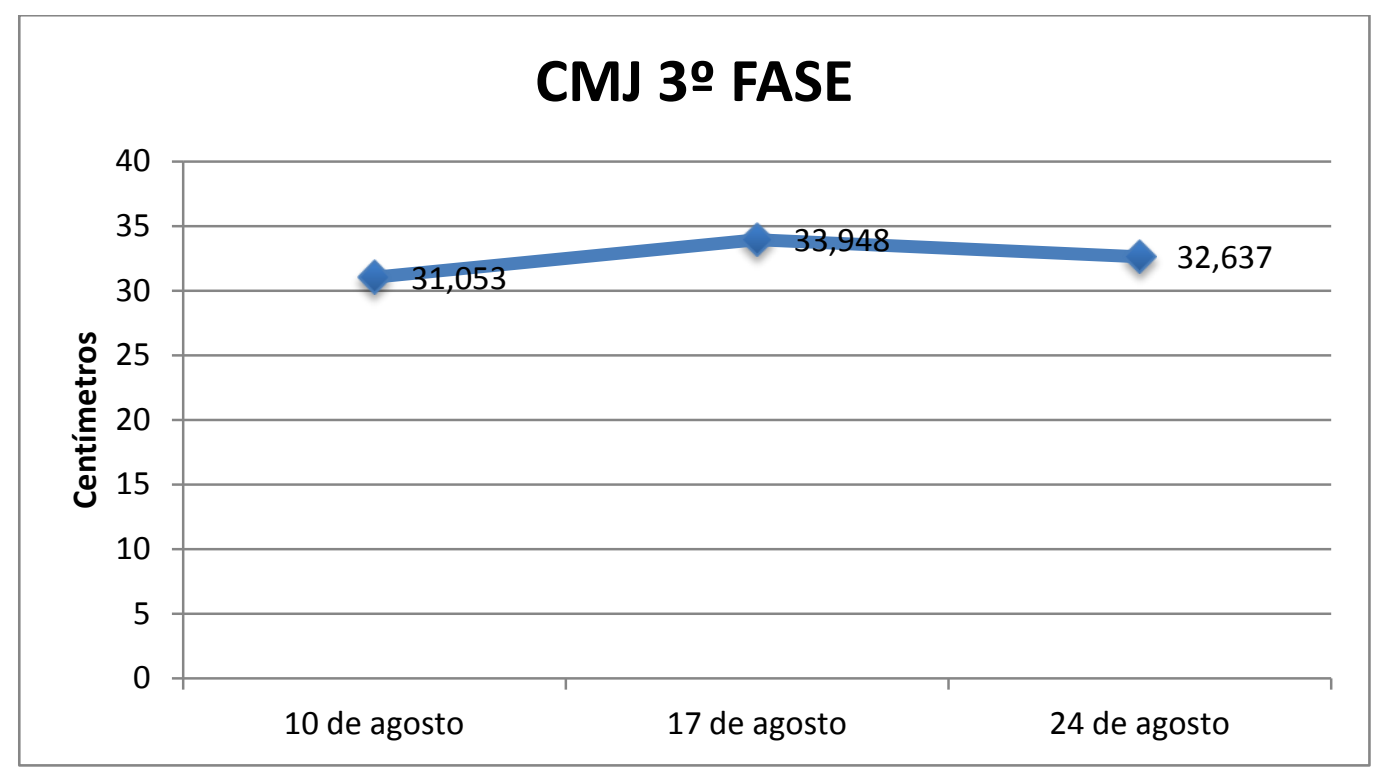

Figura 55. Monitorización del CMJ a partir de la aplicación My Jumps, (BalsalobreFernandez et al., 2015).

El sujeto nos sugirió durante esta fase del programa de intervención, ya que se iba de vacaciones el no tener que estar muy pendiente de rellenar y mandar resultados de escalas de control del entrenamiento como habíamos estado haciendo hasta el momento. Por este motivo decidimos en vez de realizar dos mediciones del CMJ a la semana como en las fases primera y segunda realizar solo una, y a su vez cambiar el cuestionario de Bienestar de McLean et al. (2010), con 5 items a rellenar y hacer el sumatorio de todos los ítems, por la escala Total Quality Recovey (TQR) (Kentta \& Hassmen, 1998). Se trata de una escala donde el sujeto valora de forma previa al comienzo de la sesión su nivel de recuperación tras el último entrenamiento, véase anexo 16 (Toscano \& Campos, 2015). La puntuación de la escala oscila entre 6-20, donde 6 representa un nivel pobre de recuperación y 20 el máximo nivel de recuperación (Toscano \& Campos, 2015).

Los datos obtenidos con la escala TQR, lo podemos observar en la figura56, las cuales muestran los resultados por días, y en la figura 57 que muestran los globales de la semanas. 


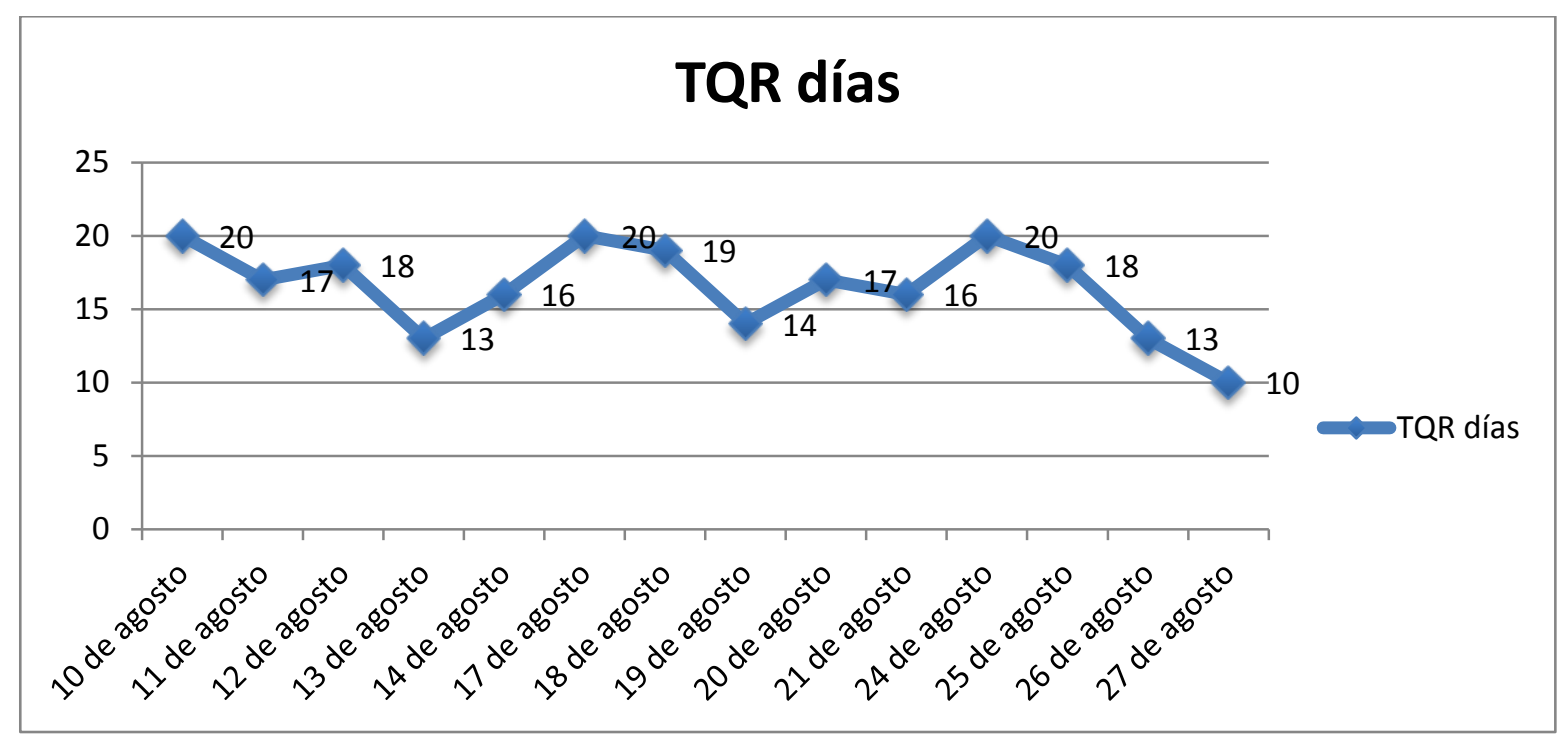

Figura 56. Monitorización por días de la escala TQR, (Kentta \& Hassmen, 1998).

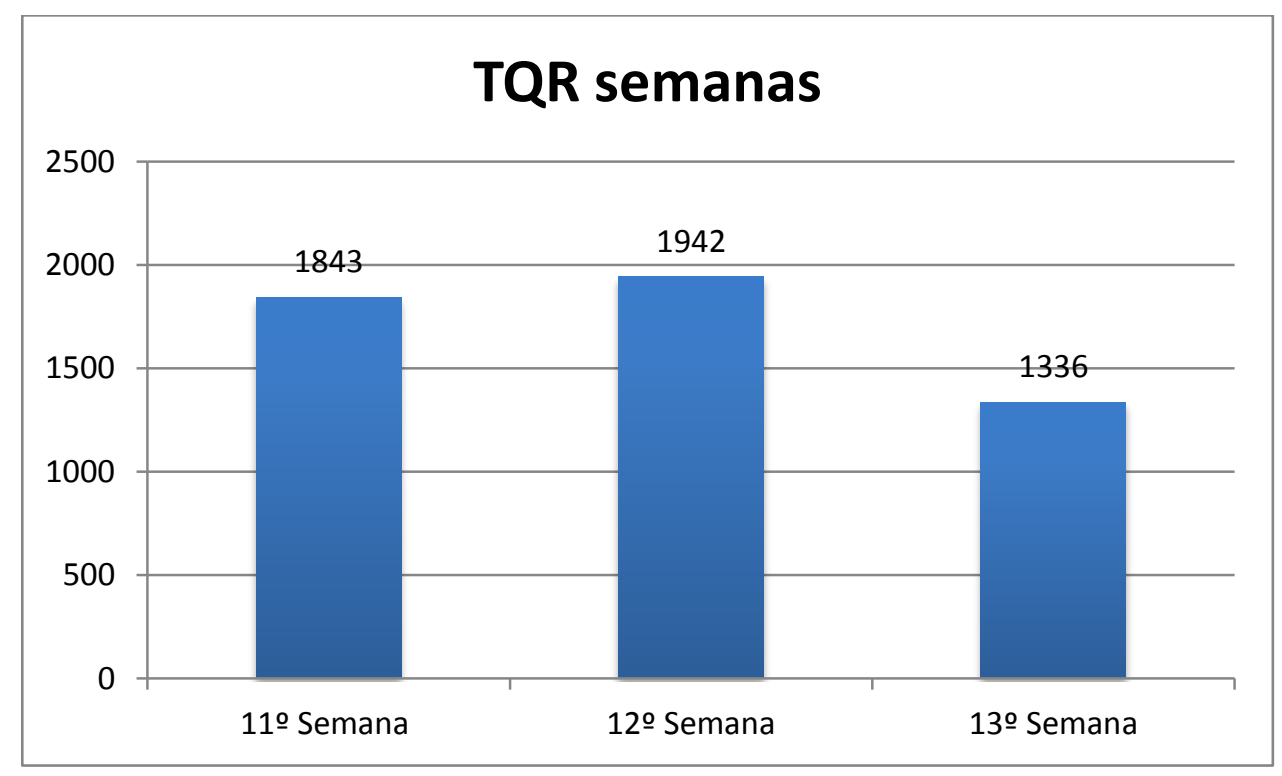

Figura 57. Monitorización por semanas de la escala TQR, (Kentta \& Hassmen, 1998).

Debido al que el sujeto empezó la temporada el Lunes 31 de Agosto, estando de vuelta de sus vacaciones el domingo 30, no pudimos realizar algunos test realizado en las otras dos fases, como el test trive basket diseñado por Vaquera et al. (2007), el test de RSA de Impellizzeri et al., (2008a), el Agility T-test propuesto por Delextrat and Cohen (2008) y la propuesta de valoración de la región del Core formulado por (Peña et al., 2012) para, poder comparar los valores que hubieran resultados con los de las evaluaciones anteriores. 


\section{RESULTADOS (EVALUACIÓN FINAL).}

Debido a la limitación que he tenido, comentada en el apartado anterior, al no poder realizar una evaluación de todos los test que me hubiera gustado al finalizar la tercera fase del programa de intervención, muchos de los resultados que se muestra en este apartado ya han sido comentado en la evaluación de la segunda fase.

En la figura 58, podemos observar los resultados obtenidos en las 4 evaluaciones realizadas del Agility-T test propuesto por Delextrat and Cohen (2008), para evaluar Potencia y velocidad en piernas y agilidad. Se puede observar que el segundo test se obtuvieron los mejores resultados.

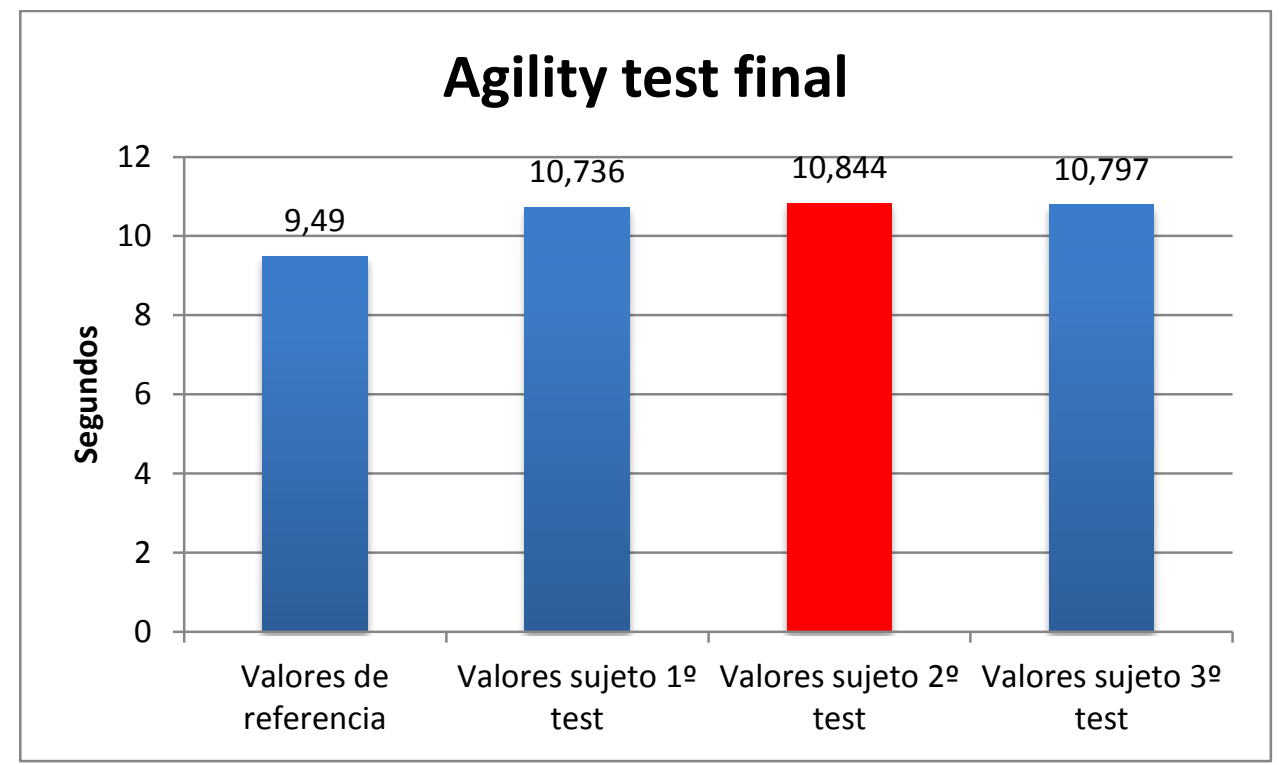

Figura 58. Comparación de los resultados de los diferentes test del Agility t-test de Delextrat and Cohen (2008).

En la figura 59, podemos observar la evolución de la estabilidad central del sujeto a partir de la propuesta de (Peña et al., 2012).

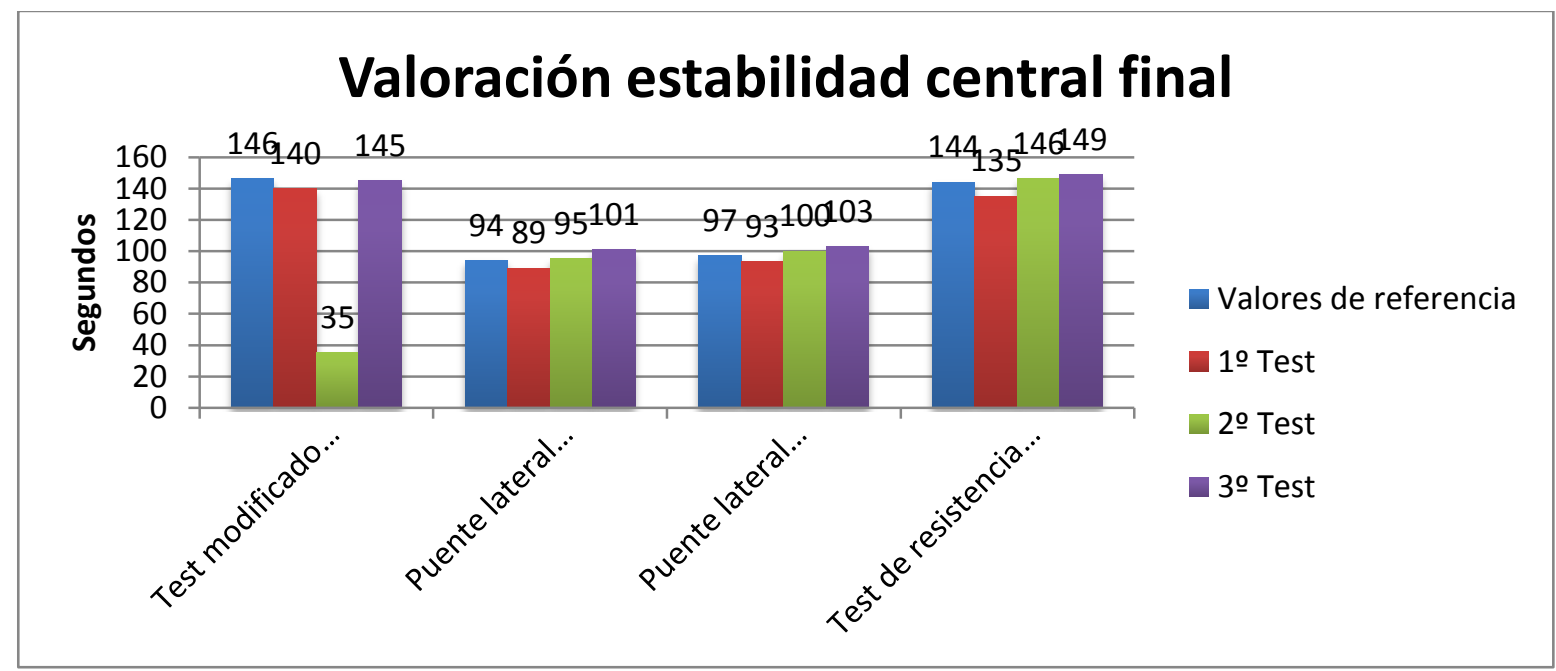

Figura 59. Comparación de los distintos test con los valores de referencia para la valoración de la estabilidad central expuesto en (Peña et al., 2012). 
La resistencia específica de baloncesto, y la capacidad de recuperación de los intervalos de esfuerzos requerido en esta modalidad deportiva se midió a partir del test tivre basket de Vaquera et al. (2007), el progreso en esta evaluación lo podemos observar en la figura 60 .

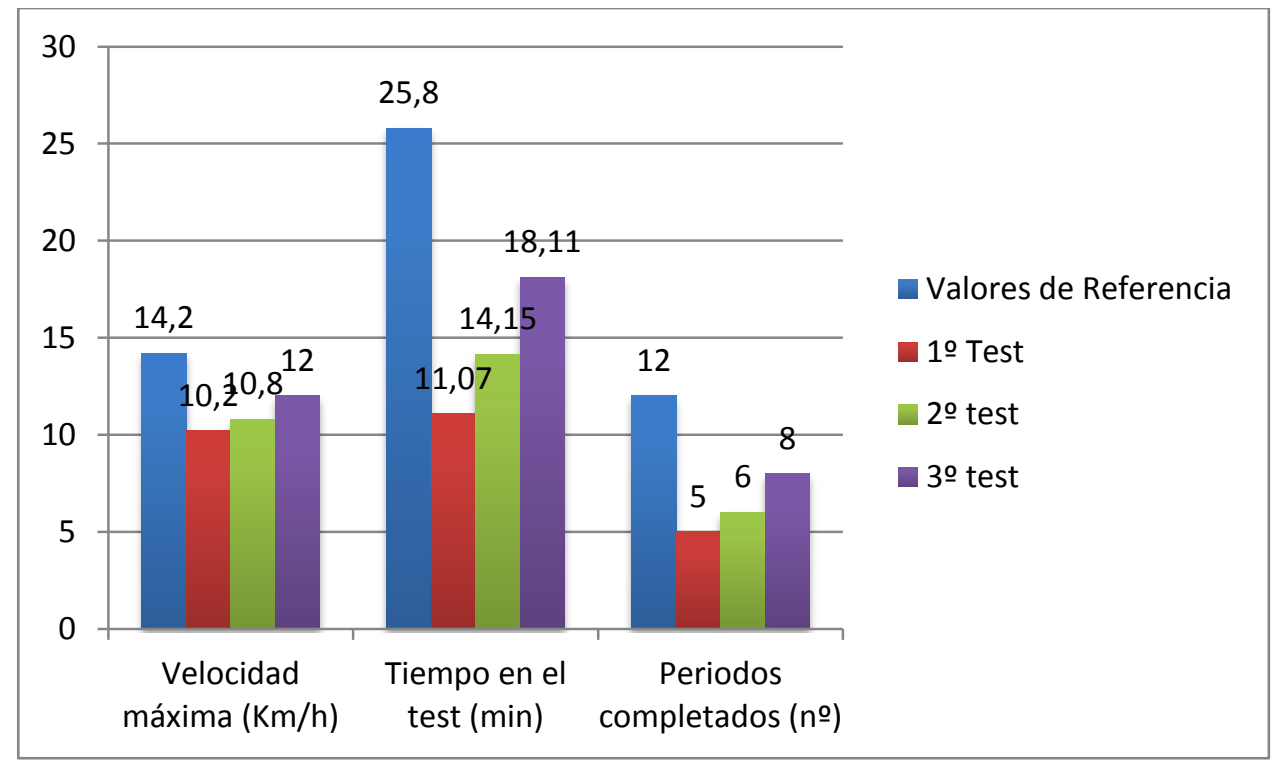

Figura 60. Valores de las diferentes evaluación del test tivre basket de referencia del estudio (Vaquera et al. (2007).

En la figura 61, podemos observar los resultados obtenidos en el test de RSA propuesto por Impellizzeri et al., (2008a), utilizado para medir la capacidad de repetir esprines y recuperación entre estos del sujeto.

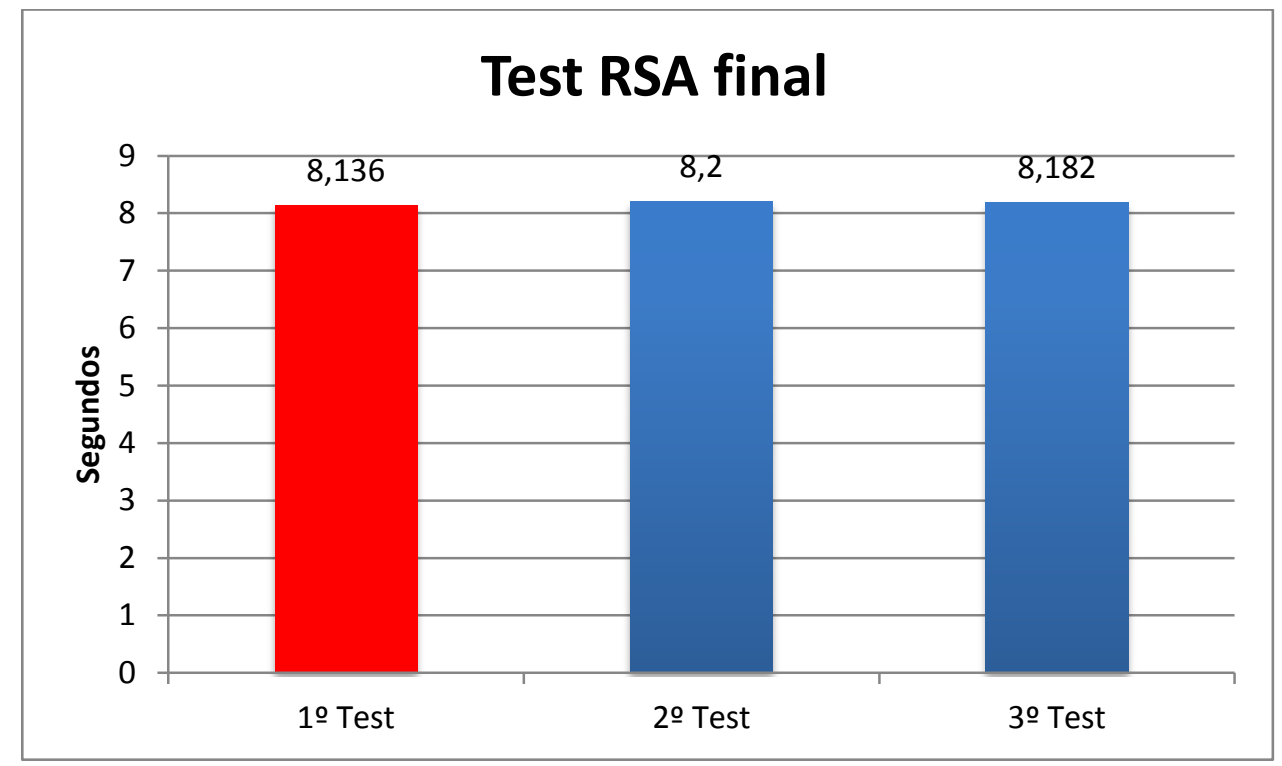

Figura 61, Comparación de los resultados obtenidos en la prueba de RSA de (Impellizzeri et al., 2008a). 
Para terminar este apartado podemos observar en la figura 62 la evolución del CMJ, como instrumento utilizado para medir la fuerza en tren inferior, CMJ (Cormack et al., 2008; Duffield et al., 2012; Jiménez-Reyes \& González-Badillo, 2011; McLean et al., 2010; Twist \& Highton, 2013; wist et al., 2012).

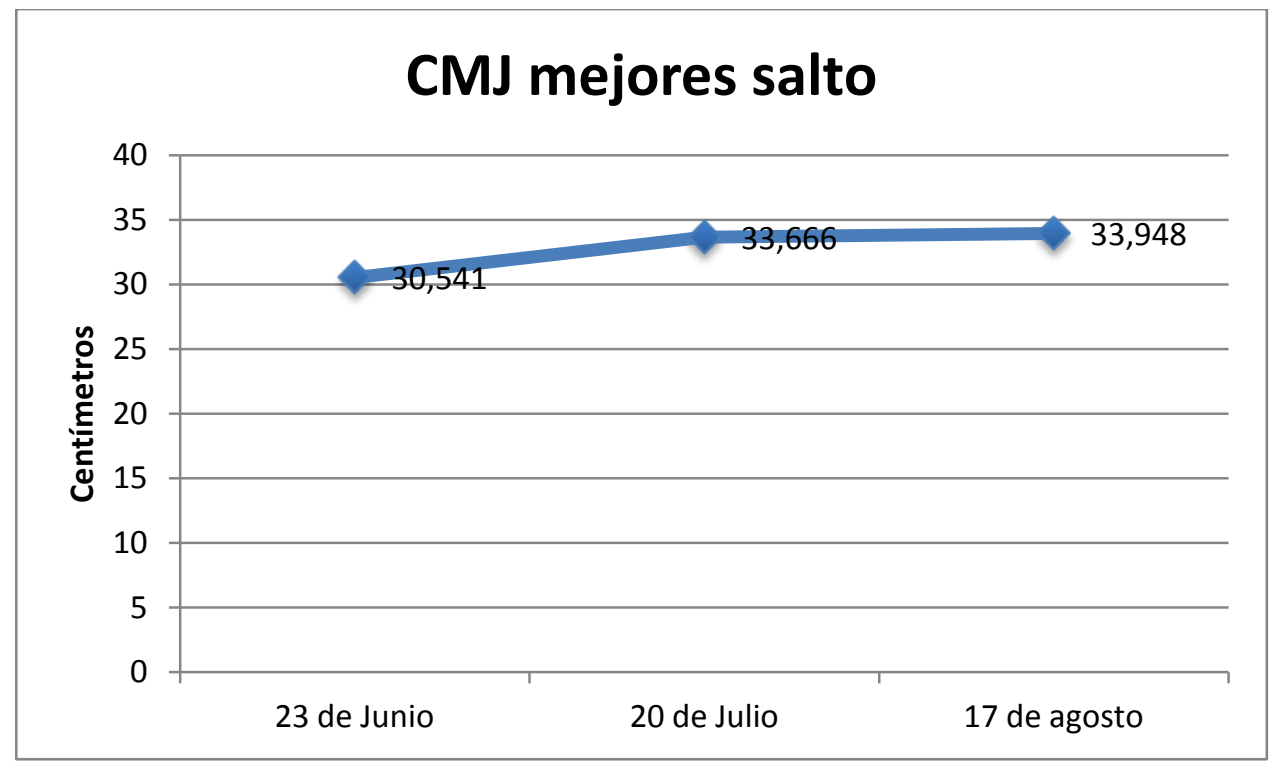

Figura 62. Mejores salto en cada fase del programa de intervención. 
8. DISCUSIÓN.

\subsection{Discusión del grado de consecución de los objetivos planteados y posibles causas.}

Objetivo A. Readaptar aquellos patrones de movimientos tantos básicos como específicos, que puedan hacer sufrir al sujeto algún tipo de lesión, y a su vez una vez modificados hacerlos útil tanto en su vida deportiva como diaria. Objetivo cumplido en la primera fase del programa de intervención ya que el sujeto consiguió realizar todos los patrones motores básicos correcto y superar los ítems que figuran en el anexo 6 , que en la evaluación inicial dieron resultados negativos. En cuanto a este objetivo, destacar que tras su consecución posiblemente evitamos lesiones por sobreuso por una mala ejecución o por tener algunas estructuras alteradas, (Bennasar, 2015; Sahrmann, 2002). Mencionar también que el sujeto gracias a la consecución de este objetivo fue capaz de realizar la última fase del programa de intervención, cuando se fue de vacaciones de forma autónoma.

Objetivo B. Desarrollar el control y estabilidad de la región coxolumbopélvica, con el fin de trasferir dicha estabilidad y fuerza al juego. Es el objetivo que más ha costado asimilar al sujeto, aunque como se muestra en la figura 59, el sujeto supero los resultados de los dos test anteriores y los valores de referencia expuesto por (Peña et al., 2012). En la evaluación final de la primera fase el sujeto mejorara los resultados del test inicial, figura 25, exceptuando el test modificado Biering-Sorensen que bajo su rendimiento con respecto a la evaluación inicial, posiblemente sabiendo el sujeto que le quedaban mas test por realizar ese mismo día y no se esforzó al máximo. A pesar de esta mejora en la primera fase del programa de intervención, al sujeto aún le constaba en algunos momento asimilar el concepto de triple activación en actividades planteadas fuera del trabajo coxolumbopélvico. Por este motivo a pesar de dispones de un encoder lineal y de realizar correctamente los patrones motores básicos trabajado durante la primera fase del programa de intervención, decidimos realizar el trabajo de sentadilla en polea cónica, en primer lugar sabiendo que el sujeto en Agosto se marchaba de vacaciones, para no perder un día en Julio para evaluar, en y en segundo lugar porque este tipo de dispositivo nos daba más facilidad a la hora de diseñar ejercicios en el concepto de la fuerza en 3 y 4 dimensiones propuesto por (Moras, 2015) para este patrón motor básico, como por ejemplo decirle un número y realizar más esfuerzo con una pierna como si fuera a batir para hacer una entrada a canasta.

Siguiendo en esta línea comentar que cuando observamos mejores resultados en el régimen coxolumpélvico fue cuando empezamos el trabajo multidireccional de salida frontal, lateral, de espalda y un desplazamiento defensivo en polea cónica, intentando de esta manera transferir el entrenamiento de fuerza a la lógica interna del juego. Este tipo de trabajo estaba en relación con el objetivo C, Modificar el entrenamiento clásico de pesas en gimnasio que venía realizando el sujeto hasta el comienzo del programa de intervención y orientarlo a mejorar su potencia máxima y la habilidad de repetir esta potencia (RPA), en patrones lineales press banca y sentadilla, y los multidireccional anteriormente enunciados. Podemos comentar con respecto a este objetivo que como se ha expuesto con anterioridad se observó una mejora a nivel de la región coxolumbopélvica en el sujeto figura 59, y en el CMJ se observó tanto una tendencia ascendente, figura 63 , como una mejora de la evaluación inicial, $28,848 \mathrm{~cm}$, con respecto a la final $32,637 \mathrm{~cm}$ y el mejor salto realizado en la penúltima semana $33,948 \mathrm{~cm}$. 


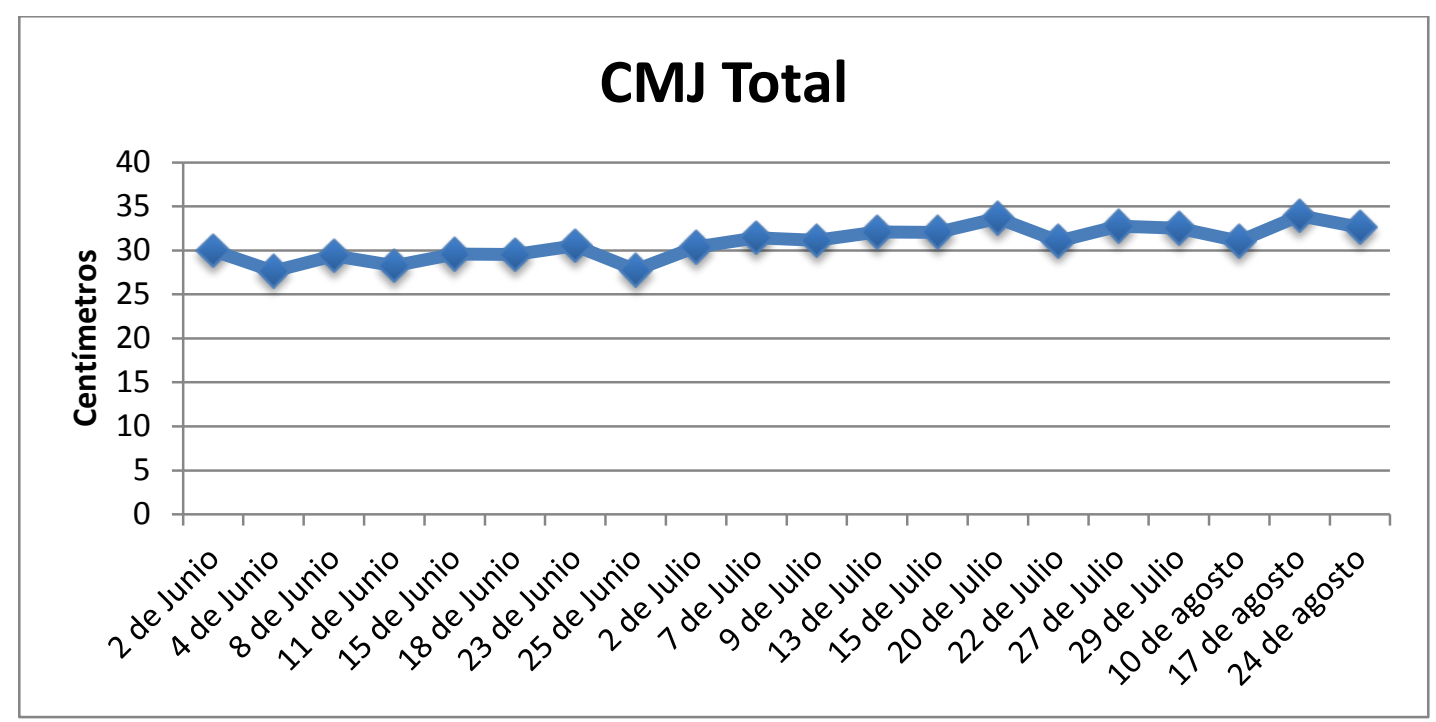

Figura 63. Monitorización y progresión del CMJ durante todo el proceso de intervención.

A su vez decir que esta mejora no la encontramos en patrones específicos como podemos comprar en la figura 58, Agility t-test de Delextrat and Cohen (2008), aunque en la segunda medición mejoro la inicial sin superar los valores de referencia, en la tercera volvió a bajar. Posiblemente deberíamos haberte tenido que intervenir según la propuesta de Moras, (2014) hasta el nivel III, técnica, y haber realizado sesiones en pista de patrones motores específicos del baloncesto, y no haber trabajado solo hasta el nivel II físico-técnico, probablemente sea una limitación en nuestro trabajo.

El objetivo D. Mejorar la tendinosis rotuliana del sujeto, podemos decir que lo hemos conseguido, como se muestra en la figura 26, el sujeto supero las molestias que tenía derivadas de una tendinosis rotuliana, y volver a remitir molestias. El sujeto como se ha mencionado con anterioridad empezó la pretemporada el día 31 de Agosto, mencionar que acude hasta el momento 30 minutos antes a la instalación para realizar los programas preventivos desarrollados durante el programa de intervención de rodilla y tobillo, siendo otro de las metas marcadas con este objetivo $\mathrm{D}$, la implantación de programas preventivo y que el sujeto sea capaza de desarrollarlo de forma autónoma una vez terminado el programa de intervención.

El objetivo E, el cual menciona la mejora de la capacidad tanto de repetir acciones de velocidad, cambios de dirección y saltos, como la recuperación entre estas acciones. Siguiendo los datos expuesto obtenidos en la figura 61, la cual muestra los resultados de la prueba de RSA de Impellizzeri et al.,( 2008a), aunque muestran resultados muy parejos el sujeto no mejora con respecto a la evaluación inicial en las dos evaluaciones posteriores. Comentar que este tipo de sesiones eran las sesiones que menos le gustaban al sujeto y donde donde mayor perceción de la fatiga y de daño muscular presentaba como se puede observar en la figura 57 y figura 64. 


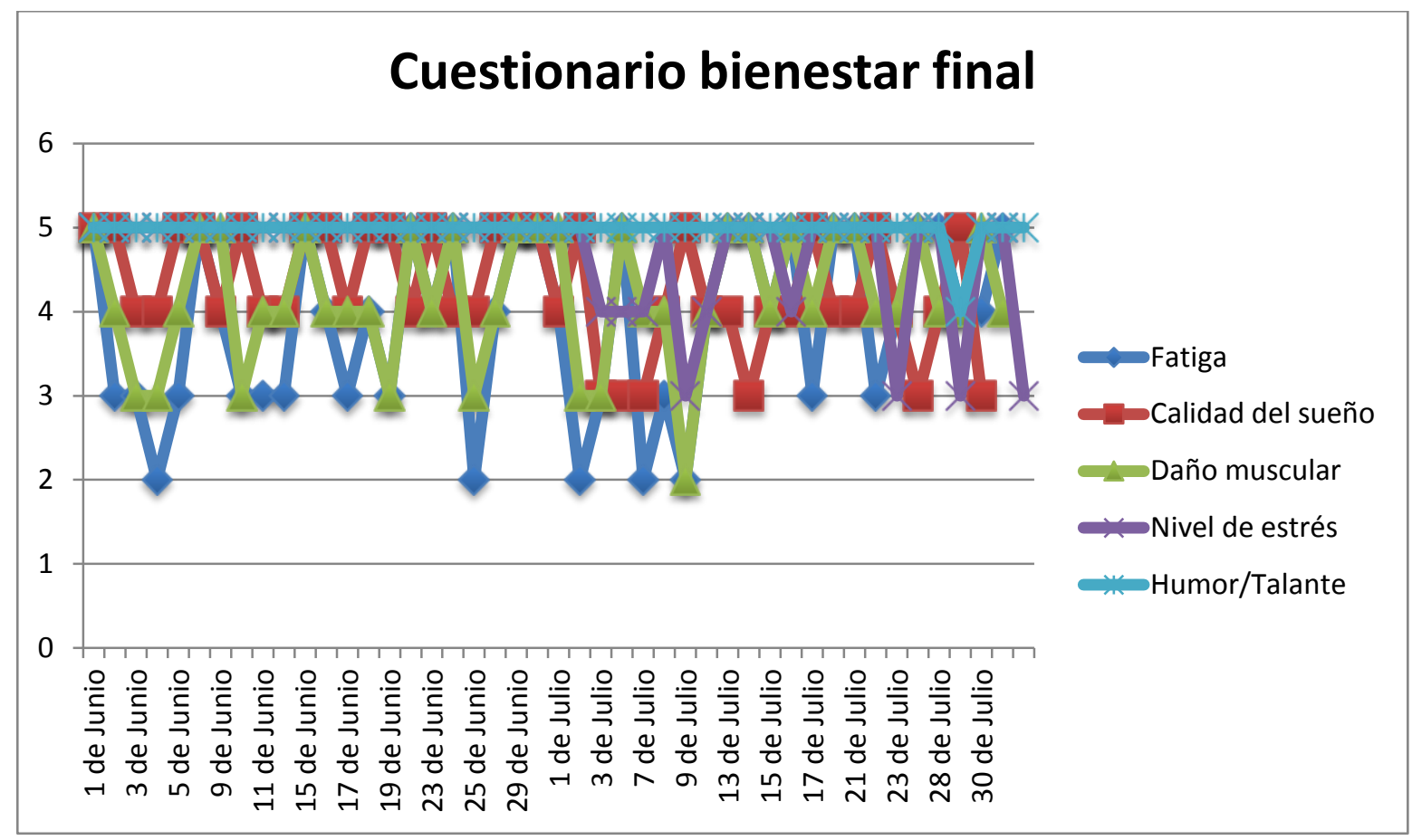

Figura 64. Monitorización durante la primera y segunda fase a partir del cuestionario de Bienestar de Bienestar de (McLean et al. (2010).

Preguntado una vez empezada la pretemporada como se encuentra cuando realiza en ejercicios específicos técnico-tacticos varias acciones continuas a una alta intensidad, y como recupera, el sujeto responde que mucho mejor que todas las pretemporadas anteriores.

Objetivo F. Mantener niveles de VO2MAX del sujeto. Observando los valores obtenidos en el test tivre basket de Vaquera et al. (2007), figura 60, midiendo la resistencia específica de baloncesto, y la capacidad de recuperación de los intervalos de esfuerzos requerido en esta modalidad deportiva, podemos decir que aunque no supera los valores de referencia Vaquera et al. (2007), el sujeto progresivamente ha ido superando los resultados que obtuvo en la evaluación inicial. 


\subsection{Puntos fuertes y débiles del programa de intervención.}

A nivel del programa de intervención encontramos las siguientes limitaciones. A pesar de tener la frecuencia cardiaca máxima real del sujeto, obtenida mediante la prueba de Yo-Yo test IR1, (Castagna, Impellizzeri, et al., 2008), tabla 26, monitorizamos todo el trabajo mediante la teórica, tabla 27.

Otra limitación al programa la encontramos en el estudio de patrones específicos del baloncesto, el análisis de los partidos visionado, para ver estudiar sus fortalezas y debilidades en el juego, lo realizamos de forma subjetiva, sin unas estructuras e ítems establecidos como expone (Anguera \& Mendo, 2015),

Comentar que con la formación que he recibido a lo largo de mi vida académica hasta el momento, no me encuentro capacitado de realizar una intervención a nivel nutricional, es por esta que no lo hemos llevado a cabo. A pesar de encontrar a nivel científico varias evaluaciones en este ámbito, cuestionario 24 horas (Mifflin et al., 1990; Sabaté, 1993), y conseguir un software para su valoración, dial, no me encontraba capacitado para emitir un juicio, es por estos motivos que a pesar de haber evaluado al sujeto en esta ámbito, no hemos ni analizado los datos obtenidos ni realizado intervención ninguna. A pesar de todo esto comentar que el sujeto ha perdido peso durante todo el programa, teniendo un peso inicial de $103 \mathrm{Kg}$ y acabando con un peso de $98 \mathrm{Kg}$.

Siguiendo en esta línea tampoco me encontraba capacitado según mi formación para realizar un análisis exhaustivo de estructuras, posturas y longitudes a nivel muscular MAT, es por esto que conté con la ayuda de un activador muscular, realizando el todas las evaluaciones previas. Una vez realizado el las valoraciones pertinentes diseñe el programa de intervención según los resultados obtenidos derivados de su estudio. 


\subsection{Limitaciones y dificultades.}

Uno de los puntos fuertes de nuestro programa de intervención posiblemente sea la disponibilidad en cuanto a instalación y material que hemos tenido durante todo el proceso, pues pocos compañeros han tenido la suerte de poder disfrutar de una sala casa en exclusividad para realizar el la intervención con sus sujetos, con polea cónica, plataforma de salto, encoder lineal, etc. A su vez pudimos realizar sesiones también en pista y agua dentro de la instalación.

Otro punto fuerte, a mi parecer es el gran análisis que se ha llevado a cabo de lo que consta hasta el momento en la literatura científica y su aplicación en las sesiones de entrenamiento.

La mayor debilidad que le encuentro a la intervención, es que la tercera fase del programa la realizamos de forma no presencial ya que el sujeto se marcho de vacaciones, la segunda semana del mes de Agosto, llegando el domingo 30. A sus vez con motivo de lo expuesto, y la iniciación de la pretemporada del equipo del entrenado, el Lunes 31 de Agosto, y la nula predisposición por parte del entrenador al que al sujeto le pudiera realizar una tercera evaluación para observar sus avances o regresiones obtenida en esta tercera parte del programa de intervención. Aun así intentamos anticiparnos a lo que pudiera ocurrir, pues hasta mitad de Agosto no supimos la negativa del entrenador a que valoráramos una tercera vez al sujeto en periodo de pretemporada, e intuyendo durante la planificación de este periodo no presencial lo que podía ocurrir, buscamos otros recursos como la escala TQR (Kentta \& Hassmen, 1998), figura 56, la aplicación de móvil My Jumps, BalsalobreFernandez et al. (2015), figura 55, y seguimos con el control del las carga de entrenamiento de Foster et al., (2001), figura 54, para poder tener datos de comparación entre las tres fases.

Por último comentar, aunque sea a nivel subjetivo, preguntado al sujeto durante los primeros días de pretemporada por cómo se encontraba a nivel de molestias de lesiones anteriores y a nivel condicional como estaba asimilando estaba asimilando el trabajo realizados durante estos primeros días de pretemporada, siendo su contestación muy positiva en ambos casos, podríamos considera esto como otro punto fuerte en nuestro programa de intervención, ya que nuestro trabajo se desarrollo durante el periodo transitorio. 


\subsection{Posibles soluciones y alternativas.}

La solución a las limitaciones del apartado anterior, desde mi perspectiva pasa por dos vías, una primera de formación continua pero teniendo siempre en cuenta cuáles son nuestras competencia y hasta donde podemos llegar, y una segunda siguiendo en esta línea de tener siempre a nuestro lado un equipo multidisciplinar para poder derivar tanto ellos como nosotros una vez que superen nuestros conocimientos y competencias, y a su vez enriqueciendo el proceso de entrenamiento y readaptación de nuestros sujetos.

En cuanto a las limitaciones encontradas en puntos anteriores como el visionado de video de forma subjetiva, intentaríamos utilizar para subsanar este error una de las propuesta de Anguera and Mendo (2015), con ítems categorizados y estructurados, a su vez la utilización de la frecuencia cardiaca máxima debería ser la real ya que la tenemos y no la teórica.

Para terminar la monitorización del dolor, mediante la escala visual analógica seria mediante la imagen presentada en la figura 65, consistiendo en una línea de $10 \mathrm{~cm}$ con un extremo marcado con "nada de dolor" y el otro "el peor dolor imaginable", donde el sujeto marca en la línea el punto que mejor describe la intensidad del dolor, no la escala de dolor presente en el anexo 14, que fue utilizada.

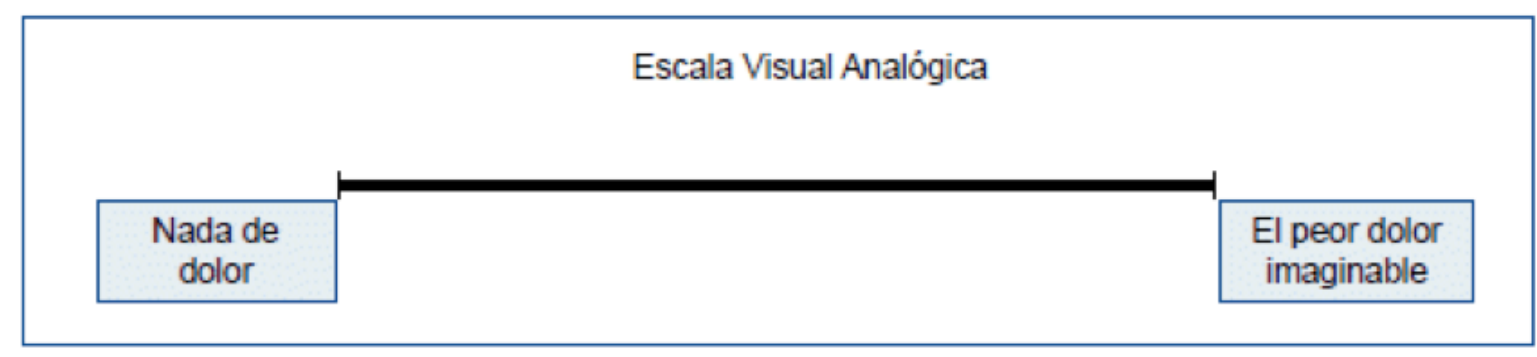

Figura 65. Escala visual analógica, extraída de http://fisioterapiasinred.com/wpcontent/uploads/2012/11/eva.png. 


\section{CONCLUSIONES.}

Como conclusión final a la intervención llevada a cabo con el sujeto podríamos concluir que hemos conseguido los objetivos generales, readaptar patrones de movimientos básicos (objetivo A), mejorar la región coxolumbopélvica (objetivo B) y modificar el entrenamiento de fuerza (objetivo C) que tenía el sujeto antes de empezar la intervención, obteniendo una mejora en la fuerza explosiva en los miembros inferiores como se muestra en la figura 62.

El objetivo secundario mejorar la recuperación del sujeto en el trabajo de RSA (objetivo E) no fue conseguido, aunque se obtuvieron valores muy cercanos en la evaluación final a la inicial, figura 61, los otros objetivos secundarios implantar programas preventivos (objetivo D), mantener los niveles de VO2MAX (objetivo F) y recuperar al sujeto de la tendinosis (objetivo G), fueron alcanzados.

A nivel del sujeto, aunque no se alcanzaran todos los objetivos y haber evaluado las posibles causas, me quedo con la valoración del sujeto una vez que ha empezado a entrenar con su equipo, comentando que nunca había tenido tan buenas sensaciones en una pretemporada a nivel condicional, teniendo una buena recuperación entre entrenamientos y sobre todo sin molestias. También me quedo con la continuidad de los programas preventivos que le hemos desarrollado al sujeto y que sigue realizando de forma autónoma antes de los entrenamientos.

A nivel personal, he de reconocer que no han sido dos años fáciles tanto a nivel laboral, cosa que me ha quitado mucho tiempo para desarrollar el TFM, como a nivel personal. Aun así y a pesar de la distancia con respecto a mi domicilio, Huelva, ya que iba y venía todos los fines de semana, la difícil compaginación con mi trabajo y algunos inconveniente más, si tuviera la oportunidad de realizar otra vez el Máster lo haría sin ninguna duda, por todo lo vivido y aprendido durante aquel año. 


\section{LÍNEAS FUTURAS DE INTERVENCIÓN.}

En un primer lugar sería dar continuidad a los puntos fuertes del programa de intervención implantado y que han producido mejora en el sujeto, como la metodología utilizado en el trabajo de fuerza o los programas preventivos utilizados.

Como he comentado en puntos anteriores, y una vez superado ya el periodo transitorio y adentrándonos en la temporada, sería fundamental realizar un volumen más amplios de trabajo de patrones motores específicos de baloncesto en pista.

A su vez me parece fundamental después de lo evaluado y de conocer un poco más las debilidades del sujeto por el trabajo realizado con el diariamente durante dos meses, la reprogramación de patrones de movimientos específicos de la técnica de carrera, siguiendo la propuesta presentada por Martínez (2014):

- Lineal, hacia delante:

- Velocidad absoluta.

- Aceleración.

- Deceleración.

- Lineal, hacia atrás:

- Backpedal.

- Deceleración.

- Lateral:

- Shuffle.

- Cutting.

- Rotacional:

- Crossover.

- Open step.

- Drop step. 


\section{BIBLIOGRAFÍA}

Agel, J., Olson, D. E., Dick, R., Arendt, E. A., Marshall, S. W., \& Sikka, R. S. . (2007). Descriptive epidemiology of collegiate women's basketball injuries: National Collegiate Athletic Association Injury Surveillance System, 1988-1989 through 2003-2004. Journal of athletic training, 42(2), 202.

Akuthota, V., Ferreiro, A., Moore, T., \& Fredericson, M. (2008). Core stability exercise principles. Current sports medicine reports, 7(1), 39-44.

Alfredson, H. (2005). The chronic painful Achilles and patellar tendon: research on basic biology and treatment. Scand J Med Sci Sports, 15(4), 252-259. doi: 10.1111/j.16000838.2005.00466.x

Alkner, B. A., \& Tesch, P. A. (2004). Knee extensor and plantar flexor muscle size and function following 90 days of bed rest with or without resistance exercise. Eur J Appl Physiol, 93(3), 294-305. doi: Doi 10.1007/S00421-004-1172-8

Anguera, M. T., \& Mendo, A. H. . (2015). Técnicas de análisis en estudios observacionales en ciencias del deporte. Cuadernos de psicología del deporte, 15(1), 13-30.

Arnason, A., Sigurdsson, S. B., Gudmundsson, A., Holme, I., Engebretsen, L., \& Bahr, R. (2004). Risk factors for injuries in football. Am J Sports Med, 32(1 Suppl), 5S-16S.

Badillo, J. J. G., \& Ayestarán, E. G. . (2002). Fundamentos del entrenamiento de la fuerza: Aplicación al alto rendimiento deportivo (Vol. 302). Inde.

Baechle, T. R. . (2004). NSCA's Essentials of Personal Training: National Strength and Conditioning Association.

Balsalobre-Fernandez, C., Glaister, M., \& Lockey, R. A. (2015). The validity and reliability of an iPhone app for measuring vertical jump performance. J Sports Sci, 33(15), 1574-1579. doi: 10.1080/02640414.2014.996184

Balsalobre-Fernández, C., Nevado-Garrosa, F., del Campo-Vecino, J., \& Ganancias-Gómez, P. . (2015). Repetición de esprints y salto vertical en jugadores jóvenes de baloncesto y fútbol de élite. Apunts. Educación física y deportes, 2(120), 52-57.

Bangsbo, J., laia, F. M., \& Krustrup, P. (2008). The Yo-Yo intermittent recovery test : a useful tool for evaluation of physical performance in intermittent sports. Sports Med, 38(1), 37-51.

Bautista, I. J., Chirosa, I. J., Robinson, J. E., Chirosa, L. J., \& Martín, I. M. . (2015). Concurrent validity of a perception velocity scale to monitor to monitor squat exercise intensity in young skiers Journal of strength and conditioning research/National Strength \& Conditioning Association.

Beardsley, C., \& Contreras, B. . (2014). The Functional Movement Screen: A Review. Strength \& Conditioning Journal, 36(5), 72-80.

Bennasar, I. (2015). II Congreso internacional de optimización del entrenamiento y readaptación físico-deportiva. Paper presented at the Análisis de difunciones del movimiento en prevención de lesiones de sobreuso, Sevilla.

Bompa, T. O. . (2006). Periodización del entrenamiento deportivo. Editorial Paidotribo, Vol. 24.

Borowski, L. A., Yard, E. E., Fields, S. K., \& Comstock, R. D. (2008). The epidemiology of US high school basketball injuries, 2005-2007. Am J Sports Med, 36(12), 2328-2335. doi: $10.1177 / 0363546508322893$

Buceta, J. M. (1998). . (1998). Psicología del entrenamiento deportivo.

Cano de la Cuerda, R., Molero-Sánchez, A., Carratalá-Tejada, M., Alguacil-Diego, I. M., Molina Rueda, F., Miangolarra-Page, J. C., \& Torricelli, D. . (2012). Teorías y modelos de control y aprendizaje motor. Aplicaciones clínicas en neurorrehabilitación. Neurología.

Castagna, C., Abt, G., Manzi, V., Annino, G., Padua, E., \& D'Ottavio, S. (2008). Effect of recovery mode on repeated sprint ability in young basketball players. J Strength Cond Res, 22(3), 923-929. doi: 10.1519/JSC.0b013e31816a4281 
Castagna, C., Impellizzeri, F. M., Rampinini, E., D'Ottavio, S., \& Manzi, V. . (2008). The Yo-Yo intermittent recovery test in basketball players. Journal of Science and Medicine in Sport, 11(2), 202-208.

Castagna, C., Manzi, V., D'Ottavio, S., Annino, G., Padua, E., \& Bishop, D. (2007). Relation between maximal aerobic power and the ability to repeat sprints in young basketball players. The Journal of Strength \& Conditioning Research, 21(4), 1172-1176.

Chéron, G. . (2011). Neurofisiología del movimiento. Aprendizaje motor. EMC-KinesiterapiaMedicina Física, 32(4), 1-10.

Chiu, L. Z., \& Salem, G. J. (2006). Comparison of joint kinetics during free weight and flywheel resistance exercise. J Strength Cond Res, 20(3), 555-562. doi: 10.1519/R-18245.1

Conde, J. (2014). Entrenamiento del Core Apuntes master propio en entrenamiento personal: Universidad de Granada.

Contreras, M., Laguado, M. J., \& Hermoso, V. S. (2013). EVALUACION DE LA ASIMETRÍA BILATERAL EN EL SALTO VERTICAL CON CONTRAMOVIMIENTO EN SUJETOS CON ACTIVIDAD FISICA FEDERADA, AFICIONADA Y SEDENTARIA. Cuidado y Ocupación Humana, 1(1).

Cook, G. . (2010). Movement: Functional movement systems: Screening, assessment, corrective strategies.

Cook, G., Burton, L., \& Hoogenboom, B. (2006a). Pre-participation screening: the use of fundamental movements as an assessment of function-part 1. North American journal of sports physical therapy: NAJSPT, 1(2), 62-72.

Cook, G., Burton, L., \& Hoogenboom, B. . (2006b). Pre-participation screening: The use of fundamental movements as an assessment of function-Part 2. North American journal of sports physical therapy: NAJSPT, 1(3), 132-139.

Cormack, S. J., Newton, R. U., McGuigan, M. R., \& Cormie, P. (2008). Neuromuscular and endocrine responses of elite players during an Australian rules football season. Int $J$ Sports Physiol Perform, 3(4), 439-453.

Cormie, P., \& Flanagan, S. P. (2008). Does an Optimal Load Exist for Power Training? Strength and Conditioning Journal, 30(2), 67-69. doi: Doi 10.1519/Ssc.0b013e31816a8776

Cruz, J. R. A., Armesilla, M. D. C., \& De Lucas, A. H. (2009). Protocolo de valoración de la composición corporal para el reconocimiento médico-deportivo. Documento de consenso del grupo español de cineantropometría de la federación española de medicina del deporte. Archivos de medicina del deporte: revista de la Federación Española de Medicina del Deporte y de la Confederación Iberoamericana de Medicina del Deporte, 131, 166-179.

Delextrat, A., \& Cohen, D. . (2008). Physiological testing of basketball players: toward a standard evaluation of anaerobic fitness. The Journal of Strength \& Conditioning Research, 22(4), 1066-1072.

Dias, G., Martens, F. M. L., Couceiro, M. S., Clemente, F. M., \& Mendes, R. (2014). A Non-Linear Understanding of Golf Putting. South African Journal for Research in Sport Physical Education and Recreation, 36(1), 29-47.

Dick, R., Hertel, J., Agel, J., Grossman, J., \& Marshall, S. W. . (2007). Descriptive epidemiology of collegiate men's basketball injuries: National Collegiate Athletic Association Injury Surveillance System, 1988-1989 through 2003-2004. Journal of athletic training, 42(2), 194.

Domingo, J., Arias, J. A. R., Martínez, F., García, P. E., \& Jiménez, J. F. . (2010). Características fisiológicas, podológicas y somatométricas del jugador profesional de baloncesto. Archivos de medicina del deporte: revista de la Federación Española de Medicina del Deporte y de la Confederación Iberoamericana de Medicina del Deporte, 136, 84-94.

Duffield, R., Murphy, A., Snape, A., Minett, G. M., \& Skein, M. (2012). Post-match changes in neuromuscular function and the relationship to match demands in amateur rugby league matches. J Sci Med Sport, 15(3), 238-243. doi: 10.1016/j.jsams.2011.10.003 
F., Drobnic, J., Puigdellivol, \& T., Bové. (2009). Bases científicas para la salud y un óptimo rendimiento en Baloncesto.

Fernández, E. M. A., Río, G. L., \& Fernández, C. A. . (2007). Propiedades psicométricas de la versión española del Inventario de Ansiedad Competitiva CSAI-2R en deportistas. Psicothema, 19(1), 150-155.

Fernandez-Berrocal, P. , Extremera, N., \& Ramos, N. . (2004). VALIDITY AND RELIABILITY OF THE SPANISH MODIFIED VERSION OF THE TRAIT META-MOOD SCALE 1, 2. Psychological reports, 94(3), 751-755.

Fernandez-Gonzalo, R., Lundberg, T. R., Alvarez-Alvarez, L., \& de Paz, J. A. (2014). Muscle damage responses and adaptations to eccentric-overload resistance exercise in men and women. Eur J Appl Physiol, 114(5), 1075-1084. doi: 10.1007/s00421-014-2836-7

Flood, L., \& Harrison, J. E. . (2009). Epidemiology of basketball and netball injuries that resulted in hospital admission in Australia, 2000-2004. Medical Journal of Australia, 190(2), 87.

Foster, C., Florhaug, J. A., Franklin, J., Gottschall, L., Hrovatin, L. A., Parker, S., . . Dodge, C. (2001). A new approach to monitoring exercise training. J Strength Cond Res, 15(1), 109-115.

Fredberg, U., Bolvig, L., \& Andersen, N. T. (2008). Prophylactic Training in Asymptomatic Soccer Players With Ultrasonographic Abnormalities in Achilles and Patellar Tendons The Danish Super League Study. Am J Sports Med, 36(3), 451-460.

Frost, D. M., Beach, T. A. C., Callaghan, J. P., \& McGill, S. M. (2012). Using the Functional Movement Screen $(\mathrm{Tm})$ to Evaluate the Effectiveness of Training. Journal of Strength and Conditioning Research, 26(6), 1620-1630. doi: Doi 10.1519/Jsc.0b013e318234ec59

García, C. B. , Melero, M. P. T., \& Salas, A. V. . (2005). La Inteligencia Emocional en alumnos de Magisterio: La percepción y comprensión de los sentimientos y las emociones. . Revista interuniversitaria de formación del profesorado, 54, 169-194.

Gonzalez-Badillo, J. J., \& Sanchez-Medina, L. (2010). Movement velocity as a measure of loading intensity in resistance training. Int J Sports Med, 31(5), 347-352. doi: 10.1055/s-0030-1248333

Gutiérrez Calvo, M., García Pérez, J., Pérez Hernández, H., \& Estévez, A. . (1997). Ansiedad y rendimiento atlético en condiciones de estrés: efectos moduladores de la práctica. Revista de Psicología del Deporte, 6, 27-46.

Hamming, B. J., Yang, H. W., \& Bensema, B. (2007). Epidemiology of basketball injuries among adults presenting to ambulatory care settings in the United States. Clinical Journal of Sport Medicine, 17(6), 446-451.

Hauschildt, M., McQueen, B., \& Stanford, G. (2014). The Core Mobility Series: A Dynamic Warm-up Tool. Strength \& Conditioning Journal, 36(5), 81-87.

Impellizzeri, F. M., Rampinini, E., Castagna, C., Bishop, D., Ferrari Bravo, D., Tibaudi, A., \& Wisloff, U. (2008a). Validity of a repeated-sprint test for football. Int I Sports Med, 29(11), 899-905. doi: 10.1055/s-2008-1038491

Impellizzeri, F. M., Rampinini, E., Castagna, C., Bishop, D., Ferrari Bravo, D., Tibaudi, A., \& Wisloff, U. . (2008b). Validity of a repeated-sprint test for football. Int J Sports Med, 29(11), 899-905.

Impellizzeri, F. M., Rampinini, E., Maffiuletti, N., \& Marcora, S. M. (2007). A vertical jump force test for assessing bilateral strength asymmetry in athletes. Med Sci Sports Exerc, 39(11), 2044-2050. doi: 10.1249/mss.0b013e31814fb55c

Jiménez-Reyes, P., \& González-Badillo, J. J. . (2011). Control de la carga de entrenamiento a través del $\mathrm{CMJ}$ en pruebas de velocidad y saltos para optimizar el rendimiento deportivo en atletismo.(Monitoring training load through the $\mathrm{CMJ}$ in sprints and jump events for optimizing performance in athletics). CCD. Cultura_Ciencia_Deporte., 6(18), 207-217.

Kannus, P. (1997). Etiology and pathophysiology of chronic tendon disorders in sports. Scand J Med Sci Sports, 7(2), 78-85. 
Karvonen, M. J., Kentala, E., \& Mustala, O. (1957). The effects of training on heart rate; a longitudinal study. Ann Med Exp Biol Fenn, 35(3), 307-315.

Kenney, W. L., Wilmore, J., \& Costill, D. . (1999). Physiology of sport and exercise with web study guide.

Kentta, G., \& Hassmen, P. (1998). Overtraining and recovery. A conceptual model. Sports Med, 26(1), 1-16.

Khan, K. M., Cook, J. L., Bonar, F., Harcourt, P., \& Åstrom, M. . (1999). Histopathology of common tendinopathies. Sports Medicine, 27(6), 393-408.

Langberg, H., \& Kongsgaard, M. . (2008). Eccentric training in tendinopathy-more questions than answers. Scandinavian journal of medicine \& science in sports, 18(5), 541-542.

Lavie, C. J., Milani, R. V., \& Ventura, H. O. (2009). Obesity and cardiovascular disease: risk factor, paradox, and impact of weight loss. J Am Coll Cardiol, 53(21), 1925-1932. doi: 10.1016/j.jacc.2008.12.068

López, M. C. , Arias, J. L., Marín, P. G. , \& Yuste, J. L. (2014). Time-Motion Analysis Procedure in Team Sports: Example for Youth Basketball. Strength \& Conditioning Journal, 36(3), 7175.

MacDonald, G. Z., Penney, M. D., Mullaley, M. E., Cuconato, A. L., Drake, C. D. , Behm, D. G., \& Button, D. C. . (2013). An acute bout of self-myofascial release increases range of motion without a subsequent decrease in muscle activation or force. The Journal of Strength \& Conditioning Research, 27(3), 812-821.

Maffulli, N., Sharma, P., \& Luscombe, K. L. (2004). Achilles tendinopathy: aetiology and management. J R Soc Med, 97(10), 472-476. doi: 10.1258/jrsm.97.10.472

Mafi, N., Lorentzon, R., \& Alfredson, H. (2001). Superior short-term results with eccentric calf muscle training compared to concentric training in a randomized prospective multicenter study on patients with chronic Achilles tendinosis. Knee Surg Sports Traumatol Arthrosc, 9(1), 42-47.

Manzi, V., Bovenzi, A., Impellizzeri, M. F., Carminati, I., \& Castagna, C. (2013). Individual Training-Load and Aerobic-Fitness Variables in Premiership Soccer Players during the Precompetitive Season. Journal of Strength and Conditioning Research, 27(3), 631-636. doi: 10.1519/JSC.0b013e31825dbd81

Marins, J. C. B., Marins, N. M. O., \& Fernández, M. D. . (2010). Aplicaciones de la frecuencia cardiaca máxima en la evaluación y prescripción de ejercicio. Apunts. Medicina de I'Esport, 45(168), 251-258.

Martínez, D. (2014). Reprogramación de patrones motores Apuntes curso reprogramación de patrones motores: Zeebra academy.

Mascaró, A. (2014). Mecanotransducción y Entrenamiento neuromuscular: Tendón Apuntes master propio en entrenamiento persona: Universidad de Granada.

McGill, S. (2010). Core Training: Evidence Translating to Better Performance and Injury Prevention. Strength and Conditioning Journal, 32(3), 33-46. doi: Doi 10.1519/Ssc.0b013e3181df4521

McGill, S. M., Childs, A., \& Liebenson, C. (1999). Endurance times for low back stabilization exercises: clinical targets for testing and training from a normal database. Arch Phys Med Rehabil, 80(8), 941-944.

McInnes, S. E., Carlson, J. S., Jones, C. J., \& McKenna, M. J. . (1995). The physiological load imposed on basketball players during competition. J Sports Sci, 13(5), 387-397.

McLean, B. D., Coutts, A. J., Kelly, V., McGuigan, M. R., \& Cormack, S. J. (2010). Neuromuscular, endocrine, and perceptual fatigue responses during different length between-match microcycles in professional rugby league players. Int J Sports Physiol Perform, 5(3), 367-383.

Mifflin, M. D., St Jeor, S. T., Hill, L. A., Scott, B. J., Daugherty, S. A., \& Koh, Y. O. . (1990). A new predictive equation for resting energy expenditure in healthy individuals. Am J Clin Nutr, 51(2), 241-247. 
Moras, G. (2014a). Diseño de programas de entrenamiento a través de los niveles de aproximación Apuntes master propio en entrenamiento persona: Universidad de Granada.

Moras, G. (2014b). Nuevas tendencias y herramientas en el entrenamiento de la fuerza Apuntes master propio en entrenamiento persona: Universidad de Granada.

Moras, G. (2015). Il Congreso internacional de optimización del entrenamiento y readaptación físico-deportiva. Paper presented at the La fuerza 3D-4D en los deportes colectivos, Sevilla.

Moras, G., Rodriguez-Jimenez, S., Tous-Fajardo, J., Ranz, D., \& Mujika, I. (2010). A vibratory bar for upper body: feasibility and acute effects on EMGrms activity. J Strength Cond Res, 24(8), 2132-2142. doi: 10.1519/JSC.0b013e3181aa3684

Norrbrand, L., Fluckey, J. D., Pozzo, M., \& Tesch, P. A. (2008). Resistance training using eccentric overload induces early adaptations in skeletal muscle size. Eur J Appl Physiol, 102(3), 271-281. doi: Doi 10.1007/S00421-007-0583-8

Onambele, G. L., Maganaris, C. N., Mian, O. S., Tam, E., Rejc, E., McEwan, I. M., \& Narici, M. V. (2008). Neuromuscular and balance responses to flywheel inertial versus weight training in older persons. J Biomech, 41(15), 3133-3138. doi: 10.1016/j.jbiomech.2008.09.004

Opar, D. A., Williams, M. D., \& Shield, A. J. (2012). Hamstring strain injuries: factors that lead to injury and re-injury. Sports Med, 42(3), 209-226. doi: 10.2165/11594800-00000000000000

Ozolin, N. G. (1995). Sistema contemporáneo de entrenamiento deportivo.

Panjabi, M. M. (1992). The stabilizing system of the spine. Part I. Function, dysfunction, adaptation, and enhancement. J Spinal Disord, 5(4), 383-389; discussion 397.

Pappas, E., Zazulak, B. T., Yard, E. E., \& Hewett, T. E. (2011). The Epidemiology of Pediatric Basketball Injuries Presenting to US Emergency Departments: 2000-2006. Sports Health, 3(4), 331-335. doi: 10.1177/1941738111409861

Pauole, K., Madole, K., Garhammer, J., Lacourse, M., \& Rozenek, R. (2000). Reliability and validity of the T-test as a measure of agility, leg power, and leg speed in college-aged men and women. Journal of Strength and Conditioning Research, 14(4), 443-450.

Peña, G., Elvar, J. R. H., Moral, S., Donate, F. I., \& Mata, F. . (2012). Revisión de los Métodos de Valoración de la Estabilidad Central (Core). G-SE.

Reed, C. A., Ford, K. R., Myer, G. D., \& Hewett, T. E. (2012). The Effects of Isolated and Integrated 'Core Stability' Training on Athletic Performance Measures A Systematic Review. Sports Med, 42(8), 697-706.

Romero Rodriguez, D., \& Tous Fajardo, J. . (2011). Prevención de lesiones en el deporte. Claves para un rendimiento deportivo óptimo.

Romero-Rodriguez, D., Gual, G., \& Tesch, P. A. (2011). Efficacy of an inertial resistance training paradigm in the treatment of patellar tendinopathy in athletes: a case-series study. Phys Ther Sport, 12(1), 43-48. doi: 10.1016/j.ptsp.2010.10.003

Sabaté, J. . (1993). Estimación de la ingesta dietética: métodos y desafíos. Med Clin (Barc), 100, 591-596.

Sahrmann, S. . (2002). Diagnosis and treatment of movement impairment syndromes.

Sammarco, V. J. . (2003a). Principles and Techniques in Rehabilitation of the Athlete's Foot: Part II-Rehabilitation of Tendon Injuries. Techniques in Foot \& Ankle Surgery, 2(2), 144-150.

Sammarco, V. J. . (2003b). Principles and Techniques in Rehabilitation of the Athlete's Foot: Part III: Rehabilitation of Ankle Sprains. Techniques in Foot \& Ankle Surgery, 2(3), 199207.

Sammarco, V. J., \& Sammarco, G. J. (2003). Principles and techniques in rehabilitation of the athlete's foot: part I-introduction of concepts and achilles' tendon rehabilitation. Techniques in Foot \& Ankle Surgery, 2(1), 51-60. 
Sanchez-Medina, L., \& Gonzalez-Badillo, J. J. (2011). Velocity loss as an indicator of neuromuscular fatigue during resistance training. Med Sci Sports Exerc, 43(9), 17251734. doi: $10.1249 / \mathrm{MSS} .0 \mathrm{~b} 013 \mathrm{e} 318213 \mathrm{f} 880$

Sandmeier, R., \& Renstrom, P. A. (1997). Diagnosis and treatment of chronic tendon disorders in sports. Scand J Med Sci Sports, 7(2), 96-106.

Schelling, X. (2012). Exigencia en baloncesto: carga externa e interna. Deportes, salud y entrenamiento, 11, 6-23.

Schelling, X., \& Torres-Ronda, L. (2013). Conditioning for Basketball: Quality and Quantity of Training. Strength and Conditioning Journal, 35(6), 89-94.

Schoenfeld, B. (2013). Strategies for Optimal Core Training Program Design. nsca's performance training journal, 10(5), 20-24.

Schutte, N. S. , Malouff, J. M., Hall, L. E., Haggerty, D. J., Cooper, J. T., Golden, C. J., \& Dornheim, L. . (1998). Development and validation of a measure of emotional intelligence. Personality and individual differences, 25(2), 167-177.

Sola, A., \& Valdivieso, Y. (2013). El fútbol y el trabajo en el medio acuático. Futbolpf: Revista de Preparacion física en el Futbol(1), 1-11.

Souchard, P. E. . (2008). Stretching Global Activo I (Vol. 1).

Spencer, M., Bishop, D., Dawson, B., \& Goodman, C. (2005). Physiological and metabolic responses of repeated-sprint activities:specific to field-based team sports. Sports Med, 35(12), 1025-1044.

Stojanovic, M. D., Ostojic, S. M., Calleja-Gonzalez, J., Milosevic, Z., \& Mikic, M. (2012). Correlation between explosive strength, aerobic power and repeated sprint ability in elite basketball players. J Sports Med Phys Fitness, 52(4), 375-381.

Suni, J., Husu, P. , \& Rinne, M. (2010). Fitness for health: the ALPHA-FIT test battery for adults aged 18-69. DG Sanco, European Union \& UKK Institute for health Promotion Research, Tampere, Finland.

Tanaka, H., Monahan, K. D., \& Seals, D. R. (2001). Age-predicted maximal heart rate revisited. J Am Coll Cardiol, 37(1), 153-156.

Terrados, N. , \& Calleja, J. . (2008). Fisiología, entrenamiento y medicina del baloncesto.

Torres, R., Ribeiro, F., Duarte, J. A., \& Cabri, J. M. H. (2012). Evidence of the physiotherapeutic interventions used currently after exercise-induced muscle damage: Systematic review and meta-analysis. Physical Therapy in Sport, 13(2), 101-114. doi: Doi 10.1016/J.Ptsp.2011.07.005

Torres-Ronda, L., \& Schelling i del Alcázar, X. . (2014). The Properties of Water and their Applications for Training. J Hum Kinet, 44(1), 237-248.

Toscano, J. , \& Campos, M. . (2015). Monitorización de la carga de entrenamiento, la condición física, la fatiga y el rendimiento durante el microciclo de competición en fútbol Futbolpf: Revista de Preparacion física en el Futbol(12), 23-36.

Tous, J. (2014). Diseño de programas avanzado del entrenamiento para la mejora de la fuerza. RPA, excéntrico y vibratorio Apuntes master propio en entrenamiento persona: Universidad de Granada.

Tous, J. . (1999). Nuevas tendencias en fuerza y musculación.

Twist, C., \& Highton, J. (2013). Monitoring fatigue and recovery in rugby league players. Int J Sports Physiol Perform, 8(5), 467-474.

Vaquera, A. , Morante, J. C., \& García - López, J. . (2007). Diseño y aplicación del test de campo TIVRE-Basket para la valoración de la resistencia aeróbica del jugador de baloncesto. Motricidad, 18, 19-40.

Vera-García, F. J., Barbado, D., Moreno-Pérez, V., Hernández-Sánchez, S., Juan-Recio, C., \& Elvira, J. L. L. . (2015). Core stability. Concepto y aportaciones al entrenamiento y la prevención de lesiones. Revista Andaluza de Medicina del Deporte, 8(2), 79-85. 
Wasielewski, N. J., \& Kotsko, K. M. (2007). Does eccentric exercise reduce pain and improve strength in physically active adults with symptomatic lower extremity tendinosis? A systematic review. Journal of athletic training, 42(3), 409-421.

Weinberg, R. S. . (2010). Fundamentos De Psicologia Del Deporte Y Del Ejercicio Fisico.

wist, C., Waldron, M., Highton, J., Burt, D., \& Daniels, M. (2012). Neuromuscular, biochemical and perceptual post-match fatigue in professional rugby league forwards and backs. . J Sports Sci, 30(4), 359-367.

Xu, Y. H., \& Murrell, G. A. C. (2008). The basic science of tendinopathy. Clinical Orthopaedics and Related Research, 466(7), 1528-1538. doi: Doi 10.1007/S11999-008-0286-4 


\section{ANEXOS}

Anexo 1.

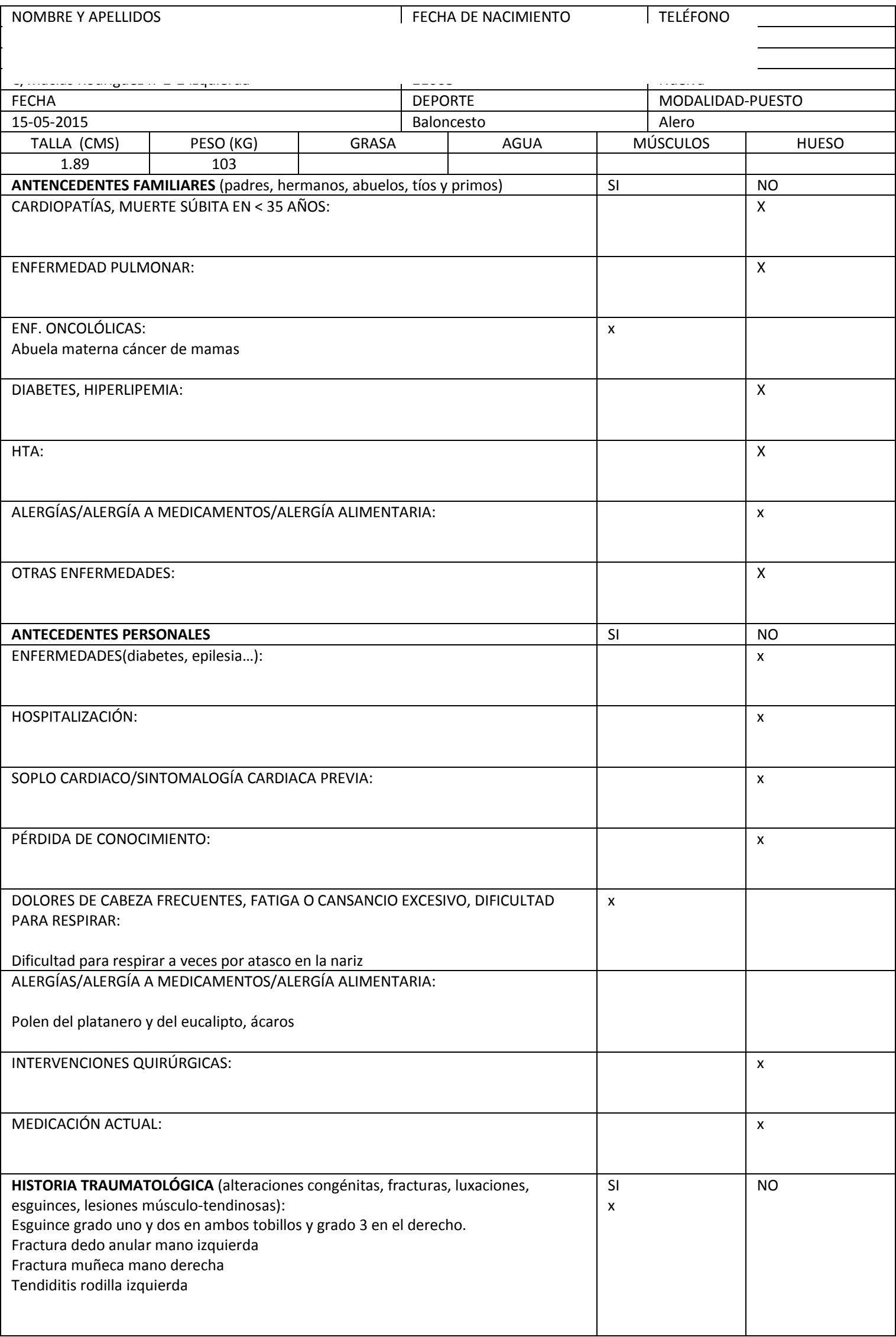




\begin{tabular}{|l|l|l|}
\hline & & \\
\hline HÁBITOS HIGÉNICO-DIETÉTICO (alcohol, café, tabaco) & $\mathrm{SI}$ & NO \\
\hline Alcohol & & \\
\hline HORAS DE SUEÑO & $9+0$ \\
\hline INGESTA DE LÍQUIDOS EN LITROS & 2 litros diarios \\
\hline NÚMEROS DE COMIDAS AL DÍA & 3 comidas sin desayuno \\
\hline
\end{tabular}




\section{Anexo 2.}

1. ¿Qué necesita el jugador para ser mejor dentro de la lógica del juego?

Desarrollar el control emocional y conducir su impulsividad trasladando la energía gastada en los agentes externos a los factores internos relacionados directamente con lo estrictamente deportivo. Ganar en musculatura, tanto de tren superior como inferior. Mejorar sus acciones de tiro de media distancia y tiro libre.

2. Función táctica en el equipo

Su función principal es la defensiva, sobre todo, de jugadores no catalogables en posiciones de 3-4. Dar equilibrio a la defensa, compensando las dificultades de otros compañeros y potenciando la agresividad e intensidad defensiva conjunta. Ayuda al rebote tanto defensivo como ofensivo

3. Puntos fuertes y débiles en el juego

Sus principales puntos fuertes son la defensa individual, la capacidad de sacrificio, la facilidad reboteadora y los movimientos en ataque tanto de cara como de espalda en distancias cortas.

Lee muy bien las primeras y segundas ayudas.

Su principal punto débil es el tiro libre, la velocidad de ejecución y el control de emociones.

4. Gesto es lo que crees que es lento el jugador y debe mejorar

Penetraciones y arrancadas

5. Que consideras clave para su rendimiento en el juego

Mejora del tiro libre y de media distancia, la rapidez en el primer paso de salida y el control de las emociones 
Anexo 3.

\section{ACUERDO ASUNCIÓN DE RIESGO}

Respecto al acceso a la participación en actividades asociadas con el Entrenamiento Personal delego toda responsabilidad de Carlos Vallés Ortega por lesiones o daños producidos durante la participación en cualquier actividad de dicho programa.

Entiendo la política y procedimiento establecidos por Carlos Vallés Ortega y he tenido la oportunidad de hablar de mis necesidades específicas en relación con la actividad, y por tanto, voluntariamente solicito el derecho a participar en este programa de ejercicio.

Además, en consideración con los factores anteriores, reconozco la existencia de riesgos relacionados con estas actividades, asumo los riesgos y acepto las responsabilidades por cualquier lesión sufrida durante la participación en el uso de las instalaciones y/o su equipamiento. Más específicamente, reconozco y acepto la responsabilidad por las lesiones que se produzcan en esas actividades que implican riesgos en cualquier de las siguientes áreas:

- El uso de equipamiento del centro.

- La ejecución de las evaluaciones para examinar la capacidad funcional.

- La participación en actividades de grupo relacionadas con el ejercicio y la actividad.

- Incidentes que ocurran en el centro deportivo, en las taquillas, en los vestuarios, duchas y otras áreas asociadas con Carlos Vallés Ortega.

Además, se me recomendó seriamente que consultara a un médico antes de realizar actividades asociadas con Carlos Vallés Ortega.

Después de leer lo precedente, reconozco que entiendo perfectamente los riesgos y acepto toda la responsabilidad por exposición a dichos riesgos y acepto toda la responsabilidad eximiendo a Carlos Vallés Ortega. 


\section{CONSENTIMIENTO INFORMADO}

Las pruebas de evaluación de la forma física valoran las siguientes áreas: resistencia cardiorrespitoria, composición corporal, resistencia y fuerza musculares y flexibilidad.

Las pruebas más exigentes físicamente son las que evalúan la resistencia cardiorrespiratoria y la resistencia y fuerza musculares.

Durante o después de estas pruebas tal vez se experimente cansancio. Las complicaciones son escasas durante las pruebas de esfuerzo, sobre todo en las de naturaleza submáxima. Si la persona que hace ejercicio no tolera bien la prueba, ésta se detendrá. Las complicaciones documentadas (1 de cada 10.000 pruebas) son desvanecimiento e irregularidades en la función cardíaca. Además, el riesgo de lesión con las maquinas de ejercicio es posible pero poco probable.

Al firmar el consentimiento informado, afirma haber leído y entendido la descripción de estas pruebas y sus complicaciones. Además acepta que todas las preguntas que se formula sobre la evaluación de la forma física han sido contestadas de forma satisfactoria. Se hará todo esfuerzo posible por garantizar la salud y seguridad. Accede voluntariamente a estas pruebas y puede dejarlas en cualquier momento.

La información, los datos y fotografías obtenidas de cualquier procedimiento en la ejecución del programa serán utilizados para la exposición y desarrollo del trabajo fin de Máster de Entrenamiento Personal de la Universidad de Granada.

Al firmar más abajo, aceptas tu total responsabilidad sobre tu salud y bienestar y declaras que sabes que los directores del programa no asumen ninguna responsabilidad. De igual forma consiento la utilización de mis datos y mi imagen para la exposición y desarrollo del trabajo fin de Máster de Entrenamiento Personal de la Universidad de Granada por parte de Carlos Vallés Ortega. 


\section{CONTRATO CON EL ENTRENADOR}

¡Enhorabuena por tu decisión de participar en un programa de ejercicio! Con la ayuda de tu entrenador personal, mejorarás tu capacidad de lograr más rápidamente tus metas de entrenamiento, con más seguridad y con los máximos beneficios. Los detalles de estas sesiones de entrenamiento pueden servirte para siempre.

Para potenciar el progreso, será necesario que sigas las pautas del programa durante los días de entrenamiento con y sin supervisión. Recuerda, el ejercicio y una alimentación sana son importantes POR IGUAL.

Durante el programa de ejercicio, se tomarán todas las medidas para garantizar tu seguridad, No obstante, como con cualquier programa de ejercicio, existen riesgos, como el aumento de estrés que soporta el corazón y la posibilidad de sufrir lesiones musculoesqueléticas. Al iniciar este programa de forma voluntaria, aceptas asumir la responsabilidad de estos riesgos y renuncias a culpar al entrenador de cualquier daño personal.

Se recomienda un reconocimiento médico a todos los participantes con algún tipo de restricción a ejercicio, así como a todos los hombres de 45 años y mayores y a todas las mujeres de 55 años o mayores. Los participantes incluidos en alguna de estas categorías que NO hayan pasado antes por un reconocimiento médico DEBEN declarar que han sido informados de su importancia. Al firmar más abajo, aceptas tu total responsabilidad sobre tu salud y bienestar y declaras que sabes que los directores del programa no asumen ninguna responsabilidad.

Se recomienda que los participantes de una programan trabajen con el entrenador personal tre veces por semana, aunque, debido a la incompatibilidad de horarios y por razones económicas, es posible una combinación de sesiones con y sin supervisión.

\section{Términos y condiciones para el entrenador personal.}

1. Los entrenamientos se realizarán de forma gratuita.

2. Las sesiones con el entrenador personal que no se cambien o cancelen con 24 horas de antelación se considerarán perdidas.

3. Si las sesiones se cancelen con 24 horas de antelación, se podrán cambiar a cualquier otro día de la semana, siempre que el entrenador personal y el cliente estén de acuerdo.

4. Los clientes que lleguen tarde entrenarán lo que quede de sesión, a menos que se haya llegado previamente a un acuerdo con el entrenador.

Descripción del programa:

Inversión total:

Forma de pago: 
Anexo 4.
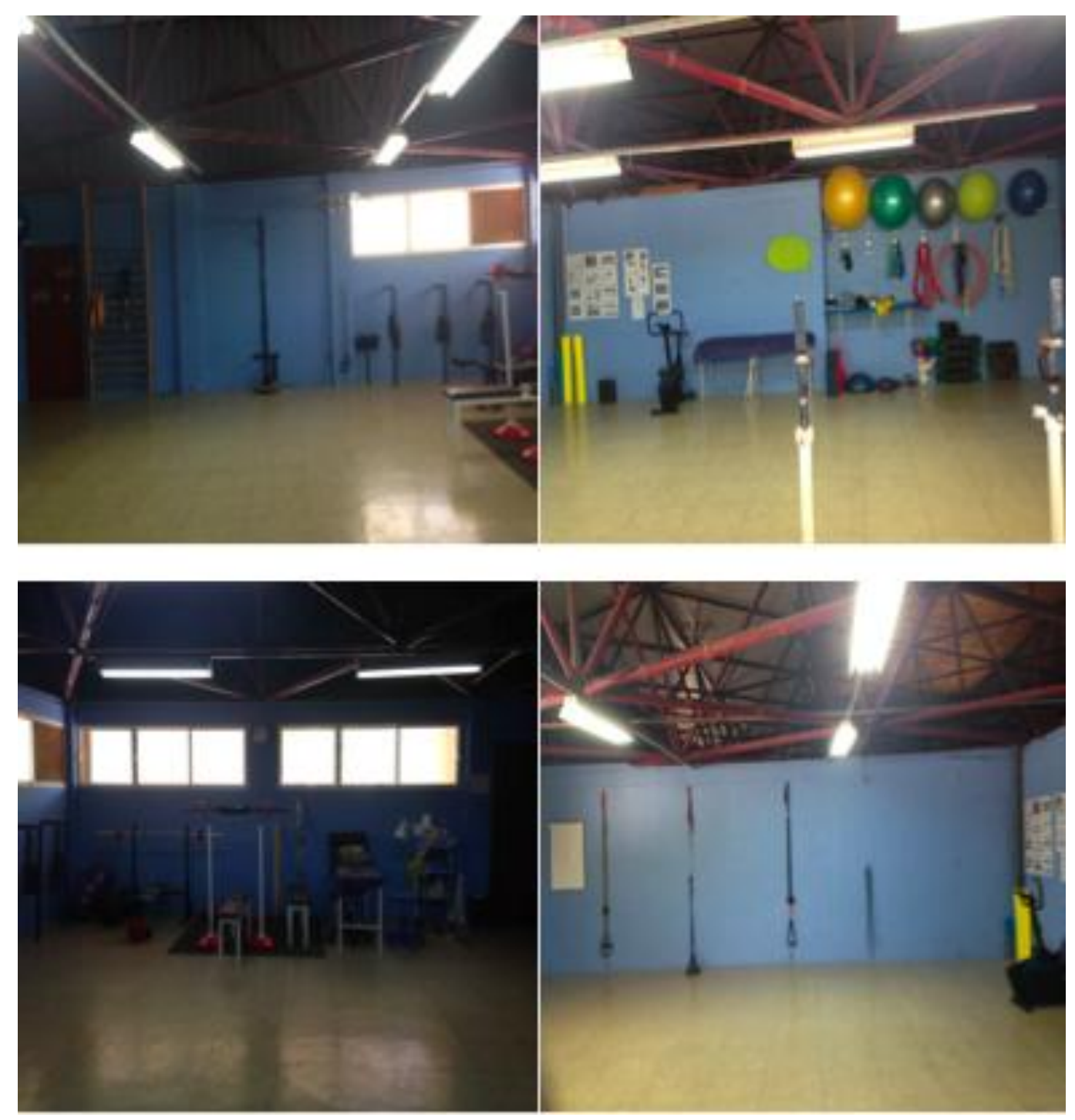
Anexo 5.

\begin{tabular}{|c|c|}
\hline Material & Unidades \\
\hline TRX & 2 \\
\hline Aerosling casero & 1 \\
\hline Cojín de equilibrio & 2 \\
\hline Bosu & 1 \\
\hline Pelotas de tenis & 10 \\
\hline Pelotas de golf & 10 \\
\hline Pelotas sensorial erizo & 3 \\
\hline Barra mancuerna de 2,3 kg & 1 \\
\hline Barra de $11 \mathrm{~kg}$ & 1 \\
\hline Barra de $8,4 \mathrm{~kg}$ & 3 \\
\hline Discos de $25 \mathrm{Kg}$ & 2 \\
\hline Discos de $10 \mathrm{Kg}$ & 4 \\
\hline Discos de $2 \mathrm{~kg}$ & 10 \\
\hline Discos de $1 \mathrm{~kg}$ & 2 \\
\hline Mancuernas de vinilo de $1 \mathrm{~kg}$ & 4 \\
\hline Kettlebell $5 \mathrm{~kg}$ & 1 \\
\hline Rueda perfilada antideslizante & 1 \\
\hline Bandas elásticas, de distintas resistencia & 7 \\
\hline Elástico resistente de 6 metros & 1 \\
\hline Arnés & 2 \\
\hline Esterilla & 3 \\
\hline FoamRoller & 2 \\
\hline $\begin{array}{c}\text { Aparato digital EMS/TENS marca } \\
\text { vitacontrol }\end{array}$ & 1 \\
\hline Cinturón Lastrado & 1 \\
\hline Combas de Saltar & 2 \\
\hline Pulsómetro polar FT 7. & 1 \\
\hline Bicicleta estática & 1 \\
\hline Escalera de coordinación & 1 \\
\hline Fitball de distintos tamaños & 5 \\
\hline $\begin{array}{l}\text { Monitor de grasa corporal modelo } \\
\text { OMRON BF } 306\end{array}$ & 1 \\
\hline Tirante muscular & 3 \\
\hline Plataforma de salto cronojump & 1 \\
\hline Encoder cronojump & 1 \\
\hline Polea cónica casera & 1 \\
\hline $\begin{array}{c}\text { Banco multifunción, con press de banca, } \\
\text { y legcurls y legextetion }\end{array}$ & 1 \\
\hline Camilla & 1 \\
\hline Monopatín & 1 \\
\hline
\end{tabular}


Anexo 6.

\begin{tabular}{|c|c|}
\hline \multicolumn{2}{|c|}{ Parámetros técnicos del Squat } \\
\hline $\begin{array}{c}\text { Apoyo de la barra en la porción baja del } \\
\text { trapecio superior y a lo largo de los } \\
\text { deltoides posteriores }\end{array}$ & Si \\
\hline Cabeza en posición neutra & Si \\
\hline $\begin{array}{l}\text { Mirada al frente sin inclinar en ningún } \\
\text { momento del movimiento }\end{array}$ & Si \\
\hline $\begin{array}{l}\text { Pecho elevado, consecuencia de una } \\
\text { buena alineación de columna }\end{array}$ & No \\
\hline $\begin{array}{c}\text { Pecho elevado, consecuencia de una } \\
\text { buena alineación de columna. }\end{array}$ & No \\
\hline $\begin{array}{l}\text { Pies separados aproximadamente a la } \\
\text { anchura de los hombros. }\end{array}$ & Si \\
\hline Activación de la zona CORE. & No \\
\hline $\begin{array}{l}\text { Inspiración profunda durante fase } \\
\text { excéntrica. }\end{array}$ & No \\
\hline $\begin{array}{l}\text { Activación y contracción de la zona } \\
\text { lumbar durante todo el movimiento. }\end{array}$ & No \\
\hline $\begin{array}{l}\text { Cadera hacia detrás (simulación de } \\
\text { sentarse en una silla). }\end{array}$ & No \\
\hline $\begin{array}{l}\text { El movimiento comienza con una flexión } \\
\text { de la rodilla y la articulación coxofemoral. }\end{array}$ & No \\
\hline $\begin{array}{l}\text { Rodilla en línea con los pies, sin que se } \\
\text { vayan hacia dentro. }\end{array}$ & Si \\
\hline $\begin{array}{l}\text { Correcta alineación de columna durante } \\
\text { la fase excéntrica. }\end{array}$ & Si \\
\hline $\begin{array}{l}\text { Talones apoyados durante todo el } \\
\text { movimiento. }\end{array}$ & No \\
\hline $\begin{array}{l}\text { Evitar retrovesión y anteversiónpelvica en } \\
\text { la parte final del movimiento (pérdida de } \\
\text { la curvatura natural de la columna). }\end{array}$ & No \\
\hline $\begin{array}{l}\text { Extensión simultanea de cadera y rodillas } \\
\text { al final del movimiento concéntrico. }\end{array}$ & Si \\
\hline $\begin{array}{l}\text { Espiración en la fase final del } \\
\text { movimiento. }\end{array}$ & No \\
\hline $\begin{array}{l}\text { Cabeza en posición neutra durante la } \\
\text { fase concéntrica. }\end{array}$ & Si \\
\hline Evitar el valgo o el varo de rodilla. & No \\
\hline Movimiento es continuo y fluido. & No \\
\hline Parámetros técnic & \\
\hline $\begin{array}{l}\text { Columna alineada correctamente en } \\
\text { posición de inicio. }\end{array}$ & No \\
\hline Piernas con ligera separación. & Si \\
\hline $\begin{array}{c}\text { Palmas de las manos en dirección al } \\
\text { centro. }\end{array}$ & No \\
\hline
\end{tabular}




\begin{tabular}{|c|c|}
\hline $\begin{array}{l}\text { Inspiración profunda al inicio del } \\
\text { movimiento para estabilizar la espalda }\end{array}$ & No \\
\hline Espiración en el movimiento ascendente. & No \\
\hline $\begin{array}{l}\text { Alineación de la columna correcta } \\
\text { durante todo el movimiento. }\end{array}$ & No \\
\hline $\begin{array}{l}\text { Brazos relajados durante todo el } \\
\text { movimiento. }\end{array}$ & Si \\
\hline $\begin{array}{l}\text { Flexo-extensión de la articulación } \\
\text { coxofemoral. }\end{array}$ & No \\
\hline $\begin{array}{l}\text { Ligera flexión mantenida de rodilla } \\
\text { (facilitadora). }\end{array}$ & No \\
\hline $\begin{array}{c}\text { Cabeza en posición neutra durante todo } \\
\text { el movimiento. }\end{array}$ & No \\
\hline $\begin{array}{l}\text { Rodillas alineadas sin introducir un valgo } \\
\qquad \text { o un varo de rodilla. }\end{array}$ & Si \\
\hline El movimiento es continuo y fluido & $\mathrm{Si}$ \\
\hline \multicolumn{2}{|c|}{ Parámetros técnicos press de pecho } \\
\hline $\begin{array}{c}\text { Glúteos pegados al banco durante el } \\
\text { movimiento. }\end{array}$ & Si \\
\hline $\begin{array}{l}\text { Cerrar dedos sobre el agarre de la barra } \\
\text { en forma de pinza. }\end{array}$ & Si \\
\hline Angulación de $45^{\circ}$ entre hombro y tronco. & Si \\
\hline $\begin{array}{c}\text { Inspiración durante contracción } \\
\text { excéntrica. }\end{array}$ & No \\
\hline $\begin{array}{l}\text { La barra se aproxima lo máximo al pecho, } \\
\text { incluso llegando a tocarlo. }\end{array}$ & Si \\
\hline Espiración durante la fase concéntrica. & No \\
\hline $\begin{array}{l}\text { Activación constante de la faja lumbo- } \\
\text { abdominal. }\end{array}$ & No \\
\hline Muñecas en ligera extensión. & Si \\
\hline Desplazamiento rectilíneo de la barra. & Si \\
\hline Evitar balanceos laterales. & Si \\
\hline Activación del pectoral mayor voluntaria. & No \\
\hline $\begin{array}{c}\text { Mantener curvatura natural de la } \\
\text { columna. }\end{array}$ & Si \\
\hline El movimiento es continuo y fluido. & Si \\
\hline \multicolumn{2}{|c|}{ Parámetros técnicos del remo } \\
\hline $\begin{array}{c}\text { Tronco se encuentra inclinado } \\
\text { ligeramente hacia delante en posición } \\
\text { inicial. }\end{array}$ & No \\
\hline $\begin{array}{c}\text { Espalda se encuentra en un posición } \\
\text { anatómica o una ligera flexión del tronco } \\
\text { en posición inicial. }\end{array}$ & No \\
\hline $\begin{array}{l}\text { Tracción acompañada con una ligera } \\
\text { extensión de la espalda si el tronco } \\
\text { estaba flexionado o con la espalda } \\
\text { estable si estaba en poción anatómica }\end{array}$ & No \\
\hline
\end{tabular}




\begin{tabular}{|c|c|}
\hline Brazos relativamente relajados. & Si \\
\hline $\begin{array}{l}\text { Mayor fatiga en la zona de la espalda que } \\
\text { en los brazos (activación correcta) }\end{array}$ & Si \\
\hline $\begin{array}{l}\text { El movimiento concéntrico de tracción se } \\
\text { acompaña de una inspiración }\end{array}$ & No \\
\hline $\begin{array}{l}\text { El movimiento excéntrico se acompaña } \\
\text { de una espiración }\end{array}$ & No \\
\hline $\begin{array}{c}\text { Hombros permanecen a la misma altura } \\
\text { durante todo el recorrido, sin realizar una } \\
\text { ascensión }\end{array}$ & No \\
\hline $\begin{array}{c}\text { Escápulas se aproximan en el } \\
\text { movimiento de contracción concéntrica }\end{array}$ & No \\
\hline $\begin{array}{l}\text { Escápulas no se alejan en exceso en el } \\
\text { movimiento de contracción excéntrica }\end{array}$ & No \\
\hline El movimiento es continuo y fluido. & Si \\
\hline \multicolumn{2}{|c|}{ Parámetros técnicos de la plancha } \\
\hline Alineación cervical, dorsal, lumbar & No \\
\hline Contracción voluntaria glúteos & No \\
\hline $\begin{array}{c}\text { Codos ejerce fuerza y presión para } \\
\text { activar dorsal ancho }\end{array}$ & No \\
\hline Evita extensión lumbar & Si \\
\hline Evita cifosis & Si \\
\hline $\begin{array}{c}\text { Codos apoyados misma altura que } \\
\text { hombro }\end{array}$ & Si \\
\hline Evitar anteversión y retroversión pélvica & Si \\
\hline \multicolumn{2}{|c|}{ Parámetros técnicos side brigde } \\
\hline Alineación cervical, dorsal, lumbar & No \\
\hline $\begin{array}{c}\text { Activación glúteo medio, al subir la } \\
\text { cadera }\end{array}$ & No \\
\hline Hombro línea con el codo & No \\
\hline Estabilidad brazo apoyado & Si \\
\hline Curvatura neutra & Si \\
\hline \multicolumn{2}{|c|}{ Parámetros técnicos del glute bridge } \\
\hline $\begin{array}{c}\text { Cabeza libre, no activación de los } \\
\text { flexores del cuello }\end{array}$ & Si \\
\hline $\begin{array}{l}\text { Curvatura neutra, vigilando no aumentar } \\
\text { la lordosis en el movimiento de extensión }\end{array}$ & Si \\
\hline Extensión de cadera no de tronco & Si \\
\hline $\begin{array}{c}\text { Rodillas separadas a la altura de la } \\
\text { cadera }\end{array}$ & Si \\
\hline $\begin{array}{l}\text { Rodillas estables, que no se adelante en } \\
\text { la extensión }\end{array}$ & Si \\
\hline
\end{tabular}




\section{Anexo 7. Análisis de las encuestas alimentarias}

\section{Recordatorios 24 Horas}

\begin{tabular}{|c|c|c|c|c|c|}
\hline \multicolumn{6}{|l|}{ Día: } \\
\hline Hora & Lugar & $\begin{array}{c}\text { Nombre de la } \\
\text { comida }\end{array}$ & $\begin{array}{c}\text { Nombre } \\
\text { preparación }\end{array}$ & Ingredientes & $\begin{array}{c}\text { Cantidad } \\
\text { en } \\
\text { medida } \\
\text { casera }\end{array}$ \\
\hline $15: 30$ & Casa & $\begin{array}{c}\text { Solomillo } \\
\text { Bebida: Agua }\end{array}$ & Almuerzo & $\begin{array}{c}\text { Solomillo, ajo, } \\
\text { vino, patatas } \\
\text { fritas }\end{array}$ & 1 plato \\
\hline $21: 00$ & Bar & $\begin{array}{l}\text { Patatas alioli } \\
\text { Bebida: } 1 \text { caña }\end{array}$ & Cena & $\begin{array}{c}\text { Patatas y } \\
\text { salsa alioli }\end{array}$ & Tapa \\
\hline $22: 00$ & Casa novia & $\begin{array}{l}\text { Pan-pizza } \\
\text { Bebida: coca- } \\
\text { cola zero }\end{array}$ & Cena & $\begin{array}{l}\text { Pan, jamón } \\
\text { york, } \\
\text { mortaleda y } \\
\text { queso }\end{array}$ & $\begin{array}{c}\text { Media } \\
\text { baguette }\end{array}$ \\
\hline $\begin{array}{l}1: 00- \\
6: 00\end{array}$ & Discoteca & Copas & Copas & $\begin{array}{l}\text { Ginebra y } \\
\text { refrescos }\end{array}$ & $\begin{array}{c}6 \text { copas } \\
\text { vaso } \\
\text { ancho }\end{array}$ \\
\hline \multicolumn{6}{|c|}{ Día: } \\
\hline Hora & Lugar & $\begin{array}{l}\text { Nombre de la } \\
\text { comida }\end{array}$ & $\begin{array}{c}\text { Nombre } \\
\text { preparación }\end{array}$ & Ingredientes & $\begin{array}{c}\text { Cantidad } \\
\text { en } \\
\text { medida } \\
\text { casera }\end{array}$ \\
\hline $15: 00$ & Casa & $\begin{array}{c}\text { Sopa } \\
\text { Bebida: Agua }\end{array}$ & Almuerzo & Caldo y fideos & $\begin{array}{l}1 \text { plato } \\
\text { sopero }\end{array}$ \\
\hline $15: 00$ & Casa & $\begin{array}{l}\text { Filete con } \\
\text { patatas }\end{array}$ & Almuerzo & $\begin{array}{l}\text { Filete ternera } \\
\text { y patata fritas }\end{array}$ & 2 filetes \\
\hline 19:00 & Casa & Plátano & Merienda & Plátano & 1 plátano \\
\hline $22: 00$ & Casa novia & $\begin{array}{c}\text { Ensalada } \\
\text { Bebida: leche } \\
\text { semidesnatada }\end{array}$ & Cena & $\begin{array}{l}\text { Maíz, pepino, } \\
\text { cebolla, } \\
\text { tomate y } \\
\text { lechuga }\end{array}$ & $\begin{array}{l}1 \text { plato } \\
\text { hondo }\end{array}$ \\
\hline $22: 30$ & Casa novia & Yogurt & Cena & Yogurt & 1 yogurt \\
\hline \multicolumn{6}{|c|}{ Día: } \\
\hline Hora & Lugar & $\begin{array}{c}\text { Nombre de la } \\
\text { comida }\end{array}$ & $\begin{array}{c}\text { Nombre } \\
\text { preparación }\end{array}$ & Ingredientes & $\begin{array}{c}\text { Cantidad } \\
\text { en } \\
\text { medida } \\
\text { casera }\end{array}$ \\
\hline $8: 30$ & Casa & Manzana roja & Desayuno & Manzana & \\
\hline $12: 00$ & Universidad & Tostada & Desayuno & $\begin{array}{c}\text { Pan, jamón } \\
\text { york y tomate }\end{array}$ & $\begin{array}{c}2 \\
\text { tostadas }\end{array}$ \\
\hline $15: 30$ & Casa novia & $\begin{array}{l}\text { Atún con } \\
\text { tomate }\end{array}$ & Almuerzo & $\begin{array}{l}\text { Atún y salsa } \\
\text { de tomate }\end{array}$ & 1 plato \\
\hline
\end{tabular}




\begin{tabular}{|c|c|c|c|c|c|}
\hline $22: 00$ & Casa & $\begin{array}{c}\text { Hamburguesa } \\
\text { de pollo }\end{array}$ & Cena & $\begin{array}{c}2 \\
\text { hamburguesas } \\
\text { y 1 huevo a la } \\
\text { plancha }\end{array}$ & 1 plato \\
\hline
\end{tabular}

\section{VALORACION DIETETICA}

Periodo: 3 días. HOMBRE Edad: 23 años. Peso: $103 \mathrm{Kg}$. Talla: 1,88 cm. IMC: 291421,5

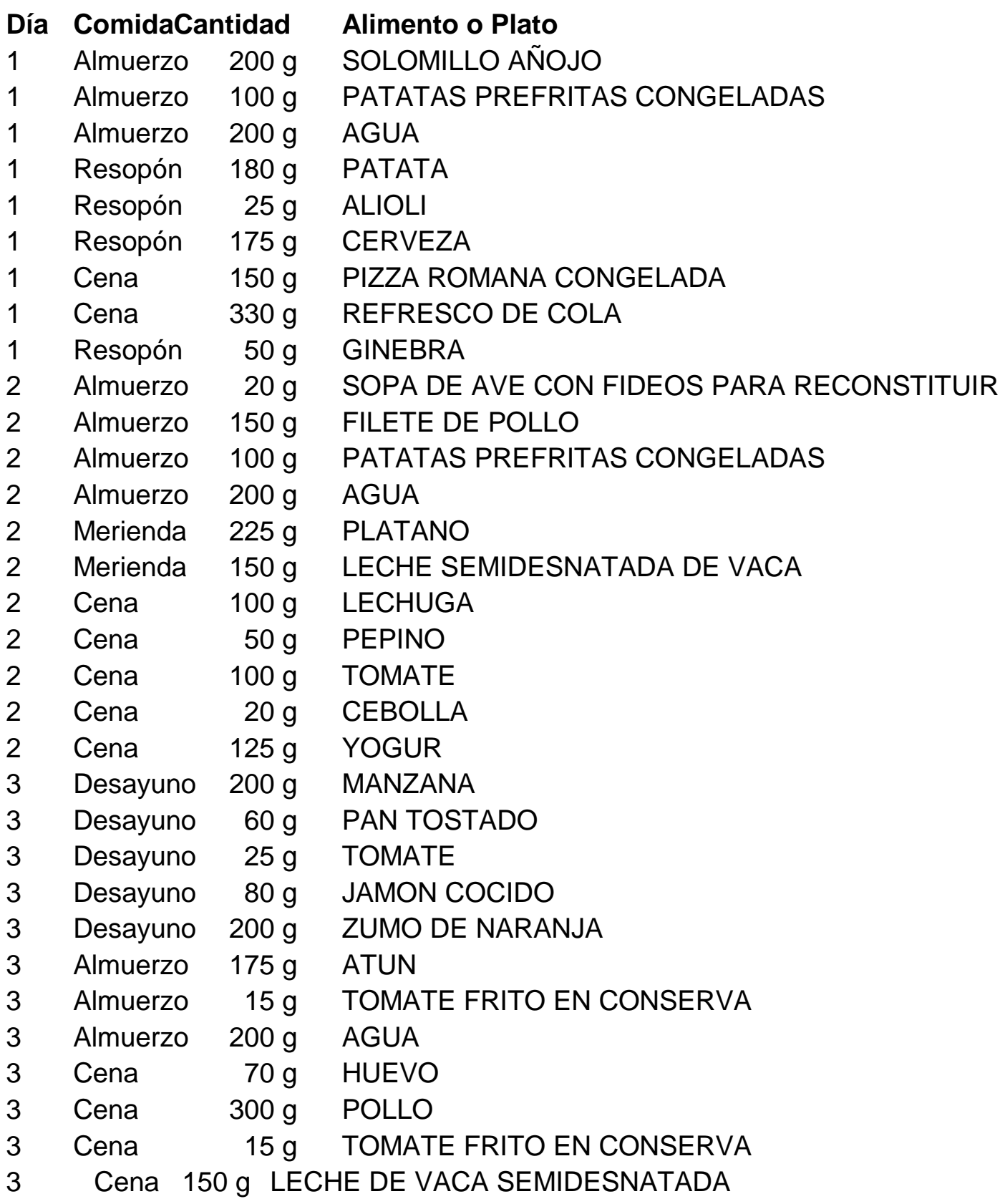




\begin{tabular}{|c|c|c|c|}
\hline Nutriente & Aporte & IR & $\%$ AP/IR \\
\hline Energía [kcal] & 1170 & 4736 & 24,7 \\
\hline Proteínas [g] & 65 & 54 & 120,3 \\
\hline Calcio [mg] & 354 & 1000 & 35,4 \\
\hline Fósforo [mg] & 886 & 700 & 126,6 \\
\hline Magnesio [mg] & 163 & 400 & 40,7 \\
\hline Hierro [mg] & 9,6 & 10 & 96,0 \\
\hline Zinc [mg] & 8,4 & 15 & 55,8 \\
\hline Yodo [ug] & 65 & 150 & 43,3 \\
\hline Flúor [ $\mu \mathrm{g}]$ & 101 & 4000 & 2,5 \\
\hline Selenio $[\mu \mathrm{g}]$ & 61,8 & 70 & 88,3 \\
\hline Vit. B1 Tiamina [mg] & 0,96 & 1,9 & 50,7 \\
\hline Vit. B2 Riboflavina [mg] & 1,1 & 2,8 & 38,4 \\
\hline Vit. B6 Piridoxina [mg] & 2,3 & 1,5 & 152,3 \\
\hline $\begin{array}{l}\text { Vit. B12 Cianocobalamina } \\
{[\mu \mathrm{g}]}\end{array}$ & $a 7,1$ & 2,4 & 296,2 \\
\hline Eq. Niacina [mg] & 34,2 & 31,3 & 109,3 \\
\hline Ac. Fólico [ $\mu \mathrm{g}$ Actividad] & 138 & 400 & 34,6 \\
\hline Vit. C Ac. Ascórbico [mg] & 79,1 & 60 & 131,8 \\
\hline Ac. Pantoténico [mg] & 3,8 & 5 & 75,5 \\
\hline Biotina $[\mu \mathrm{g}]$ & 15,8 & 30 & 52,6 \\
\hline Vit. A [ $\mu \mathrm{g}$ Eq. de retinol] & 445 & 1000 & 44,5 \\
\hline Vitamina $D[\mu \mathrm{g}]$ & 2,3 & 5 & 45,5 \\
\hline $\begin{array}{l}\text { Vit. E [mg Eq. de alfa- } \\
\text { tocoferol] }\end{array}$ & $1-4,8$ & 10 & 48,0 \\
\hline Vitamina $\mathrm{K}[\mu \mathrm{g}]$ & 66 & 70 & 94,3 \\
\hline
\end{tabular}




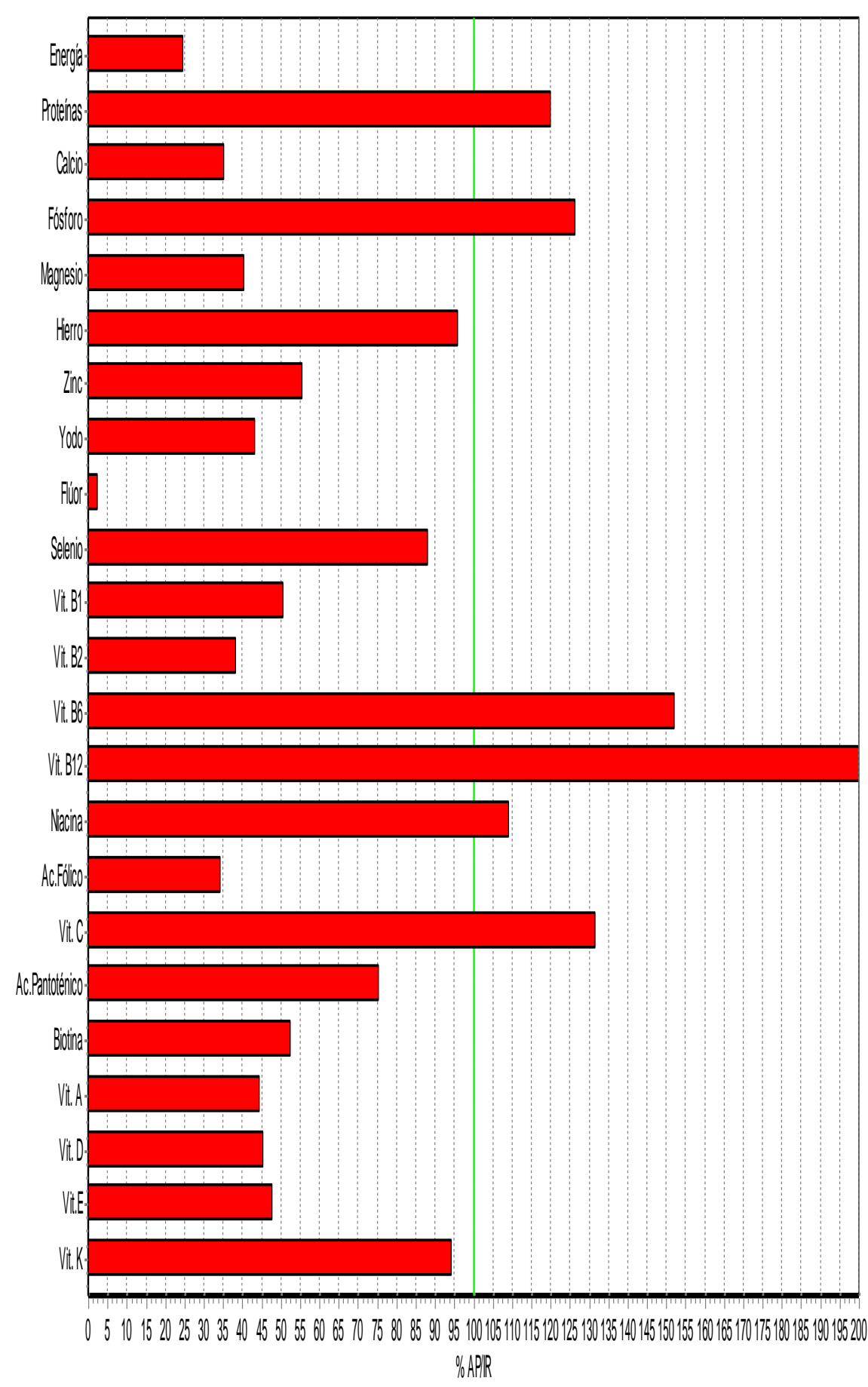


Ingesta total de Energía y nutrientes promedio diaria

\begin{tabular}{|l|l|l|l|l|l|}
\hline Energía (kcal) & 1170 & Minerales & & Vitaminas & \\
\hline Proteína $(\mathrm{g})$ & 65 & Calcio $(\mathrm{mg})$ & 354 & Vitamina $\mathrm{B}_{1}(\mathrm{mg})$ & 0,96 \\
\hline Hidratos de C $(\mathrm{g})$ & 105 & Hierro $(\mathrm{mg})$ & 9,6 & Vitamina $\mathrm{B}_{2}(\mathrm{mg})$ & 1,1 \\
\hline Fibra dietética $(\mathrm{g})$ & 10,6 & Yodo $(\square \mathrm{g})$ & 65 & Eq. Niacina $(\mathrm{mg})$ & 34,2 \\
\hline Grasa total $(\mathrm{g})$ & 46 & Magnesio $(\mathrm{mg})$ & 163 & Vitamina $\mathrm{B}_{6}(\mathrm{mg})$ & 2,3 \\
\hline AGS $(\mathrm{g})$ & 12 & Zinc $(\mathrm{mg})$ & 8,4 & Acido Fólico $(\mu \mathrm{g})$ & 138 \\
\hline AGM $(\mathrm{g})$ & 19,1 & Selenio $(\square \mathrm{g})$ & 61,8 & Vitamina $\mathrm{B}_{12}(\mu \mathrm{g})$ & \\
\hline AGP $(\mathrm{g})$ & 9,9 & Sodio $(\mathrm{mg})$ & 1230 & Vitamina C $(\mathrm{mg})$ & 79,1 \\
\hline AGP/AGS & 0,83 & Potasio $(\mathrm{mg})$ & 2362 & Retinol $(\mu \mathrm{g})$ & 173 \\
\hline [AGP+AGM]/AGS & 2,4 & Fósforo $(\mathrm{mg})$ & 886 & Carotenos $(\mu \mathrm{g})$ & 1013 \\
\hline Colesterol $(\mathrm{mg})$ & 278 & Flúor $(\square \mathrm{g})$ & 101 & Vit. A: Eq. Retinol $(\mu \mathrm{g})$ & 445 \\
\hline Agua $(\mathrm{g})$ & 1015 & & & Ac. Pantoténico $(\mathrm{mg})$ & 3,8 \\
\hline Alcohol $(\mathrm{g})$ & 7,6 & & & Biotina $(\mu \mathrm{g})$ & 15,8 \\
\hline & & & & Vitamina D $(\mu \mathrm{g})$ & 2,3 \\
\hline & & & & Vitamina E $(\mathrm{mg})$ & 4,8 \\
\hline
\end{tabular}



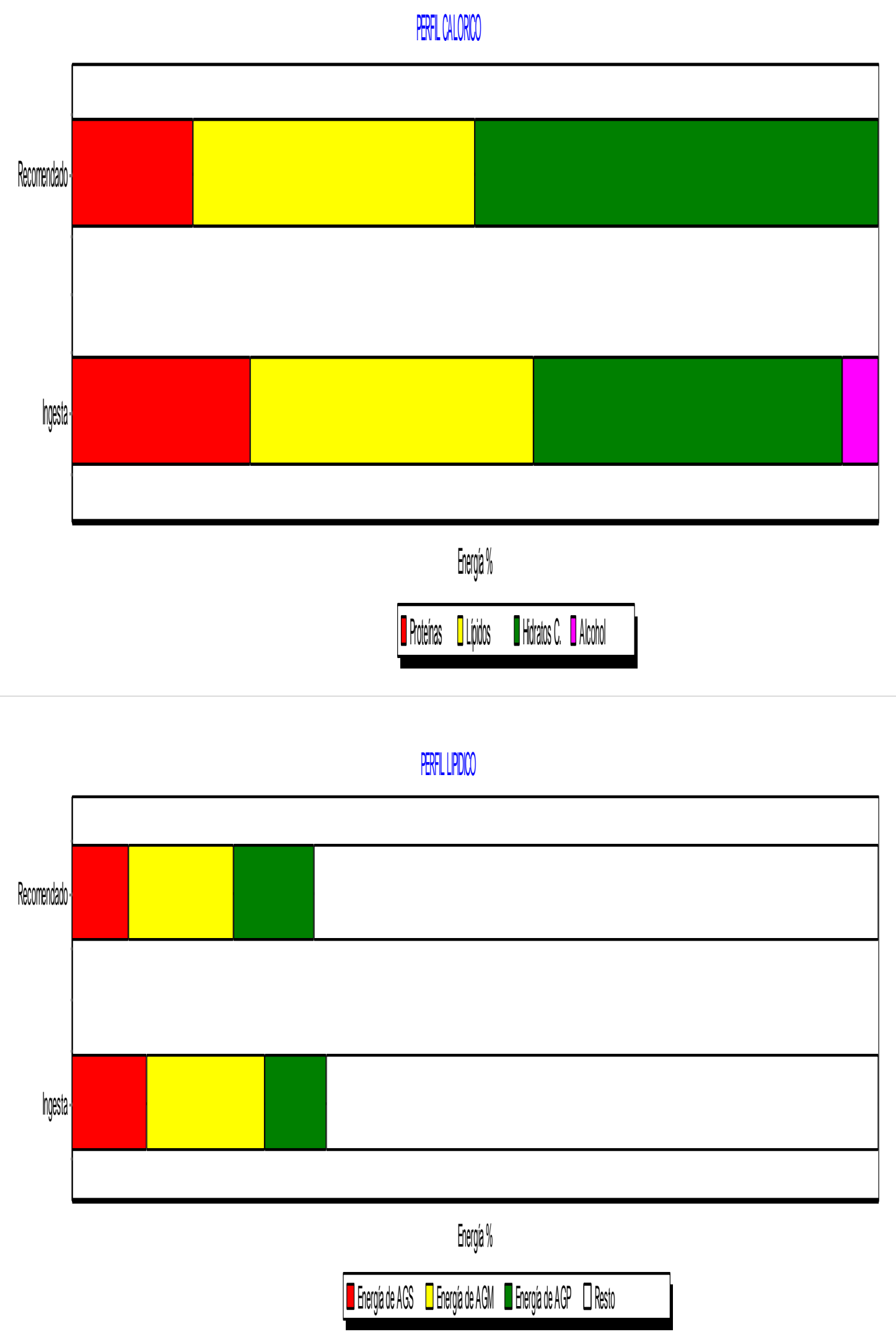


\begin{tabular}{|c|c|c|c|c|c|c|c|c|c|c|c|c|c|c|c|c|c|c|}
\hline Día & Comida & Energía & Proteínas & $\begin{array}{l}\text { Hidratos } \\
\text { Carbono }\end{array}$ & $\begin{array}{l}\text { Fibra } \\
\text { vegetal }\end{array}$ & Lípidos & Colesterol & AGS & AGM & AGP & Calcio & Hierro & Sodio & Vit. A & $\begin{array}{l}\text { Vit. } \\
\text { B1 }\end{array}$ & $\begin{array}{l}\text { Vit. } \\
\text { B2 }\end{array}$ & Ac.Fólico & $\begin{array}{l}\text { Vit. } \\
\text { C }\end{array}$ \\
\hline 1 & Almuerzo & 480 & 34,2 & 32,8 & 3,5 & 22,7 & 115 & 5,2 & 10,5 & 5,5 & 25,6 & 11,3 & 127 & Trazas & s 0,42 & 0,4 & 41 & 16 \\
\hline 1 & Cena & 409 & 10,9 & 75,6 & 5,6 & 5,7 & 52,7 & 3 & 1,6 & 0,75 & 148 & 3,5 & 1413 & 480 & 0,45 & 0,39 & 43,7 & 0 \\
\hline 1 & Resopón & 490 & 4,4 & 27,5 & 3 & 21,9 & 0 & 3,2 & 15,4 & 2,3 & 23,7 & 0,72 & 154 & 1,3 & 0,17 & 0,13 & 43 & 24,5 \\
\hline 1 & Total & 1378 & 49,5 & 136 & 12,1 & 50,3 & 167 & 11,4 & 27,6 & 8,5 & 197 & 15,6 & 1694 & 481 & 1 & 0,92 & 128 & 40,5 \\
\hline 2 & Almuerzo & 536 & 36,3 & 44,4 & 3,9 & 22,7 & 98,5 & 4,1 & 9,6 & 7 & 39,4 & 2,8 & 241 & 2,4 & 0,26 & 0,2 & 42,8 & 22,2 \\
\hline 2 & Merienda & 213 & 6,8 & 38,1 & 3,8 & 2,8 & 9,4 & 1,8 & 0,73 & 0,19 & 198 & 1 & 72 & 84,8 & 0,13 & 0,39 & 33,7 & 17,9 \\
\hline 2 & Cena & 123 & 7,2 & 12,9 & 3 & 4 & 12,7 & 2 & 0,93 & 0,59 & 225 & 1,6 & 112 & 366 & 0,18 & 0,33 & 65,3 & 39,4 \\
\hline 2 & Total & 871 & 50,3 & 95,4 & 10,7 & 29,6 & 121 & 8 & 11,3 & 7,8 & 463 & 5,5 & 425 & 453 & 0,57 & 0,92 & 142 & 79,5 \\
\hline 3 & Desayuno & 516 & 21,5 & 75,4 & 8,5 & 12,4 & 48,3 & 3,6 & 4,9 & 2,2 & 110 & 3,7 & 1109 & 61,5 & 0,81 & 0,4 & 67 & 106 \\
\hline 3 & Almuerzo & 243 & 22 & 0,78 & 0,24 & 16,7 & 48,7 & 4,3 & 3,7 & 5 & 42,5 & 1,1 & 94,6 & 79,8 & 0,17 & 0,17 & 17,8 & 2,6 \\
\hline 3 & Cena & 502 & 51,4 & 8,4 & 0,24 & 29,2 & 449 & 8,8 & 9,9 & 6,2 & 249 & 3 & 369 & 260 & 0,3 & 0,82 & 60,8 & 8,2 \\
\hline 3 & Total & 1261 & 95 & 84,6 & 9 & 58,2 & 546 & 16,6 & 18,4 & 13,4 & 401 & 7,8 & 1572 & 401 & 1,3 & 1,4 & 146 & 117 \\
\hline
\end{tabular}

\section{Distribución por comidas}

\begin{tabular}{|c|c|c|c|c|c|c|c|c|c|c|c|c|c|c|c|c|c|}
\hline Grupo & Energía & Proteínas & $\begin{array}{l}\text { Hidratos } \\
\text { Carbono }\end{array}$ & $\begin{array}{l}\text { Fibra } \\
\text { vegetal }\end{array}$ & Lípidos & Colesterol & AGS & AGM & AGP & Calcio & Hierro & Sodic & A Vit. & $\begin{array}{l}\text { Vit. } \\
\text { B1 }\end{array}$ & $\begin{array}{l}\text { Vit. } \\
\text { B2 }\end{array}$ & Ac. $F$ & $\begin{array}{l}\text { Vit. } \\
\text { C }\end{array}$ \\
\hline Otras comidas & 50 & 0 & 0 & 0 & 0 & 0 & 0 & 0 & 0 & 0 & 0 & 0 & 0 & 0 & 0 & 0 & 0 \\
\hline Desayuno & 172 & 7,2 & 25,1 & 2,8 & 4,1 & 16,1 & 1,2 & 1,6 & 0,74 & 36,6 & 1,2 & 370 & 20,5 & 0,27 & 0,13 & 22,3 & 35,4 \\
\hline $\begin{array}{l}\text { Media } \\
\text { mañana }\end{array}$ & 0 & 0 & 0 & 0 & 0 & 0 & 0 & 0 & 0 & 0 & 0 & 0 & 0 & 0 & 0 & 0 & 0 \\
\hline Almuerzo & 419 & 30,8 & 26 & 2,6 & 20,7 & 87,3 & 4,5 & 7,9 & 5,8 & 35,8 & 5,1 & 154 & 27,4 & 0,28 & 0,26 & 33,9 & 13,6 \\
\hline Merienda & 70,8 & 2,3 & 12,7 & 1,3 & 0,93 & 3,2 & 0,61 & 0,24 & 0,065 & 566,1 & 0,34 & 24 & 28,3 & 0,045 & 0,13 & 11,3 & 6 \\
\hline Cena & 345 & 23,2 & 32,3 & 3 & 12,9 & 172 & 4,6 & 4,1 & 2,5 & 207 & 2,7 & 631 & 369 & 0,31 & 0,51 & 56,6 & 15,9 \\
\hline Resopón & 163 & 1,5 & 9,2 & 1 & 7,3 & 0 & 1,1 & 5,1 & 0,75 & 7,9 & 0,24 & 51,3 & 0,42 & 0,056 & 0,042 & 14,3 & 8,2 \\
\hline
\end{tabular}


Distribución por grupo de alimentos

\begin{tabular}{|c|c|c|c|c|c|c|c|c|c|c|c|c|c|c|c|c|c|}
\hline Grupo & Energía & Proteín & $\begin{array}{l}\text { Sidratos } \\
\text { Carbono }\end{array}$ & \begin{tabular}{|l|} 
Fibra \\
vegetal
\end{tabular} & Lípido & Solesterol & |AGS & SAGM & AGP & Calcic & Hierro & Sodic & Vit. A & $\begin{array}{l}\text { Vit. } \\
\text { B1 }\end{array}$ & $\begin{array}{l}\text { Vit. } \\
\text { B2 }\end{array}$ & Ac.Fólicc & olit. \\
\hline Cereales & 52,4 & 1,4 & 9,2 & 1,1 & 0,88 & 0 & 0,19 & 0,37 & 0,2 & 22,8 & 0,2 & 110 & 0 & 0,072 & 0,054 & 4,2 & 0 \\
\hline Legumbres & 0 & 0 & 0 & 0 & 0 & 0 & 0 & 0 & 0 & 0 & 0 & 0 & 0 & 0 & 0 & 0 & 0 \\
\hline Verduras y hortalizas & 61,2 & 2,1 & 9,9 & 2,3 & 0,96 & 0 & 0,13 & 0,12 & 0,51 & 21 & 0,82 & 40,1 & 148 & 0,11 & 0,063 & 34,8 & 24,9 \\
\hline Frutas & 108 & 1,2 & 23,3 & 2,9 & 0,48 & 0 & 0,11 & 0,13 & 0,13 & 14,1 & 0,72 & 1,9 & 22,3 & 0,094 & 0,064 & 25,8 & 39 \\
\hline Lácteos y derivados & 73,2 & 5,1 & 7,1 & 0 & 2,7 & 10,5 & 1,7 & 0,75 & 0,095 & 5184 & 0,13 & 80,3 & 23 & 0,057 & 0,27 & 4,2 & 0,81 \\
\hline Carnes y derivados & 296 & 37,9 & 2,6 & 0 & 14,9 & 146 & 4,8 & 5,3 & 2,8 & 20,7 & 5 & 373 & 25 & 0,29 & 0,3 & 15,4 & 3,7 \\
\hline Pescados y derivados & $s 76,5$ & 7,3 & 0 & 0 & 5,2 & 16,2 & 1,4 & 1,2 & 1,5 & 13,5 & 0,34 & 14,5 & 20,3 & 0,054 & 0,054 & 5,1 & 0 \\
\hline Huevos y derivados & 32,9 & 2,6 & 0,14 & 0 & 2,5 & 83,2 & 0,67 & 0,99 & 0,37 & 11,4 & 0,45 & 29,2 & 46 & 0,022 & 0,075 & 10,4 & 0 \\
\hline $\begin{array}{|lll|}\text { Azúcares } & \text { dulces } & \text { y } \\
\text { pastelería } & & \\
\end{array}$ & $y 0$ & 0 & 0 & 0 & 0 & 0 & 0 & 0 & 0 & 0 & 0 & 0 & 0 & 0 & 0 & 0 & 0 \\
\hline Aceites y grasas & 0 & 0 & 0 & 0 & 0 & 0 & 0 & 0 & 0 & 0 & 0 & 0 & 0 & 0 & 0 & 0 & 0 \\
\hline Bebidas & 109 & 0,29 & 13,8 & 0 & 0 & 0 & 0 & 0 & 0 & 9,1 & 0,056 & 11,7 & Trazas & $s 0,0018$ & 80,019 & 3,7 & 0 \\
\hline $\begin{array}{l}\text { Platos preparados } \\
\text { precocinados }\end{array}$ & $y 294$ & 7,1 & 39 & 4,4 & 11,2 & 22,5 & 1,9 & 5,1 & 3,5 & 56,7 & 1,9 & 522 & 161 & 0,26 & 0,18 & 34,8 & 10,7 \\
\hline Aperitivos & 0 & 0 & 0 & 0 & 0 & 0 & 0 & 0 & 0 & 0 & 0 & 0 & 0 & 0 & 0 & 0 & 10 \\
\hline Salsas y condimentos & 66,3 & 0,042 & 0,23 & 0,0083 & 7,2 & 0 & 1,1 & 5,1 & 0,73 & 0,17 & 0,0083 & 47,1 & 0 & 0,0017 & 70 & 0,083 & 0 \\
\hline Varios & 0 & 0 & 0 & 0 & 0 & 0 & 0 & 0 & 0 & 0 & 0 & 0 & 0 & 0 & 0 & 0 & 0 \\
\hline Total & 1170 & 65 & 105 & 10,6 & 46 & 278 & 12 & 19,1 & 9,9 & 354 & 9,6 & 1230 & 445 & 0,96 & 1,1 & 138 & 79,1 \\
\hline
\end{tabular}




\section{Alimentos consumidos}

16,7 TOMATE FRITO EN CONSERVA

66,7 MANZANA

66,7 ZUMO DE NARANJA

100 POLLO ENTERO

26,7 JAMON COCIDO

58,3 ATUN

23,3 HUEVO DE GALLINA

274 AGUA CORRIENTE

110 REFRESCO SABOR COLA

16,7 GINEBRA

58,3 CERVEZA

111 PATATAS PREFRITAS CONGELADAS

50 PIZZA ROMANA CONGELADA

8,3 ALIOLI

60 PATATA NUEVA

66,7 SOLOMILLO AÑOJO

6,7 SOPA DE AVE CON FIDEOS PARA

RECONSTITUIR

6,7 CEBOLLA

33,3 LECHUGA

16,7 PEPINO

36,1 TOMATE

75 PLATANO

167 LECHE DE VACA SEMIDESNATADA

41,7 YOGUR NATURAL ENTERO

50 PECHUGA DE POLLO

20 PAN BLANCO TOSTADO 
Anexo 8: Vista lateral derecha del sujeto.

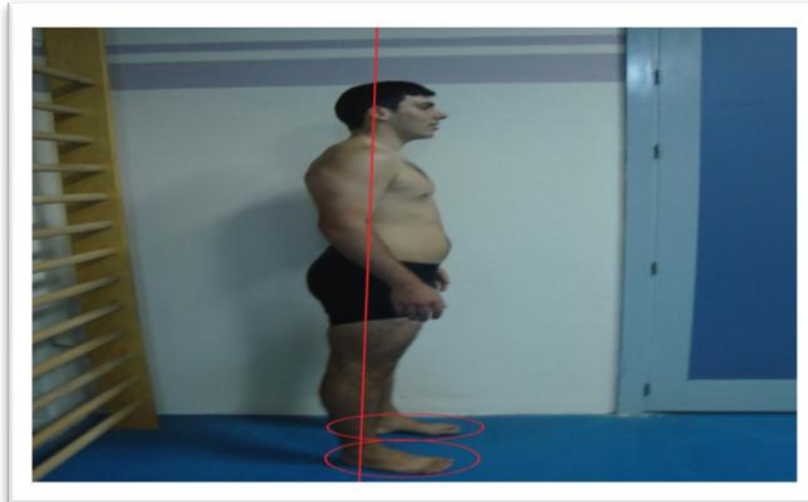

Anexo 9: Vista lateral izquierda del sujeto.

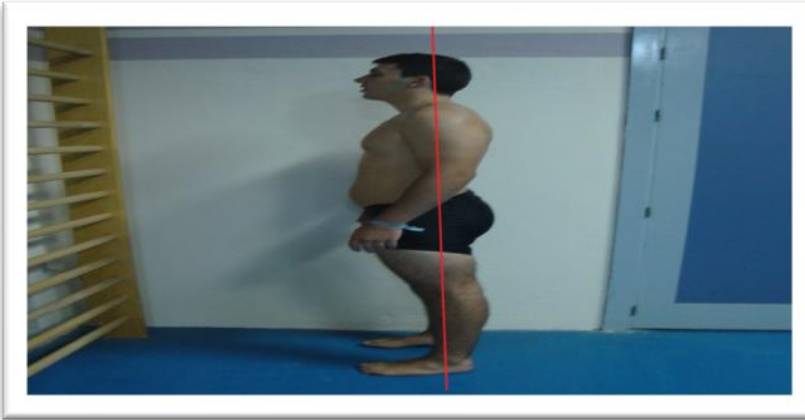

Anexo 10: Valgo de rodilla pierna derecha.

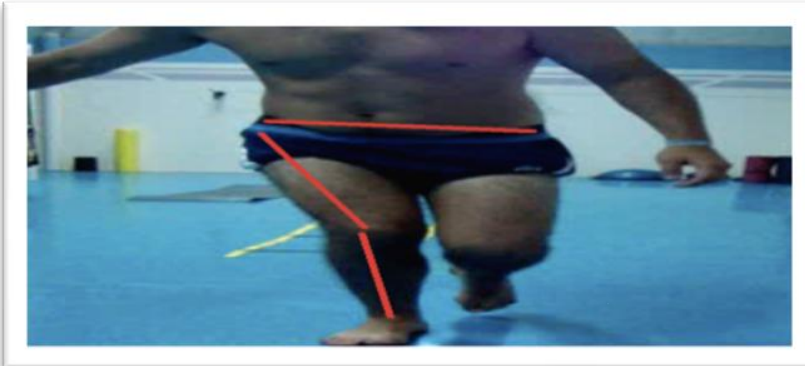

Anexo 11: Valgo de rodilla pierna izquierda.

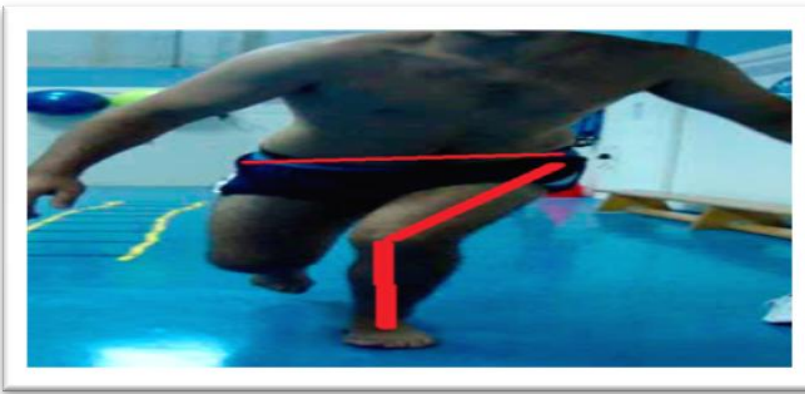


Anexo 12. Planificación del programa de intervención.

\begin{tabular}{|rl|}
\hline \multicolumn{1}{|c|}{ Mayo } \\
\hline Viernes 1 \\
\hline Sábado & 2 \\
\hline Domingo & 3 \\
\hline Lunes & 4 \\
\hline Martes & 5 \\
\hline Miércoles & 6 \\
\hline Jueves & 7 \\
\hline Viernes & 8 \\
\hline Sábado & 9 \\
\hline Domingo & 10 \\
\hline Lunes & 11 \\
\hline Martes & 12 \\
\hline Miércoles & 13 \\
\hline Jueves & 14 \\
\hline Viernes & 15 Entrevista. Test \\
\hline Sábado & 16 \\
\hline Domingo & 17 \\
\hline Lunes & 18 Test \\
\hline Martes & 19 Cuestionario; Test \\
\hline Miércoles & 20 \\
\hline Jueves & 21 Cuestionario; Test \\
\hline Viernes & 22 Test \\
\hline Sábado 23 Cuestionario \\
\hline Domingo 24 \\
\hline Lunes 25 Test \\
\hline Martes 26 \\
\hline Miércoles & 27 Test \\
\hline Jueves & 28 Test \\
\hline Viernes 29 Test \\
\hline Sábado 30 \\
\hline Domingo & 31 \\
\hline & \\
\hline
\end{tabular}

\begin{tabular}{|c|c|}
\hline & Junio \\
\hline Lunes & $1 \mathrm{VO}_{2}$ \\
\hline Martes & $2 \mathrm{CR} \cdot \mathrm{PL}$ \\
\hline Miércoles & 3 RSA - CORE \\
\hline Jueves & $4 \mathrm{CR}-\mathrm{PL}$ \\
\hline Viernes & 5 RSA - CORE \\
\hline Sábado & 6 \\
\hline Domingo & 7 \\
\hline Lunes & $8 \mathrm{CR} \cdot \mathrm{PL}$ \\
\hline Martes & 9 RSA-CORE \\
\hline Miércoles & $10 \mathrm{CR} \cdot \mathrm{PL}$ \\
\hline Jueves & 11 RSA - CORE \\
\hline Viernes & $12 \mathrm{VO}_{2}$ \\
\hline Sábado & 13 \\
\hline Domingo & 14 \\
\hline Lunes & $15 \mathrm{CR}-\mathrm{PL}$ \\
\hline Martes & 16 RSA-CORE \\
\hline Miércoles & $17 \mathrm{CR} \cdot \mathrm{PL}$ \\
\hline Jueves & 18 RSA-CORE \\
\hline Viernes & 19 PISCINA \\
\hline Sábado & 20 \\
\hline Domingo & 21 \\
\hline Lunes & $22 \mathrm{RSA}-\mathrm{CORE}$ \\
\hline Martes & $23 \mathrm{CR} ; \mathrm{PL}$ \\
\hline Miércoles & 24 Test Trive-Basket \\
\hline Jueves & $25 \mathrm{CR} ; \mathrm{PL}$ \\
\hline Viernes & 26 RSA-CORE \\
\hline Sábado & 27 \\
\hline Domingo & 28 \\
\hline Lunes & 29 Test RSA \\
\hline Martes & $30 \mathrm{~T}$-Test, Test Core \\
\hline
\end{tabular}

\begin{tabular}{|c|c|c|}
\hline \multicolumn{3}{|c|}{ Julio } \\
\hline Miercoles & 1 & $\mathrm{RSA} \cdot \mathrm{PL}$ \\
\hline Jueves & 2 & OP. CORE \\
\hline Viernes & 3 & PISCINA - CP \\
\hline Sábado & 4 & \\
\hline Domingo & 5 & \\
\hline Lunes & 6 & $\mathrm{~V} 02 \cdot \mathrm{CP}$ \\
\hline Martes & 7 & OP.CORE \\
\hline Miércoles & 8 & RSA - PL \\
\hline Jueves & 9 & OP.CORE \\
\hline Viernes & 10 & RSA - PL - CR \\
\hline Sábado & 11 & \\
\hline Domingo & 12 & \\
\hline Lunes & 13 & OP.CORE \\
\hline Martes & 14 & $\mathrm{RSA} \cdot \mathrm{PL}$ \\
\hline Miércoles & 15 & OP-CORE \\
\hline Jueves & 16 & $\mathrm{RSA} \cdot \mathrm{PL}$ \\
\hline Viernes & 17 & $\mathrm{VO}_{2} \cdot \mathrm{CP}$ \\
\hline Sábado & 18 & \\
\hline Domingo & 19 & \\
\hline Lunes & 20 & OP.CORE \\
\hline Martes & 21 & RSA-PL \\
\hline Miércoles & 22 & OP.CORE \\
\hline Jueves & 23 & $\mathrm{RSA} \cdot \mathrm{PL}$ \\
\hline Viernes & 24 & PISCINA-CP \\
\hline Sábado & 25 & \\
\hline Domingo & 26 & \\
\hline Lunes & 27 & OP-CORE \\
\hline Martes & 28 & RSA-PL \\
\hline Miércoles & 29 & $\mathrm{~V} 02 \cdot \mathrm{CP}$ \\
\hline Jueves & 30 & OP.CORE \\
\hline Viernes & 31 & $\mathrm{RSA} \cdot \mathrm{PL}$ \\
\hline
\end{tabular}

\begin{tabular}{|rl|l|}
\hline \multicolumn{3}{|c|}{ Agosto } \\
\hline Sábado & 1 \\
\hline Domingo & 2 \\
\hline Lunes & 3 & Test Trive-Basket \\
\hline Martes & 4 \\
\hline Miércoles & 5 & T-Test, Test Core \\
\hline Jueves & 6 & Test RSA \\
\hline Viernes & 7 & \\
\hline Sábado & 8 & \\
\hline Domingo & 9 & \\
\hline Lunes & 10 & VO2.CP \\
\hline Martes & 11 & OP-CORE \\
\hline Miércoles & 12 & RSA-PL \\
\hline Jueves & 13 & OP-CORE \\
\hline Viernes & 14 & RSA-PL \\
\hline Sábado & 15 & \\
\hline Domingo & 16 & \\
\hline Lunes & 17 & OP-CORE \\
\hline Martes & 18 & RSA-PL \\
\hline Miércoles & 19 & OP-CORE \\
\hline Jueves & 20 & RSA-PL \\
\hline Viernes & 21 & VO2.CP \\
\hline Sábado & 22 & \\
\hline Domingo & 23 & \\
\hline Lunes & 24 & OP-CORE \\
\hline Martes & 25 & RSA-PL \\
\hline Miércoles & 26 & OP-CORE \\
\hline Jueves & 27 & RSA-PL \\
\hline Viernes & 28 & PISCINA-CP \\
\hline Sábado & 29 & \\
\hline Domingo & 30 & \\
\hline Lunes & 31 & \\
\hline & & \\
\hline
\end{tabular}

\begin{tabular}{|l|}
\hline \multicolumn{1}{|c|}{ Leyenda } \\
\hline $\mathrm{VO}_{2}=$ Potencia aeróbica \\
\hline $\mathrm{RSA}=$ Repeat Sprint Ability \\
\hline $\mathrm{CR}=$ Trabajo correctivo \\
\hline $\mathrm{PL}=$ Prevención de lesiones \\
\hline $\mathrm{OP}=$ Fuerza, Optimización del rendimiento \\
\hline $\mathrm{CP}=$ Trabajo compensatorio \\
\hline $\mathrm{CORE}=$ Entrenamiento de la región coxolumbopélvica \\
\hline
\end{tabular}

\section{Evaluaciones iniciales}

18 de Mayo; Test composición corporal, Pruebas Mat

19 Mayo; Yo-Yo IR1, Recordatorio 24 Horas

21 de Mayo: FMS, recordatorio 24 horas

22 de Mayo: Agility T-Test

23 de Mayo: Recordatorio 24 Horas

25 de Mayo: Test Trive-Basket

27 de Mayo: Core, CMJ, VJFT

28 de Mayo: Patrones motores básicos, Test psicológicos 29 de Mayo: Test RSA

nio: Test Trive-Basket

29 Junio: Test RSA

30 de Junio: T-Test, Test de Core

Evaluación segunda fase

:Test Trive-Basket

5 de Agosto: T-Test, Test Core

6 de Agosto:Test RSA

Parte no presencial 
Anexo 13. Cuestionario Bienestar (McLean et al., 2010).

\begin{tabular}{|c|c|c|c|c|c|c|}
\hline Variable/valor & 5 & 4 & 3 & 2 & 1 & Puntuación \\
\hline Fatiga & $\begin{array}{l}\text { Muy } \\
\text { recuperado }\end{array}$ & Recuperado & Normal & $\begin{array}{l}\text { Más } \\
\text { fatigado de } \\
\text { lo normal }\end{array}$ & $\begin{array}{l}\text { Muy } \\
\text { fatigado }\end{array}$ & \\
\hline $\begin{array}{ll}\text { Calidad } & \text { del } \\
\text { sueño } & \end{array}$ & Muy relajante & Bueno & $\begin{array}{l}\text { Dificultad } \\
\text { para } \\
\text { conciliar el } \\
\text { sueño }\end{array}$ & $\begin{array}{l}\text { Sueño } \\
\text { inquieto }\end{array}$ & Insomnio & \\
\hline $\begin{array}{l}\text { Daño muscular } \\
\text { general }\end{array}$ & $\begin{array}{l}\text { Muy buenas } \\
\text { sensaciones }\end{array}$ & $\begin{array}{l}\text { Buenas } \\
\text { sensaciones }\end{array}$ & Normal & $\begin{array}{l}\text { Aumento } \\
\text { del dolor } \\
\text { muscular }\end{array}$ & $\begin{array}{l}\text { Muy } \\
\text { dolorido }\end{array}$ & \\
\hline Nivel de estrés & Muy relajado & Relajado & Normal & Estresado & $\begin{array}{l}\text { Muy } \\
\text { estresado }\end{array}$ & \\
\hline $\begin{array}{l}\text { Humor/ } \\
\text { Talante }\end{array}$ & $\begin{array}{l}\text { Talante } \\
\text { positivo }\end{array}$ & Buen humor & $\begin{array}{l}\text { Menos } \\
\text { interesado } \\
\text { en otras } \\
\text { actividades } \\
\text { de lo normal }\end{array}$ & Mal genio & $\begin{array}{l}\text { Muy } \\
\text { molesto }\end{array}$ & \\
\hline & & & & & Total & \\
\hline
\end{tabular}


Anexo 14. Escala de dolor.

\section{Escalas de dolor}
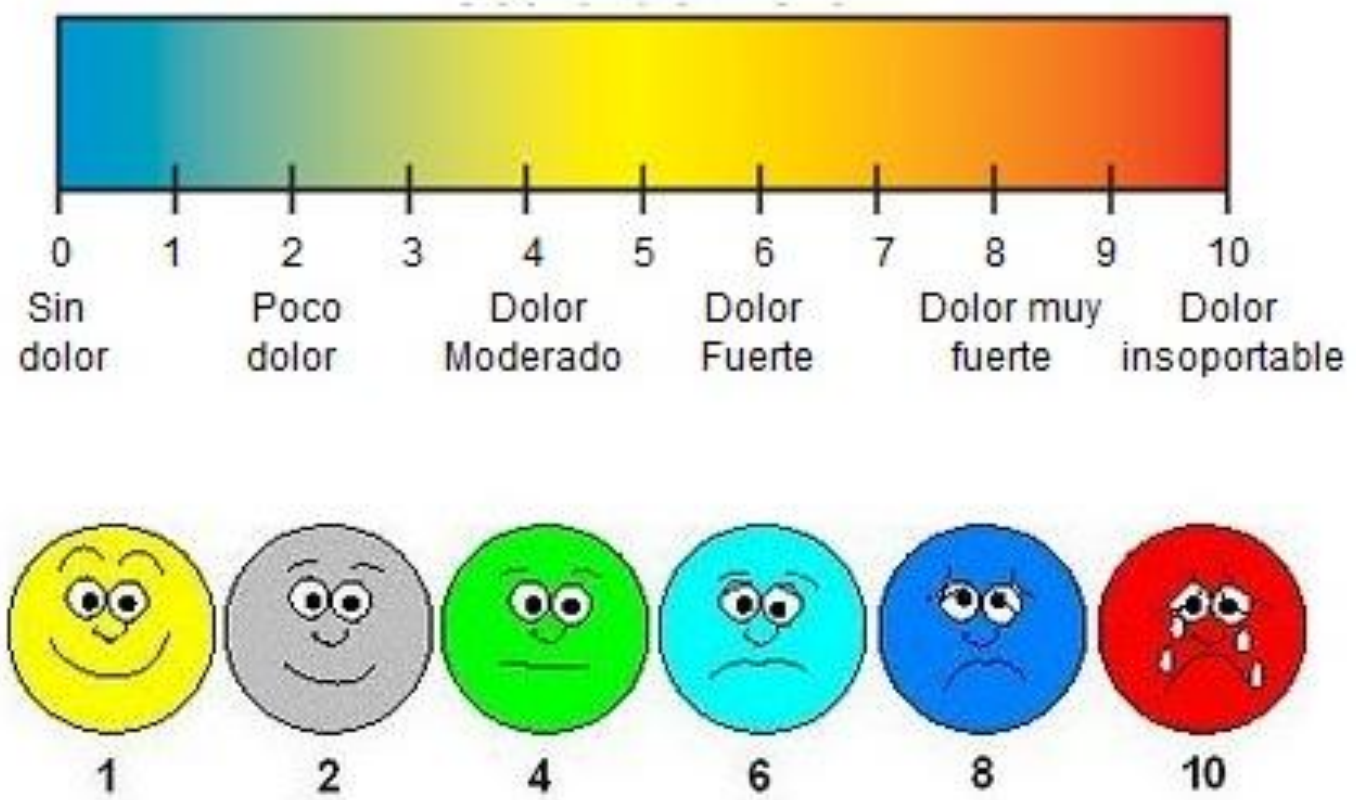
Anexo 15. Ejercicios y metodología expuesto en la hoja Excel del entregada al sujeto para la parte no presencial.

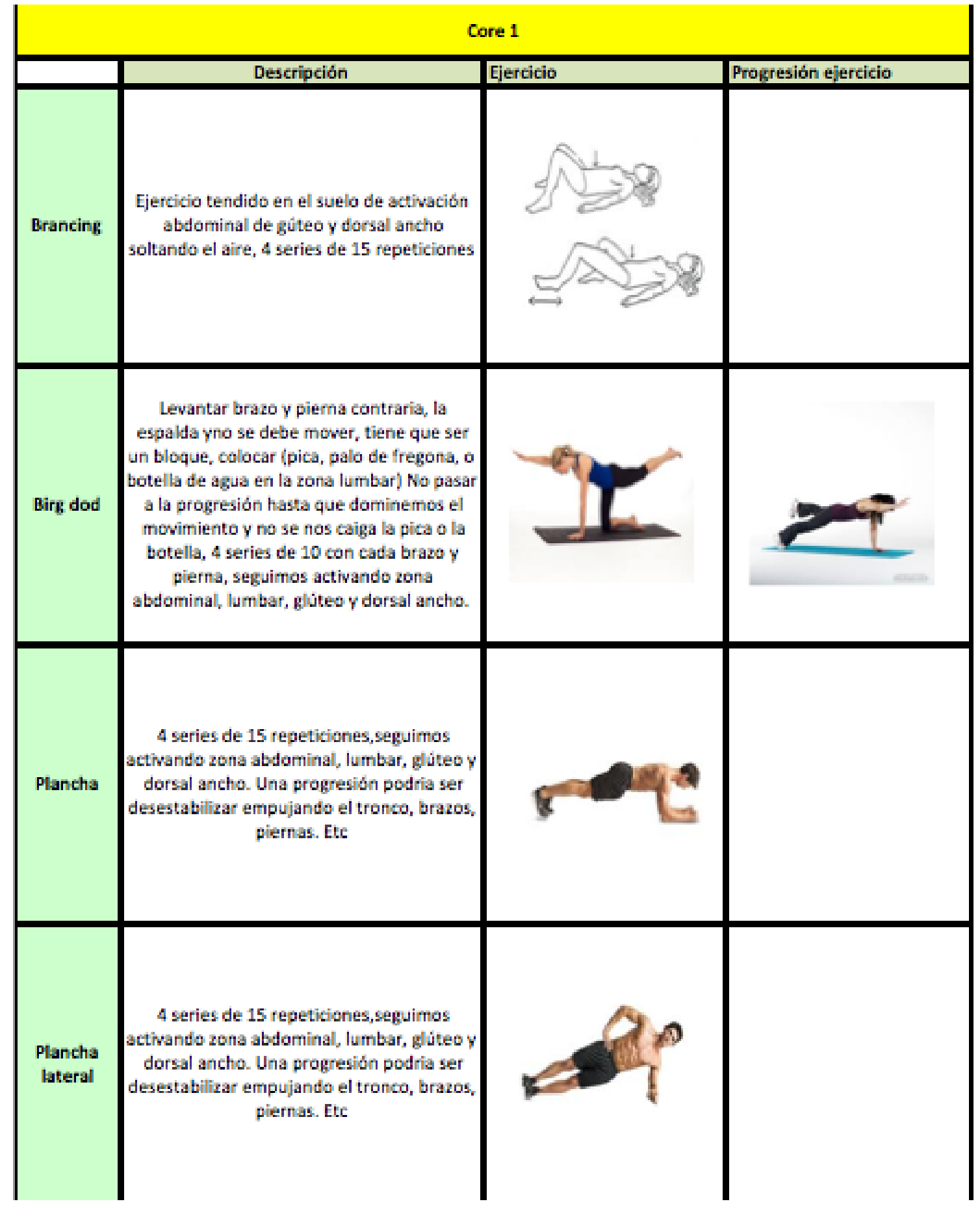




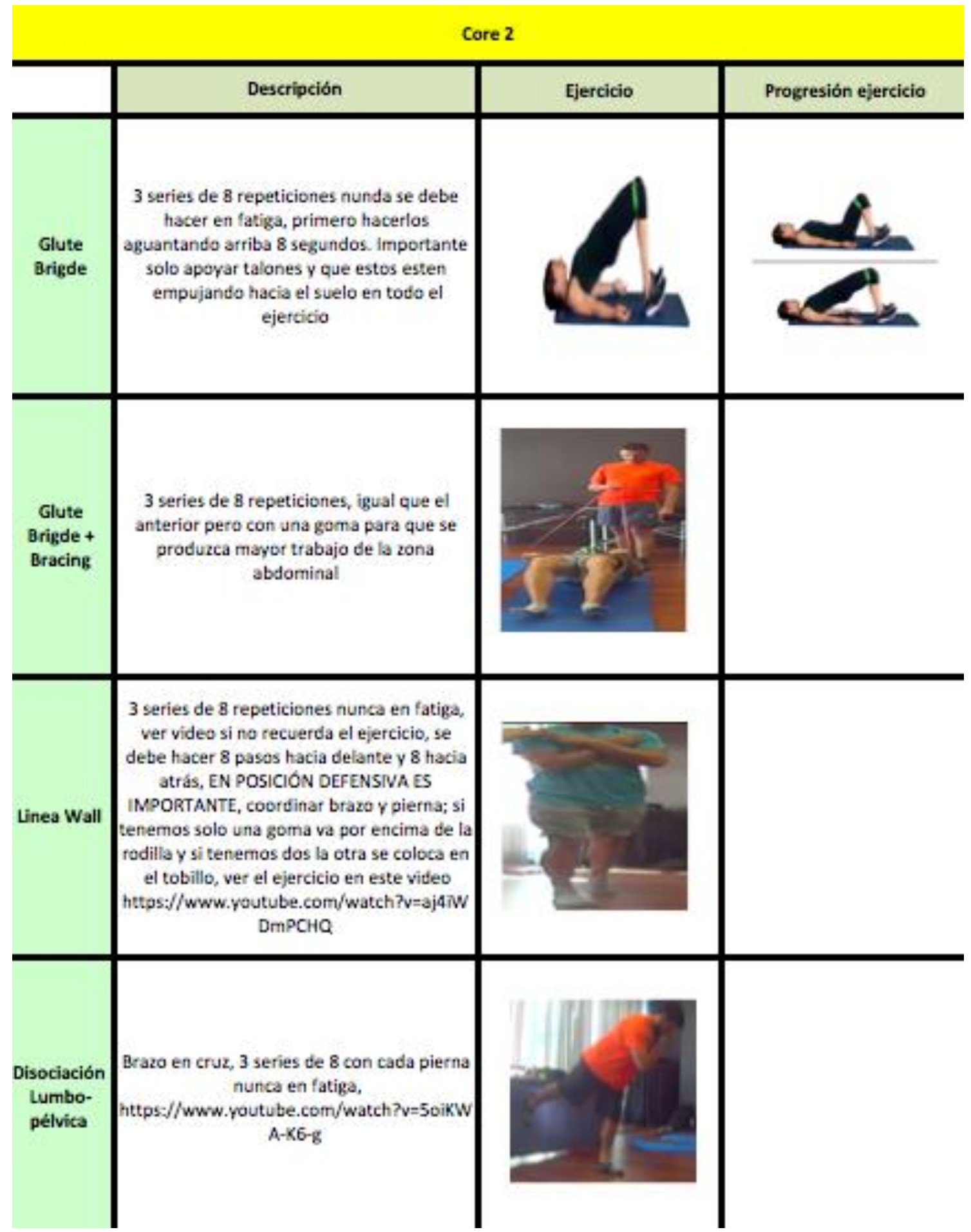




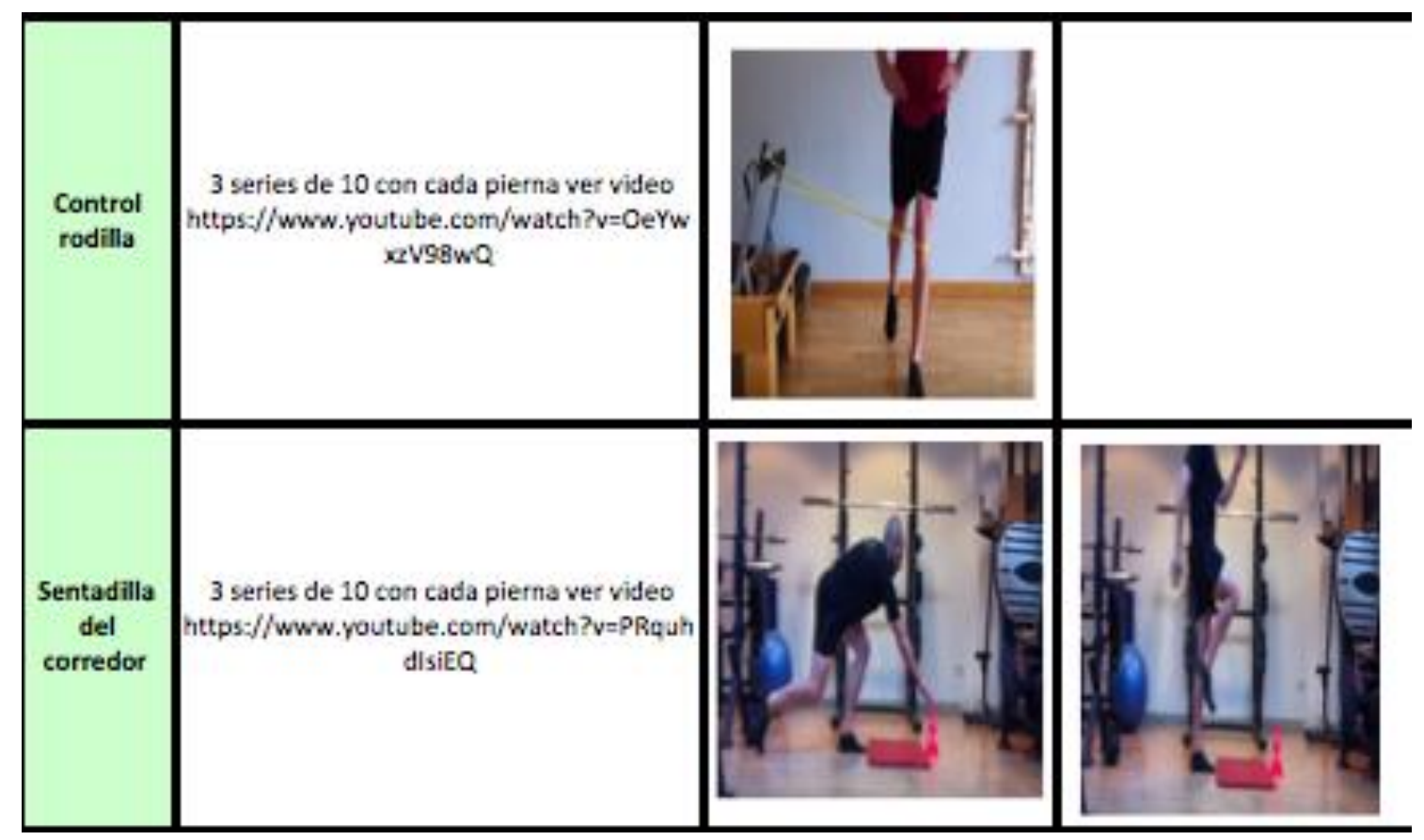


Anexo 16. Escala Total Quality Recovery (TQR), (Kentta \& Hassmen, 1998).

\begin{tabular}{|c|c|}
\hline Puntuación & Nivel de recuperación \\
\hline 6 & \\
\hline 7 & Recuperación muy, muy pobre \\
\hline 8 & \\
\hline 9 & Recuperación muy pobre \\
\hline 10 & Recuperación pobre \\
\hline 11 & Recuperación razonable \\
\hline 12 & Recuperación buena \\
\hline 13 & \\
\hline 14 & Recuperación muy buena \\
\hline 15 & \\
\hline 16 & Recuperación muy, muy buena \\
\hline 17 & \\
\hline 18 & \\
\hline 20 & \\
\hline & \\
\hline 19 & \\
\hline
\end{tabular}

